\title{
Sleep and depression
}

Citation for published version (APA):

van Dalfsen, J. H. (2019). Sleep and depression: genetic influences of the brain serotonergic system. [Doctoral Thesis, Maastricht University]. Maastricht University. https://doi.org/10.26481/dis.20190320jd

Document status and date:

Published: 01/01/2019

DOI:

10.26481/dis.20190320jd

Document Version:

Publisher's PDF, also known as Version of record

\section{Please check the document version of this publication:}

- A submitted manuscript is the version of the article upon submission and before peer-review. There can be important differences between the submitted version and the official published version of record.

People interested in the research are advised to contact the author for the final version of the publication, or visit the DOI to the publisher's website.

- The final author version and the galley proof are versions of the publication after peer review.

- The final published version features the final layout of the paper including the volume, issue and page numbers.

Link to publication

\footnotetext{
General rights rights.

- You may freely distribute the URL identifying the publication in the public portal. please follow below link for the End User Agreement:

www.umlib.nl/taverne-license

Take down policy

If you believe that this document breaches copyright please contact us at:

repository@maastrichtuniversity.nl

providing details and we will investigate your claim.
}

Copyright and moral rights for the publications made accessible in the public portal are retained by the authors and/or other copyright owners and it is a condition of accessing publications that users recognise and abide by the legal requirements associated with these

- Users may download and print one copy of any publication from the public portal for the purpose of private study or research.

- You may not further distribute the material or use it for any profit-making activity or commercial gain

If the publication is distributed under the terms of Article $25 \mathrm{fa}$ of the Dutch Copyright Act, indicated by the "Taverne" license above, 
Sleep and depression:

genetic influences of the brain serotonergic system

Jens H. van Dalfsen 
(C) Jens H. van Dalfsen, Maastricht 2019

Cover image: Serotonin transporter protein. Reproduced with permission from: Murphy and Lesch (2008). Nature Neuroscience Reviews, 9(2), 85-96.

Production: Gildeprint

All rights reserved. No parts of this thesis may be reproduced or printed in any form or by any means, without permission from the copyright holder. The copyright of the articles that have been published or have been accepted for publication has been transferred to the respective journal.

ISBN: $\quad 978-90-829801-4-1$ 


\section{Sleep and depression: genetic influences of the brain serotonergic system}

\section{PROEFSCHRIFT}

Ter verkrijging van de graad doctor aan de Universiteit Maastricht, op gezag van de Rector Magnificus, Prof. Dr. Rianne M. Letschert, volgens het besluit van het College van Decanen,

in het openbaar te verdedigen op

woensdag 20 maart 2019 om 12.00 uur.

door

Jens Henk van Dalfsen

Geboren 1987 te Smallingerland 


\section{Promotor:}

Prof. Dr. C. R. Markus

\section{Beoordelingscommissie:}

Prof. Dr. W. J. Riedel (voorzitter)

Prof. Dr. A. J. W. van der Does (Universiteit Leiden)

Prof. Dr. G. A. Kerkhof (Universiteit van Amsterdam)

Prof. Dr. F. P. M. L. Peeters

Prof. Dr. T. Smeets (Universiteit Tilburg) 
To my parents,

without their love, support and encouragement

I would not be where I am today. 

'If sleep does not serve an absolutely vital function,

then it is the biggest mistake the evolutionary process has ever made'.

Allan Rechtschaffen (1971) 


\section{Contents}

General introduction

Chapter 1

The serotonin transporter 5-HTTLPR polymorphism and the risk for insomnia: a non-replication

Chapter 2

Interaction between 5-HTTLPR genotype and cognitive stress vulnerability on sleep quality: effects of sub-chronic tryptophan administration

\section{Chapter 3}

The serotonin transporter gene-linked polymorphic region (5-HTTLPR) and the sleep-promoting effects of tryptophan: a randomized placebo-controlled crossover study

\section{Chapter 4}

The influence of sleep on human hypothalamic-pituitary-adrenal (HPA) axis reactivity: a systematic review

\section{Chapter 5}

The serotonin transporter polymorphism (5-HTTLPR) and cortisol stress responsiveness: preliminary evidence for a modulating role for sleep quality

\section{Chapter 6}

The serotonin transporter gene-linked polymorphic region (5-HTTLPR) and REM sleep regulation in healthy volunteers

\section{General discussion}


Samenvatting

Valorization addendum

Dankwoord

Curriculum Vitae 



\section{General introduction}

Parts of this introduction have been submitted for publication in revised form as:

van Dalfsen, J. H., \& Markus, C. R. (2018). The involvement of sleep in the relationship between the serotonin transporter gene-linked polymorphic region (5-HTTLPR) and depression: a systematic review. 


\section{Introduction}

Major depressive disorder is one of the most prevalent psychiatric conditions. With a point prevalence rate estimated at 5\% and a lifetime prevalence of around 15\% (Kessler et al., 2003), depression has been identified as one of the primary causes of disability worldwide (Murray \& Lopez, 1996; Vos et al., 2012). These findings emphasize the need to gain insight into the pathophysiological mechanisms of this heterogeneous (Kendler, Aggen, \& Neale, 2013) and frequently recurrent condition (Mueller et al., 1999). The identification of genetic risk factors is thought to particularly advance the understanding of depression etiology (Levinson, 2006). Despite a heritability estimate of 31\%-42\% (Sullivan, Neale, \& Kendler, 2000), genetic association studies have not produced replicable genetic variants involved in major depression (Flint \& Kendler, 2014; Ripke et al., 2013). Recent theories of depression suggest that genetic influences may depend on environmental context (i.e. gene-environment interaction) and thereby potentially explain the limited success of genetic studies (Lesch, 2004). Although initially promising, results from the explored gene-environment interactions only produced limited advances in uncovering the genetic architecture of depression (Wray et al., 2012).

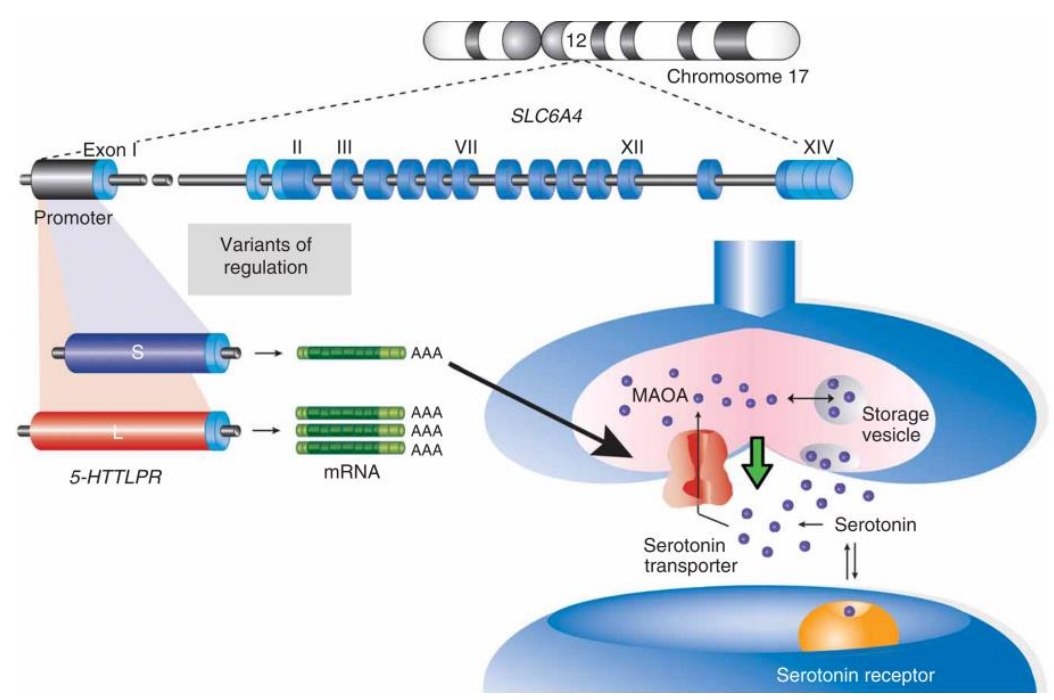

Figure 1. Allelic variation of the serotonin transporter gene-linked polymorphic region (5-HTTLPR) within the promoter region of the gene coding for the 5-HT transporter (SLC6A4). The short (S) allele (purple) is associated with reduced mRNA and protein production resulting in decreased expression and function of the 5HT transporter (green arrow) relative to the long (L) allele (red). MAOA, monoamine oxidase A. Reproduced with permission from: Canli and Lesch (2007). Nature Neuroscience, 10(9), 1103-1109. 
Reduced functioning of the serotonin (5-hydroxytriptamine; 5-HT) system has long been implicated in the pathophysiology of depression (Hasler, 2010) and therefore provides an evident source for candidate genes. By controlling 5-HT reuptake, the 5-HT transporter is a crucial regulator of 5-HT neurotransmission including the magnitude and duration of 5-HT signaling (Lesch et al., 1996). The 5-HT transporter is particularly present in cortical- and limbic regions involved in emotional processing (Varnas, Halldin, \& Hall, 2004) and represents one of the primary targets of effective and commonly prescribed antidepressants (Tamminga et al., 2002), supporting its involvement in depression. In 1996, Heils et al. reported a functional polymorphism that regulates the transcriptional efficacy of the gene coding for the 5-HT transporter (SLC6A4). This polymorphism, 5-HT transporter gene-linked polymorphic region (5-HTTLPR), comprises an allelic variation that includes a short (S) allele that is associated with reduced mRNA expression for the 5-HT transporter relative to the long (L) allele (Figure 1) (Heils et al., 1996). As a consequence, the S-allele is characterized by a reduced amount of 5-HT transporter binding sites and 5-HT reuptake (Figure 2) (Murphy \& Lesch, 2008) although a more diverse range of 5-HT influences may eventually contribute to a presumed elevated depression risk in this allelic variant (Ansorge, Zhou, Lira, Hen, \& Gingrich, 2004; Murphy \& Lesch, 2008).
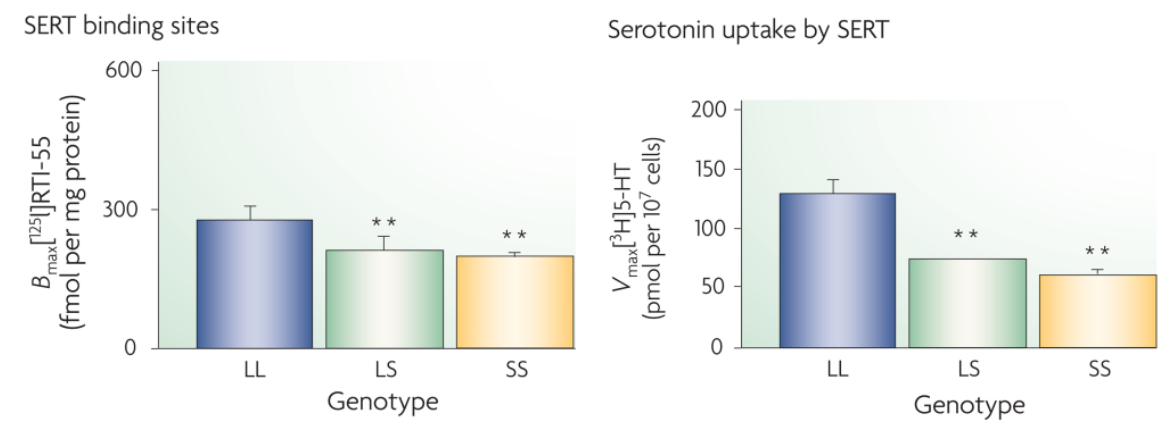

Figure 2. Influence of 5-HTTLPR genotype on 5-HT transporter (SERT) binding sites and 5-HT reuptake. Reproduced with permission from: Murphy and Lesch (2008). Nature Neuroscience Reviews, 9(2), 85-96.

Initial investigations provided promising support for the involvement of 5-HTTLPR in depression. Following the first report describing a direct relationship (Collier et al., 1996), the field gained particular momentum when a prospective longitudinal study revealed that the association between stressful life events and depression was more pronounced in individuals carrying one or two copies of the S-allele (Caspi et al., 2003). The vast amount of studies aimed to replicate the initial findings, however, produced great controversy. Recent metaanalyses demonstrate that there is little (Clarke, Flint, Attwood, \& Munafo, 2010) or no 
evidence (Culverhouse et al., 2018; Munafò, Durrant, Lewis, \& Flint, 2009; Risch, Herrell, Lehner, \& et al., 2009) for a direct relationship between 5-HTTLPR and depression. Metaanalyses evaluating the interaction between 5-HTTLPR and life adversity also produced equivocal results by either providing evidence (Bleys, Luyten, Soenens, \& Claes, 2018; Karg, Burmeister, Shedden, \& Sen, 2011) or no support (Culverhouse et al., 2018; Munafò et al., 2009; Risch et al., 2009) for this gene-environment interaction. Taken together, current literature suggests that neither 5-HTTLPR nor an interaction between 5-HTTLPR and stress reliably predicts the development of depression. It has therefore been suggested that the effect of this gene-environment interplay on the risk for depression is modest, not broadly generalizable and only observable in specific circumstances (Culverhouse et al., 2018).

In summary, available meta-analyses stimulate an ongoing debate whether allelic variation in 5-HTTLPR modulates the risk for (stress-related) depression. Elucidating the pathways by which 5-HTTLPR might contribute to the development of depression could resolve this controversy. Encouraged by the close and reciprocal relationship between sleep and depression (Riemann, Berger, \& Voderholzer, 2001), the present thesis evaluates whether sleep may have a central role in the association between 5-HTTLPR, stress and the etiology of depression. The variety of evidence supporting this hypothesis will be presented in the remainder of this introduction.

\section{Sleep and depression}

Sleep and depression are closely related and there is strong evidence for a bidirectional association (Riemann et al., 2001). Impaired sleep is typically experienced by $60 \%-90 \%$ of the depressed patients (Kloss \& Szuba, 2003). This mainly consists of symptoms of insomnia including prolonged sleep onset latency, increased wake after sleep onset, short sleep duration, early morning awakening and non-restorative sleep. Besides comprising one of the core symptoms of depression (American Psychiatric Association, 2013), it has been wellestablished that sleep impairment independently contributes to the etiology of depression. A recent meta-analysis of longitudinal studies demonstrated that insomnia confers a two-fold risk increase in non-depressed individuals, thereby classifying sleep impairment as one of the primary risk factors of depression (Baglioni et al., 2011).

Polysomnographic studies have further demonstrated that depression is associated with pronounced alterations in sleep architecture including shortened rapid eye movement (REM) sleep latency (i.e. the interval between sleep onset and the first period of REM sleep), 
increased REM sleep time, elevated REM density (i.e. the amount of rapid eye movements during REM sleep), and decreased slow wave sleep (SWS) (Figure 3) (Palagini, Baglioni, Ciapparelli, Gemignani, \& Riemann, 2013; Riemann et al., 2001). These REM sleep abnormalities represent a well-replicated biological alteration in clinical depression (Riemann et al., 2001) that is regarded as being more than an epiphenomenon of the disorder. Evidence for instance suggests that a disinhibition of REM sleep may be involved in the pathophysiology of depression and/or reflect underlying neurobiological abnormalities (Palagini et al., 2013).

Taken together, these findings illustrate that dysfunctional sleep has a prominent role in the development of depression. Elucidating how genetic variants presumed to predispose the risk for depression relate to or interact with sleep alterations could therefore provide valuable insight into the pathophysiological mechanisms of this disabling condition.
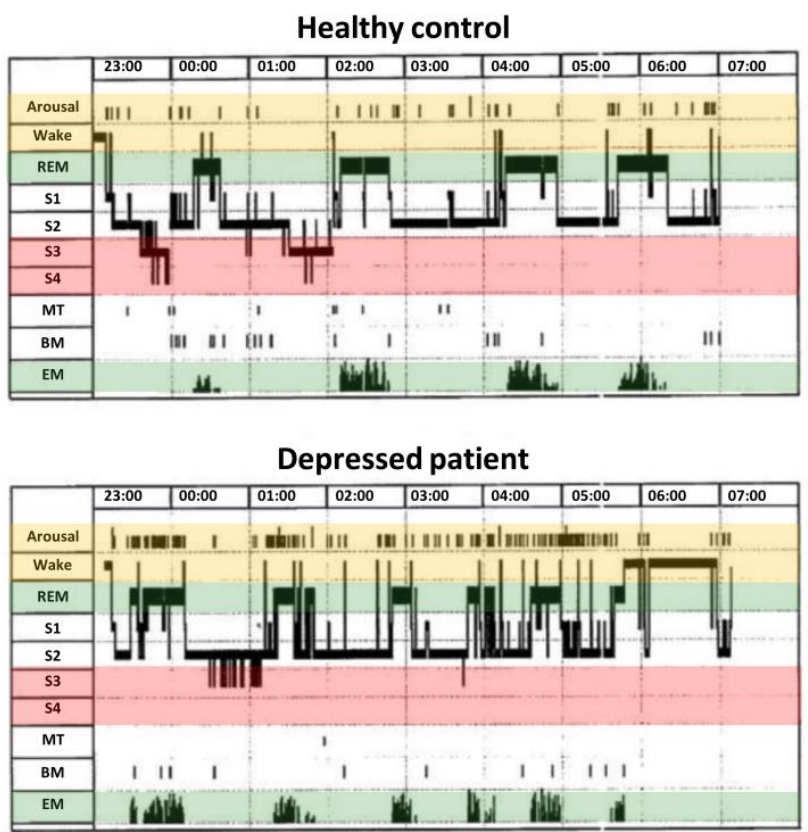

Figure 3. Representative sleep architecture in a healthy control and depressed patient. The depressed patient displays an increased amount of arousals and nocturnal awakenings (yellow), a disinhibition of REM sleep (green) and a reduction in slow wave sleep (red) relative to the healthy control. Adapted with permission from: Riemann, Berger and Volderholzer (2001). Biological Psychology, 57(1-3), 67-103.

\section{5-HTTLPR and the risk for insomnia}

Genetic factors considerably contribute to the etiology of sleep disturbance as demonstrated in heritability (Bastien \& Morin, 2000; Beaulieu-Bonneau, LeBlanc, Merette, Dauvilliers, \& 
Morin, 2007; Dauvilliers et al., 2005) and genome-wide association studies (Hammerschlag et al., 2017; Lane et al., 2017). In line with the fundamental role of 5-HT in sleep regulation (Ursin, 2002) and stress adaptation (Fuller, 1990; Porter, Gallagher, Watson, \& Young, 2004), various studies investigated whether allelic variation in 5-HTTLPR may modulate the risk for insomnia and sleep quality reductions.

The 5-HTTLPR S-allele has repeatedly been found to predispose the risk for insomnia (Deuschle et al., 2010; Huang et al., 2014). Additional evidence suggests that this association may, at least in part, arise from a modulating influence of 5-HTTLPR on the relationship between stress and insomnia, including a more pronounced association in homozygous Sallele relative to L-allele carriers (Huang et al., 2014). This finding closely converges with previous investigations revealing an interaction between 5-HTTLPR and stress on subjective sleep quality. An early investigation for instance reported a stronger negative relationship between stress and sleep quality in homozygous $\mathrm{S}$-allele relative to L-allele genotypes (Brummett et al., 2007). Comparable results have been obtained in a population of young children where a positive association between parenting stress and sleep problems was exclusively observed in children carrying at least one copy of the S-allele (Davis et al., 2017). Similarly, in an elderly population, depressive symptoms were solely related to sleep onset latency complaint in homozygous and heterozygous 5-HTTLPR S-allele carriers (Polito et al., 2015). Other investigations, however, have not always confirmed an interaction between 5HTTLPR and stress on subjective sleep quality (Barclay et al., 2011) and even reported that the L-allele may be more prone to experience poor sleep quality irrespective of stressful life events (Barclay et al., 2011).

Table 1. The influence of allelic variation in 5-HTTLPR on the risk for sleep impairment

\begin{tabular}{|c|c|c|c|c|c|c|c|}
\hline & $\mathrm{N}$ & Age (y) & $\mathrm{M} / \mathrm{F}$ & Sleep & Stress & 5-HTTLPR & 5-HTTLPR x stress \\
\hline Barclay et al., 2011 & 947 & 20.3 & 0.62 & PSQI & LTE / CLES & $\mathrm{L} / \mathrm{L}>(\mathrm{S} / \mathrm{S} / \mathrm{SL})$ & n.s. \\
\hline Brummett et al., 2007 & 288 & 58.3 & 0.34 & PSQI & Caregiver & n.s. & $\mathrm{S} / \mathrm{S}>(\mathrm{S} / \mathrm{L} / \mathrm{L} / \mathrm{L})$ \\
\hline Davis et al., 2017 & 108 & 3.5 & 1.56 & CBCL & PSI-SF & n.s. & $(\mathrm{S} / \mathrm{S} / \mathrm{S} / \mathrm{L})>\mathrm{L} / \mathrm{L}$ \\
\hline Deuschle et al., 2010 & 984 & 53.2 & 0.78 & MED & - & $\mathrm{S}>\mathrm{L}$ & - \\
\hline Huang et al., 2014 & 462 & - & 1.51 & AIS & GJSQ & $(\mathrm{S} / \mathrm{S} / \mathrm{S} / \mathrm{L})>\mathrm{L} / \mathrm{L}$ & $\mathrm{SS}>(\mathrm{S} / \mathrm{L} / \mathrm{L} / \mathrm{L})$ \\
\hline Polito et al., 2015 & 1321 & 72.2 & 0.85 & PSQI* & GDS-S & $(\mathrm{S} / \mathrm{S} / \mathrm{S} / \mathrm{L})>\mathrm{L} / \mathrm{L}$ & $(\mathrm{S} / \mathrm{S} / \mathrm{S} / \mathrm{L})>\mathrm{L} / \mathrm{L}$ \\
\hline
\end{tabular}

Note. AIS, Athens insomnia scale; CBCL, child behavior checklist; CLES, Coddington life events scale; DPI, Dutch personality inventory; GDS-S, geriatric depression scale - short form; GJSQ, general job stress questionnaire; L, 5-HTTLPR long allele; LTE, list of threatening experiences; M/F, proportion of males; MED, medical diagnosis; n.s., not significant; PSI-SF, parenting stress index - short form; PSQI, Pittsburgh sleep quality index; PSS, perceived stress scale; S, 5-HTTLPR short allele; * adapted version.

Taken together, multiple studies investigated whether allelic variation in 5-HTTLPR modulates the risk for sleep impairment (Table 1). The majority of investigations indeed 
support an increased susceptibility for sleep disturbance in 5-HTTLPR S-allele relative to Lallele carriers even though findings have been inconsistent. As a predisposition to experience sleep disturbance, particularly insomnia, is well-known to concurrently increase the risk for depression (Baglioni et al., 2011), the described literature provides some evidence for the involvement of sleep in the relationship between the 5-HTTLPR S-allele and (stress-related) depression (Figure 4). However, the limited amount of studies specifically devoted to the association between 5-HTTLPR and (stress-related) insomnia together with common inconsistencies in 5-HTTLPR research emphasizes the need to replicate these findings. Chapter 1 presents a replication study that addresses the relationship between 5-HTTLPR, stress and insomnia in order to establish the robustness of this association.

\section{5-HTTLPR in the association between sleep and affective symptomatology}

The general literature describes an intimate relationship between inadequate sleep and affective symptomatology. This includes increments in negative affect and there is some evidence for more profound decrements in positive affect (Palmer \& Alfano, 2017). Encouraged by these findings, and the presumed influence of 5-HTTLPR on the susceptibility to experience affective changes, multiple studies investigated whether allelic variation in 5HTTLPR modulates the relationship between sleep and affective symptomatology.

Carskadon et al. (2012) were one of the first to reveal a moderating influence of 5HTTLPR on the relationship between sleep and depressive symptoms. This study demonstrated that the homozygous S-allele genotype was overrepresented in individuals reporting a combination of short sleep duration and high depressive symptoms (Carskadon, Sharkey, Knopik, \& McGeary, 2012). The authors therefore proposed that a short sleep pattern particularly confers an increased likelihood to experience depressed mood in 5HTTLPR S-allele carriers. In support for this postulation, short sleep duration during early development has correspondingly been found to exclusively relate to negative emotionality and behavioral dysregulation in 5-HTTLPR S-allele carriers (Bouvette-Turcot et al., 2015). Studies investigating the effect of sleep quality on daily affective changes produced comparable results. Hartmann et al. (2014) demonstrated that the association between poor sleep quality and reduced next-day positive affect was stronger in 5-HTTLPR S-allele genotypes. While a significant interaction between 5-HTTLPR and sleep quality was observed on positive affect, allelic variation in 5-HTTLPR was not found to modulate sleeprelated changes in negative affect (J. A. Hartmann et al., 2014). The moderating influence of 
5-HTTLPR on the relationship between sleep quality and positive affective changes appears to be a robust finding as a recent replication study reported a similar moderating influence (van Roekel, Hartmann, Wichers, \& Verhagen, 2016).

Table 2. The influence of allelic variation in 5-HTTLPR on the relationship between inadequate sleep and affective symptomatology

\begin{tabular}{lllllll}
\hline & $\mathrm{N}$ & Age (y) & M/F & Sleep & Affect & 5-HTTLPR x sleep \\
\hline Carskadon et al., 2012 & 135 & 18.1 & 3.18 & SD & CES-D & S/S > (S/L / L/L) \\
Hartmann et al., 2014 & 361 & 28.0 & 0.00 & SD* $^{*}$ & ESM & (S/S / S/L) > L/L \\
Bouvette-Turcot et al., 2015 & 209 & 3.0 & 1.18 & MR & ECBQ & (S/S / S/L) > L/L \\
van Roekel et al., 2016 & 269 & 14.2 & 0.71 & $\mathrm{SD}^{*}$ & $\mathrm{ESM}$ & $(\mathrm{S} / \mathrm{S} / \mathrm{S} / \mathrm{L})>\mathrm{L} / \mathrm{L}$
\end{tabular}

Note. CES-D, center for epidemiological studies depression scale; ECBQ, early childhood behavior questionnaire; ESM, experience sampling method; L, 5-HTTLPR long allele; MR, maternal report; S, 5-HTTLPR short allele; SD, sleep diary; * adapted version.

In summary, various studies investigated whether 5-HTTLPR moderates the relationship between sleep and affective symptomatology (Table 2). These investigations consistently demonstrated that the 5-HTTLPR S-allele promotes the development of sleeprelated affective changes. These findings elaborate on the more general influence of impaired sleep on depressive symptomatology and thereby elucidate a potential pathway how this allelic variant may increase the risk for affective disorders (Figure 4). Together with a presumed elevated risk for insomnia in 5-HTTLPR S-allele carriers, these findings emphasize the significance of sleep in the relationship between 5-HTTLPR and depression susceptibility.

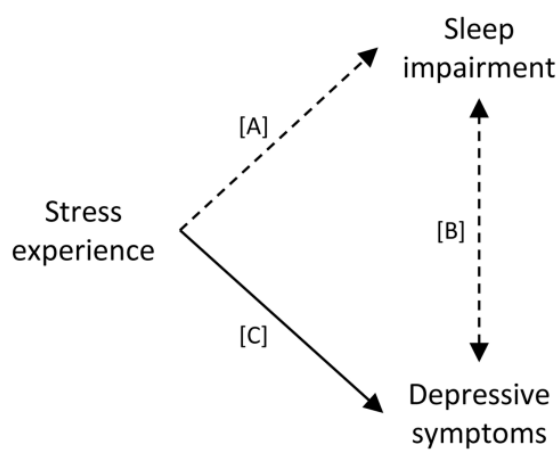

Figure 4. Involvement of sleep in the relationship between 5-HTTLPR and depression. The 5-HTTLPR S-allele relative to the L-allele predisposes the development of (stress-related) sleep impairment [A] and sleep-related depressive symptomatology [B] potentially contributing to a more pronounced association between stress and depression in this allelic variant $[\mathrm{C}]$. 


\section{5-HTTLPR and the sleep-promoting effects of brain 5-HT augmentation}

The observation that a reduced 5-HT functioning in 5-HTTLPR S-allele carriers promotes sleep disturbances encourages the search for compensatory pharmacological interventions. Moreover, from a scientific perspective, establishing an increased sensitivity to augmentation of 5-HT neurotransmission would further support the 5-HT deficiency underlying this predisposition. The synthetic pathway of 5-HT provides unique opportunities for pharmacological manipulation (Figure 5). In the brain 5-HT is synthesized from its precursor tryptophan. This is an essential amino acid meaning it cannot be produced in the human body and has to be obtained from dietary intake. The enzyme responsible for the initial conversion of tryptophan to the immediate 5-HT precursor 5-hydroxytryptophan (5-HTP) is not fully saturated providing a rate-limiting process in 5-HT synthesis depending on tryptophan availability (Fernstrom, 2012; Wurtman, Hefti, \& Melamed, 1980). The 5-HT system is therefore very sensitive to tryptophan augmentation, which is found to rapidly increase brain 5-HT levels (Eccleston, Ashcroft, \& Crawford, 1970) even at low pharmaceutical dosage (Fernstrom \& Wurtman, 1971).

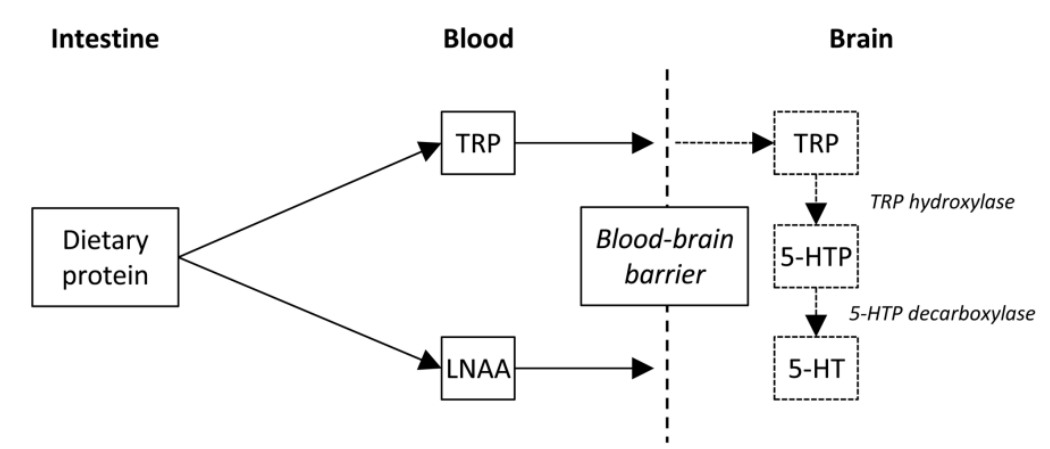

Figure 5. Synthetic pathway of serotonin (5-hydroxytriptamine; 5-HT). Tryptophan (TRP) is absorbed in the bloodstream from dietary protein and transported to the brain. At the blood brain barrier TRP competes with other large neutral amino acids (LNAA) for the same transporter. As a consequence, neural levels depend on the ratio of TRP relative to other LNAA. In the brain TRP is fist hydroxylated into the immediate 5-HT precursor 5hydroxytryptophan (5-HTP) which is subsequently decarboxylated into 5-HT.

Evidence suggests that tryptophan supplementation may have beneficial effects on sleep regulation in both healthy participants and insomnia patients. The most robust findings comprise reduced sleep onset latency, increased total sleep time and decreased wake after sleep onset (E. Hartmann \& Greenwald, 1984; Schneider-Helmert \& Spinweber, 1986; Silber $\&$ Schmitt, 2010). Since the effects most likely relate to the 5-HT system, these findings illustrate that tryptophan might be a promising agent to compensate for the elevated risk for 
insomnia and sleep quality reductions associated with the 5-HTTLPR S-allele. This is further supported by previous studies in other behavioral domains revealing particular beneficial effects in this allelic variant (Gibson, 2018). The study presented in Chapter 2 reveals some initial support for 5-HTTLPR dependent effects of tryptophan on sleep quality and Chapter 3 presents an additional investigation that aims to provide more conclusive evidence on subjective and objective sleep measures.

\section{Sleep and the relationship between 5-HTTLPR and neuroendocrine stress reactivity}

In order to explain the inconsistencies in the field of 5-HTTLPR and depression it has been suggested that genetic variants, like 5-HTTLPR, influence intermediate processes that promote depression susceptibility rather than directly contributing to the etiology of depression (Gottesman \& Gould, 2003). Studies have particularly focused on the functioning of the hypothalamic pituitary adrenal (HPA) axis, the major neuroendocrine system involved in stress adaptation (Balbo, Leproult, \& Van Cauter, 2010). Encouraged by the role of 5-HT in regulating HPA activity (Contesse et al., 2000; Lowry, 2002) and the contribution of hypercortisolism to the development of depression (Sapolsky, 2015; van Praag, 2004), a presumed elevated stress reactivity of the HPA axis in 5-HTTLPR S-allele carriers is thought to contribute to a higher risk for depression in this allelic variant (Miller, Wankerl, Stalder, Kirschbaum, \& Alexander, 2013). To further elucidate the role of sleep in the relationship between 5-HTTLPR and depression, it would therefore be valuable to elucidate how sleep influences this suggested underlying mechanism.

Given the well-established role of sleep in maintaining adequate functioning of the HPA axis (Buckley \& Schatzberg, 2005; Steiger, 2002), sleep could play an important role in the association between 5-HTTLPR and HPA reactivity. While impaired sleep clearly influences basal HPA activity, surprisingly little is known on whether sleep also affects the stress reactivity of the HPA axis (Meerlo, Sgoifo, \& Suchecki, 2008). Chapter 4 includes a systematic review demonstrating that inadequate sleep promotes the stress reactivity of the HPA axis. Inspired by these findings, Chapter 5 presents an experimental study investigating whether sleep quality modulates the association between 5-HTTLPR and HPA stress reactivity. 


\section{5-HTTLPR and REM sleep regulation}

The findings reported in the former part of this general introduction illustrate how a relationship between 5-HTTLPR and sleep impairment may theoretically contribute to the etiology of depression. Besides subjective symptoms of insomnia, evidence suggests that a disinhibition of REM sleep (i.e. reduced REM sleep latency, increased REM sleep time, elevated REM density) may also contribute to the development of depression (Palagini et al., 2013) and may serve as a genetic biomarker (Pillai, Kalmbach, \& Ciesla, 2011). Since reduced 5-HT functioning appears to have a critical role in promoting such REM sleep abnormalities (Palagini et al., 2013), 5-HTTLPR is very well-positioned to influence REM sleep regulation. Hence, this could reveal an additional pathway elucidating a role for sleep in the relationship between 5-HTTLPR and depression susceptibility.

Several lines of research directly support the involvement of the 5-HT transporter in REM sleep regulation. In contrast to the acute REM sleep suppression of 5-HT reuptake inhibition with selective serotonin reuptake inhibitors (SSRIs) (Pillai et al., 2011), animal research revealed that pharmacological blocking of 5-HT transporters during early development produces an increase in REM sleep (i.e. REM sleep disinhibition) that persist during adulthood (Frank \& Heller, 1997). While research in genetic knockout mice correspondingly demonstrated that a reduced transcriptional activity of the 5-HT transporter promotes the occurrence of REM sleep (Alexandre et al., 2006; Wisor et al., 2003), the influence of genetic variation in 5-HT transporter expression remains to be investigated in humans. Chapter 6 includes a polysomnographic study investigating the influence of 5HTTLPR on REM sleep regulation in healthy volunteers to determine whether this could serve as a possible mechanism or phenotype mediating the association between 5-HTTLPR and depression vulnerability.

\section{The present thesis}

In summary, several lines of research support the involvement of sleep in the association between 5-HTTLPR and depression. The work presented in the subsequent chapters elaborates on these findings by investigating the various pathways how sleep may contribute to this association. Comprising both association studies, pharmacological manipulations, systematic reviews, neuroendocrine measurements and polysomnographic examinations the results presented in this thesis aim to provide a comprehensive approach to elucidate the 
General introduction

potential role of sleep along the pathway of 5-HTTLPR, stress and the development of depression. 


\section{References}

Alexandre, C., Popa, D., Fabre, V., Bouali, S., Venault, P., Lesch, K. P., . . . Adrien, J. (2006). Early life blockade of 5-hydroxytryptamine 1A receptors normalizes sleep and depression-like behavior in adult knock-out mice lacking the serotonin transporter. The Journal of neuroscience : the official journal of the Society for Neuroscience, 26(20), 5554-5564. doi:10.1523/JNEUROSCI.5156-05.2006

American Psychiatric Association. (2013). Diagnostic and Statistical Manual of Mental Disorders: Dsm-5: Amer Psychiatric Pub Incorporated.

Ansorge, M. S., Zhou, M., Lira, A., Hen, R., \& Gingrich, J. A. (2004). Early-life blockade of the 5-HT transporter alters emotional behavior in adult mice. Science, 306(5697), 879881. doi:10.1126/science. 1101678

Baglioni, C., Battagliese, G., Feige, B., Spiegelhalder, K., Nissen, C., Voderholzer, U., . . . Riemann, D. (2011). Insomnia as a predictor of depression: A meta-analytic evaluation of longitudinal epidemiological studies. Journal of Affective Disorders, 135(1-3), 10-19. doi:10.1016/j.jad.2011.01.011

Balbo, M., Leproult, R., \& Van Cauter, E. (2010). Impact of sleep and its disturbances on hypothalamo-pituitary-adrenal axis activity. Int $J$ Endocrinol, 2010, 759234. doi:10.1155/2010/759234

Barclay, N. L., Eley, T. C., Mill, J., Wong, C. C., Zavos, H. M., Archer, S. N., \& Gregory, A. M. (2011). Sleep quality and diurnal preference in a sample of young adults: associations with 5HTTLPR, PER3, and CLOCK 3111. Am J Med Genet B Neuropsychiatr Genet, 156B(6), 681-690. doi:10.1002/ajmg.b.31210

Bastien, C. H., \& Morin, C. M. (2000). Familial incidence of insomnia. Journal of Sleep Research, 9(1), 49-54.

Beaulieu-Bonneau, S., LeBlanc, M., Merette, C., Dauvilliers, Y., \& Morin, C. M. (2007). Family history of insomnia in a population-based sample. Sleep, 30(12), 1739-1745.

Bleys, D., Luyten, P., Soenens, B., \& Claes, S. (2018). Gene-environment interactions between stress and 5-HTTLPR in depression: A meta-analytic update. Journal of Affective Disorders, 226, 339-345. doi:10.1016/j.jad.2017.09.050

Bouvette-Turcot, A. A., Pluess, M., Bernier, A., Pennestri, M. H., Levitan, R., Sokolowski, M. B., . . . Gaudreau, H. (2015). Effects of Genotype and Sleep on Temperament. Pediatrics, 136(4), e914-921. doi:10.1542/peds.2015-0080

Brummett, B. H., Krystal, A. D., Ashley-Koch, A., Kuhn, C. M., Zuchner, S., Siegler, I. C., . . . Williams, R. B. (2007). Sleep quality varies as a function of 5-HTTLPR genotype and stress. Psychosomatic Medicine, 69(7), 621-624. doi:10.1097/PSY.0b013e31814b8de6

Buckley, T. M., \& Schatzberg, A. F. (2005). On the interactions of the hypothalamicpituitary-adrenal (HPA) axis and sleep: normal HPA axis activity and circadian rhythm, exemplary sleep disorders. Journal of Clinical Endocrinology and Metabolism, 90(5), 3106-3114. doi:10.1210/jc.2004-1056

Carskadon, M. A., Sharkey, K. M., Knopik, V. S., \& McGeary, J. E. (2012). Short Sleep as an Environmental Exposure: A Preliminary Study Associating 5-HTTLPR Genotype to Self-Reported Sleep Duration and Depressed Mood in First-Year University Students. Sleep, 35(6), 791-796. doi:10.5665/sleep.1876

Caspi, A., Sugden, K., Moffitt, T. E., Taylor, A., Craig, I. W., Harrington, H., . . Poulton, R. (2003). Influence of life stress on depression: moderation by a polymorphism in the 5 HTT gene. Science, 301(5631), 386-389. doi:10.1126/science.1083968 
Clarke, H., Flint, J., Attwood, A. S., \& Munafo, M. R. (2010). Association of the 5- HTTLPR genotype and unipolar depression: a meta-analysis. Psychological Medicine, 40(11), 1767-1778. doi:10.1017/s0033291710000516

Collier, D. A., Stober, G., Li, T., Heils, A., Catalano, M., Di Bella, D., . . . Lesch, K. P. (1996). A novel functional polymorphism within the promoter of the serotonin transporter gene: possible role in susceptibility to affective disorders. Molecular Psychiatry, 1(6), 453-460.

Contesse, V., Lefebvre, H., Lenglet, S., Kuhn, J. M., Delarue, C., \& Vaudry, H. (2000). Role of 5-HT in the regulation of the brain-pituitary-adrenal axis: effects of 5-HT on adrenocortical cells. Canadian Journal of Physiology and Pharmacology, 78(12), 967983.

Culverhouse, R. C., Saccone, N. L., Horton, A. C., Ma, Y., Anstey, K. J., Banaschewski, T., . . . Bierut, L. J. (2018). Collaborative meta-analysis finds no evidence of a strong interaction between stress and 5-HTTLPR genotype contributing to the development of depression. Molecular Psychiatry, 23(1), 133-142. doi:10.1038/mp.2017.44

Dauvilliers, Y., Morin, C., Cervena, K., Carlander, B., Touchon, J., Besset, A., \& Billiard, M. (2005). Family studies in insomnia. Journal of Psychosomatic Research, 58(3), 271278. doi:10.1016/j.jpsychores.2004.08.012

Davis, M., Thomassin, K., Bilms, J., Suveg, C., Shaffer, A., \& Beach, S. R. H. (2017). Preschoolers' genetic, physiological, and behavioral sensitivity factors moderate links between parenting stress and child internalizing, externalizing, and sleep problems. Developmental Psychobiology, 59(4), 473-485. doi:10.1002/dev.21510

Deuschle, M., Schredl, M., Schilling, C., Wust, S., Frank, J., Witt, S. H., . . Schulze, T. G. (2010). Association between a serotonin transporter length polymorphism and primary insomnia. Sleep, 33(3), 343-347.

Eccleston, D., Ashcroft, G. W., \& Crawford, T. B. (1970). Effect of tryptophan administration on 5HIAA in cerebrospinal fluid in man. Journal of Neurology, Neurosurgery and Psychiatry, 33(2), 269-272.

Fernstrom, J. D. (2012). Effects and side effects associated with the non-nutritional use of tryptophan by humans. Journal of Nutrition, 142(12), 2236s-2244s. doi:10.3945/jn.111.157065

Fernstrom, J. D., \& Wurtman, R. J. (1971). Brain serotonin content: physiological dependence on plasma tryptophan levels. Science, 173(3992), 149-152.

Flint, J., \& Kendler, K. S. (2014). The Genetics of Major Depression. Neuron, 81(3), 484-503. doi:10.1016/j.neuron.2014.01.027

Frank, M. G., \& Heller, H. C. (1997). Neonatal treatments with the serotonin uptake inhibitors clomipramine and zimelidine, but not the noradrenaline uptake inhibitor desipramine, disrupt sleep patterns in adult rats. Brain Research, 768(1-2), 287-293.

Fuller, R. W. (1990). Serotonin receptors and neuroendocrine responses. Neuropsychopharmacology, 3(5-6), 495-502.

Gibson, E. L. (2018). Tryptophan supplementation and serotonin function: genetic variations in behavioural effects. Proceedings of the Nutrition Society, 1-15. doi:10.1017/s0029665117004451

Gottesman, II, \& Gould, T. D. (2003). The endophenotype concept in psychiatry: etymology and strategic intentions. The American journal of psychiatry, 160(4), 636-645.

Hammerschlag, A. R., Stringer, S., de Leeuw, C. A., Sniekers, S., Taskesen, E., Watanabe, K., . . . Posthuma, D. (2017). Genome-wide association analysis of insomnia complaints identifies risk genes and genetic overlap with psychiatric and metabolic traits. Nature Genetics, 49(11), 1584-1592. doi:10.1038/ng.3888 
Hartmann, E., \& Greenwald, D. (1984). Tryptophan and human sleep: an analysis of 43 studies. In Progress in tryptophan and serotonin research (pp. 297-304). Berlin: Walter de Gruyter.

Hartmann, J. A., Wichers, M., van Bemmel, A. L., Derom, C., Thiery, E., Jacobs, N., . . . Simons, C. J. P. (2014). The serotonin transporter 5-HTTLPR polymorphism in the association between sleep quality and affect. European Neuropsychopharmacology, 24(7), 1086-1090. doi:10.1016/j.euroneuro.2014.01.015

Hasler, G. (2010). Pathophysiology of depression: do we have any solid evidence of interest to clinicians? World Psychiatry, 9(3), 155-161.

Heils, A., Teufel, A., Petri, S., Stober, G., Riederer, P., Bengel, D., \& Lesch, K. P. (1996). Allelic variation of human serotonin transporter gene expression. Journal of Neurochemistry, 66(6), 2621-2624.

Huang, C., Li, J., Lu, L., Ren, X., Li, Y., Huang, Q., . . . Wang, Y. (2014). Interaction between serotonin transporter gene-linked polymorphic region (5-HTTLPR) and jobrelated stress in insomnia: a cross-sectional study in Sichuan, China. Sleep Med, 15(10), 1269-1275. doi:10.1016/j.sleep.2014.01.023

Karg, K., Burmeister, M., Shedden, K., \& Sen, S. (2011). The serotonin transporter promoter variant (5-HTTLPR), stress, and depression meta-analysis revisited: evidence of genetic moderation. Archives of General Psychiatry, 68(5), 444-454. doi:10.1001/archgenpsychiatry.2010.189

Kendler, K. S., Aggen, S. H., \& Neale, M. C. (2013). Evidence for multiple genetic factors underlying DSM-IV criteria for major depression. JAMA Psychiatry, 70(6), 599-607. doi:10.1001/jamapsychiatry.2013.751

Kessler, R. C., Berglund, P., Demler, O., Jin, R., Koretz, D., Merikangas, K. R., . . Wang, P. S. (2003). The epidemiology of major depressive disorder: results from the National Comorbidity Survey Replication (NCS-R). JAMA, 289(23), 3095-3105. doi:10.1001/jama.289.23.3095

Kloss, J., \& Szuba, M. (2003). Insomnia in psychiatric disorders. In Insomnia: Principles and Management (pp. 43-70). New York: Cambridge University Press.

Lane, J. M., Liang, J., Vlasac, I., Anderson, S. G., Bechtold, D. A., Bowden, J., . . Saxena, R. (2017). Genome-wide association analyses of sleep disturbance traits identify new loci and highlight shared genetics with neuropsychiatric and metabolic traits. Nature Genetics, 49(2), 274-281. doi:10.1038/ng.3749

Lesch, K. P. (2004). Gene-environment interaction and the genetics of depression. Journal of Psychiatry and Neuroscience, 29(3), 174-184.

Lesch, K. P., Bengel, D., Heils, A., Sabol, S. Z., Greenberg, B. D., Petri, S., . . Murphy, D. L. (1996). Association of anxiety-related traits with a polymorphism in the serotonin transporter gene regulatory region. Science, 274(5292), 1527-1531.

Levinson, D. F. (2006). The genetics of depression: a review. Biological Psychiatry, 60(2), 84-92. doi:10.1016/j.biopsych.2005.08.024

Lowry, C. A. (2002). Functional subsets of serotonergic neurones: implications for control of the hypothalamic-pituitary-adrenal axis. Journal of Neuroendocrinology, 14(11), 911923.

Meerlo, P., Sgoifo, A., \& Suchecki, D. (2008). Restricted and disrupted sleep: effects on autonomic function, neuroendocrine stress systems and stress responsivity. Sleep Med Rev, 12(3), 197-210. doi:10.1016/j.smrv.2007.07.007

Miller, R., Wankerl, M., Stalder, T., Kirschbaum, C., \& Alexander, N. (2013). The serotonin transporter gene-linked polymorphic region (5-HTTLPR) and cortisol stress reactivity: a meta-analysis. Molecular Psychiatry, 18(9), 1018-1024. doi:10.1038/mp.2012.124 
Mueller, T. I., Leon, A. C., Keller, M. B., Solomon, D. A., Endicott, J., Coryell, W., . . . Maser, J. D. (1999). Recurrence after recovery from major depressive disorder during 15 years of observational follow-up. American Journal of Psychiatry, 156(7), 10001006. doi:10.1176/ajp.156.7.1000

Munafò, M. R., Durrant, C., Lewis, G., \& Flint, J. (2009). Gene $\times$ Environment Interactions at the Serotonin Transporter Locus. Biological Psychiatry, 65(3), 211-219. doi:10.1016/j.biopsych.2008.06.009

Murphy, D. L., \& Lesch, K. P. (2008). Targeting the murine serotonin transporter: insights into human neurobiology. Nat Rev Neurosci, 9(2), 85-96. doi:10.1038/nrn2284

Murray, C. J., \& Lopez, A. D. (1996). Evidence-based health policy--lessons from the Global Burden of Disease Study. Science, 274(5288), 740-743.

Palagini, L., Baglioni, C., Ciapparelli, A., Gemignani, A., \& Riemann, D. (2013). REM sleep dysregulation in depression: state of the art. Sleep Med Rev, 17(5), 377-390. doi:10.1016/j.smrv.2012.11.001

Palmer, C. A., \& Alfano, C. A. (2017). Sleep and emotion regulation: An organizing, integrative review. Sleep Med Rev, 31, 6-16. doi:10.1016/j.smrv.2015.12.006

Pillai, V., Kalmbach, D. A., \& Ciesla, J. A. (2011). A meta-analysis of electroencephalographic sleep in depression: evidence for genetic biomarkers. Biological Psychiatry, 70(10), 912-919. doi:10.1016/j.biopsych.2011.07.016

Polito, L., Davin, A., Vaccaro, R., Abbondanza, S., Govoni, S., Racchi, M., \& Guaita, A. (2015). Serotonin transporter polymorphism modifies the association between depressive symptoms and sleep onset latency complaint in elderly people: results from the 'InveCe.Ab' study. Journal of Sleep Research, 24(2), 215-222. doi:10.1111/jsr.12248

Porter, R. J., Gallagher, P., Watson, S., \& Young, A. H. (2004). Corticosteroid-serotonin interactions in depression: a review of the human evidence. Psychopharmacology, 173(1-2), 1-17. doi:10.1007/s00213-004-1774-1

Riemann, D., Berger, M., \& Voderholzer, U. (2001). Sleep and depression - results from psychobiological studies: an overview. Biological Psychology, 57(1-3), 67-103. doi:10.1016/S0301-0511(01)00090-4

Ripke, S., Wray, N. R., Lewis, C. M., Hamilton, S. P., Weissman, M. M., Breen, G., . . . Sullivan, P. F. (2013). A mega-analysis of genome-wide association studies for major depressive disorder. Molecular Psychiatry, 18(4), 497-511. doi:10.1038/mp.2012.21

Risch, N., Herrell, R., Lehner, T., \& et al. (2009). Interaction between the serotonin transporter gene (5-httlpr), stressful life events, and risk of depression: A metaanalysis. JAMA, 301(23), 2462-2471. doi:10.1001/jama.2009.878

Sapolsky, R. M. (2015). Stress and the brain: individual variability and the inverted-U. Nature Neuroscience, 18(10), 1344-1346. doi:10.1038/nn.4109

Schneider-Helmert, D., \& Spinweber, C. L. (1986). Evaluation of L-tryptophan for treatment of insomnia: a review. Psychopharmacology, 89(1), 1-7.

Silber, B. Y., \& Schmitt, J. A. (2010). Effects of tryptophan loading on human cognition, mood, and sleep. Neuroscience and Biobehavioral Reviews, 34(3), 387-407. doi:10.1016/j.neubiorev.2009.08.005

Steiger, A. (2002). Sleep and the hypothalamo-pituitary-adrenocortical system. Sleep Med Rev, 6(2), 125-138. doi:10.1053/smrv.2001.0159

Sullivan, P. F., Neale, M. C., \& Kendler, K. S. (2000). Genetic epidemiology of major depression: review and meta-analysis. American Journal of Psychiatry, 157(10), 15521562. doi:10.1176/appi.ajp.157.10.1552

Tamminga, C. A., Nemeroff, C. B., Blakely, R. D., Brady, L., Carter, C. S., Davis, K. L., . . . Suppes, T. (2002). Developing novel treatments for mood disorders: accelerating 
discovery. Biological Psychiatry, 52(6), 589-609. doi:10.1016/S0006-3223(02)014701

Ursin, R. (2002). Serotonin and sleep. Sleep Med Rev, 6(1), 55-69.

van Praag, H. M. (2004). Can stress cause depression? Progress in NeuroPsychopharmacology and Biological Psychiatry, 28(5), 891-907. doi:10.1016/j.pnpbp.2004.05.031

van Roekel, E., Hartmann, J. A., Wichers, M., \& Verhagen, M. (2016). The 5-HTTLPR genotype moderates the association between sleep quality and positive affect: A replication study. European Neuropsychopharmacology, 26(8), 1350-1351. doi:10.1016/j.euroneuro.2016.06.001

Varnas, K., Halldin, C., \& Hall, H. (2004). Autoradiographic distribution of serotonin transporters and receptor subtypes in human brain. Human Brain Mapping, 22(3), 246-260. doi:10.1002/hbm.20035

Vos, T., Flaxman, A. D., Naghavi, M., Lozano, R., Michaud, C., Ezzati, M., . . Memish, Z. A. (2012). Years lived with disability (YLDs) for 1160 sequelae of 289 diseases and injuries 1990-2010: a systematic analysis for the Global Burden of Disease Study 2010. Lancet, 380(9859), 2163-2196. doi:10.1016/s0140-6736(12)61729-2

Wisor, J. P., Wurts, S. W., Hall, F. S., Lesch, K. P., Murphy, D. L., Uhl, G. R., \& Edgar, D. M. (2003). Altered rapid eye movement sleep timing in serotonin transporter knockout mice. Neuroreport, 14(2), 233-238. doi:10.1097/01.wnr.0000054963.21656.bf

Wray, N. R., Pergadia, M. L., Blackwood, D. H., Penninx, B. W., Gordon, S. D., Nyholt, D. R., . . . Sullivan, P. F. (2012). Genome-wide association study of major depressive disorder: new results, meta-analysis, and lessons learned. Molecular Psychiatry, 17(1), 36-48. doi:10.1038/mp.2010.109

Wurtman, R. J., Hefti, F., \& Melamed, E. (1980). Precursor control of neurotransmitter synthesis. Pharmacological Reviews, 32(4), 315-335. 
General introduction 


\section{Chapter 1}

The serotonin transporter 5-HTTLPR polymorphism and the risk for insomnia: a non-replication

Published as:

van Dalfsen, J. H., \& Markus, C. R. (2019). The serotonin transporter 5-HTTLPR polymorphism and the risk for insomnia: a non-replication. Sleep Medicine, 53, 195-196. doi:10.1016/j.sleep.2018.01.015 


\section{Letter to the Editor of Sleep Medicine}

To the Editor,

In the June 2014 issue of Sleep Medicine, Huang et al. (2014) reported a genetic association study investigating the effect of 5-HTTLPR on insomnia (Huang et al., 2014). In line with previous findings (Deuschle et al., 2010), results demonstrated that the short allele is associated with a higher insomnia risk relative to the long allele. The authors further revealed that an interaction between 5-HTTLPR and stress may contribute to this relationship which corresponds with earlier findings on subjective sleep quality (Brummett et al., 2007).

Given the common inconsistencies in candidate gene studies (Barclay et al., 2011; van Dalfsen \& Markus, 2015), we aimed to replicate these findings in a large sample of healthy participants $(n=685)$ using the same statistical procedures and outcome measures while including a commonly used measure of general stress experience (perceived stress scale; PSS). In contrast to earlier findings (Deuschle et al., 2010; Huang et al., 2014), we could not detect an association between 5-HTTLPR and insomnia (Table 1). Even though stress experience increased the risk for insomnia $(O R=4.18 ; 95 \% \mathrm{CI}=2.94,5.94 ; p<0.001)$, this was not found to interact with 5-HTTLPR (Table 2), indicating a comparable influence of stress across allelic variation (Table 3) opposed to previous assumptions (Brummett et al., 2007; Huang et al., 2014).

Table 1. Association between allelic variation in 5-HTTLPR and insomnia.

\begin{tabular}{|c|c|c|c|c|c|}
\hline 5-HTTLPR ${ }^{\mathrm{a}}$ & $n$ & Insomnia $^{\mathrm{b}}$ & Non-insomnia & OR $[95 \% \mathrm{CI}]$ & $p$-value \\
\hline $\mathrm{S}^{\prime} / \mathrm{S}^{\prime}$ & 167 & 44 & 123 & $0.73[0.46,1.17]$ & 0.191 \\
\hline $\mathrm{S}^{\prime} / \mathrm{L}^{\prime}$ & 338 & 106 & 232 & $0.94[0.64,1.38]$ & 0.742 \\
\hline $\mathrm{L}^{\prime} / \mathrm{L}^{\prime}$ & 180 & 59 & 121 & Reference & \\
\hline$p$-value for $\chi^{2}$ & & & 0.383 & & \\
\hline$p$-trend for $\mathrm{OR}$ & & & 0.199 & & \\
\hline$p$-value for HWE & 0.738 & 0.777 & 0.646 & & \\
\hline
\end{tabular}

The age of the present sample $(M=23.3 ; S D=3.3)$ was considerably lower compared to other investigations (Brummett et al., 2007; Deuschle et al., 2010; Huang et al., 2014). This might indicate that 5-HTTLPR effects on insomnia would be particularly observed with increasing age. The absence of an interaction between 5-HTTLPR and perceived stress might suggest that specific aspects of stressors used in previous studies (Brummett et al., 2007; 
Huang et al., 2014), rather than general stress experience, moderate the association between 5HTTLPR and insomnia.

Table 2. Interaction between 5-HTTLPR and stress on insomnia.

\begin{tabular}{|c|c|c|c|c|c|}
\hline 5-HTTLPR & Stress $^{\mathrm{a}}$ & Insomnia & Non-insomnia & $O R[95 \% \mathrm{CI}]$ & $p$-value \\
\hline \multirow[t]{2}{*}{$\mathrm{S}^{\prime} / \mathrm{S}^{\prime}$} & High & 28 & 36 & $3.94[1.88,8.28]$ & $<0.001$ \\
\hline & Low & 15 & 87 & $0.87[0.40,1.90]$ & 0.734 \\
\hline \multirow[t]{2}{*}{$\mathrm{S}^{\prime} / \mathrm{L}^{\prime}$} & High & 73 & 89 & $4.16[2.20,7.84]$ & $<0.001$ \\
\hline & Low & 32 & 141 & $1.15[0.59,2.26]$ & 0.685 \\
\hline \multirow[t]{2}{*}{$\mathrm{L}^{\prime} / \mathrm{L}^{\prime}$} & High & 43 & 44 & $4.95[2.47,9.92]$ & $<0.001$ \\
\hline & Low & 15 & 76 & Reference & \\
\hline
\end{tabular}

Note. CI, confidence interval; $O R$, odds ratio.

${ }^{a}$ Participants were classified as high and low stress using mean split (Huang et al., 2014) of the PSS score $(M=11.48)$.

In conclusion, results of the present study reveal that the association between 5HTTLPR and insomnia is more heterogeneous than presented in the literature. Future studies are needed to elucidate genetic, demographic and environmental factors potentially moderating this relationship.

Table 3. Conditional logistic regression analyses for the influence of 5-HTTLPR and stress on insomnia.

\begin{tabular}{|c|c|c|c|c|c|c|}
\hline \multirow[t]{2}{*}{ Stress } & \multicolumn{2}{|c|}{$\mathrm{S}^{\prime} / \mathrm{S}^{\prime}$} & \multicolumn{2}{|c|}{$\mathrm{S}^{\prime} / \mathrm{L}^{\prime}$} & \multicolumn{2}{|c|}{$\mathrm{L}^{\prime} / \mathrm{L}^{\prime}$} \\
\hline & Insomnia & Non-insomnia & Insomnia & Non-insomnia & Insomnia & Non-insomnia \\
\hline \multirow[t]{2}{*}{ High } & 28 & 36 & 73 & 89 & 43 & 44 \\
\hline & \multicolumn{2}{|c|}{$O R_{\text {genotype }}=0.80[0.42,1,52]$} & \multicolumn{2}{|c|}{$O R_{\text {genotype }}=0.84[0.50,1.41]$} & \multicolumn{2}{|c|}{ reference } \\
\hline \multirow[t]{3}{*}{ Low } & 15 & 87 & 32 & 141 & 15 & 76 \\
\hline & \multicolumn{2}{|c|}{$O R_{\text {genotype }}=0.87[0.40,1.90]$} & \multicolumn{2}{|c|}{$O R_{\text {genotype }}=1.15[0.59,2.26]$} & \multicolumn{2}{|c|}{ reference } \\
\hline & \multicolumn{2}{|c|}{$O R_{\text {stress }}=4.51[2.16,9.43]^{*}$} & \multicolumn{2}{|c|}{$O R_{\text {stress }}=3.61[2.21,5.92]^{*}$} & \multicolumn{2}{|c|}{$O R_{\text {stress }}=4.95[2.47,9.92]^{*}$} \\
\hline
\end{tabular}

Note. $O R_{\text {genotype }}$, odds ratio for genotype within the high stress or low stress group; $O R_{\text {stress, }}$ odds ratio for stress within the $\mathrm{S}^{\prime} / \mathrm{S}^{\prime}, \mathrm{S}^{\prime} / \mathrm{L}^{\prime}$ or L'/L' group.

$* p<0.001$. 


\section{References}

Barclay, N. L., Eley, T. C., Mill, J., Wong, C. C., Zavos, H. M., Archer, S. N., \& Gregory, A. M. (2011). Sleep quality and diurnal preference in a sample of young adults: associations with 5HTTLPR, PER3, and CLOCK 3111. Am J Med Genet B Neuropsychiatr Genet, 156B(6), 681-690. doi:10.1002/ajmg.b.31210

Brummett, B. H., Krystal, A. D., Ashley-Koch, A., Kuhn, C. M., Zuchner, S., Siegler, I. C., . . . Williams, R. B. (2007). Sleep quality varies as a function of 5-HTTLPR genotype $\begin{array}{llll}\text { and stress. } \quad \text { Psychosomatic } & \text { 69dicine, }\end{array}$ doi:10.1097/PSY.0b013e31814b8de6

Deuschle, M., Schredl, M., Schilling, C., Wust, S., Frank, J., Witt, S. H., . . Schulze, T. G. (2010). Association between a serotonin transporter length polymorphism and primary insomnia. Sleep, 33(3), 343-347.

Huang, C., Li, J., Lu, L., Ren, X., Li, Y., Huang, Q., . . . Wang, Y. (2014). Interaction between serotonin transporter gene-linked polymorphic region (5-HTTLPR) and jobrelated stress in insomnia: a cross-sectional study in Sichuan, China. Sleep Med, 15(10), 1269-1275. doi:10.1016/j.sleep.2014.01.023

van Dalfsen, J. H., \& Markus, C. R. (2015). Interaction between 5-HTTLPR genotype and cognitive stress vulnerability on sleep quality: effects of sub-chronic tryptophan administration. Int J Neuropsychopharmacol, 18(3). doi:10.1093/ijnp/pyu057 


\section{Chapter 2}

Interaction between 5-HTTLPR genotype and cognitive stress vulnerability on sleep quality: effects of sub-chronic tryptophan administration

Published as:

van Dalfsen, J. H., \& Markus, C. R. (2015). Interaction between 5-HTTLPR genotype and cognitive stress vulnerability on sleep quality: effects of sub-chronic tryptophan administration. International Journal of Neuropsychopharmacology, 18(3), 1-9. doi:10.1093/ijnp/pyu057 


\begin{abstract}
Background: Abundant evidence suggests that allelic variation in the serotonin transporterlinked polymorphic region (5-HTTLPR) influences susceptibility to stress and its affective consequences due to brain serotonergic vulnerability. Based on recent assumptions, the present study examined whether the 5-HTTLPR genotype may also interact with a vulnerability to chronic stress experience (conceptualized by trait neuroticism) in order to influence sleep quality and, additionally, whether this is influenced by brain serotonergic manipulations. Methods: In a well-balanced experimental design, homozygous S-allele ( $\mathrm{n}=$ 57) and L-allele $(\mathrm{n}=54)$ genotypes with high and low chronic stress vulnerability (neuroticism) were first assessed for general past sleep quality during a month before onset of the experiment. Then subjects were assessed for sleep quality following 7 days of tryptophan (3.0g/day) or placebo intake. Results: Although high neuroticism was significantly related to a higher frequency of stressful life events and daily hassles, it did not interact with the 5HTTLPR genotype on general past sleep quality. However, as expected, a 7 day period of tryptophan administration was exclusively associated with better sleep quality scores in the S'/S' genotype with high trait neuroticism. Conclusions: Current findings suggest that 5HTTLPR does not directly interact with stress vulnerability in order to influence sleep quality. Instead, based on current and previous findings, it is suggested that the S'/S' 5-HTTLPR genotype promotes the risk for stress-related sleep disturbances because of an increased susceptibility to the depressogenic consequences of stress. Accordingly, by way of reducing depressive symptomatology, tryptophan augmentation may particularly improve sleep quality in stress-vulnerable individuals carrying the 5-HTTLPR S-allele.
\end{abstract}




\section{Introduction}

Sleep disturbances are highly prevalent. In Western Europe around 30\% percent of the general population reports sleep problems (Leger, Poursain, Neubauer, \& Uchiyama, 2008). Such sleep difficulties have a high clinical significance, as they play an important role in both physical and psychological well-being (Lund, Reider, Whiting, \& Prichard, 2010). For example, sleep complaints have been associated with an increased risk of hypertension (Guo et al., 2013), cardiovascular disease (Schwartz et al., 1999), and diabetes (Beihl, Liese, \& Haffner, 2009), as well as with various psychiatric disorders (Krystal, 2006).

There is large consensus that stress plays an important role in both the etiology and persistence of sleep disturbances. For instance, sleep quality has been found to vary as a function of daily stressful life events (Åkerstedt et al., 2012; Barclay, Eley, Rijsdijk, \& Gregory, 2011; Mezick et al., 2009; Vahtera et al., 2007) and, hence, personality traits associated with stress vulnerability, like neuroticism, appear to be important predictors for sleep disturbances (Calkins, Hearon, Capozzoli, \& Otto, 2012).

In addition to studies revealing relationships between stress experiences and sleep difficulties, there are also studies investigating direct interrelationships between sleep quality and activation of the hypothalamic-pituitary-adrenal (HPA) axis: the major neuroendocrine system involved in stress responses, and, hence, stress adaptation (Markus, 2008). In general, increased HPA activation is found to impair sleep; most likely by increasing cortical arousal, resulting in lighter sleep and more nocturnal awakenings (Buckley \& Schatzberg, 2005; Rodenbeck, Huether, Rüther, \& Hajak, 2002; Steiger, 2002). These findings suggest that the negative effects of stress experience on sleep quality may, at least in part, be mediated by HPA alterations.

Taking into account the importance of stress in the onset and course of sleep disturbances, there might be a particular moderating role for the brain's serotonergic system. Brain serotonin (5-hydroxitryptamine; 5-HT) acts as a neurobiological mechanism for stress adaptation, as a stress-induced 5-HT increase is found to be involved in the negative feedback control of the HPA function and, hence, in regaining psychological balance after stressinduced alterations in HPA activation (Firk \& Markus, 2007; Markus, 2008). Therefore, it is not surprising that reduced brain 5-HT functioning is frequently implicated as a risk factor for stress-related affective disorders such as depression, as further supported by the 5-HT mechanism of action of most antidepressant drugs (Markus, 2008; van Praag, 2004; van Praag, De Kloet, \& Van Os, 2004). 
Given the association between stress and sleep complaints and, hence, the importance of 5-HT in stress resilience, it is reasonable to assume that individual differences in 5-HT functioning may accordingly moderate differences in vulnerability for stress-related sleep complaints. Research suggests that 5-HT activation and/or functioning is, at least in part, genetically influenced, involving the 5-HT transporter-linked polymorphic region (5HTTLPR). This polymorphism includes an allelic variation, of which the short (S) allele is associated with lower transcriptional efficiency compared to the long (L) allele. As a consequence, the S-allele is accompanied by a reduced number of 5-HT transporters, and, hence, lower 5-HT functioning (Heils et al., 1996; Lesch et al., 1996). In compliance with the role of 5-HT in stress adaptation, S-allele carriers are, indeed, generally found to respond with greater behavioral and HPA stress responses compared to L-allele carriers (Cerit, Jans, \& Van der Does, 2013; Gotlib, Joormann, Minor, \& Hallmayer, 2008; Miller, Wankerl, Stalder, Kirschbaum, \& Alexander, 2013; Mueller, Brocke, Fries, Lesch, \& Kirschbaum, 2010; Way $\&$ Taylor, 2010) and, hence, have an increased risk for depressive symptoms in response to stress (Caspi et al., 2003; Karg, Burmeister, Shedden, \& Sen, 2011; Miller et al., 2013).

Based on previously-described relationships between stress and sleep, and between 5HTTLPR and stress vulnerability, an intriguing possibility is that genetically 5-HT-vulnerable subjects carrying the S-allele are more prone to experience sleep difficulties as a function of high-stress experiences. To date, only a few studies have investigated this interaction between 5-HTTLPR and stress on sleep quality, revealing either indirect evidence (Brummett et al., 2007) or no evidence at all (Barclay, Eley, Mill, et al., 2011). In these studies, however, stress experience was either not directly measured (Brummett et al., 2007) or just conceptualized by the frequency of self-reported past-year life events in association with past-month sleep disturbance (Barclay, Eley, Mill, et al., 2011). Of course, the past life-event checklist approach does not account for individual differences in the experienced emotional impact an event might have.

In order to elucidate whether the frequent experience of negative stress specifically moderates the relationship between 5-HTTLPR and sleep quality, a more liable measure should be incorporated. Hence, according to the cognitive, vulnerability-transactional stress model of stress and depression (Lazarus \& Folkman, 1984), life events particularly cause mental stress when they are actually appraised as personally relevant (primary appraisal) but unmanageable due to perceived insufficient coping abilities (secondary appraisal) (Brown, Bifulco, \& Harris, 1987; Gunthert, Cohen, \& Armeli, 1999). Among the personality traits related to such a stress vulnerability, trait neuroticism has been the most recognized (Shoji, 
Harrigan, Woll, \& Miller, 2010; van Praag, 2004). Specifically, individuals with high trait neuroticism are more likely to frequently experience stress with negative emotional consequences (Gallagher, 1990; Luteijn \& Bouman, 1988; van Praag, 2004; Watson \& Clark, 1984), show low expectations for self-efficacy, possess less-adaptive coping strategies for stress events (Gunthert et al., 1999; Penley, Tomaka, \& Wiebe, 2002; Shoji et al., 2010), and are more vulnerable for development of major depression (Roberts \& Kendler, 1999; van Praag, 2004). Thus, although trait neuroticism is, as a personality trait, by definition not synonymous with stress experience, as a consequence it is thought of as a most adequate measure for the vulnerability to frequent, chronic experiences of stress and its negative emotional impact (Markus, 2013).

From both a clinical and scientific perspective, it might be additionally useful to examine the influence of 5-HT brain augmentation on stress-related sleep difficulties. Moreover, as S-allele carriers are thought to be 5-HT vulnerable and, hence, have increased stress-vulnerability due to reduced 5-HT functioning (Markus \& Capello, 2012), it might be expected that 5-HT brain augmentation is especially beneficial in reducing stress-induced sleep disturbances within this genotype. Research indicates that synthesis and release of brain 5-HT can be enhanced by increasing the availability of its precursor, tryptophan (TRP) (Markus et al., 2000). This increase in brain 5-HT can be obtained because neuronal enzymes involved in 5-HT synthesis (e.g., 1-tryptophan hydroxylase) are not fully saturated. Consequently, altering TRP plasma levels increases enzyme saturation and, hence, brain 5-HT synthesis. However, other large amino acids (LNAAs) are transported across the blood-brain barrier by the same transport carrier as TRP. Consequently, brain TRP uptake depends on the TRP/LNAAs ratio (i.e., the relative level of TRP compared to other LNAAs) rather than plasma levels alone (Markus, 2008).

In line with the importance of 5-HT in stress regulation, it has been demonstrated that sub-chronic TRP administration (for seven days) attenuates the larger cortisol stress response observed in the S-allele, thereby diminishing the difference between S- and L-allele carriers (Capello \& Markus, 2014; Cerit et al., 2013). It is likely that this results from the importance of 5-HT in regulating negative feedback systems of the HPA axis, since research indicates that sub-chronic TRP administration augments this inhibitory influence (van Praag et al., 2004). Interestingly, effects of TRP and 5-HT functioning seem to be influenced by cognitive stress vulnerability, as TRP augmentation is found to reduce cortisol stress response in stressprone individuals (Markus et al., 2000). In line with these findings, it might be speculated that TRP also attenuates the difference in sleep quality between S- and L-allele carriers, as 
previously observed by Brummett et al. (2007), and, hence, that this depends on chronic stress vulnerability.

The present study aims to investigate if the 5-HTTLPR genotype moderates sleep quality as a function of chronic stress vulnerability as measured by neuroticism and, hence, whether this may be influenced by sub-chronic TRP augmentation. In an experimental between-subject design, homozygous S-allele $(n=57)$ and L-allele carriers $(n=54)$ with either high or low scores on trait neuroticism were assessed for sleep quality after a seven-day treatment period with either TRP or placebo. Before the start of the treatment, differences in past sleep quality (over the last month) were explored between subject groups. It was hypothesized that: (1) there is a negative association between neuroticism and general past sleep quality, especially in participants with the S'/S' 5-HTTLPR genotype, and (2) TRP is especially beneficial in reducing the negative effects of stress (neuroticism) on sleep in $\mathrm{S}^{\prime} / \mathrm{S}^{\prime}$ allele carriers.

\section{Method}

\section{Participants}

Participants were selected from a previously-obtained database of Maastricht University students $(\mathrm{n}=771)$ who were genotyped for 5-HTTLPR using a buccal sample extraction (26\% S/S, $47 \% \mathrm{~S} / \mathrm{L}, 27 \% \mathrm{~L} / \mathrm{L})$ and had already completed an electronic online questionnaire package. This included questions on general health (i.e., smoking and drinking habits, past and present use of medication and psychoactive drugs, and personal or family history of medical or psychiatric complaints) and experience of stressful life events, as well as standardized questionnaires including the Beck Depression Inventory (BDI; see Method section) and the inadequacy (neuroticism) scale of the Dutch Personality Questionnaire (see Measures section below). Subjects were excluded in cases of chronic and/or current illness, current treatment by a psychiatrist, use of psychoactive medication or drugs, excessive use of alcohol (>15 per week), or pregnancy and breastfeeding. In addition, only homozygous S- and L-allele carriers were selected, since differences in stress responses related to 5-HT vulnerabilities are often more pronounced when comparing homozygous genotypes (Way \& Taylor, 2010).

Individuals that were able to participate $(\mathrm{n}=118)$ were included in the present study and subsequently divided into high and low trait neuroticism using median split $(\mathrm{Mdn}=10)$. This resulted in four groups, including 57 S'/S' carriers $(29$ high neuroticism and 28 low 
neuroticism) and $54 \mathrm{~L} / \mathrm{L}$ ' carriers (23 high neuroticism and 31 low neuroticism). Before onset of the study, these participants were first asked to fill out a Pittsburg Sleep Quality Index (PSQI) to measure possible differences in past general sleep quality (past month). During the study, a few participants $(n=6)$ reported shift work and were therefore excluded for statistical analyses. In addition, participants who missed two or more doses of supplementation $(\mathrm{n}=1)$ were also excluded. The final sample $(\mathrm{n}=111)$ included $19(17 \%)$ men and $92(83 \%)$ women, aged between 22 and 31 years $(M=23.9 \pm 1.7)$. The present study was conducted according to the guidelines laid down in the Declaration of Helsinki of 1975, as revised in 1983. The procedures were approved by the Medical Ethics Committee of the Academic Hospital Maastricht (CTCM azM). Informed consent was obtained from all subjects, and participants received payment for their participation in the experiment.

\section{Design and procedure}

The influence of a seven-day TRP treatment on sleep quality was monitored in participants with S'/S' and L'/L' 5-HTTLPR genotypes using a double-blind placebo-controlled design. Participants with S'/S' and L'/L' 5-HTTLPR genotypes, further classified as high or low neuroticism, were randomly allocated to either a TRP or placebo condition. After dividing individuals along these conditions, participants were asked to schedule a week in which they were able to participate. A week before testing, all participants picked up an envelope at the university that included instructions, relevant questionnaires, and seven packages of capsules containing daily supplementation. During the test week, participants self-administered capsules containing either TRP or placebo. In order to ensure treatment compliance, participants were instructed to provide a saliva sample every morning, and were led to believe compliance could be assessed by this means. In addition, a questionnaire measuring daily hassles was completed on a daily basis. At day eight, participants visited the university to hand in all materials and complete a PSQI questionnaire to measure their sleep quality during the test week. Figure 1 displays a schematic illustration of the experimental design and procedure. 
A.

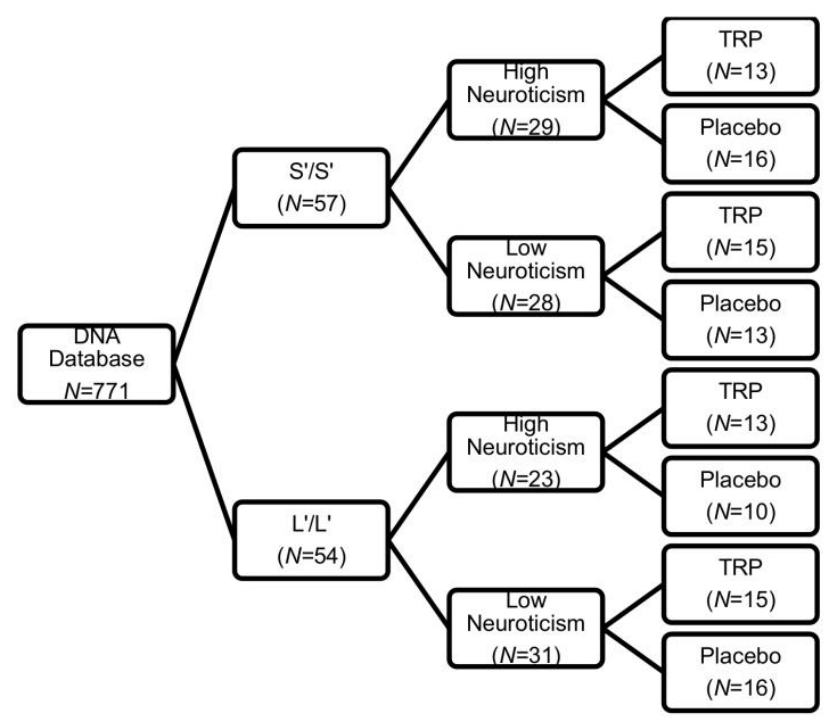

B.

Pre-Experimental
Screening

Neuroticism

Depression

Stressful life events
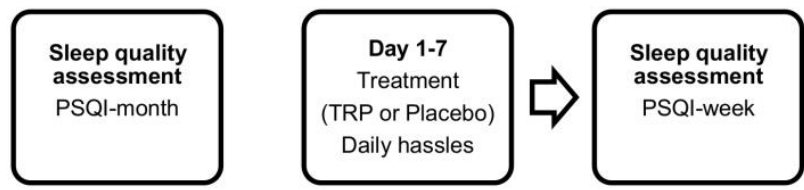

Figure 1. Experimental design (A), pre-experimental measures (B), and experimental period (C). PSQI: Pittsburgh Sleep Quality Index; TRP: tryptophan.

\section{Treatment}

During the test week, participants were instructed to administer two capsules at a time, three times a day: once each during the morning, afternoon, and evening. Capsules in the two conditions were identical in appearance: however, they contained either tryptophan $(0.5 \mathrm{~g}$ each; for a total of $3.0 \mathrm{~g} / \mathrm{day}$ ) or placebo (micorcristaline cellulose; capsules were provided by Elvitaal, Lunteren; The Netherlands). In order to support treatment compliance, a daily checklist was included and participants were instructed to write down the exact time of administration of every pair of capsules. In addition, participants provided a saliva sample every morning, to be stored in the fridge, to be delivered at the end of the experiment, and were led to believe compliance could be assessed using this sample. 


\section{Measures}

Subjective sleep quality

A slightly modified version of the PSQI (Buysse, Reynolds, Monk, Berman, \& Kupfer, 1989) was used to assess subjective sleep quality during the treatment week (PSQI-week). Participants had to respond to a variety of statements on a scale ranging from 0 (not during the past week) to 3 (three or more times during the past week). Scoring of the 19 items resulted in 7 component scores, reflecting duration of sleep, sleep disturbance, sleep latency, day dysfunction due to sleepiness, sleep efficiency, overall sleep quality, and medication needed to sleep. The total score of all sub-scores was used as an index of experienced sleep quality during the treatment week, where higher scores are indicative of poorer sleep quality. Before the start of the study, the original version of the PSQI (PSQI-month) was used to explore possible differences in general past-month sleep quality. The PSQI is a well-validated scale with good test-retest reliability (Buysse et al., 1989).

\section{Depression}

Depressive symptoms were assessed using the BDI, a self-report questionnaire consisting of 21 items that aims to measure presence and severity of depression-related symptoms (Beck, Ward, Mendelson, Mock, \& Erbaugh, 1961). The BDI has been found to have good psychometric properties regarding reliability and validity (Lasa, Ayuso-Mateos, VazquezBarquero, Diez-Manrique, \& Dowrick, 2000).

\section{Stressful life events}

Lifetime history of stressful life events was assessed using the Dutch Life Events Questionnaire (Kraaij et al., 2003). This scale includes questions about a variety of stressful life events (e.g., divorce of parents, bereavement, victim of a crime). To include more possible life events, the Life Events Inventory (Cochrane \& Robertson, 1973) was used as a complementary questionnaire. This scale comprises nine items representing different stressful experiences (e.g., social isolation, change of residence). Scoring of the items resulted in a number of experienced stressful life events (SLE), which was used as an outcome measure.

\section{Daily hassles}

In order to assesses changes in daily hassle experiences during the test week, the present study included the Daily Hassles Checklist, adapted from the Illness Management and Recovery 
Program (Mueser et al., 2006). This questionnaire comprises 20 items and aims to provide an accurate measure of daily hassle experiences.

\section{Neuroticism}

Neuroticism was assessed using the Inadequacy Scale of the Dutch Personality Inventory (Luteijn \& Starren, 1975). This scale comprises a shortened, translated version of the California Psychological Inventory (Gough, 1987). The sub-scale consists of 21 items containing statements intended to measure neuroticism, inadequate feelings, and negativism. Scores range from 0 to 42 and high scores on this scale are closely related to emotional instability and to inefficient ways to cope with negative situations (Kendler, Gardner, \& Prescott, 2003; Magnus, Diener, Fujita, \& Pavot, 1993). Individual outcomes were used to classify participants as having either high or low neuroticism using a median split $(\mathrm{Mdn}=10)$.

\section{Genotyping}

In order to determine 5-HTTLPR genotype, sterile swabs (Omni Swabs; Whatman) were used to obtain a buccal cell sample from each participant. Isolation of genomic DNA was performed using QIamp DNA Mini Kits from Qiagen. PCR protocol was followed for the subsequent genotyping (Glatz, Mossner, Heils, \& Lesch, 2003). Allelic variants were grouped into S'/S' (S/S, S/Lg, Lg/ Lg) and L'/L' (La/La). This bi-allelic classification is in line with previous studies (Cerit et al., 2013; Markus \& Capello, 2012; Markus \& de Raedt, 2011; Markus \& Firk, 2009).

\section{Statistical analyses}

Univariate analyses of variance (ANOVA), using the General Linear Model (SPSS 20.0 for Windows; IBM Corporation), were used to analyze the data regarding the two hypotheses mentioned in the introduction. Analyses regarding treatment-unrelated, general differences in sleep quality included genotype (S'/S' vs. L'/L') and neuroticism (high vs. low) as betweensubjects factors and PSQI-month scores as the dependent factor. Analyses regarding treatment-related differences during the test week included genotype ( $\mathrm{S}^{\prime} / \mathrm{S}^{\prime}$ vs. L'/L'), neuroticism (high vs. low), and condition (TRP vs. placebo) as between-subjects factors with the PSQI-week score as the dependent variable. Only significant main or interaction effects were interpreted by further post hoc analyses. Sex, age, BDI score, and SLE frequency were initially incorporated as covariates. However, in the final analyses only BDI score was 
included as a covariate because of its significance. Evaluation of the results was performed using a significance level of 5\% (two-tailed). Data are reported as means \pm standard deviation.

\section{Results}

\section{Demographics}

As indicated in Table 1 , the $\mathrm{S}^{\prime} / \mathrm{S}^{\prime}$ and L'/L' 5-HTTLPR group did not differ on a variety of relevant demographic variables, including general sleep quality, depression, neuroticism, and stressful life events.

Table 1. Demographics

\begin{tabular}{|c|c|c|c|c|}
\hline & & $\mathrm{S}^{\prime} / \mathrm{S}^{\prime}$ & $\mathrm{L}^{\prime} / \mathrm{L}^{\prime}$ & $p$ \\
\hline Men & $n$ & 11 & 8 & \\
\hline Women & $n$ & 46 & 46 & \\
\hline Age & $(\mathrm{M} \pm \mathrm{SD})$ & $23.9 \pm 1.5$ & $24 \pm 1.8$ & 0.831 \\
\hline Sleep & $(\mathrm{M} \pm \mathrm{SD})$ & $3.7 \pm 1.9$ & $3.7 \pm 1.6$ & 0.896 \\
\hline Neuroticism & $(\mathrm{M} \pm \mathrm{SD})$ & $11.1 \pm 6.3$ & $10.0 \pm 6.8$ & 0.374 \\
\hline BDI & $(\mathrm{M} \pm \mathrm{SD})$ & $3.7 \pm 3.3$ & $3.4 \pm 3.3$ & 0.604 \\
\hline SLE & $(\mathrm{M} \pm \mathrm{SD})$ & $66.9 \pm 14.2$ & $67.4 \pm 13.9$ & 0.858 \\
\hline
\end{tabular}

\section{Effect of 5-HTTLPR genotype and neuroticism on general sleep quality}

ANOVA with genotype ( $\mathrm{S}^{\prime} / \mathrm{S}^{\prime}$ vs. L'/L') and neuroticism (high vs. low) as independent variables on the PSQI-month did not reveal significant main or interaction effects. However, a near-significant main effect of neuroticism $[\mathrm{F}(1,103)=3.708 ; \mathrm{p}=0.057]$ was observed. Interestingly, it was only when BDI was excluded as a covariate that analyses revealed a significant main effect of neuroticism $[\mathrm{F}(1,104)=5.948 ; \mathrm{p}=0.016]$, indicating significantly lower sleep quality (i.e., higher PSQI score) in the high neuroticism group ( $M=3.18 \pm 1.716)$ compared to the low neuroticism group $(\mathrm{M}=2.72 \pm 1.424)$ when depressive symptoms are not taken into account.

\section{Effect of 5-HTTLPR genotype, neuroticism, and tryptophan on sleep quality}

ANOVA with genotype (S'/S' vs. L'/L'), neuroticism (high vs. low), and condition (TRP vs. placebo) as independent variables on the PSQI-week only revealed a significant genotype $\mathrm{x}$ neuroticism $\mathrm{x}$ condition interaction $[\mathrm{F}(1,98)=8.018 ; \mathrm{p}=0.006]$, indicating a differential effect of treatment on sleep quality in the $\mathrm{S}^{\prime} / \mathrm{S}^{\prime}$ versus $\mathrm{L}^{\prime} / \mathrm{L}^{\prime}$ genotypes, depending on neuroticism. Further analyses for both genotype groups only revealed a significant 
neuroticism $x$ condition interaction in the $\mathrm{S}^{\prime} / \mathrm{S}^{\prime}$ group $[\mathrm{F}(1,50)=7.005 ; \mathrm{p}=0.011]$. As illustrated in Figure 2, only S'/S' genotypes with high neuroticism reported significantly better sleep quality (i.e., lower PSQI score) after TRP $(\mathrm{M}=2.31 \pm 1.38)$ versus placebo $(\mathrm{M}=$ $3.60 \pm 2.26 ; \mathrm{p}=0.021)$, whereas an opposite effect was reported by $\mathrm{S}^{\prime} / \mathrm{S}^{\prime}$ carriers with low neuroticism $(\mathrm{p}=0.045)$. There were no other main or interaction effects. Moreover, excluding BDI as a covariate did not change the genotype $\mathrm{x}$ neuroticism $\mathrm{x}$ condition interaction $[\mathrm{F}(1,99)$ $=7.772 ; \mathrm{p}=0.006]$.

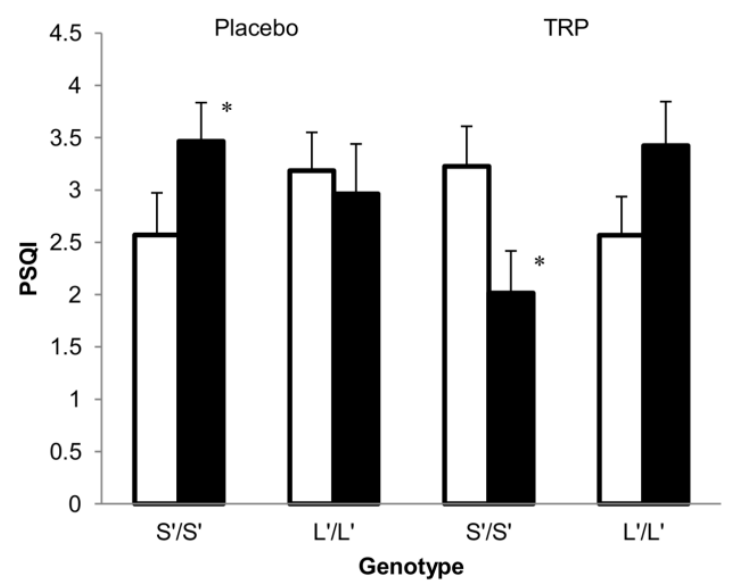

Figure 2. Estimated marginal means for the Pittsburgh Sleep Quality Index (PSQI) score after a week of tryptophan (TRP) or placebo treatment in $\mathrm{S}^{\prime} / \mathrm{S}^{\prime}$ and L'/L' genotypes classified as low (white) or high (black) neuroticism. Significant difference between the TRP and placebo conditions: $* \mathrm{p}<0.05$.

\section{Effect of neuroticism on stress experience}

In order to check the effectiveness of the neuroticism (high vs. low) classification, an ANOVA was conducted with neuroticism (high vs. low) as the independent variable on SLE frequency. Analyses revealed a significant main effect of neuroticism $[\mathrm{F}(1,109)=10.399 ; \mathrm{p}=$ 0.002], indicating more past stress experiences in the high neuroticism group $(\mathrm{M}=$ $71.52 \pm 15.69)$ compared to the low neuroticism group $(M=63.29 \pm 11.05)$. In addition, in order to examine the influence of neuroticism on stressful life experiences during the test week, a second ANOVA was performed with neuroticism (high vs. low) as the independent variable on the Daily Hassles Checklist score. This also revealed a main effect of neuroticism $[F(1,109)=9.678 ; p=0.002]$, indicating the high neuroticism group experienced more stress during the experimental period $(\mathrm{M}=2.53 \pm 1.75)$ than the low neuroticism group $(\mathrm{M}=$ $1.56 \pm 1.53)$. 


\section{Discussion}

The present study aimed to investigate the interaction between 5-HTTLPR and stress on sleep quality. In contrast to our hypothesis, no differences were found between $S^{\prime} / S^{\prime}$ and $L^{\prime} / L^{\prime}$ carriers on general past sleep quality, regardless of the vulnerability to experience chronic stress (as measured by neuroticism). However, in line with our hypothesis, 7 days of TRP supplementation was exclusively associated with better sleep quality in participants with the S'/S' 5-HTTLPR genotype who were also classified as high neuroticism.

\section{5-HTTLPR genotype and stress-related sleep quality}

Including trait neuroticism as a valid measure for the vulnerability to frequent, negative stress experiences, it was hypothesized that this would interact with 5-HTTLPR in order to influence sleep quality. To date, only a few studies have examined the influence of 5HTTLPR on sleep quality, and only one examined whether negative circumstances - as indirectly conceptualized by taking care of a close relative with dementia-may moderate the relationship between 5-HTTLPR and sleep quality (Brummett et al., 2007). Results of this previous study demonstrated that being a caregiver for a spouse or parent with dementia was associated with a reduction in sleep quality, particularly in S-allele 5-HTTLPR carriers. Assuming that this type of caregiving is associated with enhanced physical and emotional strain, the authors concluded that the 5-HTTLPR genotype plays a moderating role in stressrelated sleep disturbances. However, although caregiving has been associated with physical and emotional stress, it particularly displays a close relationship with depression (Pinquart \& Sörensen, 2003). Brummett et al., (2007) neither controlled for stress nor for depression, it remains unclear from their study whether the reduced sleep quality observed in their S-allele carriers was indeed primarily caused by stress or, instead, by its depressogenic consequences. Depressive symptoms particularly occur as a consequence of long-term uncontrollable/unchangeable negative circumstances and have already been found to be the most important predictor for sleep quality in caregivers for relatives with dementia (Peng \& Chang, 2013).

In order to determine whether stress is indeed a moderating mechanism involved, the present study included trait neuroticism as a measure for the vulnerability to frequent stress experiences while controlling for depression (i.e., excluding clinically-relevant BDI scores and including BDI score as a covariate). Results did not reveal the expected interaction between 5-HTTLPR genotype and neuroticism on general past sleep quality, even though 
high scores on neuroticism were indeed associated with increased frequencies of stressful life experiences and daily hassles. Based on these findings, it seems likely that stress experience itself is not a sufficient factor to influence sleep quality as a function of 5-HTTLPR. Combining the previous findings of Brummett et al. (2007) with our current findings, a more elaborated picture may be reached in which allelic variation in the 5-HTTLPR may influence the effects of stress on sleep quality more precisely by promoting the depressogenic consequence of stress experiences. Of course, this hypothesis can be further supported by including subjects with more profound (i.e., more clinically relevant) depression symptoms. Hence, this might also have been the confounding, uncontrolled factor mediating the interaction between 5-HTTLPR and caregiving on sleep quality as reported by Brummett et al. (2007). Since sleep and depression are closely related (Riemann, Berger, \& Voderholzer, 2001) and 5-HTTLPR S-allele carriers are already at increased risk to develop depressive symptoms in response to frequent stress experiences (Caspi et al., 2003; Karg et al., 2011), it is suggested that 5-HTTLPR may promote sleep disturbances-particularly in S-allele carriers - when stress is experienced, by way of increasing susceptibility to stress-related depressive symptoms.

\section{Differential effect of TRP in 5-HTTLPR genotype depending on neuroticism}

In order to examine whether 5-HT vulnerability (as a consequence of the S'/S' 5-HTTLPR genotype) plays an important role in stress proneness and stress-related sleep quality, the present study additionally examined the effects of brain 5-HT manipulation — by way of TRP augmentation - on sleep quality in relation to the 5-HTTLPR genotype and neuroticism. As expected, sub-chronic TRP supplementation was exclusively associated with better sleep quality in subjects with the S'/S' 5-HTTLPR genotype who were classified as high neuroticism. Based on previous findings, these beneficial effects of TRP may be related to improved stress adaptation and, hence, reduced stress experience (even though this was not directly measured). After all, S-allele carriers are found to be more prone to experience negative stress, as evidenced in a broad range of epidemiological studies (Karg et al., 2011; Risch, Herrell, Lehner, \& et al., 2009) and in acute stress exposure studies (Alexander et al., 2009; Gotlib et al., 2008; Markus \& de Raedt, 2011; Mueller et al., 2010; Way \& Taylor, 2010), probably as a consequence of 5-HT-receptor sensitization to compensate for lower 5HTT expression (David et al., 2005; Jans, Riedel, Markus, \& Blokland, 2007; Markus, 2008). Particularly in combination with chronic stress, 5-HT dysfunction in S-allele genotypes is 
expected to become worse, causing the stress system to become unbalanced (Markus, 2008, 2013; van Praag, 2004). Since TRP is found to increase brain 5-HT synthesis and to reduce stress responsiveness in 5-HTTLPR S-allele carriers (Capello \& Markus, 2014; Cerit et al., 2013), its current beneficial effect on sleep quality in $S^{\prime} / S^{\prime}$ genotype subjects with high neuroticism might thus be explained as a result of improved stress adaptation. Nevertheless, since 5-HT is commonly known to play a most important role in stress-related depression (Jans et al., 2007), and 5-HTTLPR is found to moderate the relationship between stress and depression (Caspi et al., 2003; Karg et al., 2011), the current beneficial effects of TRP on sleep quality in $S^{\prime} / S^{\prime}$ carriers might be particularly attributed to its reducing influence on stress-related depressive symptomatology. Tryptophan supplementation is known to increase brain 5-HT synthesis and may therefore compensate for reduced 5-HT functioning and, hence, reduce depressed mood in S'/S' 5-HTTLPR subjects classified as high neuroticism. This is in line with previous findings demonstrating that TRP augmentation significantly improves mood, especially in 5-HT-vulnerable subjects (Markus \& Firk, 2009) and stress-prone individuals (Markus et al., 2000). Furthermore, given the well-established relationship between sleep and depression (Riemann et al., 2001), the ability of TRP to reduce depressed moods is likely to result in a significant improvement of sleep quality. This is in agreement with the previously-described suggestion that the sleep quality reductions in caregivers with the S'/S' 5-HTTLPR genotype observed by Brummett et al. (2007) are caused by depressive symptomatology, possibly resulting from a diminished functional efficiency of the 5-HT system related to chronic stress experience.

\section{Limitations}

The present study is subjected to the following limitations. First, the small sample size might have reduced statistical power during further analyses of the observed interaction between 5 HTTLPR genotype, neuroticism, and treatment condition. Nonetheless, as expected, separate analyses still revealed a beneficial effect of TRP in participants with the S'/S' 5-HTTLPR genotype who were classified as high neuroticism. Second, although it was a major objective to isolate the effects of stress from depressive-affective symptoms, exclusion of participants with high BDI scores might have underestimated the effect of neuroticism on sleep quality. It might be possible that, if depression was not controlled for, an interaction between neuroticism and 5-HTTLPR genotype would have been observed. Future studies are needed to disentangle how stress, its depressogenic consequences, and the 5-HTTLPR genotype may 
interact with each other to exert an influence on sleep quality. In addition, polysomnographic measures need to be included as additional indices for changes in sleep quality and/or architecture.

\section{Conclusion}

The present study implies that the 5-HTTLPR genotype does not directly moderate the relationship between stress vulnerability and sleep quality. However, allelic variation in the 5HTTLPR does seem to play an important role in stress-related sleep quality, probably by its moderating influence on the relationship between stress and depressive symptomatology. More specifically, in line with previous findings, it is suggested that in response to chronic stress, individuals with the S'/S' 5-HTTLPR genotype especially experience depressive symptoms and, hence, related sleep disturbances. These mood alterations are suggested to reflect a decreased functional efficiency of the 5-HT system, resulting from a genetic 5-HT vulnerability further augmented by the negative influence of stress on 5-HT functioning. TRP augmentation may compensate for this reduced 5-HT functioning by increasing brain 5-HT synthesis, thereby reducing depressive symptomatology and, hence, improving related sleep quality. More research is necessary to determine if the potential role of the 5-HTTLPR genotype in regulating sleep quality is indeed caused by its moderating influence on the relationship between stress and depression. In addition, future studies should aim to determine the neurobiological mechanisms responsible for the moderating role of the 5-HTTLPR genotype in the relationship between stress and depression.

\section{Statement of interest}

None.

\section{Acknowledgments}

The authors would like to express their appreciation to Teunis van Eldik from Elvitaal (Elvitaal, Lunteren; The Netherlands) for the free supply of standardized L-Tryptophan and Placebo capsules that were used in the present study. The authors would further like to thank Ezgi Firat, Hille Springsfeld, and Aimee Capello for their kind contributions during the organization of the experiment. 


\section{References}

Åkerstedt, T., Orsini, N., Petersen, H., Axelsson, J., Lekander, M., \& Kecklund, G. (2012). Predicting sleep quality from stress and prior sleep - A study of day-to-day covariation across sixweeks. Sleep Med, 13(6), 674-679.

Alexander, N., Kuepper, Y., Schmitz, A., Osinsky, R., Kozyra, E., \& Hennig, J. (2009). Geneenvironment interactions predict cortisol responses after acute stress: implications for the etiology of depression. Psychoneuroendocrinology, 34(9), 1294-1303. doi:10.1016/j.psyneuen.2009.03.017

Barclay, N. L., Eley, T. C., Mill, J., Wong, C. C., Zavos, H. M., Archer, S. N., \& Gregory, A. M. (2011). Sleep quality and diurnal preference in a sample of young adults: associations with 5HTTLPR, PER3, and CLOCK 3111. Am J Med Genet B Neuropsychiatr Genet, 156B(6), 681-690. doi:10.1002/ajmg.b.31210

Barclay, N. L., Eley, T. C., Rijsdijk, F. V., \& Gregory, A. M. (2011). Dependent negative life events and sleep quality: An examination of gene-environment interplay. Sleep Med, 12(4), 403-409. doi:10.1016/j.sleep.2010.09.009

Beck, A. T., Ward, C. H., Mendelson, M., Mock, J., \& Erbaugh, J. (1961). An inventory for measuring depression. Archives of General Psychiatry, 4, 561-571.

Beihl, D. A., Liese, A. D., \& Haffner, S. M. (2009). Sleep Duration as a Risk Factor for Incident Type 2 Diabetes in a Multiethnic Cohort. Annals of Epidemiology, 19(5), 351-357. doi:10.1016/j.annepidem.2008.12.001

Brown, G. W., Bifulco, A., \& Harris, T. O. (1987). Life events, vulnerability and onset of depression: some refinements. The British Journal of Psychiatry, 150(1), 30-42. doi:10.1192/bjp.150.1.30

Brummett, B. H., Krystal, A. D., Ashley-Koch, A., Kuhn, C. M., Zuchner, S., Siegler, I. C., . . . Williams, R. B. (2007). Sleep quality varies as a function of 5-HTTLPR genotype $\begin{array}{llll}\text { and stress. } & \text { Psychosomatic }\end{array}$ doi:10.1097/PSY.0b013e31814b8de6

Buckley, T. M., \& Schatzberg, A. F. (2005). On the interactions of the hypothalamicpituitary-adrenal (HPA) axis and sleep: normal HPA axis activity and circadian rhythm, exemplary sleep disorders. Journal of Clinical Endocrinology and Metabolism, 90(5), 3106-3114. doi:jc.2004-1056 [pii] 10.1210/jc.2004-1056

Buysse, D. J., Reynolds, C. F., 3rd, Monk, T. H., Berman, S. R., \& Kupfer, D. J. (1989). The Pittsburgh Sleep Quality Index: a new instrument for psychiatric practice and research. Psychiatry Research, 28(2), 193-213.

Calkins, A. W., Hearon, B. A., Capozzoli, M. C., \& Otto, M. W. (2012). Psychosocial Predictors of Sleep Dysfunction: The Role of Anxiety Sensitivity, Dysfunctional Beliefs, and Neuroticism. Behavioral Sleep Medicine, 11(2), 133-143. doi:10.1080/15402002.2011.643968

Capello, A. E. M., \& Markus, C. R. (2014). Effect of sub chronic tryptophan supplementation on stress-induced cortisol and appetite in subjects differing in 5-HTTLPR genotype and trait neuroticism. Psychoneuroendocrinology, 45(0), 96-107. doi:10.1016/j.psyneuen.2014.03.005

Caspi, A., Sugden, K., Moffitt, T. E., Taylor, A., Craig, I. W., Harrington, H., . . Poulton, R. (2003). Influence of life stress on depression: moderation by a polymorphism in the 5HTT gene. Science, 301(5631), 386-389. doi:10.1126/science.1083968

Cerit, H., Jans, L. A., \& Van der Does, W. (2013). The effect of tryptophan on the cortisol response to social stress is modulated by the 5-HTTLPR genotype. Psychoneuroendocrinology, 38(2), 201-208. doi:10.1016/j.psyneuen.2012.05.016 
Cochrane, R., \& Robertson, A. (1973). The life events inventory: a measure of the relative severity of psycho-social stressors. Journal of Psychosomatic Research, 17(2), 135140.

David, S. P., Murthy, N. V., Rabiner, E. A., Munafo, M. R., Johnstone, E. C., Jacob, R., . . Grasby, P. M. (2005). A functional genetic variation of the serotonin (5-HT) transporter affects 5-HT1A receptor binding in humans. Journal of Neuroscience, 25(10), 2586-2590. doi:10.1523/jneurosci.3769-04.2005

Firk, C., \& Markus, C. R. (2007). Review: Serotonin by stress interaction: a susceptibility factor for the development of depression? J Psychopharmacol, 21(5), 538-544. doi:0269881106075588 [pii] 10.1177/0269881106075588

Gallagher, D. J. (1990). Extraversion, neuroticism and appraisal of stressful academic events. Personality and Individual Differences, 11(10), 1053-1057. doi:10.1016/01918869(90)90133-C

Glatz, K., Mossner, R., Heils, A., \& Lesch, K. P. (2003). Glucocorticoid-regulated human serotonin transporter (5-HTT) expression is modulated by the 5-HTT gene-promotorlinked polymorphic region. Journal of Neurochemistry, 86(5), 1072-1078.

Gotlib, I. H., Joormann, J., Minor, K. L., \& Hallmayer, J. (2008). HPA axis reactivity: a mechanism underlying the associations among 5-HTTLPR, stress, and depression. Biological Psychiatry, 63(9), 847-851. doi:10.1016/j.biopsych.2007.10.008

Gough, H. C. (1987). California Psychological Inventory Administrator's Guide. Palo Alto, CA: Consulting Psychologist Press, Inc.

Gunthert, K. C., Cohen, L. H., \& Armeli, S. (1999). The role of neuroticism in daily stress and coping. Journal of Personality and Social Psychology, 77(5), 1087-1100.

Guo, X., Zheng, L., Wang, J., Zhang, X., Zhang, X., Li, J., \& Sun, Y. (2013). Epidemiological evidence for the link between sleep duration and high blood pressure: A systematic review and meta-analysis. Sleep Med, 14(4), 324-332.

Heils, A., Teufel, A., Petri, S., Stober, G., Riederer, P., Bengel, D., \& Lesch, K. P. (1996). Allelic variation of human serotonin transporter gene expression. Journal of Neurochemistry, 66(6), 2621-2624.

Jans, L. A., Riedel, W. J., Markus, C. R., \& Blokland, A. (2007). Serotonergic vulnerability and depression: assumptions, experimental evidence and implications. Molecular Psychiatry, 12(6), 522-543. doi:10.1038/sj.mp.4001920

Karg, K., Burmeister, M., Shedden, K., \& Sen, S. (2011). The serotonin transporter promoter variant (5-HTTLPR), stress, and depression meta-analysis revisited: evidence of genetic moderation. Archives of General Psychiatry, 68(5), 444-454. doi:10.1001/archgenpsychiatry.2010.189

Kendler, K. S., Gardner, C. O., \& Prescott, C. A. (2003). Personality and the experience of environmental adversity. Psychological Medicine, 33(7), 1193-1202.

Kraaij, V., Garnefski, N., de Wilde, E., Dijkstra, A., Gebhardt, W., Maes, S., \& ter Doest, L. (2003). Negative Life Events and Depressive Symptoms in Late Adolescence: Bonding and Cognitive Coping as Vulnerability Factors? Journal of Youth and Adolescence, 32(3), 185-193. doi:10.1023/a:1022543419747

Krystal, A. D. (2006). Sleep and Psychiatric Disorders: Future Directions. Psychiatric Clinics of North America, 29(4), 1115-1130. doi:10.1016/j.psc.2006.09.001

Lasa, L., Ayuso-Mateos, J. L., Vazquez-Barquero, J. L., Diez-Manrique, F. J., \& Dowrick, C. F. (2000). The use of the Beck Depression Inventory to screen for depression in the general population: a preliminary analysis. Journal of Affective Disorders, 57(1-3), 261-265.

Lazarus, R., \& Folkman, S. (1984). Stress, Appraisal, and Coping. New York: Springer. 
Leger, D., Poursain, B., Neubauer, D., \& Uchiyama, M. (2008). An international survey of sleeping problems in the general population. Current Medical Research and Opinion, 24(1), 307-317. doi:10.1185/030079907X253771

Lesch, K. P., Bengel, D., Heils, A., Sabol, S. Z., Greenberg, B. D., Petri, S., . . Murphy, D. L. (1996). Association of anxiety-related traits with a polymorphism in the serotonin transporter gene regulatory region. Science, 274(5292), 1527-1531.

Lund, H. G., Reider, B. D., Whiting, A. B., \& Prichard, J. R. (2010). Sleep Patterns and Predictors of Disturbed Sleep in a Large Population of College Students. Journal of Adolescent Health, 46(2), 124-132. doi:10.1016/j.jadohealth.2009.06.016

Luteijn, F. E., \& Bouman, T. K. (1988). The concepts of depression, anxiety, and neuroticism in questionnaires. European Journal of Personality, 2(2), 113-120. doi:10.1002/per.2410020206

Luteijn, F. E., \& Starren, J. (1975). Dutch Personality Inventory. Lisse; The Netherlands: Swets \& Zeitlinger.

Magnus, K., Diener, E., Fujita, F., \& Pavot, W. (1993). Extraversion and neuroticism as predictors of objective life events: a longitudinal analysis. Journal of Personality and Social Psychology, 65(5), 1046-1053.

Markus, C. R. (2008). Dietary amino acids and brain serotonin function; implications for stress-related affective changes. Neuromolecular medicine, 10(4), 247-258. doi:10.1007/s12017-008-8039-9

Markus, C. R. (2013). Interaction between the 5-HTTLPR Genotype, Impact of Stressful Life Events and Trait Neuroticism on Depressive Symptoms in Healthy Volunteers. Psychiatric Genetics, 23(3), 108-116.

Markus, C. R., \& Capello, A. E. (2012). Contribution of the 5-HTTLPR gene by neuroticism on weight gain in male and female participants. Psychiatric Genetics, 22(6), 279-285. doi:10.1097/YPG.0b013e328358632a

Markus, C. R., \& de Raedt, R. (2011). Differential effects of 5-HTTLPR genotypes on inhibition of negative emotional information following acute stress exposure and tryptophan challenge. Neuropsychopharmacology : official publication of the American College of Neuropsychopharmacology, 36(4), 819-826. doi:10.1038/npp.2010.221

Markus, C. R., \& Firk, C. (2009). Differential effects of tri-allelic 5-HTTLPR polymorphisms in healthy subjects on mood and stress performance after tryptophan challenge. Neuropsychopharmacology : official publication of the American College of Neuropsychopharmacology, 34(13), 2667-2674. doi:10.1038/npp.2009.92

Markus, C. R., Olivier, B., Panhuysen, G. E., Van Der Gugten, J., Alles, M. S., Tuiten, A., .. . de Haan, E. E. (2000). The bovine protein alpha-lactalbumin increases the plasma ratio of tryptophan to the other large neutral amino acids, and in vulnerable subjects raises brain serotonin activity, reduces cortisol concentration, and improves mood under stress. The American journal of clinical nutrition, 71(6), 1536-1544.

Mezick, E. J., Matthews, K. A., Hall, M., Kamarck, T. W., Buysse, D. J., Owens, J. F., \& Reis, S. E. (2009). Intra-individual variability in sleep duration and fragmentation: associations with stress. Psychoneuroendocrinology, 34(9), 1346-1354. doi:S03064530(09)00121-8 [pii] 10.1016/j.psyneuen.2009.04.005

Miller, R., Wankerl, M., Stalder, T., Kirschbaum, C., \& Alexander, N. (2013). The serotonin transporter gene-linked polymorphic region (5-HTTLPR) and cortisol stress reactivity: a meta-analysis. Molecular Psychiatry, 18(9), 1018-1024. doi:10.1038/mp.2012.124

Mueller, A., Brocke, B., Fries, E., Lesch, K. P., \& Kirschbaum, C. (2010). The role of the serotonin transporter polymorphism for the endocrine stress response in newborns. Psychoneuroendocrinology, 35(2), 289-296. doi:10.1016/j.psyneuen.2009.07.002 
Mueser, K. T., Meyer, P. S., Penn, D. L., Clancy, R., Clancy, D. M., \& Salyers, M. P. (2006). The Illness Management and Recovery program: rationale, development, and preliminary findings. Schizophrenia Bulletin, 32 Suppl 1, S32-43. doi:10.1093/schbul/sbl022

Peng, H. L., \& Chang, Y. P. (2013). Sleep Disturbance in Family Caregivers of Individuals With Dementia: A Review of the Literature. Perspectives in Psychiatric Care, 49(2), 135-146.

Penley, J. A., Tomaka, J., \& Wiebe, J. S. (2002). The association of coping to physical and psychological health outcomes: a meta-analytic review. Journal of Behavioral Medicine, 25(6), 551-603.

Pinquart, M., \& Sörensen, S. (2003). Differences between caregivers and noncaregivers in psychological health and physical health: A meta-analysis. Psychology and Aging, 18(2), 250-267. doi:10.1037/0882-7974.18.2.250

Riemann, D., Berger, M., \& Voderholzer, U. (2001). Sleep and depression - results from psychobiological studies: an overview. Biological Psychology, 57(1-3), 67-103. doi:10.1016/S0301-0511(01)00090-4

Risch, N., Herrell, R., Lehner, T., \& et al. (2009). Interaction between the serotonin transporter gene (5-httlpr), stressful life events, and risk of depression: A metaanalysis. JAMA, 301(23), 2462-2471. doi:10.1001/jama.2009.878

Roberts, S. B., \& Kendler, K. S. (1999). Neuroticism and self-esteem as indices of the vulnerability to major depression in women. Psychological Medicine, 29(5), 11011109.

Rodenbeck, A., Huether, G., Rüther, E., \& Hajak, G. (2002). Interactions between evening and nocturnal cortisol secretion and sleep parameters in patients with severe chronic primary insomnia. Neuroscience Letters, 324(2), 159-163. doi:10.1016/S03043940(02)00192-1

Schwartz, S., Anderson, W. M., Cole, S. R., Cornoni-Huntley, J., Hays, J. C., \& Blazer, D. (1999). Insomnia and heart disease: A review of epidemiologic studies. Journal of Psychosomatic Research, 47(4), 313-333. doi:10.1016/S0022-3999(99)00029-X

Shoji, K., Harrigan, J. A., Woll, S. B., \& Miller, S. A. (2010). Interactions among situations, neuroticism, and appraisals in coping strategy choice. Personality and Individual Differences, 48(3), 270-276. doi:10.1016/j.paid.2009.10.009

Steiger, A. (2002). Sleep and the hypothalamo-pituitary-adrenocortical system. Sleep Med Rev, 6(2), 125-138. doi:10.1053/smrv.2001.0159

Vahtera, J., Kivimäki, M., Hublin, C., Korkeila, K., Suominen, S., Paunio, T., \& Koskenvuo, M. (2007). Liability to anxiety and severe life events as predictors of new-onset sleep disturbances. Sleep, 30(11), 1537-1546.

van Praag, H. M. (2004). Can stress cause depression? Progress in NeuroPsychopharmacology and Biological Psychiatry, 28(5), 891-907. doi:10.1016/j.pnpbp.2004.05.031

van Praag, H. M., De Kloet, E. R., \& Van Os, J. (2004). Stress, the brain and depresion. Cambridge: Cambridge University Press.

Watson, D., \& Clark, L. A. (1984). Negative affectivity: the disposition to experience aversive emotional states. Psychological Bulletin, 96(3), 465-490.

Way, B. M., \& Taylor, S. E. (2010). The serotonin transporter promoter polymorphism is associated with cortisol response to psychosocial stress. Biological Psychiatry, 67(5), 487-492. doi:10.1016/j.biopsych.2009.10.021 


\section{Chapter 3}

The serotonin transporter gene-linked polymorphic region (5-HTTLPR) and the sleep-promoting effects of tryptophan: a randomized placebo-controlled crossover study

Manuscript submitted for publication as:

van Dalfsen, J. H., \& Markus, C. R. (2018). The serotonin transporter gene-linked polymorphic region (5-HTTLPR) and the sleep-promoting effects of tryptophan: a randomized placebo-controlled crossover study. 


\begin{abstract}
The low expressive short (S) allele of a functional polymorphism (5-HTTLPR) within the serotonin (5-hydroxytriptamine; 5-HT) transporter gene (SLC6A4) has been associated with a reduced functioning of the brain 5-HT system relative to the long (L) allele. As a consequence, the $\mathrm{S}$-allele is found to predispose the risk for sleep quality reductions and clinical insomnia. The present study investigated whether subchronic pre-sleep tryptophan administration could compensate for this predisposition by particularly improving sleep in 5HTTLPR S-allele carriers. In a double-blind placebo-controlled crossover design a sample of homozygous 5-HTTLPR S-allele $(n=47)$ and L-allele $(n=51)$ carriers were assessed for subjective- (sleep diary) and objective- (actigraphy) sleep during a treatment protocol consisting of one week placebo and one week of tryptophan administration (1000 mg/day). Results support the sleep-promoting effects of tryptophan. While tryptophan improved objective sleep efficiency and objective wake after sleep onset irrespective of allelic variation, 5-HTTLPR was found to modulate the effect of tryptophan on subjective sleep quality by exclusively improving sleep quality in 5-HTTLPR S-allele relative to L-allele carriers. In addition to previous work, tryptophan augmentation might become a promising and valuable treatment strategy for sleep impairments related to genetic deficiencies in 5-HT functioning.
\end{abstract}




\section{Introduction}

Sleep disturbances are highly prevalent in the general population. Consensus has been reached that around $30 \%$ of the adult population reports some form of sleep complaint (Ancoli-Israel \& Roth, 1999; Leger, Poursain, Neubauer, \& Uchiyama, 2008) whereas approximately 6\%$8 \%$ meets the diagnostic criteria for clinical insomnia (Ohayon, 1997; Uhlig, Sand, Odegard, \& Hagen, 2014). This is of high clinical relevance as inadequate sleep contributes to a diversity of medical conditions (Cappuccio, D'Elia, Strazzullo, \& Miller, 2010; Palagini et al., 2013; Schwartz et al., 1999) and comprises one of the primary risk factors for major depression (Baglioni et al., 2011). These findings emphasize the need to identify factors involved in the etiology of sleep disturbances and develop adequate clinical interventions.

Genetic factors considerably contribute to the etiology of sleep disturbances as demonstrated in heritability (Bastien \& Morin, 2000; Beaulieu-Bonneau, LeBlanc, Merette, Dauvilliers, \& Morin, 2007; Dauvilliers et al., 2005; Lind, Aggen, Kirkpatrick, Kendler, \& Amstadter, 2015; Wing et al., 2012) and genome-wide association studies (Hammerschlag et al., 2017; Lane et al., 2017). As a specific candidate gene, accumulating evidence suggests that a functional polymorphism (serotonin transporter gene-linked polymorphic region; 5HTTLPR) within the promoter region of the serotonin (5-hydroxytriptamine; 5-HT) transporter gene (SLC6A4) modulates the risk for sleep impairments. This polymorphism regulates the transcriptional efficiency of the 5-HT transporter and comprises an allelic variation of which the short $(\mathrm{S})$ allele is associated with a reduced expression and functioning of the 5-HT transporter relative to long (L) allele, although complex mechanisms may mediate a more diverse influence on the 5-HT neurotransmission (Murphy \& Lesch, 2008). As a consequence of this deficient 5-HT functioning, the 5-HTTLPR S-allele is found to predispose the risk for stress- (Brummett et al., 2007; Huang et al., 2014) and depressionrelated (Polito et al., 2015) sleep disturbance as well as clinical insomnia (Deuschle et al., 2010; Huang et al., 2014), even though these findings have not always been consistently replicated (Barclay et al., 2011; van Dalfsen \& Markus, 2015, 2018). In line with the involvement of 5-HT in sleep regulation (Ursin, 2002), these findings suggest that genetic influences on 5-HT neurotransmission considerably contribute to the etiology of sleep impairments.

The observation that the 5-HTTLPR S-allele promotes sleep disturbance encourages the search for pharmacological interventions aimed to compensate for the deficient 5-HT functioning. Brain 5-HT is synthesized in serotonergic neurons from the essential amino acid 
tryptophan where it is first metabolized into the immediate 5-HT precursor 5hydroxytryptophan (5-HTP) by the enzyme tryptophan hydroxylase. Since this enzyme is not fully saturated it provides a rate-limiting step that controls further 5-HT synthesis depending on tryptophan availability (Fernstrom, 2012; Wurtman, Hefti, \& Melamed, 1980). In relation, the synthetic pathway of 5-HT is very sensitive to pharmacological increments in tryptophan availability, which are found to rapidly increase brain 5-HT levels (Eccleston, Ashcroft, \& Crawford, 1970; Fernstrom, 1983) even at low pharmaceutical dosage (Fernstrom \& Wurtman, 1971). Specific effects of tryptophan on sleep regulation have been repeatedly demonstrated in both healthy subjects and insomnia patients including a reduced sleep onset latency, increased total sleep time and decreased wake after sleep onset (for review see: (Hartmann \& Greenwald, 1984; Schneider-Helmert \& Spinweber, 1986; Silber \& Schmitt, 2010)). Taken together, these findings indicate that tryptophan augmentation might well provide a promising pathway to compensate for the 5-HT related sleep disturbances associated with the 5-HTTLPR S-allele. Although one previous investigation supports particular sleep-promoting effects in this allelic variant (van Dalfsen \& Markus, 2015), studies including evening tryptophan administration, more detailed sleep assessment and within subjects comparisons are desirable to further establish this pharmacogenetic effect.

The present study therefore investigated whether subchronic pre-sleep tryptophan administration improves sleep depending on allelic variation in 5-HTTLPR. In a double-blind placebo-controlled crossover design a well-screened sample of homozygous S-allele and Lallele carriers were monitored for subjective- (sleep diary) and objective- (actigraphy) sleep during a treatment protocol consisting of one week pre-sleep placebo and one week of presleep tryptophan administration (1000 $\mathrm{mg} / \mathrm{day})$. It is expected that tryptophan improves objectively and subjectively measured sleep, particularly in the low expressive 5-HTTLPR Sallele.

\section{Materials and methods}

\section{Participants}

Participants were obtained from a recently created 5-HTTLPR database $(n=804)$ and were carefully selected based on the following inclusion and exclusion criteria. Inclusion criteria encompassed: homozygous $\mathrm{S}^{\prime} / \mathrm{S}^{\prime}\left(\mathrm{S} / \mathrm{S}, \mathrm{S} / \mathrm{L}_{\mathrm{g}}, \mathrm{L}_{\mathrm{g}} / \mathrm{L}_{\mathrm{g}}\right)$ or $\mathrm{L}^{\prime} / \mathrm{L}^{\prime}\left(\mathrm{L}_{\mathrm{a}} / \mathrm{L}_{\mathrm{a}}\right)$ 5-HTTLPR genotype. Exclusion criteria comprised: diabetes, pregnancy or breast feeding, bladder problems (physical irritation, bladder cancer), gastrointestinal diagnosis (diminished amount of gastric 
acid, diminished absorption in the upper bowel), psychiatric diagnosis, sleep disorder diagnosis, heavy snoring, shift work (contemporary or during the past month) as well as the use of sleep medication, antidepressants, antipsychotics or recreational drugs (during or within one month prior to study participation). The final sample $(n=98)$, consisting of $\mathrm{S}^{\prime} / \mathrm{S}^{\prime}$ $(n=47)$ and L'/L' $(n=51)$ 5-HTTLPR genotypes, included 25 (25.5\%) male and 73 (74.5\%) female participants aged between 20 and 30 years of age $(M=22.21, S D=2.00)$. Followed procedures were approved by the local ethics committee of Maastricht University (Ethical Review Committee Psychology and Neuroscience; ERCPN) and are in line with the guidelines laid down in the Declaration of Helsinki (1975; as revised in 1983). Informed consent was obtained from all subjects and participants received financial compensation for their contribution to the present study.

\section{Genotyping}

Sterile swabs (Omni Swabs; Whatman, Maidstone, United Kingdom) were used to acquire buccal cell samples for 5-HTTLPR determination. Isolation of genomic DNA was performed using QIamp DNA Mini Kits (Qiagen, Leusden, The Netherlands). Polymerase chain reaction (PCR) protocol was followed for the subsequent 5-HTTLPR genotyping (Glatz, Mossner, Heils, \& Lesch, 2003). Tri-allelic variants were reclassified into a functionally relevant biallelic model including $\mathrm{S}^{\prime} / \mathrm{S}^{\prime}\left(\mathrm{S} / \mathrm{S}, \mathrm{S} / \mathrm{L}_{\mathrm{g}}, \mathrm{L}_{\mathrm{g}} / \mathrm{L}_{\mathrm{g}}\right), \mathrm{S}^{\prime} / \mathrm{L}^{\prime}\left(\mathrm{S} / \mathrm{L}_{\mathrm{a}}, \mathrm{L}_{\mathrm{g}} / \mathrm{L}_{\mathrm{a}}\right)$ and $\mathrm{L}^{\prime} / \mathrm{L}^{\prime}\left(\mathrm{L}_{\mathrm{a}} / \mathrm{L}_{\mathrm{a}}\right)$ respectively (Nakamura, Ueno, Sano, \& Tanabe, 2000). Hardy-Weinberg equilibrium (HWE) was determined for the initial database and revealed that genotype frequencies of $\mathrm{S}^{\prime} / \mathrm{S}^{\prime}(n=$ $190), \mathrm{S}^{\prime} / \mathrm{L}^{\prime}(n=405)$ and L'/L' $(n=209)$ did not differ from HWE $\left(\chi^{2}=0.052, p=0.820\right)$.

\section{Procedure}

The influence of tryptophan on objective and subjective sleep was assessed using a doubleblind placebo-controlled crossover design. Homozygous S-allele and L-allele carriers completed a within-subjects treatment protocol consisting of one week of placebo and one week of tryptophan administration (1000 mg/day; administered 20 minutes before bedtime). Treatment order was randomized across participants and counterbalanced within 5-HTTLPR genotype groups. Sleep assessment comprised a daily sleep diary and actigraphy measurements during the night. Prior to the start of the study, participants completed general questionnaires and received verbal instructions regarding the treatment administration, sleep 
diary and actigraphy device. Participants were further asked to attain similar bedtimes and rising times throughout the experimental period.

\section{Treatment}

During the treatment protocol, participants self-administered two capsules every evening exactly 20 minutes prior to bedtime (i.e. lights out). Depending on the treatment week, capsules either contained tryptophan (500 mg per capsule, $1000 \mathrm{mg}$ in total) or placebo (microcrystalline cellulose) but were identical in appearance. This administration interval allows for a substantial amount of tryptophan uptake as peak plasma levels are generally obtained between 1-2 hours after administration (Yuwiler et al., 1981). In order to assess treatment compliance participants were asked to write down the exact time of administration or indicate they did not administer the respective capsules.

\section{Sleep diary}

The morning diary of the consensus sleep diary (CSD) was used for subjective sleep assessment (Carney et al., 2012). This daily questionnaire has been developed by leading sleep experts and provides a standardized sleep diary to improve the comparability of sleep studies (Carney et al., 2012). Asides general bedtimes and rising times this sleep diary includes subjective reports of sleep onset latency, amount of nocturnal awakenings, wake after sleep onset, sleep quality (ranging from 1 very poor to 5 very good) and refreshed sleep (ranging from 1 not rested at all to 5 very well rested). Recent comparisons between insomnia patients and healthy controls support the validity and clinical utility of the CSD (Maich, Lachowski, \& Carney, 2016).

\section{Actigraphy}

Activity-based sleep-wake monitoring (i.e. actigraphy) was used for objective sleep assessment. Methodological research indicates that actigraphy is a valid and reliable method for objective sleep assessment that is particularly sensitive to detect sleep alterations related to pharmacological interventions (for review see: (Sadeh, 2011)). Sleep data was recorded using GT3X+ activity monitors (ActiGraph, Pensacola, Florida, USA). This device includes a triaxial solid state accelerometer to measure activity. The actigraph was worn on the wrist of the non-dominant hand according to common conventions. Data was recorded at a sampling rate of $30 \mathrm{~Hz}$ with a low and high pass frequency filter of $2.5 \mathrm{~Hz}$ and $0.25 \mathrm{~Hz}$ respectively. 
Recorded sleep data was processed using ActiLife software (ActiLife 6.0, ActiGraph, Pensacola, Florida, USA).

Bedtimes and rising times reported in the sleep diary were entered to indicate the sleep period for each respective night. Data of each night was visually inspected to determine whether the actigraph was worn during the night and corresponded with reported sleep times. Sleep-wake scoring of the data was performed in one-minute epochs using a commonly used algorithm validated for the age of the present sample (Sadeh, Sharkey, \& Carskadon, 1994). The scored data was subsequently used to calculate the sleep parameters of interest including sleep onset latency, sleep efficiency, time in bed, wake after sleep onset, nocturnal awakenings and average awakening length. Polysomnographic comparisons reveal that a GT3X+ actigraphy device combined with the algorithm used in the present study produces a sensitivity, specificity and accuracy of $90 \%, 46 \%$ and $84 \%$ respectively (Slater et al., 2015).

\section{Missing data}

Data concerning the sleep diary and actigraphy variables were indicated as missing for a respective night if treatment compliance could not be ensured (placebo: $M=0.22, S D=0.83$; tryptophan: $M=0.22, S D=0.78$ ); either because the time of capsule administration was missing or the participant reported that the treatment was not administered. Data on actigraphy variables were further excluded for a respective night if the device was either not worn (placebo: $M=0.34, S D=0.61$; tryptophan: $M=0.31, S D=0.58$ ) or became detached during the night (placebo: $M=0.03, S D=0.17$; tryptophan: $M=0.01, S D=0.10$ ), the sleep period could not be determined because the sleep diary bedtime or rising time was missing (placebo: $M=0.35, S D=0.92$; tryptophan: $M=0.34, S D=0.93$ ) or when the reported sleep period time was not corresponding with actigraphy data based on visual inspection (placebo: $M=0.59, S D=1.02$; tryptophan: $M=0.53, S D=0.84)$. On average $12.64(S D=2.78)$ and $11.43(S D=2.94)$ of the fourteen nights were included per participant for the sleep diary (placebo: $M=6.30, S D=1.53$; tryptophan: $M=6.35, S D=1.43$ ) and actigraphy data (placebo: $M=5.63, S D=1.74$; tryptophan: $M=5.80, S D=1.49$ ) respectively. This indicates that compliance in the present study was generally high.

\section{Statistical analyses}

Statistical analyses were conducted in SPSS (SPSS 24.0 statistics for Windows, IBM, Armonk, New York). Linear mixed model analyses including a random intercept (indicating 
repeated measurements for each participant) were performed to investigate whether the influence of treatment (tryptophan versus placebo) on subjective (sleep diary) and objective (actigraphy) sleep parameters varied as a function of 5-HTTLPR (S'/S' versus L'/L'). Sleep variables of interest were retrieved from the subjective sleep diary reports (i.e. sleep onset latency, nocturnal awakenings, wake after sleep onset, total sleep time, sleep quality, refreshed sleep) and objective actigraphy recordings (i.e. sleep onset latency, sleep efficiency, total sleep time, wake after sleep onset, nocturnal awakenings). General influences of treatment were first explored in a linear mixed model that included treatment as a single predictor for sleep variables. The differential influence of treatment depending on 5-HTTLPR was subsequently investigated in a linear mixed model that included treatment, 5-HTTLPR and an interaction term of the two predictors. Simple main effects of treatment within 5HTTLPR genotype groups and of 5-HTTLPR within treatment conditions were used to interpret significant interactions.

\section{Results}

\section{Sample characteristics}

Table 1 presents the sample characteristics in relation to allelic variation in 5-HTTLPR. As demonstrated, no significant mean differences were observed between the two genotype groups regarding relevant variables.

Table 1. Sample characteristics $M(S D)$.

\begin{tabular}{|c|c|c|c|c|}
\hline & \multirow[t]{2}{*}{$\mathrm{S}^{\prime} / \mathrm{S}^{\prime}$} & \multirow[t]{2}{*}{$\mathrm{L}^{\prime} / \mathrm{L}^{\prime}$} & \multicolumn{2}{|c|}{$t$-test } \\
\hline & & & $t(96)$ & $p$ \\
\hline$n$ & 47 & 51 & & \\
\hline Men & 11 & 14 & & \\
\hline Women & 36 & 37 & & \\
\hline Age & $22.53(2.12)$ & $21.92(1.86)$ & 1.514 & 0.133 \\
\hline PSQI & $4.47(1.97)$ & $4.10(2.42)$ & 0.820 & 0.414 \\
\hline ISI & $5.04(3.05)$ & $4.55(3.88)$ & 0.703 & 0.484 \\
\hline CES-D & $7.43(7.39)$ & $7.00(7.00)$ & 0.291 & 0.771 \\
\hline
\end{tabular}

Note. CES-D, Center for Epidemiological Studies Depression Scale; ISI, Insomnia Severity Index; $M$, mean; $n$, number of participants; $p$, p-value; PSQI, Pittsburgh Sleep Quality Index; $S D$, standard deviation; $t$, t-statistic.

\section{Subjective sleep}

Linear mixed model analyses including treatment (tryptophan versus placebo) as a single predictor revealed no significant main effects on any of the subjective sleep variables (Table 2). This indicates that tryptophan did not improve subjective sleep in the general sample. 
Linear mixed model analyses including treatment (tryptophan versus placebo), 5HTTLPR ( $\mathrm{S}^{\prime} / \mathrm{S}^{\prime}$ versus $\left.\mathrm{L}^{\prime} / \mathrm{L}^{\prime}\right)$ and an interaction term as predictors for subjective sleep variables revealed a significant interaction between treatment and 5-HTTLPR on subjective sleep quality $(b=0.200, t(1208.72)=2.490, p=0.013)$ and subjective amount of nocturnal awakenings $(b=-0.296, t(1216.69)=-2.045, p=0.041)$. This indicates that 5-HTTLPR moderates the effect of tryptophan on these sleep parameters. Simple effects within 5HTTLPR genotype groups revealed a near significant main effect of treatment on subjective sleep quality in the $\mathrm{S}^{\prime} / \mathrm{S}^{\prime}(b=0.111, t(1208.23)=1.929, p=0.054)$ but not in the $\mathrm{L}^{\prime} / \mathrm{L}^{\prime}$ group $(b=-0.89, t(1209.24)=-1.587, p=0.113)$, suggesting that tryptophan exclusively improved subjective sleep quality in the S'/S' group. Moreover, a significant main effect of 5-HTTLPR on subjective sleep quality was observed in the placebo condition $(b=-0.300, t(133.92)=-$ 2.985, $p=0.003)$ whereas this was not found in the tryptophan condition $(b=-0.099$, $t(133.65)=-0.990, p=0.324)$. This indicates that a significantly lower sleep quality in the $\mathrm{S}$ '/S' relative to the L'/L' group during placebo intake is markedly reduced during tryptophan intake. Regarding subjective amount of nocturnal awakenings, simple effects within 5HTTLPR and treatment groups did not reveal any significant main effects except for a marginally significant effect of treatment in the L'/L' group $(b=0.175, t(1216,80)=1.740, p$ $=0.082$ ). No significant interactions were observed for the remainder of subjective sleep variables (Table 2).

Table 2. Estimated marginal means $M(S E)$ of sleep variables within treatment conditions.

\begin{tabular}{|c|c|c|c|c|c|c|}
\hline & \multicolumn{3}{|c|}{ Placebo } & \multicolumn{3}{|c|}{ Tryptophan } \\
\hline & $\mathrm{S}^{\prime} / \mathrm{S}^{\prime}$ & $\mathrm{L}^{\prime} / \mathrm{L}^{\prime}$ & Total & $\mathrm{S}^{\prime} / \mathrm{S}^{\prime}$ & $\mathrm{L}^{\prime} / \mathrm{L}^{\prime}$ & Total \\
\hline \multicolumn{7}{|l|}{ Sleep diary } \\
\hline Sleep onset latency (min.) & $20.11(2.53)$ & $17.05(2.46)$ & $18.53(1.76)$ & $18.78(2.53)$ & $15.48(2.46)$ & $17.08(1.76)$ \\
\hline Nocturnal awakenings & $1.61(0.13)$ & $1.36(0.13)$ & $1.48(0.09)$ & $1.49(0.13)$ & $1.54(0.13)$ & $1.51(0.09)$ \\
\hline Wake after sleep onset (min.) & $11.93(1.69)$ & $8.83(1.63)$ & $10.33(1.18)$ & $12.77(1.69)$ & $10.44(1.64)$ & $11.57(1.18)$ \\
\hline Total sleep time $(\mathrm{h})$ & $7.67(0.11)$ & $7.58(0.10)$ & $7.62(0.07)$ & $7.58(0.11)$ & $7.66(0.10)$ & $7.62(0.07)$ \\
\hline Sleep quality & $3.60(0.07)^{*}$ & $3.90(0.07)^{*}$ & $3.75(0.05)$ & $3.71(0.07)$ & $3.81(0.07)$ & $3.76(0.05)$ \\
\hline Refreshed sleep & $3.26(0.09)$ & $3.43(0.88)$ & $3.35(0.06)$ & $3.28(0.09)$ & $3.37(0.88)$ & $3.24(0.06)$ \\
\hline \multicolumn{7}{|l|}{ Actigraphy } \\
\hline Sleep onset latency (min.) & $6.64(0.72)$ & $6.06(0.70)$ & $6.34(0.50)$ & $6.96(0.71)$ & $6.03(0.69)$ & $6.48(0.50)$ \\
\hline Sleep efficiency $(\%)$ & $84.42(0.75)$ & $84.97(0.73)$ & $84.70(0.52)^{* *}$ & $85.26(0.74)$ & $86.08(0.73)$ & $85.68(0.52)^{* *}$ \\
\hline Total sleep time (h) & $6.78(0.12)$ & $6.71(0.11)$ & $6.74(0.08)$ & $6.76(0.12)$ & $6.86(0.11)$ & $6.81(0.08)$ \\
\hline Wake after sleep onset (min.) & $68.06(3.60)$ & $65.53(3.50)$ & $66.76(2.50)^{* *}$ & $63.13(3.57)$ & $60.09(3.49)$ & $61.57(2.49)^{* *}$ \\
\hline Nocturnal awakenings & $24.34(0.92)$ & $23.54(0.89)$ & $23.93(0.64)$ & $23.69(0.91)$ & $23.37(0.89)$ & $23.52(0.64)$ \\
\hline $\begin{array}{cl}\text { Note. } & M \text {, mean; } S E \text {, standard error. } \\
& \\
* & p<0.01 \\
{ }^{* *} & p<0.001\end{array}$ & & & \multicolumn{3}{|c|}{ Note. $M$, mean; $S E$, standard error. } & \\
\hline
\end{tabular}




\section{Objective sleep}

Linear mixed model analyses with treatment (tryptophan versus placebo) as a single predictor for objective sleep variables revealed a significant main effect on objective sleep efficiency $(b$ $=0.977, t(1027.10)=3.337, p<0.001)$ and objective wake after sleep onset $(b=-5.188$, $t(1027.83)=-3.502, p<0.001)$. As shown in Table 2, this indicates that tryptophan administration improved sleep efficiency and reduces wake after sleep onset in the general sample. No significant main effects of treatment were observed on the remainder of the objective sleep variables.

Linear mixed model analyses with treatment (tryptophan versus placebo) and 5HTTLPR (S'/S' versus L'/L') and an interaction term as predictors for objective sleep variables revealed no significant interactions. This indicates that 5-HTTLPR does not moderate the effect of tryptophan on objectively measured sleep.

\section{Discussion}

The results of the present study indicate that some of the sleep-promoting effects of tryptophan depend on allelic variation in 5-HTTLPR. While improvements on objective sleep efficiency and objective wake after sleep onset were observed irrespective of allelic variation, 5-HTTLPR was found to moderate the influence of tryptophan on subjective sleep quality and subjective amount of nocturnal awakenings. Current findings suggest that these 5-HTTLPR dependent effects presumably arise from subjective sleep quality improvements in the 5HTTLPR S-allele. This is further supported by the observation that a significantly lower subjective sleep quality in the S-allele relative to the L-allele in the placebo condition diminished following tryptophan treatment.

The significantly lower sleep quality in the 5-HTTLPR S-allele during placebo administration corresponds with previous work revealing an increased susceptibility for sleep quality reductions (Brummett et al., 2007) and clinical insomnia (Deuschle et al., 2010; Huang et al., 2014). While 5-HTTLPR dependent differences were observed on subjective sleep quality, no genetic influences were found on objective measurements. A low correspondence between subjective sleep quality and actigraphy has been commonly reported (Sadeh, 2011) and it has been suggested that the two assessment methods capture different sleep dimensions (Aili, Astrom-Paulsson, Stoetzer, Svartengren, \& Hillert, 2017). This distinction might be particularly relevant to the field of 5-HTTLPR as previous research mainly included subjective sleep reports (Barclay et al., 2011; Brummett et al., 2007; Huang 
et al., 2014; Polito et al., 2015; van Dalfsen \& Markus, 2015, 2018), suggesting that 5HTTLPR particularly modulates subjective aspects of sleep. Nonetheless, given the enduring validity issues with actigraphy (Sadeh, 2011), in the absence of polysomnographic studies it cannot be excluded that objective sleep alterations account for 5-HTTLPR dependent differences in subjective sleep quality.

The present study reveals that 5-HTTLPR modulates the effect of tryptophan on subjective sleep quality and subjective amount of nocturnal awakenings, conceivably by improving sleep quality in the 5-HTTLPR S-allele. This finding is in accordance with previous work demonstrating that tryptophan administration is associated with significantly better sleep quality in stress vulnerable individuals carrying two copies of the S-allele (van Dalfsen \& Markus, 2015). However, in the present study 5-HTTLPR dependent treatment effects were relatively small and only approached statistical significance within the 5HTTLPR S-allele. Although this may intrinsically relate to the effect of tryptophan, it is likely that this at least in part reflects a ceiling effect related to the high sleep quality of the studied sample. Hence, this profoundly limits the room for improvement on the already restricted response options of the subjective sleep quality assessment.

In line with a large body of research supporting the sleep-promoting effects of tryptophan (Hartmann \& Greenwald, 1984; Schneider-Helmert \& Spinweber, 1986; Silber \& Schmitt, 2010), current findings reveal that tryptophan improves sleep efficiency and reduces wake after sleep onset irrespective of allelic 5-HTTLPR variation. Although the precise mechanism of action remains largely unknown, there is specific evidence that the biosynthetic pathway of 5-HT is involved in sleep regulation. This is mainly derived from animal research revealing that pharmacological blocking of the enzyme tryptophan hydroxylase with parachlorophenylalanine (pCPA) results in profound sleep impairments (Borbely, Neuhaus, \& Tobler, 1981; Jouvet, 1972; Koella, Feldstein, \& Czicman, 1968; Ursin, 1972) that can be reversed by 5-HTP (Koella et al., 1968; Pujol, Buguet, Froment, Jones, \& Jouvet, 1971) and tryptophan (Borbely et al., 1981) administration. Since this rate-limiting enzyme is also thought to mediate the effects of tryptophan on 5-HT synthesis, these findings provide indirect support for the sleep promoting effects of tryptophan augmentation. It remains uncertain, however, how general increments in brain 5-HT synthesis exert sleep inducing effects. This relates to the complex involvement of 5-HT in sleep-wake regulation as its activity promotes both sleep and wakefulness depending on current behavioral state, brain region, 5-HT receptor type as well as its interrelationships with other neurotransmitter and hormonal systems (for review see: (Ursin, 2002)). 
The diminished expression of the 5-HT transporter in the 5-HTTLPR S-allele produces a variety of neurochemical changes in the brain 5-HT system. Expanding on the influence of tryptophan on 5-HT mediated sleep regulation, such alterations might explain why sleep improving effects may particularly occur in this allelic variant. As comprehensively reviewed (Murphy \& Lesch, 2008), research in humans and mice with comparable levels of 5HT transporter expression as homozygous S-allele carriers (i.e. SLC6A4 ${ }^{+/-}$) indicates that a diminished transcriptional activity of the 5-HT transporter decreases the amount of 5-HT transporter binding sites. This reduces 5-HT reuptake resulting in elevated extracellular 5-HT concentrations and prolonged 5-HT clearance. This augmented 5-HT signaling is accompanied by a reduced basal 5-HT firing rate in the dorsal raphe as well as a downregulation of 5- $\mathrm{HT}_{1 \mathrm{~A}}, 5-\mathrm{HT}_{1 \mathrm{~B}}$ and 5- $\mathrm{HT}_{3}$ receptors. Since the $5-\mathrm{HT}_{1 \mathrm{~A}}$ receptor is thought to facilitate sleep (for review see: (Ursin, 2002)) a decreased sensitivity might theoretically contribute to the sleep quality reductions associated with the 5-HTTLPR S-allele. Research in mice lacking 5-HT transporter expression (i.e. SLC6A4 ${ }^{--}$) further suggests that 5-HT synthesis and turnover might increase to compensate for the reduced recycling of 5-HT (for review see: (Murphy \& Lesch, 2008)). Since an elevation in tryptophan availability increases 5-HT synthesis and release (Fernstrom, 2012; Wurtman et al., 1980), such mechanisms provide a potential pathway how tryptophan might compensate for the deficient 5-HT functioning and related sleep disturbances in the 5-HTTLPR S-allele. Regardless of the precise molecular mechanism of action, research on a variety of outcome measures supports the assumption that the 5-HTTLPR S-allele is generally more susceptible to manipulations of tryptophan availability (for review see: (Gibson, 2018)).

The following limitations should be considered for the present study. The first limitation relates to the relatively high sleep quality of the present sample. This is an important issue as this may considerably reduce potential treatment effects and future research in clinical populations is therefore encouraged. The second limitation pertains to the objective sleep assessment. Although one week of actigraphy sleep assessment is found to provide a reliable estimate of sleep parameters (Aili et al., 2017) the accuracy to detect nocturnal awakenings during sleep periods (i.e. specificity) is relatively limited and polysomnographic studies are needed to detect more valid objective influences. Further research incorporating different doses of tryptophan is further desirable as higher doses of tryptophan administration might produce more profound effects on sleep regulation.

In conclusion, current findings support the sleep-promoting effects of tryptophan augmentation. The present study elaborates on more general findings revealing that 
tryptophan may particularly improve subjective sleep quality in genetic variants associated with deficient 5-HT functioning. Given the involvement of the 5-HTTLPR S-allele in the etiology of sleep quality reductions and clinical insomnia, tryptophan supplementation might become a promising and valuable treatment strategy to compensate for this predisposition although research in clinical populations is desirable.

\section{Acknowledgements}

None.

\section{Funding and disclosure}

The authors declare no conflict of interest. 


\section{References}

Aili, K., Astrom-Paulsson, S., Stoetzer, U., Svartengren, M., \& Hillert, L. (2017). Reliability of Actigraphy and Subjective Sleep Measurements in Adults: The Design of Sleep Assessments. J Clin Sleep Med, 13(1), 39-47. doi:10.5664/jcsm.6384

Ancoli-Israel, S., \& Roth, T. (1999). Characteristics of insomnia in the United States: results of the 1991 National Sleep Foundation Survey. I. Sleep, 22(2), S347-353.

Baglioni, C., Battagliese, G., Feige, B., Spiegelhalder, K., Nissen, C., Voderholzer, U., . . . Riemann, D. (2011). Insomnia as a predictor of depression: A meta-analytic evaluation of longitudinal epidemiological studies. Journal of Affective Disorders, 135(1-3), 10-19. doi:10.1016/j.jad.2011.01.011

Barclay, N. L., Eley, T. C., Mill, J., Wong, C. C., Zavos, H. M., Archer, S. N., \& Gregory, A. M. (2011). Sleep quality and diurnal preference in a sample of young adults: associations with 5HTTLPR, PER3, and CLOCK 3111. Am J Med Genet B Neuropsychiatr Genet, 156B(6), 681-690. doi:10.1002/ajmg.b.31210

Bastien, C. H., \& Morin, C. M. (2000). Familial incidence of insomnia. Journal of Sleep Research, 9(1), 49-54.

Beaulieu-Bonneau, S., LeBlanc, M., Merette, C., Dauvilliers, Y., \& Morin, C. M. (2007). Family history of insomnia in a population-based sample. Sleep, 30(12), 1739-1745.

Borbely, A. A., Neuhaus, H. U., \& Tobler, I. (1981). Effect of p-chlorophenylalanine and tryptophan on sleep, EEG and motor activity in the rat. Behavioural Brain Research, 2(1), 1-22.

Brummett, B. H., Krystal, A. D., Ashley-Koch, A., Kuhn, C. M., Zuchner, S., Siegler, I. C., . . . Williams, R. B. (2007). Sleep quality varies as a function of 5-HTTLPR genotype $\begin{array}{llll}\text { and stress. } & \text { Psychosomatic }\end{array}$ doi:10.1097/PSY.0b013e31814b8de6

Cappuccio, F. P., D'Elia, L., Strazzullo, P., \& Miller, M. A. (2010). Quantity and quality of sleep and incidence of type 2 diabetes: a systematic review and meta-analysis. Diabetes Care, 33(2), 414-420. doi:10.2337/dc09-1124

Carney, C. E., Buysse, D. J., Ancoli-Israel, S., Edinger, J. D., Krystal, A. D., Lichstein, K. L., \& Morin, C. M. (2012). The consensus sleep diary: standardizing prospective sleep self-monitoring. Sleep, 35(2), 287-302. doi:10.5665/sleep.1642

Dauvilliers, Y., Morin, C., Cervena, K., Carlander, B., Touchon, J., Besset, A., \& Billiard, M. (2005). Family studies in insomnia. Journal of Psychosomatic Research, 58(3), 271278. doi:10.1016/j.jpsychores.2004.08.012

Deuschle, M., Schredl, M., Schilling, C., Wust, S., Frank, J., Witt, S. H., . . Schulze, T. G. (2010). Association between a serotonin transporter length polymorphism and primary insomnia. Sleep, 33(3), 343-347.

Eccleston, D., Ashcroft, G. W., \& Crawford, T. B. (1970). Effect of tryptophan administration on 5HIAA in cerebrospinal fluid in man. Journal of Neurology, Neurosurgery and Psychiatry, 33(2), 269-272.

Fernstrom, J. D. (1983). Role of precursor availability in control of monoamine biosynthesis in brain. Physiological Reviews, 63(2), 484-546.

Fernstrom, J. D. (2012). Effects and side effects associated with the non-nutritional use of tryptophan by humans. Journal of Nutrition, 142(12), 2236s-2244s. doi:10.3945/jn.111.157065

Fernstrom, J. D., \& Wurtman, R. J. (1971). Brain serotonin content: physiological dependence on plasma tryptophan levels. Science, 173(3992), 149-152. 
Gibson, E. L. (2018). Tryptophan supplementation and serotonin function: genetic variations in behavioural effects. Proceedings of the Nutrition Society, 1-15. doi:10.1017/s0029665117004451

Glatz, K., Mossner, R., Heils, A., \& Lesch, K. P. (2003). Glucocorticoid-regulated human serotonin transporter (5-HTT) expression is modulated by the 5-HTT gene-promotorlinked polymorphic region. Journal of Neurochemistry, 86(5), 1072-1078.

Hammerschlag, A. R., Stringer, S., de Leeuw, C. A., Sniekers, S., Taskesen, E., Watanabe, K., . . . Posthuma, D. (2017). Genome-wide association analysis of insomnia complaints identifies risk genes and genetic overlap with psychiatric and metabolic traits. Nature Genetics, 49(11), 1584-1592. doi:10.1038/ng.3888

Hartmann, E., \& Greenwald, D. (1984). Tryptophan and human sleep: an analysis of 43 studies. In Progress in tryptophan and serotonin research (pp. 297-304). Berlin: Walter de Gruyter.

Huang, C., Li, J., Lu, L., Ren, X., Li, Y., Huang, Q., . . . Wang, Y. (2014). Interaction between serotonin transporter gene-linked polymorphic region (5-HTTLPR) and jobrelated stress in insomnia: a cross-sectional study in Sichuan, China. Sleep Med, 15(10), 1269-1275. doi:10.1016/j.sleep.2014.01.023

Jouvet, M. (1972). The role of monoamines and acetylcholine-containing neurons in the regulation of the sleep-waking cycle. Ergebnisse der Physiologie, Biologischen Chemie und Experimentellen Pharmakologie, 64, 166-307.

Koella, W. P., Feldstein, A., \& Czicman, J. S. (1968). The effect of para-chlorophenylalanine on the sleep of cats. Electroencephalography and Clinical Neurophysiology, 25(5), 481-490. doi:10.1016/0013-4694(68)90158-2

Lane, J. M., Liang, J., Vlasac, I., Anderson, S. G., Bechtold, D. A., Bowden, J., . . Saxena, R. (2017). Genome-wide association analyses of sleep disturbance traits identify new loci and highlight shared genetics with neuropsychiatric and metabolic traits. Nature Genetics, 49(2), 274-281. doi:10.1038/ng.3749

Leger, D., Poursain, B., Neubauer, D., \& Uchiyama, M. (2008). An international survey of sleeping problems in the general population. Current Medical Research and Opinion, 24(1), 307-317. doi:10.1185/030079907X253771

Lind, M. J., Aggen, S. H., Kirkpatrick, R. M., Kendler, K. S., \& Amstadter, A. B. (2015). A Longitudinal Twin Study of Insomnia Symptoms in Adults. Sleep, 38(9), 1423-1430. doi:10.5665/sleep.4982

Maich, K. H. G., Lachowski, A. M., \& Carney, C. E. (2016). Psychometric Properties of the Consensus Sleep Diary in Those With Insomnia Disorder. Behav Sleep Med, 1-18. doi:10.1080/15402002.2016.1173556

Murphy, D. L., \& Lesch, K. P. (2008). Targeting the murine serotonin transporter: insights into human neurobiology. Nat Rev Neurosci, 9(2), 85-96. doi:10.1038/nrn2284

Nakamura, M., Ueno, S., Sano, A., \& Tanabe, H. (2000). The human serotonin transporter gene linked polymorphism (5-HTTLPR) shows ten novel allelic variants. Molecular Psychiatry, 5(1), 32-38.

Ohayon, M. M. (1997). Prevalence of DSM-IV diagnostic criteria of insomnia: distinguishing insomnia related to mental disorders from sleep disorders. Journal of Psychiatric Research, 31(3), 333-346.

Palagini, L., Bruno, R. M., Gemignani, A., Baglioni, C., Ghiadoni, L., \& Riemann, D. (2013). Sleep loss and hypertension: a systematic review. Current Pharmaceutical Design, 19(13), 2409-2419.

Polito, L., Davin, A., Vaccaro, R., Abbondanza, S., Govoni, S., Racchi, M., \& Guaita, A. (2015). Serotonin transporter polymorphism modifies the association between depressive symptoms and sleep onset latency complaint in elderly people: results from 
the 'InveCe.Ab' study. Journal of Sleep Research, 24(2), 215-222. doi:10.1111/jsr.12248

Pujol, J. F., Buguet, A., Froment, J. L., Jones, B., \& Jouvet, M. (1971). The central metabolism of serotonin in the cat during insomnia. A neurophysiological and biochemical study after administration of P-chlorophenylalanine or destruction of the Raphe system. Brain Research, 29(2), 195-212.

Sadeh, A. (2011). The role and validity of actigraphy in sleep medicine: an update. Sleep Med Rev, 15(4), 259-267. doi:10.1016/j.smrv.2010.10.001

Sadeh, A., Sharkey, K. M., \& Carskadon, M. A. (1994). Activity-based sleep-wake identification: an empirical test of methodological issues. Sleep, 17(3), 201-207.

Schneider-Helmert, D., \& Spinweber, C. L. (1986). Evaluation of L-tryptophan for treatment of insomnia: a review. Psychopharmacology, 89(1), 1-7.

Schwartz, S., Anderson, W. M., Cole, S. R., Cornoni-Huntley, J., Hays, J. C., \& Blazer, D. (1999). Insomnia and heart disease: A review of epidemiologic studies. Journal of Psychosomatic Research, 47(4), 313-333. doi:10.1016/S0022-3999(99)00029-X

Silber, B. Y., \& Schmitt, J. A. (2010). Effects of tryptophan loading on human cognition, mood, and sleep. Neuroscience and Biobehavioral Reviews, 34(3), 387-407. doi:10.1016/j.neubiorev.2009.08.005

Slater, J. A., Botsis, T., Walsh, J., King, S., Straker, L. M., \& Eastwood, P. R. (2015). Assessing sleep using hip and wrist actigraphy. Sleep and biological rhythms, 13(2), 172-180. doi:10.1111/sbr.12103

Uhlig, B. L., Sand, T., Odegard, S. S., \& Hagen, K. (2014). Prevalence and associated factors of DSM-V insomnia in Norway: the Nord-Trondelag Health Study (HUNT 3). Sleep Med, 15(6), 708-713. doi:10.1016/j.sleep.2014.01.018

Ursin, R. (1972). Differential effect of para-chlorophenylalanine on the two slow wave sleep stages in the cat. Acta Physiologica Scandinavica, 86(2), 278-285. doi:10.1111/j.17481716.1972.tb05333.x

Ursin, R. (2002). Serotonin and sleep. Sleep Med Rev, 6(1), 55-69.

van Dalfsen, J. H., \& Markus, C. R. (2015). Interaction between 5-HTTLPR genotype and cognitive stress vulnerability on sleep quality: effects of sub-chronic tryptophan administration. Int J Neuropsychopharmacol, 18(3). doi:10.1093/ijnp/pyu057

van Dalfsen, J. H., \& Markus, C. R. (2018). The serotonin transporter 5-HTTLPR polymorphism and the risk for insomnia: a non-replication. Sleep Med. doi:10.1016/j.sleep.2018.01.015

Wing, Y. K., Zhang, J., Lam, S. P., Li, S. X., Tang, N. L., Lai, K. Y., \& Li, A. M. (2012). Familial aggregation and heritability of insomnia in a community-based study. Sleep Med, 13(8), 985-990. doi:10.1016/j.sleep.2012.04.013

Wurtman, R. J., Hefti, F., \& Melamed, E. (1980). Precursor control of neurotransmitter synthesis. Pharmacological Reviews, 32(4), 315-335.

Yuwiler, A., Brammer, G. L., Morley, J. E., Raleigh, M. J., Flannery, J. W., \& Geller, E. (1981). Short-term and repetitive administration of oral tryptophan in normal men. Effects on blood tryptophan, serotonin, and kynurenine concentrations. Archives of General Psychiatry, 38(6), 619-626. 


\section{Chapter 4}

The influence of sleep on human hypothalamic-pituitary-adrenal (HPA) axis reactivity: a systematic review

Published as:

van Dalfsen, J. H., \& Markus, C. R. (2018). The influence of sleep on human hypothalamicpituitary-adrenal (HPA) axis reactivity: A systematic review. Sleep Medicine Reviews, 39, 187-194. doi:10.1016/j.smrv.2017.10.002 


\section{Summary}

Inadequate sleep is highly prevalent and known to decline both physical- and mental health. Literature suggests that altered functioning of the hypothalamic-pituitary-adrenal (HPA) axis might underlie this association. This assumption is mainly based on changes in basal neuroendocrine activity and it is of equal importance to elucidate whether sleep may also influence HPA stress responsiveness. The present review provides a complete outline of recent human studies that have investigated how different aspects of sleep influence cortisol reactivity to laboratory stress. From the available data it can be concluded that both objective and subjective decrements in sleep quality potentiate the stress reactivity of the HPA axis. On the contrary, normal variations in sleep duration do not seem to influence cortisol stress responsiveness whereas excessive daytime sleepiness is associated with a blunting of the cortisol response. Given its well-established health consequences, sensitization of the HPA axis might well be a crucial component linking inadequate sleep to stress-related pathology. 


\section{Introduction}

Inadequate sleep is highly prevalent in the general population. Consensus has been reached that around 30\% of the adult population reports some form of sleep complaint (Ancoli-Israel \& Roth, 1999; Leger, Poursain, Neubauer, \& Uchiyama, 2008) whereas approximately 6\%$8 \%$ meets the diagnostic criteria for clinical insomnia (Ohayon, 1997; Uhlig, Sand, Odegard, \& Hagen, 2014). Epidemiological studies have convincingly demonstrated that sleep plays an important role in the perseveration of physical- and mental health (Buysse, 2014; Taylor, Lichstein, \& Durrence, 2003). For instance, sleep impairments have been associated with an elevated risk for cardiovascular disease (Schwartz et al., 1999), hypertension (Guo et al., 2013), as well as various psychiatric disorders (Krystal, 2006). Although these findings clearly illustrate the clinical significance of sleep, the underlying mechanisms remain to be elucidated. Recent literature suggests that the involvement of sleep in the regulation of neuroendocrine stress adaptation systems might play an important mediating role.

It has been commonly acknowledged that stress constitutes a major risk factor for the development of medical (Schneiderman, Ironson, \& Siegel, 2005) and psychiatric conditions (Sapolsky, 2015). The hypothalamic-pituitary-adrenal (HPA) axis is the brain's main circuit that integrates a perceived stressful event into a pattern of autonomic, neuroendocrine changes needed to regain physiological balance (Balbo, Leproult, \& Van Cauter, 2010). In response to stress, corticotrophin releasing hormone $(\mathrm{CRH})$ is released by the paraventricular nucleus of the hypothalamus which in turn initiates the secretion of adrenocorticotropic hormone (ACTH) by the anterior pituitary. The successive cortisol secretion by the adrenal cortex is considered the main stress response as it initiates numerous physiological changes aimed to compensate for the additional demands (Kudielka, Buske-Kirschbaum, Hellhammer, \& Kirschbaum, 2004) and reduces further HPA activity by feedback inhibition (Balbo et al., 2010). Although this dynamic responsiveness of the HPA axis is crucial for stress adaptation, prolonged over- or under activation may become detrimental for both physical- and mental health (for review see: (Chrousos \& Gold, 1992; Heim, Ehlert, \& Hellhammer, 2000; Holsboer, 1989; Raison \& Miller, 2003; Tsigos \& Chrousos, 2002; Young, 1998)).

The adverse health consequences of inadequate sleep might as well result from deficient HPA functioning. It has been well-documented that sleep displays a close and reciprocal relationship with the functioning of the HPA axis (Balbo et al., 2010; Buckley \& Schatzberg, 2005; Meerlo, Sgoifo, \& Suchecki, 2008; Steiger, 2002). In general, elevated HPA activation results in lighter sleep and more nocturnal awakenings (Buckley \& 
Schatzberg, 2005) whereas inadequate sleep is found to promote the basal activity of the HPA axis (Balbo et al., 2010; Meerlo et al., 2008). Animal studies further revealed that chronically impaired sleep may induce fundamental neuroendocrine changes that may ultimately influence HPA stress reactivity (Meerlo et al., 2008). It remains unclear from these findings, however, how sleep might generally influence HPA stress reactivity in humans. Although the significance of exploring this relationship has been clearly acknowledged (Meerlo et al., 2008), studies have only more recently investigated this association.

The aim of the present review is to provide an outline of human experimental studies that have investigated the influence of sleep on acute stress reactivity of the HPA axis. More specifically, this systematic review intends to determine how various aspects of sleep (i.e. subjective sleep quality, objective sleep efficiency, awakenings during the night, sleep architecture, sleep duration, daytime sleepiness) may differentially influence cortisol responsiveness to laboratory stress. Categorizing these findings into the various aspects of sleep will enhance the ability to draw general conclusions and contributes to an ecologically valid understanding of this complex relationship. Although the relationship between sleep and HPA activity is clearly bidirectional, the purpose of the present review is to mainly outline the one-directional influence of sleep on HPA stress reactivity.

\section{Methods}

\section{Search strategy}

The electronic databases PubMed and PsycINFO were selected to perform a search for available human English language studies (up to November 2016) by combining 'sleep' with 'HPA axis' or 'cortisol' and 'stress' or 'distress'.

\section{Inclusion of studies}

The present review comprises studies exploring the influence of sleep on HPA cortisol reactivity under experimental laboratory stress. Predefined inclusion- and exclusion criteria were used to evaluate the retrieved articles. In partial compliance with previous work (Otte et al., 2005), inclusion criteria encompassed: 1) inclusion of healthy human subjects 2) incorporation of a standardized psychosocial- (e.g. free speech task, mental arithmetic), physical- (e.g. cold pressure task), cognitive- (e.g. Stroop task) or pharmacological dexamethasone (DEX)/corticotropin releasing hormone (CRH) laboratory challenge, 3) inclusion of sleep assessment procedures (questionnaires, actigraphy, polysomnography), 4) 
assessment of salivary or plasma cortisol values. In correspondence to previous work (Otte et al., 2005), exclusion criteria comprised: 1) results comprised only unchallenged cortisol values, 2) inclusion of participants with medical conditions known to affect the functioning of the HPA axis (not including clinical insomnia).

Titles and abstracts of the retrieved articles were evaluated by the authors in order to determine the applicability of each individual study. If needed, full text articles were additionally explored to determine inclusion. The bibliographies of relevant studies were subsequently reviewed for complementary references.

\section{Included articles}

During the initial literature search 1137 articles were retrieved from the two databases PubMed $(n=702)$ and PsycINFO $(n=435)$. Automatic filters were subsequently applied to exclusively retrieve English language studies conducted in human participants; resulting in 918 remaining articles (PubMed: $\mathrm{n}=$ 532; PsycINFO: $\mathrm{n}=386$ ). After removing 240 duplicates among the two databases, the final collection of retrieved articles comprised 678 studies. Given the information provided in the titles and abstracts, 27 studies were considered potentially relevant. Following detailed examination, 10 articles were excluded based on various inclusion and exclusion criteria: four articles did not include a laboratory challenge, one evaluated stress-related cortisol values during the night, one exclusively included pregnant individuals, two did not report data in healthy controls and two did not incorporate sufficient information to determine the relationship of interest. Findings of the retained 17 articles were evaluated in detail and reported in the present review (see figure 1 for a schematic illustration of the article selection). 


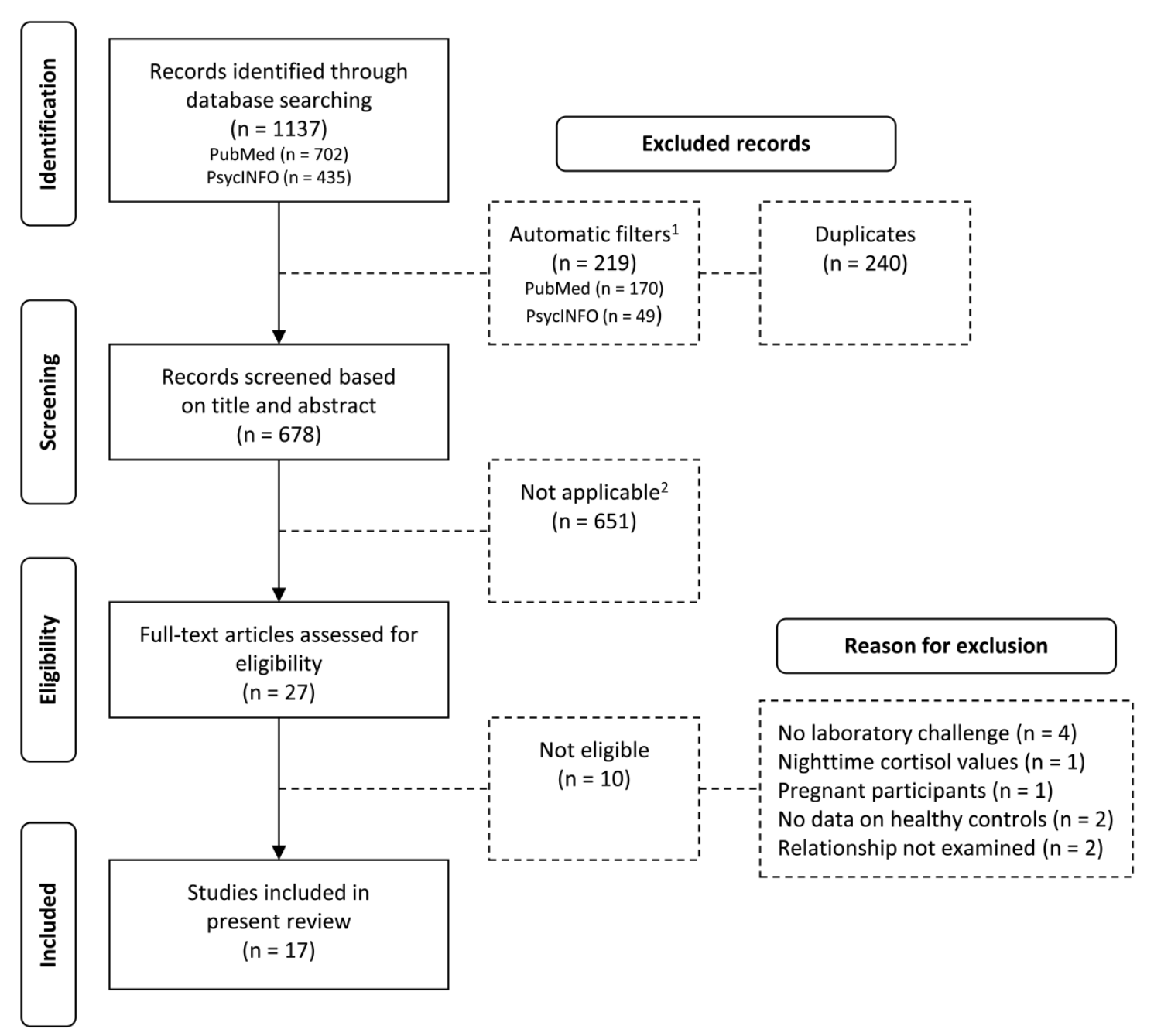

Figure 1. Flowchart of literature selection. ${ }^{1}$ Automatic filters eliminating non-English and non-human studies. ${ }^{2}$ Study objective unrelated to the relationship of interest.

\section{Sleep and stress reactivity of the HPA axis}

Elaborating on the relationship between sleep and basal HPA activity (Balbo et al., 2010; Buckley \& Schatzberg, 2005; Meerlo et al., 2008; Steiger, 2002), various studies have more recently investigated how sleep influences the stress reactivity of the HPA axis to a laboratory challenge (table 1). Given the large variety of sleep assessment procedures, an important distinction can be made in how various aspects of sleep may differentially influence neuroendocrine stress responsiveness. In the following subsections, the findings that have emerged from these studies will be summarized for each respective aspect of sleep (i.e. subjective sleep quality, objective sleep efficiency and awakenings during the night, sleep architecture, sleep duration, daytime sleepiness). 


\section{Subjective sleep quality}

Few studies have explored the influence of subjectively experienced sleep quality on the stress reactivity of the HPA axis. Goodin et al. (2012) reported greater cortisol responses to a physical stressor (cold pressor task) in poor sleepers relative to good sleepers (Goodin, Smith, Quinn, King, \& McGuire, 2012). In contrast, reduced sleep quality was not found to potentiate cortisol reactivity to a psychosocial stressor (Brooks \& Robles, 2009) or a cognitive-interference (Stroop) task (Wright, Valdimarsdottir, Erblich, \& Bovbjerg, 2007) although the outcome of these studies should be approached with caution as they either exclusively reported data of a subsample of male participants (Brooks \& Robles, 2009) or implemented a cognitive- instead of a psychosocial threatening paradigm (Wright et al., 2007). Results of a more recent study revealed gender dependent effects when using a psychosocial stress induction (Bassett, Lupis, Gianferante, Rohleder, \& Wolf, 2015). Compared to fairly good sleep quality, poor sleep quality significantly increased cortisol stress responsiveness in male but not in female participants. However, since male participants with very good sleep quality were found to display the highest cortisol responses, the effect of sleep quality in this particular study remains inconclusive.

From a pharmacological perspective, poor subjective sleep quality was found to exaggerate cortisol reactivity to a combined DEX/CRH challenge test (Hori et al., 2011). This procedure allows to separately assess the reactivity $(\mathrm{CRH})$ and the inhibitory capacity (DEX) of the HPA axis. Since poor sleep quality was exclusively found to potentiate the effect of CRH administration (i.e. greater cortisol responsiveness), the authors concluded that sleep quality may directly influence the sensitivity of the HPA axis rather than influencing its inhibitory capacity (Hori et al., 2011).

Taken together, these findings suggest that reduced subjective sleep quality might potentiate the reactivity of the HPA axis, particularly to physical- and psychosocial stressors. More evidence is needed to confirm this initial assumption.

\section{Objective sleep efficiency and awakenings during the night}

As an objective analog of sleep quality, various studies have explored the influence of sleep efficiency and/or nocturnal awakenings on HPA stress reactivity. In a polysomnographic study, cortisol responsiveness to a psychosocial stressor was found to increase with the number of awakenings during the night (M. Hatzinger et al., 2008) while no significant relationship was observed during a one year follow-up of the same sample of individuals 
including both polysomnographic (M. Hatzinger et al., 2013) and actigraphic (M. Hatzinger et al., 2014) measurements. Räikkönen et al. (2010) did however replicate the initial findings. This actigraphic study revealed lower sleep efficiency was associated with increased cortisol secretion to a psychosocial stressor (Räikkönen et al., 2010). Although the two original investigations were consistent, an earlier study revealed that lower sleep efficiency was related to reduced (instead of enhanced) cortisol stress responsiveness to a cognitive challenge (Wright et al., 2007). However, as mentioned earlier this laboratory challenge might meaningfully differ from more emotionally relevant psychosocial stressors (Dickerson \& Kemeny, 2004), thereby limiting the comparability of the results.

Pharmacological studies indicated that neither sleep efficiency nor the time spent awake after sleep onset were found to alter the effects of DEX on salivary cortisol concentration (Pesonen et al., 2014). This supports the earlier finding that sleep does not seem to affect feedback inhibition within the HPA axis (Hori et al., 2011). Since this study (Pesonen et al., 2014) did not include pharmacological HPA stimulation (i.e. CRH administration) it remains to be elucidated whether reduced sleep efficiency and increased awakenings during the night also potentiate the biological sensitivity of the HPA axis.

Taken together, available findings reveal that diminished sleep efficiency and/or increased awakenings during the night may enhance cortisol responsiveness, particularly to psychosocial stress. Such sleep-related influences appear to be more likely caused by an enhanced sensitivity of the HPA axis rather than reduced feedback inhibition.

\section{Sleep architecture}

In line with exploring more objective indices of sleep, a polysomnographic study revealed that spending either more time in stage 1, stage 2, or rapid eye movement (REM) sleep increased cortisol reactivity to psychosocial stress (M. Hatzinger et al., 2008), although this was not replicated during a one year follow-up study (M. Hatzinger et al., 2013). The finding that lighter sleep phases are associated with elevated cortisol reactivity is in accordance with the observation that poor subjective sleep quality and fragmented sleep may potentiate HPA stress reactivity. Taken together, it seems reasonable to conclude that a generally reduced quality of sleep, either subjective or objective, may enhance the stress reactivity of the HPA axis. 
Table 1. Sleep and cortisol stress reactivity: characteristics and main findings of included studies

\begin{tabular}{|c|c|c|c|c|c|c|c|c|c|c|c|}
\hline Study & $\mathrm{n}$ & $\begin{array}{l}\text { Age } \\
\text { (y) }\end{array}$ & $\mathrm{M} / \mathrm{F}$ & Sleep & Stressor & Sleep quality $\downarrow$ & Sleep efficiency $\downarrow$ & Sleep architecture & Sleep duration $\downarrow$ & Daytime sleepiness $\uparrow$ & Sleep problems $\uparrow$ \\
\hline Bassett et al., 2015 & 73 & 19.7 & 0.40 & PSQI & TSST & $\begin{array}{l}\Delta \text { Cortisol } \\
\text { Male } \uparrow \downarrow ; \text { Female }=\end{array}$ & - & - & $\Delta$ Cortisol $=$ & $\Delta$ Cortisol $\downarrow$ & - \\
\hline Brooks \& Robles, 2009 & 76 & 22.6 & 0.54 & PSQI & TSST & $\Delta$ Cortisol $=$ & - & - & - & - & - \\
\hline Capaldi et al., 2005 & 31 & 13.1 & 0.48 & SHS & $\begin{array}{l}\text { TSST-C* } \\
\text { MTT }\end{array}$ & - & - & - & $\Delta$ Cortisol $=$ & $\Delta$ Cortisol $\downarrow$ & $\Delta$ Cortisol $\downarrow$ \\
\hline Goodin et al., 2012 & 40 & 20.2 & 0.50 & PSQI & $\mathrm{CPT}$ & $\Delta$ Cortisol $\uparrow$ & - & - & - & - & - \\
\hline Hatzinger et al., 2008 & 67 & 5.3 & 0.52 & PSG & $\begin{array}{l}\text { TSST-C* } \\
\text { MSSB }\end{array}$ & - & $\Delta$ Cortisol $\uparrow$ & $\begin{array}{l}\Delta \text { Cortisol } \\
\text { S1 } \uparrow ; \mathrm{S} 2 \uparrow ; \mathrm{REM} \uparrow\end{array}$ & $\Delta$ Cortisol $=$ & - & - \\
\hline Hatzinger et al., 2010 & 82 & 4.9 & 0.60 & ACT & MSSB & - & - & - & - & - & - \\
\hline Hatzinger et al., 2013 & 5.8 & 6.4 & 0.53 & PSG & MSSB & - & $\Delta$ Cortisol $=$ & $\Delta$ Cortisol $=$ & - & - & - \\
\hline Hatzinger et al., 2014 & 73 & 6.4 & 0.47 & ACT & MSSB & - & $\Delta$ Cortisol $=$ & - & - & - & - \\
\hline Hori et al., 2011 & 139 & 42.7 & 0.29 & PSQI & $\begin{array}{l}\text { DEX/ } \\
\text { CRH }\end{array}$ & $\begin{array}{l}\Delta \text { Cortisol } \\
\text { DEX }=; \mathrm{CRH} \uparrow\end{array}$ & - & - & $\begin{array}{l}\Delta \text { Cortisol } \\
\text { DEX }=; C R H=\end{array}$ & $\begin{array}{l}\Delta \text { Cortisol } \\
\text { DEX }=; C R H=\end{array}$ & - \\
\hline Hyyppä et al., 1990 & 257 & 52.2 & 0.48 & $\begin{array}{l}\text { RRC- } \\
\text { SHQ }\end{array}$ & DEX & - & - & - & - & - & - \\
\hline Lattova et al., 2011 & 97 & 49.7 & 0.59 & MED & $\begin{array}{l}\text { DEX/ } \\
\text { CRH }\end{array}$ & - & - & - & - & - & $\begin{array}{l}\Delta \text { Cortisol } \\
\text { DEX=; } \mathrm{CRH}=\end{array}$ \\
\hline Minkel et al., 2014 & 26 & 34.9 & 0.54 & TSD & TSST & - & - & - & $\Delta$ Cortisol $\uparrow$ & - & - \\
\hline Mrug et al., 2016 & 84 & 13.4 & 0.50 & ASHS & TSST-C & - & - & - & $\Delta$ Cortisol $\downarrow$ & - & $\begin{array}{l}\Delta \text { Cortisol } \uparrow \\
\text { Male }<\text { Female }\end{array}$ \\
\hline Pesonen et al., 2012 & 284 & 8.1 & 0.49 & $\begin{array}{l}\text { ACT/ } \\
\text { SDSC }\end{array}$ & TSST-C & - & - & - & - & $\Delta$ Cortisol $\downarrow$ & $\begin{array}{l}\Delta \text { Cortisol } \\
\text { Male } \downarrow ; \text { Female } \uparrow\end{array}$ \\
\hline Pesonen et al., 2014 & 305 & 12.4 & 0.47 & ACT & DEX & - & $\begin{array}{l}\Delta \text { Cortisol } \\
\text { DEX }=\end{array}$ & - & $\begin{array}{l}\Delta \text { Cortisol } \\
\text { DEX }=\end{array}$ & - & - \\
\hline Räikkönen et al., 2010 & 282 & 8.1 & 0.48 & $\mathrm{ACT}$ & TSST-C & - & $\Delta$ Cortisol $\uparrow$ & - & $\Delta$ Cortisol $=$ & - & - \\
\hline Wright et al., 2007 & 53 & 37.3 & 0.00 & $\begin{array}{l}\mathrm{ACT} / \\
\mathrm{SD}\end{array}$ & Stroop & $\Delta$ Cortisol $=$ & $\Delta$ Cortisol $\downarrow$ & - & $\Delta$ Cortisol $=$ & $\Delta$ Cortisol $=$ & - \\
\hline
\end{tabular}

Note. ACT, actigraphy; ASHS, adolescent sleep history survey; $\triangle$ Cortisol, cortisol stress response; CPT, cold pressor task; CRH: corticotrophin releasing hormone; DEX: dexamethasone; M/F, proportion of males; MED, medical diagnoses; MSSB, MacArthur story stem battery; MTT, mirror tracing task; n, number of participants; PSG, polysomnography; PSQI, Pittsburgh sleep quality index; REM, rapid eye movement sleep; RRC-HSQ, rehabilitation research center sleep habit questionnaire; S1, stage 1; S2, stage 2; SD, sleep diary; SDSC, sleep disturbance scale children; SHS, sleep habits survey; TSD, total sleep deprivation; TSST, Trier social stress test; TSST-C, Trier social stress test for children; *: modified version; $\uparrow:$ increase; $\downarrow$ : decrease; =: no influence. 


\section{Sleep duration}

In contrast to the quality of sleep, normal variations in sleep quantity (i.e. sleep duration) do not influence cortisol stress responsiveness (Bassett et al., 2015; Capaldi, Handwerger, Richardson, \& Stroud, 2005; M. Hatzinger et al., 2008; Räikkönen et al., 2010; Wright et al., 2007) although one study reported that longer sleep duration was associated with higher cortisol stress responsiveness (Mrug, Tyson, Turan, \& Granger, 2016). One night of total sleep deprivation is however found to exaggerate cortisol reactivity to psychosocial stress (Minkel et al., 2014), highlighting the importance of sleep in regulating neuroendocrine stress sensitivity. Pharmacological studies further confirm that sleep duration does not influence the reactivity of the HPA axis as this is related to cortisol levels neither after CRH (Hori et al., 2011) nor DEX administration (Hori et al., 2011; Pesonen et al., 2014).

Collectively, these findings clearly demonstrate that normal variations in sleep duration do not influence the stress responsiveness of the HPA axis, although the specific amount of sleep needed to preserve adequate HPA reactivity remains to be established.

\section{Daytime sleepiness}

Although being one of the most apparent consequences of inadequate sleep, daytime sleepiness has been repeatedly found to reduce (instead of enhance) cortisol stress responsiveness to psychosocial stress (Bassett et al., 2015; Capaldi et al., 2005; Pesonen et al., 2012) in contrast to a cognitive challenge task (Wright et al., 2007). Hence, again this inconsistency most likely reflects the type of stressor used. Importantly, daytime sleepiness does not seem to influence cortisol levels following a pharmacological (CRH/DEX) challenge (Hori et al., 2011). Hence, this indicates that daytime sleepiness is not associated with biological alterations within the HPA axis, suggesting that more psychological/attentional factors might mediate this association.

\section{Sleep-wake problems}

Some studies have incorporated more ambiguous measures of sleep- and sleep-related problems. These investigations did not yield consistent results as they either revealed that sleep-wake problems were associated with increased (Mrug et al., 2016) or decreased (Capaldi et al., 2005) cortisol stress responses to psychosocial stress. Although this equivocality might relate to the strong overrepresentation of daytime sleepiness items included in the latter study (see previous paragraph), it remains difficult to draw definitive 
conclusions. In a related study, explicit sleep problems (dyssomnia and parasomnia) were found to increase cortisol responses to psychological stress in female participants, while male participants with sleep problems displayed diminished cortisol stress responsiveness (Pesonen et al., 2012). This gender dependent effect is consistent with a later study that revealed a more pronounced association between sleep-wake problems and elevated cortisol reactivity in female relative to male participants (Mrug et al., 2016).

Cautiously considering these studies together, it might be possible that sleep-wake problems also enhance cortisol stress responsiveness, especially in female participants. However, the ambiguity of these measures severely limits the comparability and integration of the findings.

\section{Clinical sleep disturbances}

Only very limited research is available regarding the stress reactivity of the HPA axis in clinical sleep disturbances. Lattova et al. (2011) demonstrated that relative to healthy controls, primary insomnia was not associated with altered cortisol levels following CRH and DEX administration (Lattova et al., 2011), suggesting normal HPA functioning. Hence, this finding contrasts with the observation that reduced sleep quality potentiates cortisol values after pharmacological stimulation (Hori et al., 2011).

\section{Combination of sleep variables}

Although specific information about the influence of the various aspects of sleep could be derived from most studies, some included a combination of variables to define poor and good sleepers. Hatzinger et al. (2008) for instance used a combination of polysomnographic measurements including sleep onset latency, wake after sleep onset and sleep period time (i.e. time between sleep onset and final morning awakening) to classify poor, normal and good sleepers. Results did not reveal any significant group differences in cortisol reactivity (M. Hatzinger et al., 2008). Using a similar classification, a later study confirmed no differences in stress reactivity between the three subgroups when using actigraphic sleep assessment (Martin Hatzinger et al., 2010). An early pharmacological study further established that poor, intermediate and good sleepers (based on various sleep variables) do not differ in cortisol levels following DEX administration (Hyyppä, Lindholm, Kronholm, \& Lehtinen, 1990). Hence, this in line with later findings demonstrating that sleep does not influence the feedback inhibition within the HPA axis (Hori et al., 2011; Lattova et al., 2011; Pesonen et al., 2014). 
Taken together, these findings illustrate that good- and poor sleepers as defined by a combination of sleep variables do not differ in cortisol stress responsiveness. However, this observation most likely relates to the use of sleep duration in the group classification since individual aspects relating to the quality of sleep are generally found to promote cortisol stress responsiveness, highlighting the importance of separating the various aspects of sleep.

\section{Effect size and power}

In order to determine the magnitude of the influence of sleep on HPA reactivity, effect sizes were retrieved from studies that reported significant effects. According to common conventions for the interpretation of effect size (Cohen, 1988), these studies reported a smallmedium (Hori et al., 2011), medium-large (Bassett et al., 2015) or large (Goodin et al., 2012) effect size for subjective sleep quality, a medium-large effect size for sleep efficiency and awakenings during the night (M. Hatzinger et al., 2008; Wright et al., 2007), a medium effect size for specific sleep phases (M. Hatzinger et al., 2008), a small-medium effect size for sleep duration (Mrug et al., 2016), a large effect size for sleep deprivation (Minkel et al., 2014), a medium effect size for daytime sleepiness (Bassett et al., 2015; Capaldi et al., 2005), and a medium effect size for the influence of sleep-wake problems (Capaldi et al., 2005; Mrug et al., 2016). Of note, although effect sizes could be obtained from most investigations, few studies reported actual group differences in percentages instead of measures of effect size and provided too little information to calculate these values (Pesonen et al., 2012; Räikkönen et al., 2010). Taken together, regardless of the variable of interest sleep seems to exert a medium effect on the stress reactivity of the HPA axis.

The statistical power of each individual study was estimated ( $\alpha=0.05$; two-tailed) to determine whether the sample size was sufficient to detect an influence of medium effect size. This revealed that most studies comprised (Bassett et al., 2015; Goodin et al., 2012; Martin Hatzinger et al., 2010; Hori et al., 2011; Hyyppä et al., 1990; Lattova et al., 2011; Mrug et al., 2016; Pesonen et al., 2012; Pesonen et al., 2014; Räikkönen et al., 2010) or approached (Brooks \& Robles, 2009; M. Hatzinger et al., 2008; M. Hatzinger et al., 2014) adequate statistical power $(1-\beta=0.80)$ according to suggested criteria (Cohen, 1988). However, few studies seem to be relatively underpowered (Capaldi et al., 2005; M. Hatzinger et al., 2013; Minkel et al., 2014; Wright et al., 2007). As this might relate to the deviant findings observed in some of these investigations (Capaldi et al., 2005; M. Hatzinger et al., 2013; Wright et al., 2007), the reported data of interest should be more carefully interpreted. 


\section{Methodological issues}

Investigating the influence of sleep on stress reactivity of the HPA axis is subjected to some apparent methodological issues. The following section comprises a brief outline of factors and concepts that are considered particularly relevant when exploring this specific association. Of note, other factors also known to influence HPA functioning are beyond the scope of the present review.

\section{Type of stressor}

The influence of sleep on the stress reactivity of the HPA axis might vary substantially depending on the selected laboratory stressor. As extensively reviewed (Dickerson \& Kemeny, 2004), the type of experimental stressor may significantly influence the magnitude of cortisol responses. As opposed to physical- and cognitive stressors, uncontrollable psychosocial evaluative stress (e.g. Trier social stress test, TSST) seems to be most successful in inducing strong and reliable cortisol responses (Dickerson \& Kemeny, 2004). In line with this assumption, in the present review sleep was most consistently found to influence cortisol reactivity to psychosocial- (Bassett et al., 2015; M. Hatzinger et al., 2008; Minkel et al., 2014; Mrug et al., 2016; Pesonen et al., 2012; Räikkönen et al., 2010) and physical stressors (Goodin et al., 2012) while most deviant findings were observed on cognitive paradigms (Wright et al., 2007).

\section{Gender}

Although the encompassed literature does not reveal a consistent gender-dependent effect, some studies indicate that gender might be an important factor modulating the influence of sleep on the stress sensitivity of the HPA axis (Bassett et al., 2015; Mrug et al., 2016; Pesonen et al., 2012). Whereas two studies revealed that the potentiating influence of inadequate sleep may be more pronounced in female relative to male participants (Mrug et al., 2016; Pesonen et al., 2012) another study exclusively observed sleep-related effects in male but not female participants (Bassett et al., 2015). In the general literature, human studies have either revealed no significant effect of gender or reported stronger cortisol stress responses in male relative to female participants (for review see: (Kudielka \& Kirschbaum, 2005)). There is some evidence however that female participants display enhanced reactivity to pharmacological stimulation of the HPA axis (Heuser et al., 1994; Hori et al., 2011), although this has not been consistently observed (Kudielka \& Kirschbaum, 2005). Combining this finding with the 
presumed potentiating influence of reduced sleep quality, this may in theory make female participants more susceptible for sleep-related changes in the sensitivity of the HPA axis. Although two studies indeed confirmed this preliminary assumption (Mrug et al., 2016; Pesonen et al., 2012), more research will be necessary to determine how gender may affect the relationship between sleep and cortisol stress responsiveness.

\section{Age}

The included studies differ substantially regarding the age of the studied population as a considerable amount of studies have been conducted in children (M. Hatzinger et al., 2008; Martin Hatzinger et al., 2010; M. Hatzinger et al., 2013, 2014; Pesonen et al., 2012; Räikkönen et al., 2010) and/or adolescents (Capaldi et al., 2005; Mrug et al., 2016; Pesonen et al., 2014) while others included a sample of adult participants (Bassett et al., 2015; Brooks \& Robles, 2009; Goodin et al., 2012; Hori et al., 2011; Hyyppä et al., 1990; Lattova et al., 2011; Minkel et al., 2014; Wright et al., 2007). Although it would be valuable to explore potential differences among these investigations, the amount of studies is too limited to reach adequate conclusions for the respective aspects of sleep. It is unlikely however that this substantially influenced the results as no significant differences in cortisol stress responsiveness are generally observed between children and adults (Kudielka et al., 2004) or younger and older children (Kudielka \& Kirschbaum, 2005). Nonetheless, given the profound alterations in sleep across the life span (Ohayon, Carskadon, Guilleminault, \& Vitiello, 2004; Skeldon, Derks, \& Dijk, 2016) together with age-related neuroendocrine alterations (Kajantie \& Phillips, 2006) age might still be a relevant factor to take into account when exploring the influence of sleep on cortisol stress responsiveness.

\section{Causality}

The numerous interconnections between sleep, stress and functioning of the HPA axis pose some important challenges regarding causality. Stress experience is well-known to reduce the quality of sleep (Åkerstedt et al., 2012) which in turn may potentiate HPA stress reactivity as demonstrated in the present review. On the contrary, sustained HPA over activation, resulting from prolonged stress experience or chronic sleep disturbances, may eventually reduce cortisol stress responsiveness by means of self-adjusting mechanisms (Fries, Hesse, Hellhammer, \& Hellhammer, 2005; Miller, Chen, \& Zhou, 2007). Although speculative, similar mechanisms may relate to the blunted cortisol reactivity observed in excessive 
daytime sleepiness (see previous section), which is in line with the state of hypocortisolism associated with high levels of fatigue (Bower, Ganz, \& Aziz, 2005; Fries et al., 2005; Gaab et al., 2002). Interestingly, Hori et al. (2011) demonstrated that the enhanced HPA reactivity resulting from poor sleep quality indeed becomes more pronounced after controlling for prior stress experience (Hori et al., 2011). Collectively, these findings illustrate that although impaired sleep may initially enhance neuroendocrine stress reactivity, the sensitivity of the HPA axis may eventually decrease when sleep disturbances and/or stress experiences are more persistent.

The bidirectional relationship between sleep and secretory activity of the HPA axis further enhances the complexity of causality. Hence, while impaired sleep enhances the secretory activity of the HPA axis (Balbo et al., 2010; Meerlo et al., 2008), elevated levels of HPA hormones are found to result in inadequate sleep (Gillin, Jacobs, Fram, \& Snyder, 1972; Holsboer, von Bardeleben, \& Steiger, 1988; Rodenbeck \& Hajak, 2001; Rodenbeck, Huether, Ruther, \& Hajak, 2002). In the light of these findings, it remains uncertain whether an elevated stress sensitivity of the HPA axis is either cause or consequence of sleep impairments. Nonetheless, experimental studies including sleep deprivation (Leproult, Copinschi, Buxton, \& Van Cauter, 1997; Minkel et al., 2014) and sleep restriction (Spiegel, Leproult, \& Van Cauter, 1999) strategies have convincingly established that sleep indeed affects HPA functioning. Although the relationship between sleep and the HPA axis is clearly bidirectional, these findings support the assumption that sleep specifically modulates the stress sensitivity of the HPA axis.

\section{Depression}

Depression is characterized by profound abnormalities in HPA functioning. These generally include elevated basal levels of HPA hormones (Nemeroff \& Vale, 2005; van Praag, 2004), presumably resulting from deficient feedback inhibition (Pariante \& Lightman, 2008). In line with these findings, a recent meta-analysis revealed that clinical depression is associated with a blunted cortisol stress response and impaired stress recovery (Burke, Davis, Otte, \& Mohr, 2005). Since close associations between sleep and depression have been well-established, a potential role for affective symptomatology in the relationship between sleep and HPA stress reactivity cannot be excluded. Hence, sleep alterations comprise one of the core symptoms of clinical depression (American Psychiatric Association, 2013) and associations between inadequate sleep and affective changes have been commonly acknowledged (Palmer \& 
Alfano, 2017). Longitudinal studies further demonstrate that insomnia represents an independent risk factor for the development of depression (for meta-analysis see: (Baglioni et al., 2011)). Taken together, these findings illustrate the potential involvement of depressive symptomatology in the association between sleep and HPA reactivity. Given the causal contribution of hypercortisolism to the etiology of depression (Sapolsky, 2015; van Praag, 2004), elevated HPA stress-sensitivity might as well be a potential mechanism relating to the association between sleep and depression.

\section{Underlying mechanisms}

The mechanisms underlying the influence of sleep on the stress reactivity of the HPA axis are complex and multifaceted. These include acute effects on various arousal systems as well as alterations in neurotransmitter systems when sleep disturbances are prolonged (for review see: (Meerlo et al., 2008)). Although these neurobiological alterations are clearly relevant, increasing evidence suggests that sleep particularly influences emotion regulation and emotional reactivity (for review see: (Palmer \& Alfano, 2017)), presumably resulting from alterations in frontal-limbic systems (Gruber \& Cassoff, 2014). Neuroimaging studies have consistently demonstrated that impaired sleep enhances (limbic) amygdala reactivity to negative emotional stimuli (Motomura et al., 2013; Yoo, Gujar, Hu, Jolesz, \& Walker, 2007) as well as lowering its threshold for emotional activation (Simon et al., 2015). Efferent connections from the amygdala to the HPA axis reveal a potential pathway how this sleeprelated sensitivity of the limbic system may simultaneously enhance neuroendocrine reactivity (Feldman, Conforti, \& Siegel, 1982). Sustained elevation of cortisol levels resulting from insufficient recovery sleep (Meerlo et al., 2008) might even further deteriorate adequate emotional responses by causing limbic hypertrophy (i.e. enhanced reactivity) and frontal atrophy (i.e. reduced cognitive control) when sleep disturbances are prolonged (Sapolsky, 2015). Taken together, these findings suggest that sleep-induced alterations in frontal-limbic systems may enhance the emotional impact of stress which may indirectly influence the sensitivity of the HPA axis. Although this represents only one of the suggested mechanisms underlying sleep-related alterations in HPA reactivity (Meerlo et al., 2008), these recent insights illustrate that sleep-induced alterations in frontal-limbic systems may indirectly influence the sensitivity of the HPA axis. 


\section{Future directions}

Although the reviewed findings provide valuable insights in how sleep may influence the reactivity of the HPA axis, more research is necessary to confirm the initial conclusions. Future studies should particularly investigate how the core aspects of sleep may differentially influence HPA reactivity to psychosocial stress, while paying close attention to important modulating factors (see methodological issues). Longitudinal studies are desirable to determine how intraindividual variations in sleep quality relate to the stress sensitivity of the HPA axis as well as its functional health outcomes. Similarly, studies incorporating sleep restriction or sleep deprivation strategies could help to further clarify this association. The implementation of pharmacological stimulation is encouraged to further establish how sleep may modulate the biological sensitivity of the HPA axis. On the other hand, several lines of research suggest that sleep-induced alterations in emotional systems may particularly underlie altered HPA reactivity, although more research is needed to establish this particular involvement.

\section{Conclusions}

The reviewed findings suggest that inadequate sleep may profoundly potentiate the stress reactivity of the HPA axis. Among the various aspects, the quality of sleep is found to particularly influence cortisol stress responsiveness. This relates to both subjectively reported sleep quality as well as objectively measured sleep efficiency, awakenings during the night and time spent in lighter sleep phases. On the contrary, normal variations in sleep duration do not seem to influence HPA reactivity whereas daytime sleepiness is associated with blunted cortisol stress responsiveness. The reviewed findings further emphasize the importance to separately investigate the various aspects of sleep given their differential influence on HPA reactivity. From a methodological perspective, several potential interfering factors have been identified that may potentially modulate the observed association. Most relevant factors to control for in future investigations comprise type of stressor, gender, prior stress experience and depression. Given the well-established relationships between impaired sleep and the risk for medical- and psychopathological illness, current findings support the assumption that enhanced sensitization of the HPA axis may be a crucial component along the pathway of sleep and stress-related disease. 


\section{References}

Åkerstedt, T., Orsini, N., Petersen, H., Axelsson, J., Lekander, M., \& Kecklund, G. (2012). Predicting sleep quality from stress and prior sleep - A study of day-to-day covariation across sixweeks. Sleep Med, 13(6), 674-679.

American Psychiatric Association. (2013). Diagnostic and Statistical Manual of Mental Disorders: Dsm-5: Amer Psychiatric Pub Incorporated.

Ancoli-Israel, S., \& Roth, T. (1999). Characteristics of insomnia in the United States: results of the 1991 National Sleep Foundation Survey. I. Sleep, 22(2), S347-353.

Baglioni, C., Battagliese, G., Feige, B., Spiegelhalder, K., Nissen, C., Voderholzer, U., . . . Riemann, D. (2011). Insomnia as a predictor of depression: A meta-analytic evaluation of longitudinal epidemiological studies. Journal of Affective Disorders, 135(1-3), 10-19. doi:10.1016/j.jad.2011.01.011

Balbo, M., Leproult, R., \& Van Cauter, E. (2010). Impact of sleep and its disturbances on hypothalamo-pituitary-adrenal axis activity. Int $J$ Endocrinol, 2010, 759234. doi:10.1155/2010/759234

Bassett, S. M., Lupis, S. B., Gianferante, D., Rohleder, N., \& Wolf, J. M. (2015). Sleep quality but not sleep quantity effects on cortisol responses to acute psychosocial stress. Stress, 18(6), 638-644. doi:10.3109/10253890.2015.1087503

Bower, J. E., Ganz, P. A., \& Aziz, N. (2005). Altered cortisol response to psychologic stress in breast cancer survivors with persistent fatigue. Psychosomatic Medicine, 67(2), 277-280. doi:10.1097/01.psy.0000155666.55034.c6

Brooks, K. P., \& Robles, T. F. (2009). Recent depressive and anxious symptoms predict cortisol responses to stress in men. Psychoneuroendocrinology, 34(7), 1041-1049. doi:10.1016/j.psyneuen.2009.02.005

Buckley, T. M., \& Schatzberg, A. F. (2005). On the interactions of the hypothalamicpituitary-adrenal (HPA) axis and sleep: normal HPA axis activity and circadian rhythm, exemplary sleep disorders. Journal of Clinical Endocrinology and Metabolism, 90(5), 3106-3114. doi:10.1210/jc.2004-1056

Burke, H. M., Davis, M. C., Otte, C., \& Mohr, D. C. (2005). Depression and cortisol responses to psychological stress: a meta-analysis. Psychoneuroendocrinology, 30(9), 846-856. doi:10.1016/j.psyneuen.2005.02.010

Buysse, D. J. (2014). Sleep health: can we define it? Does it matter? Sleep, 37(1), 9-17. doi:10.5665/sleep.3298

Capaldi, I. I. V. F., Handwerger, K., Richardson, E., \& Stroud, L. R. (2005). Associations Between Sleep and Cortisol Responses to Stress in Children and Adolescents: A Pilot Study. Behavioral Sleep Medicine, 3(4), 177-192. doi:10.1207/s15402010bsm0304_1

Chrousos, G. P., \& Gold, P. W. (1992). The concepts of stress and stress system disorders. Overview of physical and behavioral homeostasis. JAMA, 267(9), 1244-1252.

Cohen, J. (1988). Statistical power analysis for the behavioral sciences. Hillsdale, N.J.: L. Erlbaum Associates.

Dickerson, S. S., \& Kemeny, M. E. (2004). Acute stressors and cortisol responses: a theoretical integration and synthesis of laboratory research. Psychological Bulletin, 130(3), 355-391. doi:10.1037/0033-2909.130.3.355

Feldman, S., Conforti, N., \& Siegel, R. A. (1982). Adrenocortical responses following limbic stimulation in rats with hypothalamic deafferentations. Neuroendocrinology, 35(3), 205-211.

Fries, E., Hesse, J., Hellhammer, J., \& Hellhammer, D. H. (2005). A new view on hypocortisolism. Psychoneuroendocrinology, 30(10), 1010-1016. doi:10.1016/j.psyneuen.2005.04.006 
Gaab, J., Huster, D., Peisen, R., Engert, V., Heitz, V., Schad, T., . . . Ehlert, U. (2002). Hypothalamic-pituitary-adrenal axis reactivity in chronic fatigue syndrome and health under psychological, physiological, and pharmacological stimulation. Psychosomatic Medicine, 64(6), 951-962.

Gillin, J. C., Jacobs, L. S., Fram, D. H., \& Snyder, F. (1972). Acute effect of a glucocorticoid on normal human sleep. Nature, 237(5355), 398-399.

Goodin, B. R., Smith, M. T., Quinn, N. B., King, C. D., \& McGuire, L. (2012). Poor sleep quality and exaggerated salivary cortisol reactivity to the cold pressor task predict greater acute pain severity in a non-clinical sample. Biological Psychology, 91(1), 3641. doi:10.1016/j.biopsycho.2012.02.020

Gruber, R., \& Cassoff, J. (2014). The Interplay Between Sleep and Emotion Regulation: Conceptual Framework Empirical Evidence and Future Directions. Current Psychiatry Reports, 16(11), 1-9. doi:10.1007/s11920-014-0500-x

Guo, X., Zheng, L., Wang, J., Zhang, X., Zhang, X., Li, J., \& Sun, Y. (2013). Epidemiological evidence for the link between sleep duration and high blood pressure: A systematic review and meta-analysis. Sleep Med, 14(4), 324-332.

Hatzinger, M., Brand, S., Perren, S., Stadelmann, S., von Wyl, A., von Klitzing, K., \& Holsboer-Trachsler, E. (2008). Electroencephalographic sleep profiles and hypothalamic-pituitary-adrenocortical (HPA)-activity in kindergarten children: early indication of poor sleep quality associated with increased cortisol secretion. Journal of Psychiatric Research, 42(7), 532-543. doi:10.1016/j.jpsychires.2007.05.010

Hatzinger, M., Brand, S., Perren, S., Stadelmann, S., Wyl, A. v., Klitzing, K. v., \& HolsboerTrachsler, E. (2010). Sleep actigraphy pattern and behavioral/emotional difficulties in kindergarten children: Association with hypothalamic-pituitary-adrenocortical (HPA) activity. Journal of Psychiatric Research, 44(4), 253-261. doi:10.1016/j.jpsychires.2009.08.012

Hatzinger, M., Brand, S., Perren, S., Von Wyl, A., Stadelmann, S., von Klitzing, K., \& Holsboer-Trachsler, E. (2013). In pre-school children, sleep objectively assessed via sleep-EEGs remains stable over 12 months and is related to psychological functioning, but not to cortisol secretion. Journal of Psychiatric Research, 47(11), 1809-1814. doi:10.1016/j.jpsychires.2013.08.007

Hatzinger, M., Brand, S., Perren, S., Von Wyl, A., Stadelmann, S., von Klitzing, K., \& Holsboer-Trachsler, E. (2014). In pre-school children, sleep objectively assessed via actigraphy remains stable over 12 months and is related to psychological functioning, but not to cortisol secretion. Journal of Psychiatric Research, 55, 22-28. doi:10.1016/j.jpsychires.2014.04.008

Heim, C., Ehlert, U., \& Hellhammer, D. H. (2000). The potential role of hypocortisolism in the pathophysiology of stress-related bodily disorders. Psychoneuroendocrinology, 25(1), 1-35.

Heuser, I. J., Gotthardt, U., Schweiger, U., Schmider, J., Lammers, C. H., Dettling, M., \& Holsboer, F. (1994). Age-associated changes of pituitary-adrenocortical hormone regulation in humans: importance of gender. Neurobiology of Aging, 15(2), 227-231.

Holsboer, F. (1989). Psychiatric implications of altered limbic-hypothalamic-pituitaryadrenocortical activity. European Archives of Psychiatry and Neurologicl Sciences, 238(5-6), 302-322.

Holsboer, F., von Bardeleben, U., \& Steiger, A. (1988). Effects of intravenous corticotropinreleasing hormone upon sleep-related growth hormone surge and sleep EEG in man. Neuroendocrinology, 48(1), 32-38.

Hori, H., Teraishi, T., Sasayama, D., Ozeki, Y., Matsuo, J., Kawamoto, Y., . . Kunugi, H. (2011). Poor sleep is associated with exaggerated cortisol response to the combined 
dexamethasone/CRH test in a non-clinical population. Journal of Psychiatric Research, 45(9), 1257-1263. doi:10.1016/j.jpsychires.2011.04.001

Hyyppä, M. T., Lindholm, T., Kronholm, E., \& Lehtinen, V. (1990). Functional insomnia in relation to alexithymic features and cortisol hypersecretion in a community sample. Stress Medicine, 6(4), 277-283. doi:10.1002/smi.2460060406

Kajantie, E., \& Phillips, D. I. (2006). The effects of sex and hormonal status on the physiological response to acute psychosocial stress. Psychoneuroendocrinology, 31(2), 151-178. doi:10.1016/j.psyneuen.2005.07.002

Krystal, A. D. (2006). Sleep and Psychiatric Disorders: Future Directions. Psychiatric Clinics of North America, 29(4), 1115-1130. doi:10.1016/j.psc.2006.09.001

Kudielka, B. M., Buske-Kirschbaum, A., Hellhammer, D. H., \& Kirschbaum, C. (2004). HPA axis responses to laboratory psychosocial stress in healthy elderly adults, younger adults, and children: impact of age and gender. Psychoneuroendocrinology, 29(1), 8398.

Kudielka, B. M., \& Kirschbaum, C. (2005). Sex differences in HPA axis responses to stress: a review. Biological Psychology, 69(1), 113-132. doi:10.1016/j.biopsycho.2004.11.009

Lattova, Z., Keckeis, M., Maurovich-Horvat, E., Wetter, T. C., Wilde-Frenz, J., Schuld, A., \& Pollmacher, T. (2011). The stress hormone system in various sleep disorders. Journal of Psychiatric Research, 45(9), 1223-1228. doi:10.1016/j.jpsychires.2011.03.013

Leger, D., Poursain, B., Neubauer, D., \& Uchiyama, M. (2008). An international survey of sleeping problems in the general population. Current Medical Research and Opinion, 24(1), 307-317. doi:10.1185/030079907X253771

Leproult, R., Copinschi, G., Buxton, O., \& Van Cauter, E. (1997). Sleep loss results in an elevation of cortisol levels the next evening. Sleep, 20(10), 865-870.

Meerlo, P., Sgoifo, A., \& Suchecki, D. (2008). Restricted and disrupted sleep: effects on autonomic function, neuroendocrine stress systems and stress responsivity. Sleep Med Rev, 12(3), 197-210. doi:10.1016/j.smrv.2007.07.007

Miller, G. E., Chen, E., \& Zhou, E. S. (2007). If it goes up, must it come down? Chronic stress and the hypothalamic-pituitary-adrenocortical axis in humans. Psychological Bulletin, 133(1), 25-45. doi:10.1037/0033-2909.133.1.25

Minkel, J., Moreta, M., Muto, J., Htaik, O., Jones, C., Basner, M., \& Dinges, D. (2014). Sleep deprivation potentiates HPA axis stress reactivity in healthy adults. Health Psychology, 33(11), 1430-1434. doi:10.1037/a0034219

Motomura, Y., Kitamura, S., Oba, K., Terasawa, Y., Enomoto, M., Katayose, Y., . . . Mishima, K. (2013). Sleep Debt Elicits Negative Emotional Reaction through Diminished Amygdala-Anterior Cingulate Functional Connectivity. PLoS ONE, 8(2), e56578. doi:10.1371/journal.pone.0056578

Mrug, S., Tyson, A., Turan, B., \& Granger, D. A. (2016). Sleep problems predict cortisol reactivity to stress in urban adolescents. Physiology and Behavior, 155, 95-101. doi:10.1016/j.physbeh.2015.12.003

Nemeroff, C. B., \& Vale, W. W. (2005). The neurobiology of depression: inroads to treatment and new drug discovery. Journal of Clinical Psychiatry, 66 Suppl 7, 5-13.

Ohayon, M. M. (1997). Prevalence of DSM-IV diagnostic criteria of insomnia: distinguishing insomnia related to mental disorders from sleep disorders. Journal of Psychiatric Research, 31(3), 333-346.

Ohayon, M. M., Carskadon, M. A., Guilleminault, C., \& Vitiello, M. V. (2004). Meta-analysis of quantitative sleep parameters from childhood to old age in healthy individuals: developing normative sleep values across the human lifespan. Sleep, 27(7), 12551273. 
Otte, C., Hart, S., Neylan, T. C., Marmar, C. R., Yaffe, K., \& Mohr, D. C. (2005). A metaanalysis of cortisol response to challenge in human aging: importance of gender. Psychoneuroendocrinology, 30(1), 80-91. doi:10.1016/j.psyneuen.2004.06.002

Palmer, C. A., \& Alfano, C. A. (2017). Sleep and emotion regulation: An organizing, integrative review. Sleep Med Rev, 31, 6-16. doi:10.1016/j.smrv.2015.12.006

Pariante, C. M., \& Lightman, S. L. (2008). The HPA axis in major depression: classical theories and new developments. Trends in Neurosciences, 31(9), 464-468. doi:10.1016/j.tins.2008.06.006

Pesonen, A. K., Kajantie, E., Heinonen, K., Pyhala, R., Lahti, J., Jones, A., . . Raikkonen, K. (2012). Sex-specific associations between sleep problems and hypothalamic-pituitaryadrenocortical axis activity in children. Psychoneuroendocrinology, 37(2), 238-248. doi:10.1016/j.psyneuen.2011.06.008

Pesonen, A. K., Martikainen, S., Kajantie, E., Heinonen, K., Wehkalampi, K., Lahti, J., .. . Raikkonen, K. (2014). The associations between adolescent sleep, diurnal cortisol patterns and cortisol reactivity to dexamethasone suppression test. Psychoneuroendocrinology, 49, 150-160. doi:10.1016/j.psyneuen.2014.07.005

Räikkönen, K., Matthews, K. A., Pesonen, A.-K., Pyhälä, R., Paavonen, E. J., Feldt, K., . . . Kajantie, E. (2010). Poor Sleep and Altered Hypothalamic-Pituitary-Adrenocortical and Sympatho-Adrenal-Medullary System Activity in Children. The Journal of Clinical Endocrinology \& Metabolism, 95(5), 2254-2261. doi:10.1210/jc.2009-0943

Raison, C. L., \& Miller, A. H. (2003). When not enough is too much: the role of insufficient glucocorticoid signaling in the pathophysiology of stress-related disorders. American Journal of Psychiatry, 160(9), 1554-1565. doi:10.1176/appi.ajp.160.9.1554

Rodenbeck, A., \& Hajak, G. (2001). Neuroendocrine dysregulation in primary insomnia. Revue Neurologique, 157(11 Pt 2), S57-61.

Rodenbeck, A., Huether, G., Ruther, E., \& Hajak, G. (2002). Interactions between evening and nocturnal cortisol secretion and sleep parameters in patients with severe chronic primary insomnia. Neuroscience Letters, 324(2), 159-163.

Sapolsky, R. M. (2015). Stress and the brain: individual variability and the inverted-U. Nature Neuroscience, 18(10), 1344-1346. doi:10.1038/nn.4109

Schneiderman, N., Ironson, G., \& Siegel, S. D. (2005). STRESS AND HEALTH: Psychological, Behavioral, and Biological Determinants. Annual review of clinical psychology, 1, 607-628. doi:10.1146/annurev.clinpsy.1.102803.144141

Schwartz, S., Anderson, W. M., Cole, S. R., Cornoni-Huntley, J., Hays, J. C., \& Blazer, D. (1999). Insomnia and heart disease: A review of epidemiologic studies. Journal of Psychosomatic Research, 47(4), 313-333. doi:10.1016/S0022-3999(99)00029-X

Simon, E. B., Oren, N., Sharon, H., Kirschner, A., Goldway, N., Okon-Singer, H., . . . Hendler, T. (2015). Losing Neutrality: The Neural Basis of Impaired Emotional Control without Sleep. Journal of Neuroscience, 35(38), 13194-13205. doi:10.1523/jneurosci.1314-15.2015

Skeldon, A. C., Derks, G., \& Dijk, D.-J. (2016). Modelling changes in sleep timing and duration across the lifespan: Changes in circadian rhythmicity or sleep homeostasis? Sleep Med Rev, 28, 96-107. doi:10.1016/j.smrv.2015.05.011

Spiegel, K., Leproult, R., \& Van Cauter, E. (1999). Impact of sleep debt on metabolic and endocrine function. Lancet, 354(9188), 1435-1439. doi:10.1016/s01406736(99)01376-8

Steiger, A. (2002). Sleep and the hypothalamo-pituitary-adrenocortical system. Sleep Med Rev, 6(2), 125-138.

Taylor, D. J., Lichstein, K. L., \& Durrence, H. H. (2003). Insomnia as a health risk factor. Behav Sleep Med, 1(4), 227-247. doi:10.1207/s15402010bsm0104_5 
Tsigos, C., \& Chrousos, G. P. (2002). Hypothalamic-pituitary-adrenal axis, neuroendocrine factors and stress. Journal of Psychosomatic Research, 53(4), 865-871.

Uhlig, B. L., Sand, T., Odegard, S. S., \& Hagen, K. (2014). Prevalence and associated factors of DSM-V insomnia in Norway: the Nord-Trondelag Health Study (HUNT 3). Sleep Med, 15(6), 708-713. doi:10.1016/j.sleep.2014.01.018

van Praag, H. M. (2004). Can stress cause depression? Progress in NeuroPsychopharmacology and Biological Psychiatry, 28(5), 891-907. doi:10.1016/j.pnpbp.2004.05.031

Wright, C. E., Valdimarsdottir, H. B., Erblich, J., \& Bovbjerg, D. H. (2007). Poor sleep the night before an experimental stress task is associated with reduced cortisol reactivity in healthy women. Biological Psychology, 74(3), 319-327. doi:10.1016/j.biopsycho.2006.08.003

Yoo, S. S., Gujar, N., Hu, P., Jolesz, F. A., \& Walker, M. P. (2007). The human emotional brain without sleep--a prefrontal amygdala disconnect. Current Biology, 17(20), R877-878. doi:10.1016/j.cub.2007.08.007

Young, E. A. (1998). Sex differences and the HPA axis: implications for psychiatric disease. $J$ Gend Specif Med, 1(1), 21-27. 


\section{Chapter 5}

The serotonin transporter polymorphism (5-HTTLPR) and cortisol stress responsiveness: preliminary evidence for a modulating role for sleep quality

Published as:

van Dalfsen, J. H., \& Markus, C. R. (2018). The serotonin transporter polymorphism (5HTTLPR) and cortisol stress responsiveness: preliminary evidence for a modulating role for sleep quality. Stress, 21(6), 503-510. doi:10.1080/10253890.2018.1475472 


\begin{abstract}
The short (S) allele of a functional polymorphism (5-HTTLPR) within the promoter region of the serotonin transporter gene (SLC6A4) is found to predispose the risk for stress-related affective disorders relative to the long (L) allele. Evidence suggests that elevated stress reactivity of the hypothalamic-pituitary-adrenal (HPA) axis might underlie this association although there is little understanding about the origin of inconsistent findings. Since inadequate sleep is commonly known to promote HPA stress reactivity, it might well play an important modulating role. The present study tested this hypothesis by investigating whether sleep quality moderates the relationship between 5-HTTLPR and cortisol stress responsiveness. From a large 5-HTTLPR database $(n=771)$, a sample of healthy male and female participants homozygous for either the 5-HTTLPR S-allele $(n=25)$ or L-allele $(n=$ 25) were assessed for sleep quality and salivary cortisol secretion during acute laboratory stress. Diminished sleep quality was found to exclusively potentiate cortisol stress reactivity in the homozygous L-allele genotype. Accounting for this 5-HTTLPR dependent influence enhanced the predictive value of 5-HTTLPR on cortisol stress responsiveness, revealing greater HPA reactivity in S-allele relative to L-allele carriers. Current findings suggest that variations in sleep quality may serve as a confounding factor in the search for genetic differences in stress sensitivity and related affective disorders.
\end{abstract}




\section{Introduction}

It is well-recognized that stress predisposes the risk for affective disorders (Sapolsky, 2015; van Praag, 2004) although the psychopathological consequences vary considerably across individuals. There is increasing consensus that genetic variations relate to these interindividual differences (Kendler \& Prescott, 2006). Particular emphasis has been placed on the serotonin (5-hydroxytryptamine; 5-HT) transporter gene-linked polymorphic region (5HTTLPR). This functional polymorphism within the promotor region of the serotonin transporter gene (SLC6A4) regulates the expression of the serotonin transporter and comprises an allelic variation that includes a short $(\mathrm{S})$ allele that is associated with lower transcriptional efficacy relative to the long (L) allele (Greenberg et al., 1999; Lesch et al., 1996).

Following the initial observations (Caspi et al., 2003; Hariri et al., 2002; Lesch et al., 1996), accumulating evidence suggests that the 5-HTTLPR S-allele is associated with an elevated susceptibility for stress-related affective disorders (Uher \& McGuffin, 2008, 2010). However, recent meta-analyses yielded inconclusive results by either providing evidence (Karg, Burmeister, Shedden, \& Sen, 2011) or reporting no support for this association (Munafò, Durrant, Lewis, \& Flint, 2009; Risch, Herrell, Lehner, \& et al., 2009). As a possible explanation for these equivocal findings, it has been suggested that 5-HTTLPR indirectly contributes to depression etiology by influencing the stress sensitivity of the hypothalamicpituitary-adrenal (HPA) axis (Way \& Taylor, 2010). This postulation is based on the role of 5HT in HPA regulation (Fuller, 1990; Porter, Gallagher, Watson, \& Young, 2004) together with the causal involvement of hypercortisolism in the development of depression (Sapolsky, 2015; van Praag, 2004).

Although multiple studies confirmed that the 5-HTTLPR S-allele potentiates cortisol stress responsiveness (Dougherty, Klein, Congdon, Canli, \& Hayden, 2010; Gotlib, Joormann, Minor, \& Hallmayer, 2008; Way \& Taylor, 2010) this finding has not been consistently replicated (Alexander et al., 2009; Bouma, Riese, Nederhof, Ormel, \& Oldehinkel, 2010; Verschoor \& Markus, 2011; Wüst et al., 2009) and effects in the opposite direction have been reported (Mueller et al., 2011). A recent meta-analysis revealed that Sallele carriers on average display higher cortisol responses relative to L-allele carriers, even though the effect size was smaller than anticipated for intermediate biological phenotypes (Miller, Wankerl, Stalder, Kirschbaum, \& Alexander, 2013). The authors argued that additional moderating variables potentially concealed stronger 5-HTTLPR dependent effects 
(Miller et al., 2013). Recent insights reveal that sleep quality profoundly influences the stress reactivity of the HPA axis (for review see: (van Dalfsen \& Markus, 2018)). Together with consistent evidence demonstrating the relevance of sleep in the association between 5HTTLPR and affective symptomatology (Carskadon, Sharkey, Knopik, \& McGeary, 2012; Hartmann et al., 2014; van Roekel, Hartmann, Wichers, \& Verhagen, 2016), these findings indicate that sleep quality might potentially moderate the relationship between 5-HTTLPR and cortisol stress responsiveness.

The aim of the present study was therefore to determine whether sleep quality moderates the association between 5-HTTLPR and cortisol stress reactivity. Accounting for the potential influence of sleep quality might reveal more consistent 5-HTTLPR dependent effects, further clarifying the relevance of HPA stress reactivity in the relationship between 5HTTLPR and affective disorders.

\section{Methods}

\section{Participants}

Individuals that were included in a recently obtained 5-HTTLPR database of Maastricht University graduates and undergraduates $(n=771)$ were invited to complete an online screening. The sample that completed the screening questionnaires $(n=366)$ was carefully screened based on the following inclusion and exclusion criteria. Inclusion criteria comprised: homozygous $\mathrm{S}^{\prime} / \mathrm{S}^{\prime}\left(\mathrm{S} / \mathrm{S}, \mathrm{S} / \mathrm{L}_{\mathrm{g}}, \mathrm{L}_{\mathrm{g}} / \mathrm{L}_{\mathrm{g}}\right)$ or $\mathrm{L}^{\prime} / \mathrm{L}^{\prime}\left(\mathrm{L}_{\mathrm{a}} / \mathrm{L}_{\mathrm{a}}\right)$ 5-HTTLPR genotype. This choice was based on previous findings demonstrating that genetic differences in stress reactivity are most consistently observed when comparing homozygous 5-HTTLPR genotypes (Miller et al., 2013). Exclusion criteria encompassed: moderate to severe depressive symptoms (BDI $\geq 14$ ), current psychiatric diagnosis, contemporary medical condition, medication use, recreational drug use and excessive alcohol intake (units a week > 15). These inclusion and exclusion criteria were met by 196 participants who were invited to participate in the acute stress experiment. The subsequent inclusion was monitored to include an equal distribution of 5HTTLPR genotypes as well as a similar amount of male and female participants within these groups resulting in the inclusion of the current sample $(n=53)$.

Initial data examination using the outlier labeling rule (Hoaglin, Iglewicz, \& Tukey, 1986; Tukey, 1977) revealed one outlier concerning sleep quality (PSQI = 9) and was therefore excluded prior to final analyses. Few saliva samples contained too little amount of saliva for the determination of cortisol values. Cortisol parameters could not be computed for 
these participants $(n=2)$ and were therefore not incorporated in the statistical analyses. The final sample $(n=50)$, consisting of S'/S' $(n=25)$ and L'/L' $(n=25) 5$-HTTLPR genotypes, included $10(20 \%)$ male and $40(80 \%)$ female participants, aged between 22 and 31 years of age $(M=24.0, S D=2.0)$. The present study was conducted according to the guidelines laid down in the Declaration of Helsinki (1975; as revised in 1983). Followed procedures were approved by the Medical Ethics Committee of Maastricht University Medical Centre (Maastricht UMC). Informed consent was obtained from all subjects and participants received a financial compensation for their contribution to the experiment.

\section{Genotyping}

Sterile swabs (Omni Swabs; Whatman, 's Hertogenbosch, the Netherlands) were used to acquire buccal cell samples for 5-HTTLPR determination. Isolation of genomic DNA was performed using QIamp DNA Mini Kits (Qiagen, Leusden, The Netherlands). PCR protocol was followed for the subsequent 5-HTTLPR genotyping (Glatz, Mossner, Heils, \& Lesch, 2003). Tri-allelic variants were reclassified into a functionally relevant bi-allelic model including $\mathrm{S}^{\prime} / \mathrm{S}^{\prime}\left(\mathrm{S} / \mathrm{S}, \mathrm{S} / \mathrm{L}_{\mathrm{g}}, \mathrm{L}_{\mathrm{g}} / \mathrm{L}_{\mathrm{g}}\right)$ and $\mathrm{L}^{\prime} / \mathrm{L}^{\prime}\left(\mathrm{L}_{\mathrm{a}} / \mathrm{L}_{\mathrm{a}}\right)$ respectively. On the original database $(n=$ 771), Hardy-Weinberg equilibrium (HWE) was determined using $\chi^{2}$ test and revealed that genotype frequencies of S'/S' $(n=158), \mathrm{S}^{\prime} / \mathrm{L}^{\prime}(n=396)$ and L'/L' $(n=217)$ did not differ from the HWE $\left(\chi^{2}=0.87, p=0.35\right)$.

\section{Design and procedure}

In order to control for circadian variation in cortisol secretion (Balbo, Leproult, \& Van Cauter, 2010), experimental sessions were exclusively scheduled in the middle and late afternoon. During the day of the study, participants were instructed to refrain from any caffeinated beverages. Upon arrival, subjects were seated in a waiting room in order to allow cortisol levels to reach normal basal levels. During this resting period, participants completed a general sleep questionnaire (Pittsburgh Sleep Quality Index, PSQI; see 2.4.1). Participants were subsequently guided to a behavioral lab where they were subjected to a psychosocial laboratory stress paradigm (Maastricht Acute Stress Task, MAST; see 2.5). In order to assess stress-related cortisol secretion, salivary cortisol samples were collected at predefined time points: after completing the sleep questionnaire (baseline), immediately before commencing the experimental stress induction (pre-stress), as well as 20 minutes (post-stress) and 40 minutes (recovery) after the onset of the laboratory stress procedure. 


\section{Instruments}

Sleep quality

Sleep quality was evaluated using the Pittsburgh Sleep Quality Index (PSQI) (Buysse, Reynolds, Monk, Berman, \& Kupfer, 1989). In order to ensure that the PSQI captured recent sleep quality, the phrasing of the questions was slightly adjusted to assess sleep quality during the past week (instead of the past month). Completing the PSQI requires participants to respond to a variety of statements on a scale ranging from 0 (not during the past week) to 3 (three or more times during the past week). Scoring of the 19 items resulted in 7 component scores, reflecting duration of sleep, sleep disturbance, sleep latency, day dysfunction due to sleepiness, sleep efficiency, overall sleep quality, and medications needed to sleep. The total score (sum of all sub-scores) comprises a general index of sleep quality, where higher scores are indicative of poorer sleep quality. The PSQI is a commonly used and well-validated scale with good psychometric properties (Buysse et al., 1989).

\section{Stress induction}

The Maastricht Acute Stress Task (MAST) (Smeets et al., 2012) has been developed to capture the most important features of frequently used laboratory stress paradigms by combining both the physical aspects of the Cold Pressor Task (CPT) (Lovallo, 1975), and the psychosocial aspects of the Trier Social Stress Task (TSST) (Kirschbaum, Pirke, \& Hellhammer, 1993). The procedure of the MAST is as follows. After a brief instruction phase (5 minutes), participants have to perform various cold pressor trials of unpredictable duration (60-90 seconds) within a constant water temperature $\left(2{ }^{\circ} \mathrm{C}\right)$. In between these trials participants are instructed to, equivalent to the TSST, perform mental arithmetic (i.e. counting down in steps of 17 starting at a random number) of unpredictable duration (45-90 seconds). During both tasks, performance is socially evaluated by the experimenter, who additionally provides negative feedback in case of incorrect performance or delayed responding. The alternating trials last for 10 minutes in total and subsequently participants are led to believe that the second part of the task will start in 5 minutes. However, after this resting period participants are informed that this was the end of the task. Hence, by encompassing both the lack of control (unpredictable duration) and a potential threat to self-esteem or status (social evaluation) the MAST is thought to capture the key psychological factors mediating the influence of psychological stress on cortisol reactivity (Dickerson \& Kemeny, 2004). The MAST has been proven to have comparable stress-inducing properties as the TSST. For a 
more detailed description of the procedure and validation of the MAST see (Smeets et al., 2012).

\section{Salivary cortisol}

\section{Saliva sampling}

Cotton swabs (Salivette, Sarstedt, Etten-Leur, the Netherlands) were used to obtain salivary cortisol samples. Immediately after collection, saliva samples were stored at $-25{ }^{\circ} \mathrm{C}$ up until free cortisol levels were determined using a commercially available luminescence immunoassay (IBL, Hamburg, Germany). Mean intra and interassay coefficients of variability were respectively lower than $4 \%$ and $8 \%$.

\section{Cortisol parameters}

Area under the curve (AUC, arbitrary units) was used to determine the amount of cortisol secretion (nmol/l) during the experiment. AUC represents a reliable estimation of total cortisol secretion as it is able to incorporate both the magnitude of the response (intensity) as well as the difference between repeated measurements (sensitivity) within a single outcome measure (Fekedulegn et al., 2007). Standardized formulas (Pruessner, Kirschbaum, Meinlschmid, \& Hellhammer, 2003) were used to calculate the total amount of cortisol secretion during the experiment (AUCg) as well as the stress-induced increase in cortisol levels (AUCi). Hence, since the main objective of the present study was to explore differences in cortisol responses to laboratory stress, AUCi was used as the main outcome measure for statistical analyses.

\section{Statistical analyses}

Statistical analyses were conducted in SPSS (SPSS Statistics 22.0 for Windows, IBM, Armonk, New York). Mean differences between 5-HTTLPR genotype groups (S'/S' versus L'/L') regarding demographic variables and cortisol parameters were evaluated using independent samples t-tests. Hierarchical multiple regression analysis was conducted to examine whether sleep quality moderates the association between 5-HTTLPR and cortisol stress responsiveness. In this regard, 5-HTTLPR genotype (i.e. a two-level categorical variable representing $S^{\prime} / S^{\prime}$ and L'/L'), sleep quality (i.e. a continuous variable representing total PSQI score), and a 5-HTTLPR genotype by sleep quality interaction term were sequentially added as a predictor for stress-induced change in cortisol levels (AUCi). In order 
to further interpret the results, univariate analysis of variance (ANOVA) was performed with 5-HTTLPR genotype (S'/S' versus L'/L') and sleep quality (high versus low; median split; $M d n=3$ ) as between-subject factors on stress-induced increase in cortisol levels (AUCi). This analysis included four subgroups including high sleep quality $\mathrm{S}^{\prime} / \mathrm{S}^{\prime}(n=18)$ and L'/L' $(n=$ 13) as well as low sleep quality $\mathrm{S}^{\prime} / \mathrm{S}^{\prime}(n=12)$ and L'/L' $(n=7)$ respectively. Significant interaction effects were further interpreted with follow-up analyses. For all analyses a twotailed significance level of 5\% was adopted. Data are reported in means and standard deviation $(M, S D)$.

\section{Results}

\section{Sample characteristics}

Table 1 displays the sample characteristics in relation to allelic variation in 5-HTTLPR. As demonstrated, no significant differences between the $\mathrm{S}^{\prime} / \mathrm{S}^{\prime}$ and the $\mathrm{L}^{\prime} / \mathrm{L}$ ' group have been observed regarding relevant demographic variables. As indicated in Table 2, only baseline cortisol levels (upon arrival) were significantly higher in the $\mathrm{L}^{\prime} / \mathrm{L}^{\prime}(M=8.48, S D=3.41)$ relative to the $\mathrm{S}^{\prime} / \mathrm{S}^{\prime}(M=6.73, S D=2.22)$ group $(t(48)=2.147, p=0.038, d=0.61)$.

Table 1. Sample characteristics $M(S D)$

\begin{tabular}{|c|c|c|c|c|}
\hline & \multirow[t]{2}{*}{$\mathrm{S}^{\prime} / \mathrm{S}^{\prime}$} & \multirow[t]{2}{*}{$\mathrm{L}^{\prime} / \mathrm{L}^{\prime}$} & \multicolumn{2}{|c|}{$t$-test } \\
\hline & & & $t(48)$ & $p$ \\
\hline$n$ & 25 & 25 & & \\
\hline Men & 5 & 5 & & \\
\hline Women & 20 & 20 & & \\
\hline Age & $23.9(1.7)$ & $24.0(2.2)$ & 0.215 & 0.831 \\
\hline PSQI & $2.9(1.4)$ & $2.9(1.7)$ & 0.090 & 0.929 \\
\hline BDI & $2.9(2.4)$ & $2.5(3.1)$ & -0.507 & 0.615 \\
\hline
\end{tabular}

Note. BDI, Beck Depression Inventory; $M$, mean; $n$, number of participants; $p$, p-value; PSQI, Pittsburgh Sleep Quality Index; $S D$, standard deviation.

\section{Effectiveness of the stress procedure}

Repeated measures analysis of variance (ANOVA) was conducted in order to determine whether the laboratory stress procedure induced a significant cortisol response. Repeated measures ANOVA with time (pre-stress cortisol level versus post-stress cortisol level) as within-subject factor revealed a significant main effect of time $(F(1,49)=84.674, p<0.001$, $\left.\eta^{2}=0.633\right)$, indicating that post-stress cortisol values $(M=12.5, S D=4.8)$ were significantly higher than pre-stress cortisol values $(M=7.0, S D=2.1)$. 
Table 2. Cortisol values (nmol/l)

\begin{tabular}{|c|c|c|c|c|c|c|}
\hline & \multicolumn{2}{|c|}{$\mathrm{S}^{\prime} / \mathrm{S}^{\prime}$} & \multicolumn{2}{|c|}{$\mathrm{L}^{\prime} / \mathrm{L}^{\prime}$} & \multicolumn{2}{|c|}{$t$-test } \\
\hline & $M$ & $S D$ & $M$ & $S D$ & $t(48)$ & $p$ \\
\hline Baseline & 6.73 & 2.22 & 8.48 & 3.41 & 2.147 & 0.038 \\
\hline Pre-stress & 6.42 & 1.83 & 7.48 & 2.34 & 1.774 & 0.082 \\
\hline Post-stress & 12.61 & 4.86 & 12.47 & 4.79 & -0.103 & 0.919 \\
\hline Recovery & 13.57 & 6.70 & 13.29 & 7.32 & -0.139 & 0.890 \\
\hline Increment & 6.18 & 4.60 & 4.99 & 3.97 & -0.984 & 0.330 \\
\hline AUCg & 29.18 & 9.15 & 30.83 & 10.25 & 0.600 & 0.551 \\
\hline AUCi & 8.98 & 8.14 & 5.39 & 8.22 & -1.551 & 0.127 \\
\hline
\end{tabular}

Note. AUCg, Area Under the Curve ground; AUCi, Area Under the Curve increase; $M$, mean; $n$, number of participants; $p$, p-value; $S D$, standard deviation.

Table 3. Summary of hierarchical regression analysis for variables predicting AUCi

\begin{tabular}{|c|c|c|c|c|c|c|c|c|c|}
\hline & \multicolumn{3}{|c|}{ Model 1} & \multicolumn{3}{|c|}{ Model 2} & \multicolumn{3}{|c|}{ Model 3} \\
\hline & $B$ & $S E B$ & $\beta$ & $B$ & $S E B$ & $\beta$ & $B$ & $S E B$ & $\beta$ \\
\hline \multicolumn{10}{|l|}{ Genotype } \\
\hline$S^{\prime} / S^{\prime}$ vs L'/L' & 3.59 & 2.31 & .22 & 3.62 & 2.32 & .22 & 15.83 & 4.63 & $.96 * *$ \\
\hline Sleep Quality & & & & 0.71 & 0.75 & .13 & 2.44 & 0.91 & $.46 *$ \\
\hline \multicolumn{10}{|l|}{ Genotype x Sleep Quality } \\
\hline S'/S' vs L'/L' x Sleep Quality & & & & & & & -4.22 & 1.42 & $-.90 * *$ \\
\hline$R^{2}$ & & 0.05 & & & 0.07 & & & $0.22 *$ & \\
\hline$F\left(\Delta R^{2}\right)$ & & 2.41 & & & 0.88 & & & $8.87 * *$ & \\
\hline
\end{tabular}

Note. Allelic variation within 5-HTTLPR is represented by the variable 'Genotype' coded in the regression model as S'/S' (1) and L'/L' (0). $* p<0.05$

$* * p<0.01$.

\section{Effect of sleep on the relationship between 5-HTTLPR and cortisol responsiveness}

Hierarchical multiple regression analysis was performed to determine whether sleep quality moderates the association between 5-HTTLPR and cortisol stress responsiveness (AUCi). In this regard, 5-HTTLPR (Model 1), sleep quality (Model 2) and a 5-HTTLPR by sleep quality interaction term (Model 3) were sequentially added as predictor for AUCi (Table 3). Analyses revealed that either including 5-HTTLPR as a single predictor (Model 1: $F(1,48)=2.407, p=$ $0.127, R^{2}=0.048$ ) or 5-HTTLPR together with sleep quality (Model 2: $F(2,47)=1,636, p=$ $\left.0.205, R^{2}=0.065\right)$ did not significantly predict AUCi. However, adding the 5-HTTLPR by sleep quality interaction term in the final regression model (Model 3: $F(3,46)=4.231, p=$ $\left.0.010, R^{2}=0.216\right)$ significantly improved predictive capacity $\left(\Delta R^{2}=0.151, p=0.005\right)$, producing a regression model that explained $21.6 \%$ of the variance in cortisol stress responsiveness (AUCi). As illustrated in Figure 1, the influence of 5-HTTLPR on cortisol stress responsiveness (AUCi) changes significantly as a function of sleep quality $(\beta=-0.896$, $t(46)=-2.978, p=0.005)$. The regression model indicates that while $\mathrm{S}^{\prime} / \mathrm{S}^{\prime}$ genotypes display 
significantly greater cortisol stress responsiveness relative to L'/L' genotypes in the absence of reduced sleep quality $(\beta=0.964, t(46)=3.420, p=0.001)$, this pattern gradually changes as a function of sleep quality decrements. Further regression analyses for both genotype groups separately revealed a significant increase in AUCi as a function of lower sleep quality in the $\mathrm{L}^{\prime} / \mathrm{L}^{\prime}$ group $(\beta=0.506, t(23)=2.811, p=0.010)$ whereas the apparent decrease in the $\mathrm{S}^{\prime} / \mathrm{S}^{\prime}$ group was not statistically significant $(\beta=-0.311, t(23)=-1.570, p=0.130)$.

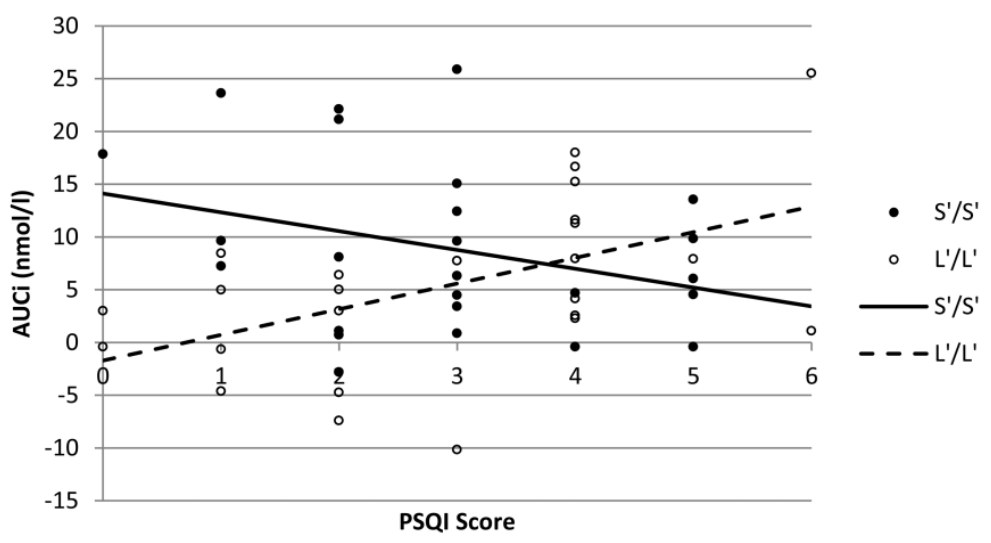

Figure 1. Stress-related change in salivary cortisol (AUCi) as a function of sleep quality in $S^{\prime} / S^{\prime}$ and L'/L' 5HTTLPR genotype. Interaction: $p<0.01$.

To further elucidate how sleep quality may alter the association between 5-HTTLPR and cortisol stress responsiveness from a more ecologically valid perspective, an univariate analysis of variance (ANOVA) was conducted with 5-HTTLPR (S'/S' versus L'/L') and sleep quality (high versus low) as independent variables on stress-induced cortisol levels (AUCi). Analyses indeed revealed a significant interaction between 5-HTTLPR and sleep quality $\left(F(1,46)=10.747, p=0.002, \eta^{2}=0.189\right)$, indicating that the influence of 5-HTTLPR on cortisol stress responsiveness varied as a function of sleep quality. Further analysis for both sleep quality groups separately revealed a significant main effect of 5-HTTLPR on AUCi in the high sleep quality group $\left(F(1,29)=11.477, p=0.002, \eta^{2}=0.284\right)$ but not in the low sleep quality group $\left(F(1,17)=2.393, p=0.140, \eta^{2}=0.123\right)$. As indicated in Figure 2, exclusively in the high sleep quality group $\mathrm{S}^{\prime} / \mathrm{S}^{\prime}$ genotypes displayed higher cortisol stress responses $(M=$ $10.4, S D=8.8)$ relative to the $\mathrm{L}^{\prime} / \mathrm{L}^{\prime}$ group $(M=0.8, S D=6.0)$. 

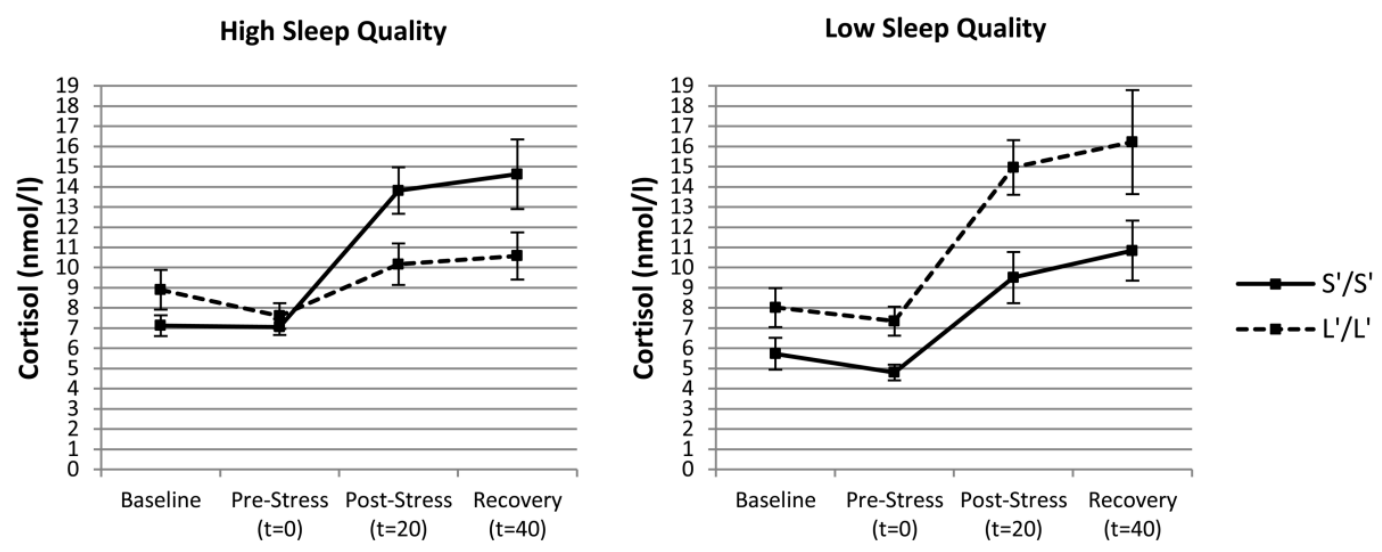

Figure 2. Mean $( \pm$ SEM) cortisol levels as a function of 5-HTTLPR genotype in individuals reporting high (PSQI $\leq 3$ ) or low (PSQI $\geq 4$ ) sleep quality.

\section{Additional analyses}

\section{Control variables}

In order to determine whether potential moderating factors influenced current results, the main analyses were repeated with gender, age or baseline cortisol values as control variable. While gender $(\beta=-0.163, t(45)=-1.252, p=0.217)$ and age $(\beta=0.181, t(45)=1.340, p=$ 0.187) were not significantly associated with AUCi in the final regression model (Model 3), a significant effect of baseline cortisol was observed $(\beta=-0.359, t(45)=-2.798, p=0.008)$. However, this was not found to influence the main findings. Including baseline cortisol in the final regression model (Model 3) revealed a similar interaction between 5-HTTLPR and sleep quality $(\beta=-0.946, t(45)=-3.363, p=0.002)$ as well as a significant simple main effect of 5HTTLPR $(\beta=0.899, t(45)=3.406, p=0.001)$. Similarly, including baseline cortisol values as a covariate in the categorical analyses $\left(F(1,45)=6.915, p=0.012, \eta^{2}=0.133\right)$ also revealed a comparable interaction between 5-HTTLPR and sleep quality $(F(1,45)=12.920, p=0.001$, $\left.\eta^{2}=0.223\right)$.

\section{Outliers}

As reported, initial data examination revealed one outlier concerning sleep quality $(\mathrm{PSQI}=9)$ and was therefore excluded in the reported analyses. Including this outlier during statistical analyses did not influence the main findings. Hierarchical multiple regression analyses revealed a similar interaction between 5-HTTLPR and sleep quality $(\beta=-0.987, t(47)=-$ $3.288, p=0.002)$ as well as a simple main effect of 5-HTTLPR $(\beta=0.933, t(47)=3.618, p=$ 0.001) in the final regression model (Model 3). Correspondingly, univariate ANOVA also 
produced comparable results revealing a significant interaction between 5-HTTLPR and sleep quality $\left(F(1,47)=12.311, p=0.001, \eta^{2}=0.208\right)$.

\section{Discussion}

Results of the present study reveal that the relationship between 5-HTTLPR and cortisol stress responsiveness may vary as a function of sleep quality. In conditions of relatively good sleep quality, 5-HTTLPR predicts an elevated cortisol stress reactivity in $\mathrm{S}^{\prime} / \mathrm{S}^{\prime}$ relative to L'/L' genotype in accordance with general assumptions. However, as sleep quality declines 5HTTLPR dependent differences in HPA reactivity gradually reduce since this exclusively potentiates cortisol stress responsiveness in L'/L' carriers.

In line with the established influence of sleep quality on the stress reactivity of the HPA axis (for review see: (van Dalfsen \& Markus, 2018)), the present study demonstrates that not controlling for inadequate sleep may substantially confound the association between 5-HTTLPR and cortisol stress responsiveness. This might be particularly relevant given the frequent inconsistencies among previous investigations (for meta-analysis see: (Miller et al., 2013)), as variations in sleep quality may apparently conceal more consistent 5-HTTLPR dependent effects. This is supported by the current observation that a robust effect of 5HTTLPR on HPA reactivity could only be detected when accounting for the interfering influence of sleep quality. As demonstrated, analyses exclusively revealed a significantly greater cortisol stress responsiveness in $\mathrm{S}^{\prime} / \mathrm{S}^{\prime}$ relative to $\mathrm{L}^{\prime} / \mathrm{L}^{\prime}$ genotypes when either statistically controlling for the influence of sleep quality or when analyzing a subsample of participants that experienced relatively good sleep quality. Interestingly, the observed effect size of 5-HTTLPR was relatively large compared to previous investigations, supporting the assumption that accounting for additional moderating factors may enhance the predictive capacity of 5-HTTLPR (Miller et al., 2013).

Elevated stress reactivity of the HPA axis has been regarded as an important risk factor for affective disorders (Sapolsky, 2015; van Praag, 2004). In line with this assumption, greater cortisol stress responsiveness has been suggested as one of the primary mechanisms underlying the elevated depression susceptibility associated with the 5-HTTLPR S-allele (Way \& Taylor, 2010). Current findings support this assumption by confirming an elevated cortisol responsiveness in $\mathrm{S}^{\prime} / \mathrm{S}^{\prime}$ relative to $\mathrm{L}^{\prime} / \mathrm{L}^{\prime}$ carriers when controlling for the influence of sleep quality reductions. However, from this prospective, the 5-HTTLPR L-allele might as well promote depression susceptibility when sleep quality declines. Although the S-allele is 
commonly regarded as the more susceptible genetic variant (for review see: (Uher \& McGuffin, 2008, 2010)), an association between the L-allele and depression has also been repeatedly reported (Chorbov et al., 2007; Laucht et al., 2009; Ritchie et al., 2009; Sjoberg et al., 2006; Zhang et al., 2009), suggesting that the influence of 5-HTTLPR can be heterogeneous. The present findings suggest that sleep-related alterations in the association between 5-HTTLPR and cortisol stress responsiveness might contribute to such heterogeneity.

Even though elevations in HPA reactivity associated with reduced sleep quality might indeed promote depression susceptibility in L'/L' carriers, recent studies consistently revealed that the 5-HTTLPR S-allele promotes the negative affective consequences of inadequate sleep (Carskadon et al., 2012; Hartmann et al., 2014; van Roekel et al., 2016). Whereas different mechanisms may be involved, an intriguing possibility might be that the increased cortisol reactivity in L'/L' carriers actually reflects an adaptive mechanism to cope with the additional demands of reduced sleep quality, whereas the generally elevated cortisol reactivity in $S^{\prime} / S^{\prime}$ carriers might limit such ability. In support for this postulation, increased basal HPA activity following sleep deprivation is generally regarded as an adaptive arousal mechanism (Balbo et al., 2010) and, hence, a similar mechanism might account for a stress-induced increase in cortisol levels. The HPA stress reactivity in the L-allele is further found to be more variable over time compared to S-allele carriers (Hankin, Badanes, Smolen, \& Young, 2015), possibly relating to an increased adaptation to additional environmental influences.

The mechanisms thought to underlie the difference in cortisol stress responsiveness between 5-HTTLPR S-allele and L-allele carriers closely converge with the influence of sleep on these processes. Based on neuroanatomical connections between the amygdala and the HPA axis, it has been proposed that an elevated amygdala reactivity to adverse stimuli observed in S-allele carriers (for meta-analyses see: (Munafò, Brown, \& Hariri, 2008; Murphy et al., 2013)) has a central role in promoting cortisol stress responsiveness (Way \& Taylor, 2010). Since impaired sleep is also found to promote amygdala reactivity (Motomura et al., 2013, 2014; Simon et al., 2015; Yoo, Gujar, Hu, Jolesz, \& Walker, 2007), it could be argued that 5-HTTLPR and sleep may target shared regulatory mechanisms of the HPA axis. Hence, these findings may be seen as further support for the involvement of sleep in the association between 5-HTTLPR and HPA reactivity, emphasizing the relevance to study these factors in concert. 


\section{Limitations and future directions}

The following limitations should be considered. Although the sample size is comparable to the homozygous 5-HTTLPR groups of previous studies exploring the influence of 5-HTTLPR on cortisol stress responsiveness (Alexander et al., 2009; Dougherty et al., 2010; Gotlib et al., 2008; Mueller, Brocke, Fries, Lesch, \& Kirschbaum, 2010; Way \& Taylor, 2010), also when performing additional group- (Gotlib et al., 2008) and correlational- (Alexander et al., 2009) analyses, larger sample sizes are desirable when replicating current findings. Nonetheless, already observing large and highly significant effects in a relatively small sample may strongly support the assumed associations. Although the sleep assessment included in the present study is a frequently used and well-validated measure, future studies should also incorporate more objective indices of sleep quality (i.e. polysomnography, actigraphy) or include sleep manipulation strategies (i.e. sleep restriction, sleep deprivation). Finally, it remains to be resolved how the current findings translate to real-life stressors and longitudinal studies are needed to elucidate how sleep-related alterations in stress reactivity may influence the development of affective disorders.

\section{Conclusions}

The present study provides preliminary evidence that sleep quality could play an important modulating role in the relationship between 5-HTTLPR and cortisol stress responsiveness. Together with earlier findings revealing an important role for sleep in the association between 5-HTTLPR and affective symptomatology, current results emphasize the relevance of incorporating sleep quality in future studies. This may enhance the predictive value as well as the interpretation of 5-HTTLPR dependent effects.

\section{Acknowledgements}

None.

\section{Disclosure of interest}

The authors report no conflicts of interest. 


\section{Funding}

This research did not receive any specific grant from funding agencies in the public, commercial, or not-for-profit sectors. 


\section{References}

Alexander, N., Kuepper, Y., Schmitz, A., Osinsky, R., Kozyra, E., \& Hennig, J. (2009). Geneenvironment interactions predict cortisol responses after acute stress: implications for the etiology of depression. Psychoneuroendocrinology, 34(9), 1294-1303. doi:10.1016/j.psyneuen.2009.03.017

Balbo, M., Leproult, R., \& Van Cauter, E. (2010). Impact of sleep and its disturbances on hypothalamo-pituitary-adrenal axis activity. Int $J$ Endocrinol, 2010, 759234. doi:10.1155/2010/759234

Bouma, E., Riese, H., Nederhof, E., Ormel, J., \& Oldehinkel, A. (2010). No Replication of Genotype Effect of 5-HTTLPR on Cortisol Response to Social Stress in Larger Adolescent Sample. Biological Psychiatry, 68(11), e33-e34. doi:10.1016/j.biopsych.2010.04.041

Buysse, D. J., Reynolds, C. F., 3rd, Monk, T. H., Berman, S. R., \& Kupfer, D. J. (1989). The Pittsburgh Sleep Quality Index: a new instrument for psychiatric practice and research. Psychiatry Research, 28(2), 193-213.

Carskadon, M. A., Sharkey, K. M., Knopik, V. S., \& McGeary, J. E. (2012). Short Sleep as an Environmental Exposure: A Preliminary Study Associating 5-HTTLPR Genotype to Self-Reported Sleep Duration and Depressed Mood in First-Year University Students. Sleep, 35(6), 791-796. doi:10.5665/sleep.1876

Caspi, A., Sugden, K., Moffitt, T. E., Taylor, A., Craig, I. W., Harrington, H., . . Poulton, R. (2003). Influence of life stress on depression: moderation by a polymorphism in the 5HTT gene. Science, 301(5631), 386-389. doi:10.1126/science.1083968

Chorbov, V. M., Lobos, E. A., Todorov, A. A., Heath, A. C., Botteron, K. N., \& Todd, R. D. (2007). Relationship of 5-HTTLPR genotypes and depression risk in the presence of trauma in a female twin sample. Am J Med Genet B Neuropsychiatr Genet, 144b(6), 830-833. doi:10.1002/ajmg.b.30534

Dickerson, S. S., \& Kemeny, M. E. (2004). Acute stressors and cortisol responses: a theoretical integration and synthesis of laboratory research. Psychological Bulletin, 130(3), 355-391. doi:10.1037/0033-2909.130.3.355

Dougherty, L. R., Klein, D. N., Congdon, E., Canli, T., \& Hayden, E. P. (2010). Interaction between 5-HTTLPR and BDNF Val66Met polymorphisms on HPA axis reactivity in $\begin{array}{llll}\text { preschoolers. } & \text { Biological } & \text { 83ychology, } & \text { 93-100. }\end{array}$ doi:10.1016/j.biopsycho.2009.10.009

Fekedulegn, D. B., Andrew, M. E., Burchfiel, C. M., Violanti, J. M., Hartley, T. A., Charles, L. E., \& Miller, D. B. (2007). Area under the curve and other summary indicators of repeated waking cortisol measurements. Psychosomatic Medicine, 69(7), 651-659. doi:10.1097/PSY.0b013e31814c405c

Fuller, R. W. (1990). Serotonin receptors and neuroendocrine responses. Neuropsychopharmacology, 3(5-6), 495-502.

Glatz, K., Mossner, R., Heils, A., \& Lesch, K. P. (2003). Glucocorticoid-regulated human serotonin transporter (5-HTT) expression is modulated by the 5-HTT gene-promotorlinked polymorphic region. Journal of Neurochemistry, 86(5), 1072-1078.

Gotlib, I. H., Joormann, J., Minor, K. L., \& Hallmayer, J. (2008). HPA axis reactivity: a mechanism underlying the associations among 5-HTTLPR, stress, and depression. Biological Psychiatry, 63(9), 847-851. doi:10.1016/j.biopsych.2007.10.008

Greenberg, B. D., Tolliver, T. J., Huang, S. J., Li, Q., Bengel, D., \& Murphy, D. L. (1999). Genetic variation in the serotonin transporter promoter region affects serotonin uptake in human blood platelets. American Journal of Medical Genetics, 88(1), 83-87. 
Hankin, B. L., Badanes, L. S., Smolen, A., \& Young, J. F. (2015). Cortisol reactivity to stress among youth: stability over time and genetic variants for stress sensitivity. Journal of Abnormal Psychology, 124(1), 54-67. doi:10.1037/abn0000030

Hariri, A. R., Mattay, V. S., Tessitore, A., Kolachana, B., Fera, F., Goldman, D., . . . Weinberger, D. R. (2002). Serotonin Transporter Genetic Variation and the Response of the Human Amygdala. Science, 297(5580), 400-403. doi:10.1126/science.1071829

Hartmann, J. A., Wichers, M., van Bemmel, A. L., Derom, C., Thiery, E., Jacobs, N., . . . Simons, C. J. P. (2014). The serotonin transporter 5-HTTLPR polymorphism in the association between sleep quality and affect. European Neuropsychopharmacology, 24(7), 1086-1090. doi:10.1016/j.euroneuro.2014.01.015

Hoaglin, D. C., Iglewicz, B., \& Tukey, J. W. (1986). Performance of Some Resistant Rules for Outlier Labeling. Journal of the American Statistical Association, 81(396), 991999. doi:10.1080/01621459.1986.10478363

Karg, K., Burmeister, M., Shedden, K., \& Sen, S. (2011). The serotonin transporter promoter variant (5-HTTLPR), stress, and depression meta-analysis revisited: evidence of genetic moderation. Archives of General Psychiatry, 68(5), 444-454. doi:10.1001/archgenpsychiatry.2010.189

Kendler, K. S., \& Prescott, C. A. (2006). Genes, environment, and psychopathology: understanding the causes of psychiatric and substance use disorders. New York: Guilford Publications.

Kirschbaum, C., Pirke, K. M., \& Hellhammer, D. H. (1993). The 'Trier Social Stress Test'--a tool for investigating psychobiological stress responses in a laboratory setting. Neuropsychobiology, 28(1-2), 76-81. doi:119004

Laucht, M., Treutlein, J., Blomeyer, D., Buchmann, A. F., Schmid, B., Becker, K., . . . Banaschewski, T. (2009). Interaction between the 5-HTTLPR serotonin transporter polymorphism and environmental adversity for mood and anxiety psychopathology: evidence from a high-risk community sample of young adults. Int $J$ Neuropsychopharmacol, 12(6), 737-747. doi:10.1017/s1461145708009875

Lesch, K. P., Bengel, D., Heils, A., Sabol, S. Z., Greenberg, B. D., Petri, S., . . Murphy, D. L. (1996). Association of anxiety-related traits with a polymorphism in the serotonin transporter gene regulatory region. Science, 274(5292), 1527-1531.

Lovallo, W. (1975). The Cold Pressor Test and Autonomic Function: A Review and Integration. Psychophysiology, 12(3), 268-282. doi:10.1111/j.14698986.1975.tb01289.x

Miller, R., Wankerl, M., Stalder, T., Kirschbaum, C., \& Alexander, N. (2013). The serotonin transporter gene-linked polymorphic region (5-HTTLPR) and cortisol stress reactivity: a meta-analysis. Molecular Psychiatry, 18(9), 1018-1024. doi:10.1038/mp.2012.124

Motomura, Y., Kitamura, S., Oba, K., Terasawa, Y., Enomoto, M., Katayose, Y., . . . Mishima, K. (2013). Sleep Debt Elicits Negative Emotional Reaction through Diminished Amygdala-Anterior Cingulate Functional Connectivity. PLoS ONE, 8(2), e56578. doi:10.1371/journal.pone.0056578

Motomura, Y., Kitamura, S., Oba, K., Terasawa, Y., Enomoto, M., Katayose, Y., . . . Mishima, K. (2014). Sleepiness induced by sleep-debt enhanced amygdala activity for subliminal signals of fear. BMC Neuroscience, 15(1), 97.

Mueller, A., Armbruster, D., Moser, D. A., Canli, T., Lesch, K. P., Brocke, B., \& Kirschbaum, C. (2011). Interaction of serotonin transporter gene-linked polymorphic region and stressful life events predicts cortisol stress response. Neuropsychopharmacology, 36(7), 1332-1339. doi:10.1038/npp.2011.11 
Mueller, A., Brocke, B., Fries, E., Lesch, K. P., \& Kirschbaum, C. (2010). The role of the serotonin transporter polymorphism for the endocrine stress response in newborns. Psychoneuroendocrinology, 35(2), 289-296. doi:10.1016/j.psyneuen.2009.07.002

Munafò, M. R., Brown, S. M., \& Hariri, A. R. (2008). Serotonin Transporter (5-HTTLPR) Genotype and Amygdala Activation: A Meta-Analysis. Biological Psychiatry, 63(9), 852-857. doi:10.1016/j.biopsych.2007.08.016

Munafò, M. R., Durrant, C., Lewis, G., \& Flint, J. (2009). Gene $\times$ Environment Interactions at the Serotonin Transporter Locus. Biological Psychiatry, 65(3), 211-219. doi:10.1016/j.biopsych.2008.06.009

Murphy, S. E., Norbury, R., Godlewska, B. R., Cowen, P. J., Mannie, Z. M., Harmer, C. J., \& Munafo, M. R. (2013). The effect of the serotonin transporter polymorphism (5HTTLPR) on amygdala function: a meta-analysis. Molecular Psychiatry, 18(4), $512-$ 520. doi:10.1038/mp.2012.19

Porter, R. J., Gallagher, P., Watson, S., \& Young, A. H. (2004). Corticosteroid-serotonin interactions in depression: a review of the human evidence. Psychopharmacology, 173(1-2), 1-17. doi:10.1007/s00213-004-1774-1

Pruessner, J. C., Kirschbaum, C., Meinlschmid, G., \& Hellhammer, D. H. (2003). Two formulas for computation of the area under the curve represent measures of total hormone concentration versus time-dependent change. Psychoneuroendocrinology, 28(7), 916-931.

Risch, N., Herrell, R., Lehner, T., \& et al. (2009). Interaction between the serotonin transporter gene (5-httlpr), stressful life events, and risk of depression: A metaanalysis. JAMA, 301(23), 2462-2471. doi:10.1001/jama.2009.878

Ritchie, K., Jaussent, I., Stewart, R., Dupuy, A. M., Courtet, P., Ancelin, M. L., \& Malafosse, A. (2009). Association of adverse childhood environment and 5-HTTLPR Genotype with late-life depression. Journal of Clinical Psychiatry, 70(9), 1281-1288. doi: $10.4088 / \mathrm{JCP} .08 \mathrm{~m} 04510$

Sapolsky, R. M. (2015). Stress and the brain: individual variability and the inverted-U. Nature Neuroscience, 18(10), 1344-1346. doi:10.1038/nn.4109

Simon, E. B., Oren, N., Sharon, H., Kirschner, A., Goldway, N., Okon-Singer, H., . . . Hendler, T. (2015). Losing Neutrality: The Neural Basis of Impaired Emotional Control without Sleep. Journal of Neuroscience, 35(38), 13194-13205. doi:10.1523/jneurosci.1314-15.2015

Sjoberg, R. L., Nilsson, K. W., Nordquist, N., Ohrvik, J., Leppert, J., Lindstrom, L., \& Oreland, L. (2006). Development of depression: sex and the interaction between environment and a promoter polymorphism of the serotonin transporter gene. Int $J$ Neuropsychopharmacol, 9(4), 443-449. doi:10.1017/s1461145705005936

Smeets, T., Cornelisse, S., Quaedflieg, C. W. E. M., Meyer, T., Jelicic, M., \& Merckelbach, H. (2012). Introducing the Maastricht Acute Stress Test (MAST): A quick and noninvasive approach to elicit robust autonomic and glucocorticoid stress responses. Psychoneuroendocrinology, 37(12), 1998-2008. doi:10.1016/j.psyneuen.2012.04.012

Tukey, J. W. (1977). Exploratory Data Analysis. Reading, Massachusetts: Addison-Wesley Publishing Company.

Uher, R., \& McGuffin, P. (2008). The moderation by the serotonin transporter gene of environmental adversity in the aetiology of mental illness: review and methodological analysis. Molecular Psychiatry, 13(2), 131-146. doi:10.1038/sj.mp.4002067

Uher, R., \& McGuffin, P. (2010). The moderation by the serotonin transporter gene of environmental adversity in the etiology of depression: 2009 update. Molecular Psychiatry, 15(1), 18-22. doi:10.1038/mp.2009.123 
van Dalfsen, J. H., \& Markus, C. R. (2018). The influence of sleep on human hypothalamicpituitary-adrenal (HPA) axis reactivity: A systematic review. Sleep Med Rev, 39, 187194. doi:10.1016/j.smrv.2017.10.002

van Praag, H. M. (2004). Can stress cause depression? Progress in NeuroPsychopharmacology and Biological Psychiatry, 28(5), 891-907. doi:10.1016/j.pnpbp.2004.05.031

van Roekel, E., Hartmann, J. A., Wichers, M., \& Verhagen, M. (2016). The 5-HTTLPR genotype moderates the association between sleep quality and positive affect: A replication study. European Neuropsychopharmacology, 26(8), 1350-1351. doi:10.1016/j.euroneuro.2016.06.001

Verschoor, E., \& Markus, C. R. (2011). Effects of acute psychosocial stress exposure on endocrine and affective reactivity in college students differing in the 5-HTTLPR genotype and trait neuroticism. Stress, 14(4), 407-419. doi:10.3109/10253890.2010.548886

Way, B. M., \& Taylor, S. E. (2010). The serotonin transporter promoter polymorphism is associated with cortisol response to psychosocial stress. Biological Psychiatry, 67(5), 487-492. doi:10.1016/j.biopsych.2009.10.021

Wüst, S., Kumsta, R., Treutlein, J., Frank, J., Entringer, S., Schulze, T. G., \& Rietschel, M. (2009). Sex-specific association between the 5-HTT gene-linked polymorphic region and basal cortisol secretion. Psychoneuroendocrinology, 34(7), 972-982. doi:10.1016/j.psyneuen.2009.01.011

Yoo, S. S., Gujar, N., Hu, P., Jolesz, F. A., \& Walker, M. P. (2007). The human emotional brain without sleep--a prefrontal amygdala disconnect. Current Biology, 17(20), R877-878. doi:10.1016/j.cub.2007.08.007

Zhang, K., Xu, Q., Xu, Y., Yang, H., Luo, J., Sun, Y., . . . Shen, Y. (2009). The combined effects of the 5-HTTLPR and 5-HTR1A genes modulates the relationship between negative life events and major depressive disorder in a Chinese population. Journal of Affective Disorders, 114(1-3), 224-231. doi:10.1016/j.jad.2008.07.012 
Chapter 5 


\section{Chapter 6}

The serotonin transporter gene-linked polymorphic region (5-HTTLPR) and REM sleep regulation in healthy volunteers

Manuscript submitted for publication as:

van Dalfsen, J. H., Jonkman, L. M. \& Markus, C. R. (2018). The serotonin transporter genelinked polymorphic region (5-HTTLPR) and REM sleep regulation in healthy volunteers. 


\begin{abstract}
The short (S) allele of the serotonin transporter gene-linked polymorphic region (5-HTTLPR) has been identified as a potential risk factor for depression relative to the long (L) allele. However, inconsistent findings continually challenge this genetic contribution. Elucidating relationships between 5-HTTLPR and intermediate phenotypes of depression would further establish the involvement of this allelic variation. Evidence suggests that a disinhibition of rapid eye movement (REM) sleep serves as a genetic biomarker for depression vulnerability and several lines of research support the involvement of the serotonin transporter. The present study therefore investigated whether allelic variation in 5-HTTLPR modulates REM sleep architecture. A sample of healthy participants $(n=46)$ homozygous for either the 5-HTTLPR S-allele or L-allele were carefully screened from an obtained 5-HTTLPR database $(n=542)$. Sleep architecture was assessed during two nights of polysomnographic recordings in a sleep laboratory. In contrast to the expectations, results revealed a significantly lower REM sleep percentage in the S-allele relative to L-allele genotype while no effects were found on REM sleep variables predominantly related to depression. Even though the direction of results does not support a depressogenic REM sleep pattern in healthy S-allele carriers, a lower REM sleep percentage may support the elevated risk for insomnia associated with this allelic variant. This might ultimately promote a characteristic REM sleep disinhibition predisposing the development of depression although future research is needed to establish such clinical implications.
\end{abstract}




\section{Introduction}

Major depressive disorder is one of the most prevalent psychiatric conditions. With a point prevalence rate estimated at 5\% and a life time prevalence of around 15\% (Kessler et al., 2003), depression has been identified as one of the primary causes of disability worldwide (Vos et al., 2012). Despite a heritability estimate of 31\%-42\% (Sullivan, Neale, \& Kendler, 2000), genetic association studies have not revealed replicable genetic variants involved in major depression (Flint \& Kendler, 2014).

The short (S) allele of the serotonin (5-hydroxytriptamine; 5-HT) transporter (5-HTT) gene-linked polymorphic region (5-HTTLPR) has been identified as a potential risk factor for depression relative to the long (L) allele. This relates to a diminished transcription of the gene coding for the 5-HTT (SLC6A4) resulting in reduced 5-HTT expression and functioning (D. L. Murphy \& Lesch, 2008). While several meta-analyses support an association between the 5-HTTLPR S-allele and depression (Clarke, Flint, Attwood, \& Munafo, 2010; Furlong et al., 1998; Lopez-Leon et al., 2008) this finding has not been consistently observed (Anguelova, Benkelfat, \& Turecki, 2003; Lasky-Su, Faraone, Glatt, \& Tsuang, 2005). There are some indications that the relationship between 5-HTTLPR and depression may depend on environmental context (i.e. gene-environment interaction), however, available meta-analyses also yielded inconclusive results by either reporting evidence (Bleys, Luyten, Soenens, \& Claes, 2018; Karg, Burmeister, Shedden, \& Sen, 2011) or no support for this association (Munafò, Durrant, Lewis, \& Flint, 2009; Risch, Herrell, Lehner, \& et al., 2009).

Establishing relationships between 5-HTTLPR and intermediate phenotypes (i.e. 'endophenotypes') of depression may further establish the relevance of this genetic contribution. An 'endophenotype' comprises a measurable '... neurophysiological, biochemical, endocrinological, neuroanatomical, cognitive, or neuropsychological ...' marker presumed to encompass relatively modest genetic underpinnings compared to more complex psychiatric conditions (Gottesman \& Gould, 2003). Even though the 5-HTTLPR S-allele has been associated with multiple endophenotypes of depression, effect sizes are generally small and inconsistent findings are common (for meta-analyses see: (Miller, Wankerl, Stalder, Kirschbaum, \& Alexander, 2013; S. E. Murphy et al., 2013; Pergamin-Hight, BakermansKranenburg, van Ijzendoorn, \& Bar-Haim, 2012)). This raises the question whether there are other depressogenic processes that more consistently related to 5-HTTLPR.

A disinhibition of rapid eye movement (REM) sleep (i.e. reduced REM sleep latency, increased REM sleep percentage, elevated REM density) has been identified as a robust 
endophenotype for depression (Palagini, Baglioni, Ciapparelli, Gemignani, \& Riemann, 2013). These REM sleep abnormalities represent a well-replicated biological alteration in clinical depression (Riemann, Berger, \& Voderholzer, 2001) and may be involved in the pathophysiology and/or reflect neurobiological abnormalities (Palagini et al., 2013). An elevated REM density particularly serves as a genetic biomarker for depression (Pillai, Kalmbach, \& Ciesla, 2011) although other REM sleep variables, especially reduced REM latency, have also been implicated (Palagini et al., 2013), supporting the relevance of a general REM sleep disinhibition.

Neurobiological findings indicate that 5-HTTLPR is very well-positioned to influence REM sleep regulation. The almost complete cessation of 5-HT activity during REM sleep appears to be a crucial condition for REM sleep initiation and maintenance (Ursin, 2002). The specific involvement of the 5-HTT is directly supported by the REM sleep suppression of selective serotonin reuptake inhibitors (SSRIs) (Palagini et al., 2013). Moreover, animal studies suggest an opposing developmental influence of reduced 5-HTT transporter functioning following neonatal SSRI treatment (Frank \& Heller, 1997) and genetic 5-HTT knockout (Alexandre et al., 2006; Wisor et al., 2003), both found to induce a persistent increase in REM sleep (i.e. REM sleep disinhibition).

Encouraged by these findings, the present study investigated whether allelic variation in 5-HTTLPR influences REM sleep regulation in a non-clinical sample of healthy participants. Hence, this might contribute to an increased understanding of possible mechanisms or phenotypes mediating the differential depression predisposition associated with this genetic variation.

\section{Methods}

\section{Participants}

Individuals that were included in a recently obtained 5-HTTLPR database $(n=804)$ were invited to complete an extensive online screening. The sample of participants that completed the screening questionnaires $(n=542)$ were carefully selected based on the following inclusion and exclusion criteria. Inclusion criteria encompassed: homozygous $S^{\prime} / S^{\prime}(S / S$, $\left.\mathrm{S} / \mathrm{L}_{\mathrm{g}}, \mathrm{L}_{\mathrm{g}} / \mathrm{L}_{\mathrm{g}}\right)$ or L'/L' ( $\left.\mathrm{L}_{\mathrm{a}} / \mathrm{L}_{\mathrm{a}}\right)$ 5-HTTLPR genotype and female gender. These choices were respectively based on findings that: 1) 5-HTTLPR dependent differences in 5-HTT expression and functioning are most pronounced when comparing homozygous 5-HTTLPR genotypes (D. L. Murphy \& Lesch, 2008), 2) substantial gender differences in depression vulnerability 
have been established indicating an increased susceptibility in female relative to male participants (Piccinelli \& Wilkinson, 2000) and 3) changes in 5-HT neurotransmission related to 5-HTT expression are thought to be larger in females relative to males (D. L. Murphy \& Lesch, 2008). Exclusion criteria comprised: current medical or psychological condition, poor medical or psychological health, past or current depression diagnosis, having a first degree relative with depression diagnosis, clinical levels of depressive symptomatology (center for epidemiological studies depression scale $\geq 16$ ), recreational drug use (past month), shiftwork (past month), use of sleep medication (past month), clinical levels of insomnia (Athens insomnia scale $\geq 6$ ), smoking and excessive alcohol intake ( $>15$ units a week). These inclusion and exclusion criteria were met by 87 participants who were subsequently invited to participate in the sleep study. The final sample $(n=46)$, consisting of S'/S' $(n=23)$ and L'/L' ( $n=23)$ 5-HTTLPR genotypes, included exclusively female participants aged between 19 and 30 years $(21.8 \pm 2.3)$. The present study was conducted according to the guidelines laid down in the Deceleration of Helsinki (1975; as revised in 1983). Followed procedures were approved by the local ethics committee of Maastricht University (ethical review committee psychology and neuroscience; ERCPN). Informed consent was obtained from all subjects and participants received a financial compensation for their contribution to the experiment.

\section{Genotyping}

Sterile swabs (Omni Swabs, Whatman, Maidstone, United Kingdom) were used to acquire buccal cell samples for 5-HTTLPR determination. Isolation of genomic DNA was performed using QIamp DNA Mini Kits (Qiagen, Leusden, the Netherlands). Polymerase chain reaction (PCR) protocol was followed for the 5-HTTLPR genotyping (Glatz, Mossner, Heils, \& Lesch, 2003). Tri-allelic variants were reclassified into a functionally relevant bi-allelic model comprising $\mathrm{S}^{\prime} / \mathrm{S}^{\prime}\left(\mathrm{S} / \mathrm{S}, \mathrm{S} / \mathrm{L}_{\mathrm{g}}, \mathrm{L}_{\mathrm{g}} / \mathrm{L}_{\mathrm{g}}\right), \mathrm{S}^{\prime} / \mathrm{L}^{\prime}\left(\mathrm{S} / \mathrm{L}_{\mathrm{a}}, \mathrm{L}_{\mathrm{g}} / \mathrm{L}_{\mathrm{a}}\right)$ and $\mathrm{L}^{\prime} / \mathrm{L}^{\prime}\left(\mathrm{L}_{\mathrm{a}} / \mathrm{L}_{\mathrm{a}}\right)$ respectively (Nakamura, Ueno, Sano, \& Tanabe, 2000). Hardy-Weinberg equilibrium (HWE) was determined for the initial screening database and revealed that genotype frequencies of $S^{\prime} / S^{\prime}$ $(n=190), \mathrm{S}^{\prime} / \mathrm{L}^{\prime}(n=405)$ and $\mathrm{L}^{\prime} / \mathrm{L}^{\prime}(n=209)$ did not differ from HWE $\left(\chi^{2}=0.052, p=\right.$ $0.820)$.

\section{Procedure}

Polysomnographic recordings were conducted on two consecutive nights. The first night was intended as an adaptation night whereas the second night was used to obtain the actual sleep 
recordings used for the reported analyses. On the days prior to the recording nights, participants were instructed to avoid excessive exercise, not consume caffeinated beverages, not take daytime naps and were further asked to refrain from alcohol 72 hours before the start of the study. The procedures on both nights were identical: participants arrived at the sleep laboratory at 20.00 where they were first given instructions and completed general questionnaires. After the participants had prepared for the night, electrodes were placed (see section 2.4) and subsequently participants were given some leisure time before going to bed around 23.00 while instructed to avoid excessive screen time to prevent undesirable influences on sleep.

\section{Polysomnographic recordings}

Polysomnographic recordings were performed between 23.00 ( $\pm 30 \mathrm{~min})$ and $07.30( \pm 30$ min) and comprised two electroencephalographic (EEG) derivations (C3-M2 and C4-M1), two electrooculographic (EOG) derivations (LOC-M2 and ROC-M1) and one bipolar submental chin electromyographic (EMG) derivation. Portable recorders (Vitaport 3 digital recorder, TEMEC Instruments, Kerkrade, the Netherlands) and gold-plated pure silver electrodes (Genuine Grass Cup Electrodes, Natus Manufacturing Limited, Galway, Ireland) were used to conduct the sleep measurements. In accordance with the recommended settings for polysomnography (Berry et al., 2016), sleep data was recorded at a sampling rate of 256 $\mathrm{Hz}$ with low and high frequency filters of $0.2 \mathrm{~Hz}$ and $35 \mathrm{~Hz}$ for EEG and EOG data and $11 \mathrm{~Hz}$ and $100 \mathrm{~Hz}$ for EMG data. All impedances were below $5 \mathrm{~K} \Omega$ prior to recording.

Sleep stages were scored according to standardized criteria (Rechtschaffen \& Kales, 1968) using an automated sleep scoring system (Michele Sleep Scoring System 1.03.013, Younes Medical Technologies, Winnipeg, Canada). This scoring algorithm has been extensively validated and proven to have comparable reliability as manual scoring by experienced sleep technologists (Malhotra et al., 2013). All sleep variables were computed as per standardized criteria (Carskadon \& Rechtschaffen, 2005) and calculated for both the total night and the first sleep cycle as defined in standard criteria (Aeschbach \& Borbely, 1993). In accordance with common procedures in the field, REM density was calculated as the ratio of 3 second mini-epochs of REM sleep containing REMs to the total amount of 3 second miniepochs of REM sleep (Wichniak, Riemann, Kiemen, Voderholzer, \& Jernajczyk, 2000). 


\section{Statistical analyses}

Statistical analyses were conducted in SPSS (SPSS Statistics 24.0 for Windows, IBM, Armonk, New York). Mean differences between the 5-HTTLPR genotype groups (S'/S' versus L'/L') regarding polysomnographic variables were evaluated using independent samples t-tests. For all analyses a two-tailed significance level of 5\% was adopted. Data are reported in mean and standard deviation $(M, S D)$.

\section{Results}

\section{Sample characteristics}

Table 1 presents the sample characteristics in relation to allelic variation in 5-HTTLPR. As demonstrated, no significant mean differences between the genotype groups were observed regarding age, depressive symptomatology and subjective sleep quality.

Table 1. Sample characteristics $M(S D)$

\begin{tabular}{|c|c|c|c|c|}
\hline & \multirow[t]{2}{*}{$\mathrm{S}^{\prime} / \mathrm{S}^{\prime}$} & \multirow[t]{2}{*}{$\mathrm{L}^{\prime} / \mathrm{L}^{\prime}$} & \multicolumn{2}{|c|}{$t$-test } \\
\hline & & & $t(44)$ & $p$ \\
\hline$n$ & 23 & 23 & & \\
\hline Age & $21.78(1.76)$ & $21.78(2.80)$ & 0.000 & $>0.999$ \\
\hline CES-D & 4.22 (3.69) & 4.39 (4.29) & 0.147 & 0.884 \\
\hline PSQI & $3.04(1.72)$ & $3.09(1.44)$ & 0.093 & 0.926 \\
\hline
\end{tabular}

Note. CES-D, Center for Epidemiological Studies Depression Scale; M, mean; $n$, number of participants; $p$, p-value; PSQI, Pittsburgh Sleep Quality Index; SD, standard deviation; $t$, t-statistic.

\section{The effect of 5-HTTLPR on sleep architecture}

Independent samples t-test with 5-HTTLPR (S'/S' versus L'/L') as grouping variable revealed that the amount of REM sleep (percentage of the total sleep time) was significantly lower in the $\mathrm{S}^{\prime} / \mathrm{S}^{\prime}(M=22.30, S D=3.95)$ relative to the $\mathrm{L}^{\prime} / \mathrm{L}^{\prime}(M=25.22, S D=3.52)$ group $(t(44)=$ 2.642, $p=0.011, d=0.78$ ). No significant differences between the 5-HTTLPR genotype groups were observed for the remainder of the REM sleep variables. Moreover, statistical analyses revealed no significant differences on other polysomnographic variables indicating that influence of 5-HTTLPR on REM sleep percentage does not result from effects on other sleep parameters (Table 2). 
Table 2. Polysomnographic variables of sleep continuity and architecture for allelic variation in 5-HTTLPR

\begin{tabular}{|c|c|c|c|c|c|c|}
\hline & \multicolumn{2}{|c|}{$\mathrm{S}^{\prime} / \mathrm{S}^{\prime}$} & \multicolumn{2}{|c|}{$\mathrm{L}^{\prime} / \mathrm{L}^{\prime}$} & \multicolumn{2}{|c|}{$t$-test } \\
\hline & $M$ & $S D$ & $M$ & $S D$ & $t(44)$ & $p$ \\
\hline \multicolumn{7}{|l|}{ Total night } \\
\hline Sleep period time (min.) & 491.74 & 14.94 & 493.28 & 13.31 & 0.370 & 0.713 \\
\hline Total sleep time (min.) & 475.26 & 16.57 & 476.91 & 17.92 & 0.325 & 0.747 \\
\hline Sleep onset latency (min.) & 7.26 & 7.20 & 5.13 & 5.15 & -1.155 & 0.255 \\
\hline Sleep efficiency index $(\%)$ & 95.09 & 2.10 & 95.65 & 2.17 & 0.890 & 0.378 \\
\hline Wake after sleep onset (min.) & 16.48 & 8.96 & 16.37 & 9.78 & -0.039 & 0.969 \\
\hline Nocturnal awakenings $(n)$ & 20.61 & 7.90 & 19.91 & 6.74 & -0.321 & 0.750 \\
\hline Stage 1 sleep (\% total sleep time) & 7.70 & 3.61 & 7.24 & 2.12 & -0.535 & 0.596 \\
\hline Stage 2 sleep (\% total sleep time) & 46.42 & 5.53 & 44.97 & 5.11 & -0.920 & 0.362 \\
\hline Slow wave sleep (\% total sleep time) & 23.58 & 6.69 & 22.58 & 4.47 & -0.597 & 0.553 \\
\hline REM sleep (\% total sleep time) & 22.30 & 3.95 & 25.22 & 3.52 & 2.642 & 0.011 \\
\hline REM latency (min.) & 106.37 & 53.73 & 117.20 & 39.76 & 0.777 & 0.441 \\
\hline REM density & 0.12 & 0.05 & 0.11 & 0.04 & -0.778 & 0.440 \\
\hline \multicolumn{7}{|l|}{ First sleep cycle } \\
\hline Wake time (\% of NREM sleep) & 7.13 & 17.81 & 3.71 & 3.11 & -0.909 & 0.368 \\
\hline Slow wave sleep ( $\%$ of NREM sleep) & 55.43 & 17.61 & 56.22 & 13.64 & 0.171 & 0.865 \\
\hline REM period (min.) & 18.65 & 8.84 & 21.41 & 10.79 & 0.949 & 0.348 \\
\hline REM density & 0.06 & 0.04 & 0.08 & 0.06 & 1.446 & 0.155 \\
\hline
\end{tabular}

Note. $M$, mean; min., minutes; $n$, absolute frequency; NREM, non-REM; $p$, p-value; REM, rapid eye movement; $S D$, standard deviation; $t$, tstatistic.

\section{Outliers}

In order to ensure that the reported findings were not resulting from individual cases, the presence of outliers within each genotype group was evaluated for all sleep variables using the outlier labeling rule (Hoaglin, Iglewicz, \& Tukey, 1986). Outliers were identified for total sleep time $(n=1)$, wake after sleep onset $(n=1)$, REM sleep percentage $(n=1)$, wake time percentage during the first sleep cycle $(n=1)$ and slow wave sleep percentage during the first sleep cycle $(n=1)$. Excluding these individual values during statistical analyses did not alter the main findings. Independent samples t-test revealed a comparable significantly lower REM sleep percentage in the $\mathrm{S}^{\prime} / \mathrm{S}^{\prime}(M=22.30, S D=3.95)$ relative to the $\mathrm{L}^{\prime} / \mathrm{L}^{\prime}(M=24.75, S D=$ 2.76) group $(t(43)=2.395, p=0.021, d=0.72)$ and no significant influence of 5-HTTLPR on other sleep parameters.

\section{Discussion}

The aim of the present study was to investigate the influence of 5-HTTLPR on REM sleep regulation. While allelic variation in 5-HTTLPR was not found to influence REM density and REM sleep latency, results revealed a large effect of 5-HTTLPR on the percentage of REM 
sleep, revealing that the 5-HTTLPR S-allele is associated with a significantly lower amount of REM sleep relative to the L-allele.

Encouraged by previous findings indicating that a disinhibition of REM sleep serves as a robust endophenotype for major depression as well as the presumed involvement of the 5HTT in promoting such REM sleep abnormalities, it was expected that the more susceptible 5-HTTLPR S-allele would be associated with a depressogenic REM sleep architecture (i.e. REM sleep disinhibition). In contrast to the expectations, S-allele carriers displayed a significantly lower REM sleep percentage relative to L-allele carriers and no difference on other REM sleep variables predominantly related to major depression (i.e. REM density, REM sleep latency). In first instance, these findings therefore do not support a role for REM sleep in predisposing the risk for depression in healthy non-depressed S-allele carriers.

Recent insights however suggest that reduced or fragmented REM sleep may be an important process in the pathophysiology of insomnia (Riemann et al., 2012). The lower REM sleep percentage observed in S-allele carriers may therefore support the elevated risk for insomnia commonly (Deuschle et al., 2010; Huang et al., 2014), although not consistently (van Dalfsen \& Markus, 2018), related to this allelic variant. In line with the independent contribution of insomnia to the etiology of depression (Baglioni et al., 2011), it has been proposed that the modest chronic reductions in REM sleep observed in insomnia might ultimately induce a rebound in REM sleep resulting in the characteristic REM sleep disinhibition associated with depression vulnerability (Riemann et al., 2012). These postulations therefore suggest that even though the 5-HTTLPR S-allele may not initially promote a depressogenic REM sleep pattern, the lower amount of REM sleep may precede REM sleep disinhibition and, eventually, predispose the risk for depression. Since the 5HTTLPR S-allele is associated with a comparable emotional (S. E. Murphy et al., 2013) and neuroendocrine (Miller et al., 2013) hyperarousal related to such REM sleep instability, this might reveal a potential pathway by which 5-HTTLPR may contribute to the development of depression.

From a neurobiological perspective, the relatively lower amount of REM sleep observed in 5-HTTLPR S-allele carriers might well be a direct biochemical consequence of an elevated 5-HT tone resulting from reduced 5-HTT functioning. Under normal circumstances, activity of the 5-HT system is known to suppress REM sleep by tonic inhibition and a complete cessation of 5-HT signaling therefore appears to be a crucial condition for REM sleep initiation and maintenance (Ursin, 2002). Since 5-HT reuptake is markedly reduced in 5-HTTLPR S-allele carriers (D. L. Murphy \& Lesch, 2008), its consequent prolonged 5-HT 
signaling might contribute to the reduced (suppressed) REM sleep. Nonetheless, it should be noted that the variety of neuroadaptive changes that may arise from diminished 5-HTT expression (for review see: (D. L. Murphy \& Lesch, 2008)) may both promote and suppress REM sleep, limiting the theoretical interpretation of the present findings.

The lower REM sleep percentage associated with a reduced human expression of the 5-HTT (i.e. the 5-HTTLPR S-allele) contrasts findings from animal research. Genetic knockout studies in mice conversely suggest that a diminished 5-HTT expression promotes, instead of reduces, the amount of REM sleep (Alexandre et al., 2006; Wisor et al., 2003). Yet, these investigations incorporated mice with a complete abrogation of 5-HTT transcription (i.e. Slc6a $4^{-/-}$), which is markedly different from a reduction in 5-HTT transcription (i.e. Slc6a $4^{+/}$) and, hence, the 5-HTTLPR S-allele (D. L. Murphy \& Lesch, 2008). While the elevated amount of REM sleep associated with a complete blocking of 5-HTT transcription (i.e. Slc6a $4^{--}$) is found to result from functional alterations in the 5-HT system related to an elevated 5-HT tone during early development (Alexandre et al., 2006; Wisor et al., 2003), reducing but retaining 5-HTT functioning in homozygous S-allele carriers might be insufficient to induce such profound neurobiological alterations. Conceivably, this results in the more acute effects of reduced 5-HTT functioning that, to a lesser extent, resemble the REM sleep suppressive effects of pharmacological blocking of 5-HTT with SSRIs (Palagini et al., 2013).

The following limitations should be considered for the present study. Even though results indicate a large effect size for the influence of 5-HTTLPR on REM sleep architecture, findings require replication given the common inconsistencies in 5-HTTLPR research. While the present study specifically focused on untainted genetic influences, it would be valuable to investigate whether similar associations would be observed in clinical populations. Hence, as current findings indicate that the 5-HTTLPR S-allele is associated with a lower amount of REM sleep, allelic variation in 5-HTTLPR might clarify why a disinhibition of REM sleep is typically observed in 50\%-70\% of the depressed patients (Riemann et al., 2001). Given the polygenetic nature of REM sleep regulation and depression it cannot be excluded that other genetic variants concurrently influenced the results of the present study. Although other neurotransmitter and neuroendocrine systems are clearly involved in REM sleep regulation, given the prominent role of 5-HT it would be valuable to explore interactions with other 5-HT functional polymorphisms. Genes regulating the expression of the 5-HT $1 \mathrm{~A}$ receptor are considered of particular relevance given its predominant role in REM sleep regulation and depression. 
In conclusion, the present study reveals that allelic variation in 5-HTTLPR influences REM sleep regulation. The direction of results suggests that the 5-HTTLPR S-allele is associated with a REM sleep architecture that resembles insomnia rather than depression. This may arise from the acute effects of reduced 5-HTT functioning rather than reflecting developmental component. Future research is needed to establish whether the relatively lower amount of REM sleep associated with the 5-HTTLPR S-allele may contribute to the depression predisposition related to this allelic variant.

\section{Role of the funding source}

This research did not receive any specific grant from funding agencies in the public, commercial, or not-for-profit sectors.

\section{Conflict of interest}

None.

\section{Acknowledgements}

None. 


\section{References}

Aeschbach, D., \& Borbely, A. A. (1993). All-night dynamics of the human sleep EEG. Journal of Sleep Research, 2(2), 70-81.

Alexandre, C., Popa, D., Fabre, V., Bouali, S., Venault, P., Lesch, K. P., . . . Adrien, J. (2006). Early life blockade of 5-hydroxytryptamine 1A receptors normalizes sleep and depression-like behavior in adult knock-out mice lacking the serotonin transporter. The Journal of neuroscience : the official journal of the Society for Neuroscience, 26(20), 5554-5564. doi:10.1523/JNEUROSCI.5156-05.2006

Anguelova, M., Benkelfat, C., \& Turecki, G. (2003). A systematic review of association studies investigating genes coding for serotonin receptors and the serotonin transporter: II. Suicidal behavior. Molecular Psychiatry, 8(7), 646-653. doi:10.1038/sj.mp.4001336

Baglioni, C., Battagliese, G., Feige, B., Spiegelhalder, K., Nissen, C., Voderholzer, U., . . . Riemann, D. (2011). Insomnia as a predictor of depression: A meta-analytic evaluation of longitudinal epidemiological studies. Journal of Affective Disorders, 135(1-3), 10-19. doi:10.1016/j.jad.2011.01.011

Berry, R. B., Brooks, R., Gamaldo, C. E., Harding, S. M., Lloyd, R. M., Marcus, C. L., \& Vaughn, B. V. (2016). The AASM Manual for the Scoring of Sleep and Associated Events: Rules, Terminology and Technical Specifications : Version 2.3: American Academy of Sleep Medicine.

Bleys, D., Luyten, P., Soenens, B., \& Claes, S. (2018). Gene-environment interactions between stress and 5-HTTLPR in depression: A meta-analytic update. Journal of Affective Disorders, 226, 339-345. doi:10.1016/j.jad.2017.09.050

Carskadon, M. A., \& Rechtschaffen, A. (2005). Monitoring and Staging Human Sleep. In M. H. Kryger, T. Roth, \& W. C. Dement (Eds.), Principles and Practices of Sleep Medicine (4th ed., pp. 1359-1377). Philadelphia, PA: Elsevier Saunders.

Clarke, H., Flint, J., Attwood, A. S., \& Munafo, M. R. (2010). Association of the 5- HTTLPR genotype and unipolar depression: a meta-analysis. Psychological Medicine, 40(11), 1767-1778. doi:10.1017/s0033291710000516

Deuschle, M., Schredl, M., Schilling, C., Wust, S., Frank, J., Witt, S. H., . . Schulze, T. G. (2010). Association between a serotonin transporter length polymorphism and primary insomnia. Sleep, 33(3), 343-347.

Flint, J., \& Kendler, K. S. (2014). The Genetics of Major Depression. Neuron, 81(3), 484-503. doi:10.1016/j.neuron.2014.01.027

Frank, M. G., \& Heller, H. C. (1997). Neonatal treatments with the serotonin uptake inhibitors clomipramine and zimelidine, but not the noradrenaline uptake inhibitor desipramine, disrupt sleep patterns in adult rats. Brain Research, 768(1-2), 287-293.

Furlong, R. A., Ho, L., Walsh, C., Rubinsztein, J. S., Jain, S., Paykel, E. S., . . Rubinsztein, D. C. (1998). Analysis and meta-analysis of two serotonin transporter gene polymorphisms in bipolar and unipolar affective disorders. American Journal of Medical Genetics, 81(1), 58-63.

Glatz, K., Mossner, R., Heils, A., \& Lesch, K. P. (2003). Glucocorticoid-regulated human serotonin transporter (5-HTT) expression is modulated by the 5-HTT gene-promotorlinked polymorphic region. Journal of Neurochemistry, 86(5), 1072-1078.

Gottesman, II, \& Gould, T. D. (2003). The endophenotype concept in psychiatry: etymology and strategic intentions. The American journal of psychiatry, 160(4), 636-645.

Hoaglin, D. C., Iglewicz, B., \& Tukey, J. W. (1986). Performance of Some Resistant Rules for Outlier Labeling. Journal of the American Statistical Association, 81(396), 991999. doi:10.1080/01621459.1986.10478363 
Huang, C., Li, J., Lu, L., Ren, X., Li, Y., Huang, Q., . . . Wang, Y. (2014). Interaction between serotonin transporter gene-linked polymorphic region (5-HTTLPR) and jobrelated stress in insomnia: a cross-sectional study in Sichuan, China. Sleep Med, 15(10), 1269-1275. doi:10.1016/j.sleep.2014.01.023

Karg, K., Burmeister, M., Shedden, K., \& Sen, S. (2011). The serotonin transporter promoter variant (5-HTTLPR), stress, and depression meta-analysis revisited: evidence of genetic moderation. Archives of General Psychiatry, 68(5), 444-454. doi:10.1001/archgenpsychiatry.2010.189

Kessler, R. C., Berglund, P., Demler, O., Jin, R., Koretz, D., Merikangas, K. R., . . Wang, P. S. (2003). The epidemiology of major depressive disorder: results from the National Comorbidity Survey Replication (NCS-R). JAMA, 289(23), 3095-3105. doi:10.1001/jama.289.23.3095

Lasky-Su, J. A., Faraone, S. V., Glatt, S. J., \& Tsuang, M. T. (2005). Meta-analysis of the association between two polymorphisms in the serotonin transporter gene and affective disorders. Am J Med Genet B Neuropsychiatr Genet, 133b(1), 110-115. doi:10.1002/ajmg.b.30104

Lopez-Leon, S., Janssens, A. C., Gonzalez-Zuloeta Ladd, A. M., Del-Favero, J., Claes, S. J., Oostra, B. A., \& van Duijn, C. M. (2008). Meta-analyses of genetic studies on major depressive disorder. Molecular Psychiatry, 13(8), 772-785. doi:10.1038/sj.mp.4002088

Malhotra, A., Younes, M., Kuna, S. T., Benca, R., Kushida, C. A., Walsh, J., . . . Pien, G. W. (2013). Performance of an automated polysomnography scoring system versus computer-assisted manual scoring. Sleep, 36(4), 573-582. doi:10.5665/sleep.2548

Miller, R., Wankerl, M., Stalder, T., Kirschbaum, C., \& Alexander, N. (2013). The serotonin transporter gene-linked polymorphic region (5-HTTLPR) and cortisol stress reactivity: a meta-analysis. Molecular Psychiatry, 18(9), 1018-1024. doi:10.1038/mp.2012.124

Munafò, M. R., Durrant, C., Lewis, G., \& Flint, J. (2009). Gene $\times$ Environment Interactions at the Serotonin Transporter Locus. Biological Psychiatry, 65(3), 211-219. doi:10.1016/j.biopsych.2008.06.009

Murphy, D. L., \& Lesch, K. P. (2008). Targeting the murine serotonin transporter: insights into human neurobiology. Nat Rev Neurosci, 9(2), 85-96. doi:10.1038/nrn2284

Murphy, S. E., Norbury, R., Godlewska, B. R., Cowen, P. J., Mannie, Z. M., Harmer, C. J., \& Munafo, M. R. (2013). The effect of the serotonin transporter polymorphism (5HTTLPR) on amygdala function: a meta-analysis. Molecular Psychiatry, 18(4), 512520. doi:10.1038/mp.2012.19

Nakamura, M., Ueno, S., Sano, A., \& Tanabe, H. (2000). The human serotonin transporter gene linked polymorphism (5-HTTLPR) shows ten novel allelic variants. Molecular Psychiatry, 5(1), 32-38.

Palagini, L., Baglioni, C., Ciapparelli, A., Gemignani, A., \& Riemann, D. (2013). REM sleep dysregulation in depression: state of the art. Sleep Med Rev, 17(5), 377-390. doi:10.1016/j.smrv.2012.11.001

Pergamin-Hight, L., Bakermans-Kranenburg, M. J., van Ijzendoorn, M. H., \& Bar-Haim, Y. (2012). Variations in the Promoter Region of the Serotonin Transporter Gene and Biased Attention for Emotional Information: A Meta-Analysis. Biological Psychiatry, 71(4), 373-379. doi:10.1016/j.biopsych.2011.10.030

Piccinelli, M., \& Wilkinson, G. (2000). Gender differences in depression. The British Journal of Psychiatry, 177(6), 486.

Pillai, V., Kalmbach, D. A., \& Ciesla, J. A. (2011). A meta-analysis of electroencephalographic sleep in depression: evidence for genetic biomarkers. Biological Psychiatry, 70(10), 912-919. doi:10.1016/j.biopsych.2011.07.016 
Rechtschaffen, A., \& Kales, A. (1968). A Manual of Standardized Terminology, Techniques and Scoring System for Sleep Stages of Human Subjects: Brain Information Service/Brain Research Institute, University of California.

Riemann, D., Berger, M., \& Voderholzer, U. (2001). Sleep and depression - results from psychobiological studies: an overview. Biological Psychology, 57(1-3), 67-103. doi:10.1016/S0301-0511(01)00090-4

Riemann, D., Spiegelhalder, K., Nissen, C., Hirscher, V., Baglioni, C., \& Feige, B. (2012). REM sleep instability--a new pathway for insomnia? Pharmacopsychiatry, 45(5), 167176. doi:10.1055/s-0031-1299721

Risch, N., Herrell, R., Lehner, T., \& et al. (2009). Interaction between the serotonin transporter gene (5-httlpr), stressful life events, and risk of depression: A metaanalysis. JAMA, 301(23), 2462-2471. doi:10.1001/jama.2009.878

Sullivan, P. F., Neale, M. C., \& Kendler, K. S. (2000). Genetic epidemiology of major depression: review and meta-analysis. American Journal of Psychiatry, 157(10), 15521562. doi:10.1176/appi.ajp.157.10.1552

Ursin, R. (2002). Serotonin and sleep. Sleep Med Rev, 6(1), 55-69.

van Dalfsen, J. H., \& Markus, C. R. (2018). The serotonin transporter 5-HTTLPR polymorphism and the risk for insomnia: a non-replication. Sleep Med. doi:10.1016/j.sleep.2018.01.015

Vos, T., Flaxman, A. D., Naghavi, M., Lozano, R., Michaud, C., Ezzati, M., . . . Memish, Z. A. (2012). Years lived with disability (YLDs) for 1160 sequelae of 289 diseases and injuries 1990-2010: a systematic analysis for the Global Burden of Disease Study 2010. Lancet, 380(9859), 2163-2196. doi:10.1016/s0140-6736(12)61729-2

Wichniak, A., Riemann, D., Kiemen, A., Voderholzer, U., \& Jernajczyk, W. (2000). Comparison between eye movement latency and REM sleep parameters in major depression. European Archives of Psychiatry and Clinical Neuroscience, 250(1), 4852.

Wisor, J. P., Wurts, S. W., Hall, F. S., Lesch, K. P., Murphy, D. L., Uhl, G. R., \& Edgar, D. M. (2003). Altered rapid eye movement sleep timing in serotonin transporter knockout mice. Neuroreport, 14(2), 233-238. doi:10.1097/01.wnr.0000054963.21656.bf 
General discussion 


\section{Introduction}

Major depressive disorder is one of the most prevalent psychiatric conditions. With a point prevalence rate estimated at 5\% and a life time prevalence of around 15\% (Kessler et al., 2003), depression has been identified as one of the primary causes of disability worldwide (Murray \& Lopez, 1996; Vos et al., 2012). These findings emphasize the need to gain insight into the pathophysiological mechanisms contributing to this condition. The identification of genetic risk factors is thought to particularly advance the understanding of depression etiology (Levinson, 2006). Despite a heritability estimate of 31\%-42\% (Sullivan, Neale, \& Kendler, 2000), genetic association studies have not produced replicable genetic variants involved in major depression (Flint \& Kendler, 2014; Ripke et al., 2013). Recent theories suggest that genetic influences may depend on environmental context (i.e. gene-environment interaction) and thereby provide a more comprehensive approach to elucidate the genetic architecture of depression. Although initially promising, results from the explored gene-environment interactions only produced limited advances (Wray et al., 2012).

The serotonin (5-hydroxytriptamine; 5-HT) transporter gene-linked polymorphic region (5-HTTLPR) comprises one of the most frequently studied genetic variations in the context of affective disorders. Following the first report describing a direct relationship (Collier et al., 1996), the field gained particular momentum when a prospective longitudinal study revealed that the association between stressful life events and depression was more pronounced in 5-HTTLPR short (S) allele relative to the long (L) allele carriers (Caspi et al., 2003). The vast amount of studies aimed to replicate these initial findings, however, produced great controversy. Even though recent meta-analyses provide some support for both a direct relationship (Clarke, Flint, Attwood, \& Munafo, 2010) as well as a gene-environment interaction (Bleys, Luyten, Soenens, \& Claes, 2018) results remain inconclusive (Culverhouse et al., 2018). In the light of these equivocal findings, it has been suggested that the effect of this genetic predisposition is modest, not broadly generalizable and only observable in specific circumstances (Culverhouse et al., 2018). Elucidating the pathways by which 5HTTLPR contributes to the development of depression would therefore profoundly advance current understanding of this relationship.

Evidence from multiple research disciplines suggests that dysfunctional sleep might be a promising pathway predisposing the risk for depression in 5-HTTLPR S-allele carriers. The present thesis evaluates this hypothesis using a multi-disciplinary approach. Encouraged by the causal involvement of sleep in the development of depression (Baglioni et al., 2011; 
Palagini, Baglioni, Ciapparelli, Gemignani, \& Riemann, 2013), it was examined whether allelic variation in 5-HTTLPR modulates the risk for insomnia (Chapter 1), and, in addition whether this genetic variation moderates the sleep-promoting effects of brain 5-HT augmentation (Chapter $\mathbf{2}$ and 3). It was further investigated whether sleep affects the stress reactivity of the hypothalamic-pituitary-adrenal (HPA) axis (Chapter 4), an intermediate process frequently implicated in the pathophysiology of depression. Encouraged by the observed relationships, it was additionally examined whether sleep may modulate the presumed association between 5-HTTLPR and HPA stress responsiveness (Chapter 5). In line with the view that such intermediate processes may contribute to a relationship between 5-HTTLPR and depression, it was further investigated whether 5-HTTLPR influences REM sleep disinhibition (Chapter 6), a neurophysiological marker that displays close connections with genetic depression vulnerability. The following sections summarize the main findings derived from these investigations and discuss the theoretical implications for the relationship between 5-HTTLPR and depression.

\section{5-HTTLPR and the risk for insomnia}

Previous studies have consistently demonstrated that the 5-HTTLPR S-allele predisposes the risk for insomnia (Deuschle et al., 2010; Huang et al., 2014). In line with findings on subjective sleep quality (Brummett et al., 2007), additional evidence suggests that an interaction between 5-HTTLPR and stress may contribute to this association (Huang et al., 2014). Since insomnia comprises one of the primary risk factors for depression (Baglioni et al., 2011), these findings reveal a potential pathway how 5-HTTLPR, either directly or in interaction with stress, may influence depression susceptibility. However, given the common inconsistent and false positive findings in candidate gene research (Flint \& Kendler, 2014), replication studies are highly desirable.

The study described in Chapter 1 was specifically designed to replicate established associations between 5-HTTLPR, stress and insomnia. In contrast to previous findings (Deuschle et al., 2010; Huang et al., 2014) results neither revealed a direct association between 5-HTTLPR and insomnia nor a moderating influence of 5-HTTLPR on the relationship between stress and insomnia. Correspondingly, the study presented in Chapter 2 also failed to detect an interaction between 5-HTTLPR and stress on subjective sleep quality as previously suggested (Brummett et al., 2007). The results described in Chapter $\mathbf{3}$ did, however, reveal significantly poorer sleep quality in S-allele relative to L-allele carriers even 
though this association was not confirmed by objective sleep assessment. These equivocal findings elaborate on one other non-replication in the field (Barclay et al., 2011), suggesting that the influence of 5-HTTLPR on sleep impairment is more heterogeneous than presented in the literature.

Although not consistently observed in the studies presented this thesis, the majority of available investigations support an increased risk for sleep impairment in 5-HTTLPR S-allele relative to L-allele carriers (Brummett et al., 2007; Davis et al., 2017; Deuschle et al., 2010; Huang et al., 2014; Polito et al., 2015). Since the 5-HTTLPR S-allele is found to particularly promote the development of sleep impairment (Brummett et al., 2007; Davis et al., 2017; Huang et al., 2014) and depression (Bleys et al., 2018; Karg, Burmeister, Shedden, \& Sen, 2011) in interaction with stress experience, it seems reasonable to assume that a more general stress sensitivity underlies both these predispositions. This postulation closely converges with the elevated neuroendocrine stress sensitivity associated with the 5-HTTLPR S-allele (Miller, Wankerl, Stalder, Kirschbaum, \& Alexander, 2013) and, hence, the persistent neuroendocrine hyperarousal implicated in both the pathophysiology of insomnia (Bonnet \& Arand, 2010; Riemann et al., 2010) and depression (Sapolsky, 2015; van Praag, 2004). Since insomnia comprises one of the primary risk factors for depression (Baglioni et al., 2011), a concurrent elevated risk for insomnia in S-allele carriers may reinforce the presumed interaction between 5-HTTLPR and stress on depression.

The significance of sleep in the relationship between 5-HTTLPR and depression is further supported by the consistent observation that allelic variation in 5-HTTLPR modulates the development of sleep-related depressive symptomatology (Carskadon, Sharkey, Knopik, \& McGeary, 2012; J. A. Hartmann et al., 2014; van Roekel, Hartmann, Wichers, \& Verhagen, 2016). Together with a presumed elevated risk for insomnia, these findings suggest that allelic variation in 5-HTTLPR may specifically contribute to interindividual differences in depression susceptibility by modulating the affective consequences of inadequate sleep. It could therefore be argued that an increased risk for depression in S-allele relative to L-allele carriers would be particularly observed in the context of sleep impairment, providing one of the possible circumstances in which 5-HTTLPR contributes to the development of depression (Culverhouse et al., 2018).

In summary, available findings suggest that sleep might have a prominent role in the relationship between 5-HTTLPR and depression. Since previous studies exploring this association have not generally accounted for such sleep-related influences, this could explain 
some of the equivocal findings characterizing this field of research (Bleys et al., 2018; Clarke et al., 2010; Culverhouse et al., 2018).

\section{5-HTTLPR and the sleep-promoting effects of brain 5-HT augmentation}

The observation that the 5-HTTLPR S-allele has been associated with an increased risk to experience sleep impairment (Brummett et al., 2007; Davis et al., 2017; Deuschle et al., 2010; Huang et al., 2014; Polito et al., 2015), illustrates the need to develop pharmacological interventions aimed to compensate for this 5-HT predisposition. Moreover, from a scientific perspective, establishing an enhanced sensitivity to 5-HT manipulations in S-allele carriers would further elucidate the 5-HT deficiency contributing to this relationship.

Evidence suggests that brain 5-HT synthesis can be enhanced by increasing the availability of its precursor tryptophan (Eccleston, Ashcroft, \& Crawford, 1970; Fernstrom, 1983). Encouraged by the presumed sleep-promoting effects (E. Hartmann \& Greenwald, 1984; Schneider-Helmert \& Spinweber, 1986; Silber \& Schmitt, 2010) the studies presented in Chapter $\mathbf{2}$ and $\mathbf{3}$ investigated whether tryptophan administration could compensate for the elevated susceptibility for sleep impairment in S-allele carriers by particularly facilitating sleep in this allelic variant. The results described in Chapter 2 demonstrate that tryptophan administration was exclusively associated with better sleep quality in 5-HTTLPR S-allele carriers who experienced high levels of chronic stress. In line with these findings, the complementary study included in Chapter 3 confirmed that some of the sleep-promoting effects of tryptophan depend on 5-HTTLPR genotype. While tryptophan improved objective sleep efficiency and objective wake after sleep onset irrespective of allelic variation, 5HTTLPR was found to modulate the effect of tryptophan on subjective sleep quality by exclusively improving sleep in 5-HTTLPR S-allele relative to L-allele carriers.

The observation that tryptophan especially improves sleep in the S-allele is in line with studies in other domains revealing similar 5-HTTLPR dependent effects (Gibson, 2018). Although contemporary findings thus support a 5-HT vulnerability for sleep impairment in 5HTTLPR S-allele carriers (Brummett et al., 2007; Davis et al., 2017; Deuschle et al., 2010; Huang et al., 2014; Polito et al., 2015), the underlying deficit and clinical implications remain subjected to speculation. Improving sleep in S-allele carriers is, however, of particular interest given the increased susceptibility for sleep-related affective changes (Carskadon et al., 2012; J. A. Hartmann et al., 2014; van Roekel et al., 2016). The specific improvement in subjective sleep quality described in Chapter $\mathbf{2}$ and $\mathbf{3}$ appears to be of notable importance as sleep 
quality is found to especially modulate affective changes (Palmer \& Alfano, 2017), particularly in 5-HTTLPR S-allele carriers (J. A. Hartmann et al., 2014; van Roekel et al., 2016).

Taken together, the results presented in this thesis demonstrate that tryptophan augmentation might become a promising treatment strategy for sleep impairment related to genetic deficiencies in 5-HT functioning. Moreover, given the elevated susceptibility for sleep-related affective symptomatology in 5-HTTLPR S-allele carriers, improving sleep quality by means of tryptophan augmentation might concurrently alleviate the elevated risk for depression in this allelic variant.

\section{Sleep and the relationship between 5-HTTLPR and neuroendocrine stress reactivity}

An elevated stress reactivity of the HPA axis has been proposed as one of the main mechanisms contributing to the higher depression risk in 5-HTTLPR S-allele carriers (Way \& Taylor, 2010). Elucidating an influence of sleep on HPA stress responsiveness may therefore further establish the relevance of sleep in the association between 5-HTTLPR and depression. Investigating whether sleep may serve as an additional moderating factor in the relationship between 5-HTTLPR and HPA stress sensitivity might be of particular relevance given the common contradictory findings in this field of research (Miller et al., 2013). Hence, while a recent meta-analysis confirmed a modest but significantly higher cortisol stress response in Sallele relative to L-allele carriers (Miller et al., 2013), the origin of common inconsistencies remains largely unknown.

In an attempt to resolve this apparent issue, the investigations described in Chapter 4 and 5 examined the possible role of sleep in the association between 5-HTTLPR and neuroendocrine stress reactivity. The systematic review included in Chapter 4 revealed that a reduced sleep quality potentiates the stress sensitivity of the HPA axis, suggesting that sleep could indeed play an important role in this relationship. In line with this assumption, the study presented in Chapter 5 provides preliminary evidence that sleep quality modulates the association between 5-HTTLPR and HPA stress reactivity. While reduced sleep quality was not found to underlie the elevated cortisol reactivity in S-allele carriers, the relationship between 5-HTTLPR and cortisol stress responsiveness varied considerably as a function of sleep quality. In conditions of relatively good sleep quality, 5-HTTLPR was found to predict an elevated cortisol stress reactivity in S-allele relative to L-allele carriers in line with general assumptions (Miller et al., 2013). In contrast, as sleep quality declines 5-HTTLPR dependent 
differences in HPA reactivity may gradually reduce as this was found to exclusively potentiate cortisol stress responsiveness in L-allele carriers.

The observation that inadequate sleep promotes neuroendocrine stress responsiveness, elaborates on previous findings demonstrating similar increments in basal HPA activity (Meerlo, Sgoifo, \& Suchecki, 2008). Since such elevated stress reactivity of the HPA axis is commonly regarded as an important risk factor for the development of depression (Sapolsky, 2015; van Praag, 2004), the results presented in Chapter 4 elucidate a potential mechanism by which inadequate sleep may contribute to the etiology of depression. While the findings discussed in Chapter 5 confirm that an elevated HPA reactivity may indeed contribute to the depression susceptibility of S-allele carriers, inadequate sleep was not found to underlie this stress sensitivity. In contrast, results indicate that variations in sleep quality may considerably confound the influence of 5-HTTLPR on HPA reactivity. Hence, while the S-allele initially promotes hormonal stress reactivity and, in relation, the risk for depression, the sleep-related increase in the stress responsiveness observed in L-allele carriers may gradually reduce this apparent difference in depression susceptibility.

Taken together, the influence of sleep on the stress reactivity of the HPA axis established in this dissertation may have important implications for the relationship between 5-HTTLPR and depression susceptibility. Although the clinical implications remain to be elucidated, current findings suggest that variations in sleep quality might be an important confounder in the search for genetic differences in stress sensitivity and related affective disorders.

\section{5-HTTLPR and REM sleep regulation}

Besides symptoms of insomnia, clinical depression is associated with profound abnormalities in REM sleep including a reduced REM sleep latency (i.e. the interval between sleep onset and the first period of REM sleep), increased REM sleep time and an elevated REM density (i.e. the amount of rapid eye movements during REM sleep) (Palagini et al., 2013; Riemann, Berger, \& Voderholzer, 2001). Evidence suggests that such REM sleep abnormalities may be involved in the pathophysiology of depression and/or reflect neurobiological abnormalities (Palagini et al., 2013). Establishing an association between 5-HTTLPR and REM sleep regulation may therefore contribute to an increased understanding of possible mechanisms or phenotypes mediating the differential depression predisposition associated with this genetic variation. 
In line with the prominent role of 5-HT in the neurobiology of REM sleep (Ursin, 2002), findings from multiple research disciplines indicate that 5-HTTLPR is very wellpositioned to influence REM sleep regulation. The involvement of the 5-HT transporter is directly supported by the REM sleep suppressive effect of selective serotonin reuptake inhibitors (SSRIs) (Palagini et al., 2013). Animal studies have further demonstrated that SSRI treatment during early development (Frank \& Heller, 1997) as well as genetic knockout of the 5-HT transporter (Alexandre et al., 2006; Wisor et al., 2003) induces a persistent increase in the occurrence of REM sleep (i.e. REM sleep disinhibition). Encouraged by these findings, the polysomnographic study presented in Chapter 6 investigated the influence of 5-HTTLPR on REM sleep regulation. While allelic variation in 5-HTTLPR was not found to influence REM density and REM sleep latency, results revealed a large effect of 5-HTTLPR on the percentage of REM sleep, indicating that the 5-HTTLPR S-allele is associated with a significantly lower amount of REM sleep relative to the L-allele.

Since 5-HTTLPR was not found to influence the features of REM sleep predominantly associated with depression vulnerability (i.e. REM sleep latency, REM density), the findings presented in this thesis do not support a role for REM sleep in predisposing the risk for depression in healthy 5-HTTLPR S-allele carriers. Correspondingly, the lower amount of REM sleep associated with this allelic variant is, in first instance, also contraindicative for a depression predisposition. However, recent insights suggest that a reduced or fragmented REM sleep might contribute to the development of insomnia (Riemann et al., 2012). The lower amount of REM sleep observed in 5-HTTLR S-allele carriers may therefore provide additional support for the presumed elevated risk for insomnia in this allelic variant (Deuschle et al., 2010; Huang et al., 2014). Moreover, in line with the independent contribution of insomnia to the etiology of depression (Baglioni et al., 2011), it has been suggested that such modest chronic reductions in REM sleep might ultimately induce a REM sleep rebound resulting in the characteristic REM sleep disinhibition associated with depression vulnerability (Riemann et al., 2012). These postulations suggest that even though the 5HTTLPR S-allele may not initially promote a depressogenic REM sleep pattern, the lower amount of REM sleep may precede REM sleep disinhibition and, eventually, predispose the risk for depression.

Taken together, current findings do not support a depressogenic REM sleep pattern in 5-HTTLPR S-allele carriers. However, the reduced amount of REM sleep observed in 5HTTLPR S-allele relative to L-allele carriers might support an elevated risk for insomnia in this allelic variant. This could reveal a potential pathway how sleep may contribute to an 
association between 5-HTTLPR and depression vulnerability, potentially by ultimately promoting a disinhibition of REM sleep.

\section{Limitations and suggestions for future research}

The following general limitations should be considered for the studies presented in this thesis. Even though the included studies provide valuable first insights regarding the possible role of sleep in the association between 5-HTTLPR, stress and depression, this specific involvement was not directly examined. Hence, investigating the influence of sleep on this relationship is complex and can best be explored in a longitudinal research design. In line with the original investigation (Caspi et al., 2003), birth cohorts should ideally be followed over the years to examine whether inter- and intraindividual variations in sleep may contribute to this geneenvironment interaction in depression. A specific emphasis should be placed on the temporal dynamics of environmental stress and sleep alterations to establish whether 5-HTTLPR contributes to the etiology of sleep impairment (Brummett et al., 2007; Davis et al., 2017; Deuschle et al., 2010; Huang et al., 2014; Polito et al., 2015) and/or promotes the development of depression in relation to sleep impairment (Carskadon et al., 2012; J. A. Hartmann et al., 2014; van Roekel et al., 2016).

Even though the literature and findings described in this thesis provide some support for the involvement of sleep in the association between 5-HTTLPR and depression, this only comprises one of the many possible pathways involved in the etiology of this heterogeneous condition. Hence, it has been estimated that thousands of genetic variants may contribute to the risk for depression (Flint \& Kendler, 2014) and the diversity of environmental factors might be of equal proportion. The generous literature on the genetics of depression has for instance identified the potential involvement of multiple candidate genes relating to different neurobiological mechanisms and neurotransmitter systems (Clarke et al., 2010; Kishi et al., 2013; Lopez-Leon et al., 2008; Lopez Leon et al., 2005). Nonetheless, the contribution of any of these genetic variants has been challenged by genome-wide association studies which could not replicate these associations despite superior statistical power (Flint \& Kendler, 2014). The assumption that genetic influences may depend on environmental context could theoretically resolve these divergent findings but the general conclusions derived from the explored gene-environment interactions to date remain uncertain (Wray et al., 2012).

Particular advances in uncovering the genetic architecture of depression might be made by exploring how a combination of multiple genes (i.e. gene-gene interaction) 
contribute to the etiology of depression against a homogenous environmental background (i.e. gene-environment interaction). As the involvement of 5-HTTLPR finds some support in recent evaluations (Bleys et al., 2018; Clarke et al., 2010; Karg et al., 2011), a promising first approach might be to investigate 5-HTTLPR in concert with other single nucleotide polymorphisms affecting the brain 5-HT system, preferably those already associated with depression in recent meta-analyses (i.e. 5-HTR1A). In line with the causal involvement of sleep in the development of depression (Baglioni et al., 2011), the literature and results presented in this thesis suggest that either adequate or inadequate sleep may provide a promising environmental background to elucidate more consistent genetic effects.

Even though depression presumably arises from a combination of genetic and environmental factors, methodological aspects may also explain the divergent findings in 5HTTLPR research. While most of the studies included in this dissertation were adequately powered to examine the relationship of interest, recent recommendations suggest that genetic analysis of complex traits requires a large sample size and direct replication (Hewitt, 2012). This particularly relates to the prevention of false positive findings and attempts to replicate the described associations between 5-HTTLPR and sleep are therefore paramount. While the present thesis incorporates studies specifically aimed to replicate previous (Chapter 1) and contemporary (Chapter 3) findings, the more recent insights of this dissertation (Chapter $\mathbf{5}$ and 6) should be treated with caution prior to replication in larger samples.

Besides sample size and replication, there is an ongoing debate whether subjective instead of objective assessment of life adversity and depression contributes to the divergent findings in 5-HTTLPR research. While this assumption is supported by a previous review (Uher \& McGuffin, 2010) and meta-analysis (Karg et al., 2011), one of the most recent metaanalysis investigating the interaction between 5-HTTLPR and stress in depression revealed that $46 \%$ of the heterogeneity could not be explained by methodological factors (Bleys et al., 2018). Since some of the studies presented in this thesis also included subjective measures of environmental adversity (Chapter 1 and 2) it cannot be excluded that this may have contributed to the contradictory results in the association between 5-HTTLPR and sleep impairment. It is therefore recommended to include objective or contextual indices of life adversity when exploring the involvement of 5-HTTLPR in the association between stress and sleep parameters. Whether the inclusion of either objective or subjective sleep assessment may also affect the influence of 5-HTTLPR on sleep is uncertain. However, as the present thesis includes one of the few objective sleep investigations in the field of 5-HTTLPR, future polysomnographic and actigraphic studies devoted to this topic are desirable. 


\section{Conclusions}

The identification of genetic variants involved in major depression has been recognized as one of the greatest challenges in mental health research (Collins et al., 2011). Recent metaanalyses stimulate an ongoing debate regarding the involvement of 5-HTTLPR in the etiology of depression (Bleys et al., 2018; Clarke et al., 2010; Culverhouse et al., 2018). Inspired by the causal involvement of sleep in the etiology of depression (Baglioni et al., 2011; Palagini et al., 2013) and previous research supporting a role for 5-HTTLPR in the etiology of sleep impairment (Brummett et al., 2007; Davis et al., 2017; Deuschle et al., 2010; Huang et al., 2014; Polito et al., 2015) and its affective consequences (Bouvette-Turcot et al., 2015; Carskadon et al., 2012; J. A. Hartmann et al., 2014; van Roekel et al., 2016), the present thesis investigated whether sleep may have a central role in the association between 5-HTTLPR, stress and depression.

The results presented in this thesis further emphasize the complexity of linking genetic variants to complex disorders and conditions. Even though the association between 5HTTLPR and insomnia appeared quite robust in previous investigations (Brummett et al., 2007; Davis et al., 2017; Deuschle et al., 2010; Huang et al., 2014; Polito et al., 2015), the conflicting results presented in this thesis demonstrate that this association more heterogeneous than presented in the literature. These findings elaborate on the divergent findings commonly observed in 5-HTTLPR research and elucidating the origin of the equivocal phenotypic expression of 5-HTTLPR comprises one of the main challenges for future research. As demonstrated, some advantages can be made by studying 5-HTTLPR dependent effects of 5-HT manipulation even though the underlying deficits and related clinical implications remain uncertain. The results of this thesis further illustrate that individual variations in sleep may conceal more consistent 5-HTTLPR dependent differences in stress sensitivity, and, hence, related depression vulnerability. Moreover, the presented findings indicate that the influence of 5-HTTLPR on REM sleep regulation may support an association between 5-HTTLPR and insomnia. Although the clinical utility of this observation is subjected to speculation, this may reveal an additional process contributing to the differential depression susceptibility associated with genetic variation in 5-HT transporter expression.

In summary, the results and literature presented in this dissertation suggest that sleep might be an important factor in the association between 5-HTTLPR and depression. Together these findings indicate that dysfunctional sleep could either be a contributing or confounding 
factor in this relationship. Inconsistent findings however challenge the hypothesis that the influence of 5-HTTLPR on sleep may explain the differential depression susceptibility ascribed to this allelic variation. Although the present results reveal that sleep could profoundly influence the depressogenic expression of 5-HTTLPR, more research is necessary to confirm initial assumptions. To conclude, in line with the close relationship between sleep and depression the studies presented in this thesis indicate that incorporating sleep in future research may provide valuable opportunities to elucidate the genetic basis of depression. 


\section{References}

Alexandre, C., Popa, D., Fabre, V., Bouali, S., Venault, P., Lesch, K. P., . . . Adrien, J. (2006). Early life blockade of 5-hydroxytryptamine 1A receptors normalizes sleep and depression-like behavior in adult knock-out mice lacking the serotonin transporter. The Journal of neuroscience : the official journal of the Society for Neuroscience, 26(20), 5554-5564. doi:10.1523/JNEUROSCI.5156-05.2006

Baglioni, C., Battagliese, G., Feige, B., Spiegelhalder, K., Nissen, C., Voderholzer, U., . . . Riemann, D. (2011). Insomnia as a predictor of depression: A meta-analytic evaluation of longitudinal epidemiological studies. Journal of Affective Disorders, 135(1-3), 10-19. doi:10.1016/j.jad.2011.01.011

Barclay, N. L., Eley, T. C., Mill, J., Wong, C. C., Zavos, H. M., Archer, S. N., \& Gregory, A. M. (2011). Sleep quality and diurnal preference in a sample of young adults: associations with 5HTTLPR, PER3, and CLOCK 3111. Am J Med Genet B Neuropsychiatr Genet, 156B(6), 681-690. doi:10.1002/ajmg.b.31210

Bleys, D., Luyten, P., Soenens, B., \& Claes, S. (2018). Gene-environment interactions between stress and 5-HTTLPR in depression: A meta-analytic update. Journal of Affective Disorders, 226, 339-345. doi:10.1016/j.jad.2017.09.050

Bonnet, M. H., \& Arand, D. L. (2010). Hyperarousal and insomnia: state of the science. Sleep Med Rev, 14(1), 9-15. doi:10.1016/j.smrv.2009.05.002

Bouvette-Turcot, A. A., Pluess, M., Bernier, A., Pennestri, M. H., Levitan, R., Sokolowski, M. B., . . G Gaudreau, H. (2015). Effects of Genotype and Sleep on Temperament. Pediatrics, 136(4), e914-921. doi:10.1542/peds.2015-0080

Brummett, B. H., Krystal, A. D., Ashley-Koch, A., Kuhn, C. M., Zuchner, S., Siegler, I. C., . . . Williams, R. B. (2007). Sleep quality varies as a function of 5-HTTLPR genotype $\begin{array}{llll}\text { and stress. } \quad \text { Psychosomatic } & \text { 69dicine, }\end{array}$ doi:10.1097/PSY.0b013e31814b8de6

Carskadon, M. A., Sharkey, K. M., Knopik, V. S., \& McGeary, J. E. (2012). Short Sleep as an Environmental Exposure: A Preliminary Study Associating 5-HTTLPR Genotype to Self-Reported Sleep Duration and Depressed Mood in First-Year University Students. Sleep, 35(6), 791-796. doi:10.5665/sleep.1876

Caspi, A., Sugden, K., Moffitt, T. E., Taylor, A., Craig, I. W., Harrington, H., . . Poulton, R. (2003). Influence of life stress on depression: moderation by a polymorphism in the 5HTT gene. Science, 301(5631), 386-389. doi:10.1126/science.1083968

Clarke, H., Flint, J., Attwood, A. S., \& Munafo, M. R. (2010). Association of the 5- HTTLPR genotype and unipolar depression: a meta-analysis. Psychological Medicine, 40(11), 1767-1778. doi:10.1017/s0033291710000516

Collier, D. A., Stober, G., Li, T., Heils, A., Catalano, M., Di Bella, D., . . . Lesch, K. P. (1996). A novel functional polymorphism within the promoter of the serotonin transporter gene: possible role in susceptibility to affective disorders. Molecular Psychiatry, 1(6), 453-460.

Collins, P. Y., Patel, V., Joestl, S. S., March, D., Insel, T. R., \& Daar, A. S. (2011). Grand challenges in global mental health: A consortium of researchers, advocates and clinicians announces here research priorities for improving the lives of people with mental illness around the world, and calls for urgent action and investment. Nature, 475(7354), 27-30. doi:10.1038/475027a

Culverhouse, R. C., Saccone, N. L., Horton, A. C., Ma, Y., Anstey, K. J., Banaschewski, T., . . . Bierut, L. J. (2018). Collaborative meta-analysis finds no evidence of a strong interaction between stress and 5-HTTLPR genotype contributing to the development of depression. Molecular Psychiatry, 23(1), 133-142. doi:10.1038/mp.2017.44 
Davis, M., Thomassin, K., Bilms, J., Suveg, C., Shaffer, A., \& Beach, S. R. H. (2017). Preschoolers' genetic, physiological, and behavioral sensitivity factors moderate links between parenting stress and child internalizing, externalizing, and sleep problems. Developmental Psychobiology, 59(4), 473-485. doi:10.1002/dev.21510

Deuschle, M., Schredl, M., Schilling, C., Wust, S., Frank, J., Witt, S. H., . . Schulze, T. G. (2010). Association between a serotonin transporter length polymorphism and primary insomnia. Sleep, 33(3), 343-347.

Eccleston, D., Ashcroft, G. W., \& Crawford, T. B. (1970). Effect of tryptophan administration on 5HIAA in cerebrospinal fluid in man. Journal of Neurology, Neurosurgery and Psychiatry, 33(2), 269-272.

Fernstrom, J. D. (1983). Role of precursor availability in control of monoamine biosynthesis in brain. Physiological Reviews, 63(2), 484-546.

Flint, J., \& Kendler, K. S. (2014). The Genetics of Major Depression. Neuron, 81(3), 484-503. doi:10.1016/j.neuron.2014.01.027

Frank, M. G., \& Heller, H. C. (1997). Neonatal treatments with the serotonin uptake inhibitors clomipramine and zimelidine, but not the noradrenaline uptake inhibitor desipramine, disrupt sleep patterns in adult rats. Brain Research, 768(1-2), 287-293.

Gibson, E. L. (2018). Tryptophan supplementation and serotonin function: genetic variations in behavioural effects. Proceedings of the Nutrition Society, 1-15. doi:10.1017/s0029665117004451

Hartmann, E., \& Greenwald, D. (1984). Tryptophan and human sleep: an analysis of 43 studies. In Progress in tryptophan and serotonin research (pp. 297-304). Berlin: Walter de Gruyter.

Hartmann, J. A., Wichers, M., van Bemmel, A. L., Derom, C., Thiery, E., Jacobs, N., . . . Simons, C. J. P. (2014). The serotonin transporter 5-HTTLPR polymorphism in the association between sleep quality and affect. European Neuropsychopharmacology, 24(7), 1086-1090. doi:10.1016/j.euroneuro.2014.01.015

Hewitt, J. K. (2012). Editorial policy on candidate gene association and candidate gene-byenvironment interaction studies of complex traits. Behavior Genetics, 42(1), 1-2. doi:10.1007/s 10519-011-9504-z

Huang, C., Li, J., Lu, L., Ren, X., Li, Y., Huang, Q., . . . Wang, Y. (2014). Interaction between serotonin transporter gene-linked polymorphic region (5-HTTLPR) and jobrelated stress in insomnia: a cross-sectional study in Sichuan, China. Sleep Med, 15(10), 1269-1275. doi:10.1016/j.sleep.2014.01.023

Karg, K., Burmeister, M., Shedden, K., \& Sen, S. (2011). The serotonin transporter promoter variant (5-HTTLPR), stress, and depression meta-analysis revisited: evidence of genetic moderation. Archives of General Psychiatry, 68(5), 444-454. doi:10.1001/archgenpsychiatry.2010.189

Kessler, R. C., Berglund, P., Demler, O., Jin, R., Koretz, D., Merikangas, K. R., . . Wang, P. S. (2003). The epidemiology of major depressive disorder: results from the National Comorbidity Survey Replication (NCS-R). JAMA, 289(23), 3095-3105. doi:10.1001/jama.289.23.3095

Kishi, T., Yoshimura, R., Fukuo, Y., Okochi, T., Matsunaga, S., Umene-Nakano, W., . . . Iwata, N. (2013). The serotonin 1A receptor gene confer susceptibility to mood disorders: results from an extended meta-analysis of patients with major depression and bipolar disorder. European Archives of Psychiatry and Clinical Neuroscience, 263(2), 105-118. doi:10.1007/s00406-012-0337-4

Levinson, D. F. (2006). The genetics of depression: a review. Biological Psychiatry, 60(2), 84-92. doi:10.1016/j.biopsych.2005.08.024 
Lopez-Leon, S., Janssens, A. C., Gonzalez-Zuloeta Ladd, A. M., Del-Favero, J., Claes, S. J., Oostra, B. A., \& van Duijn, C. M. (2008). Meta-analyses of genetic studies on major depressive disorder. Molecular Psychiatry, 13(8), 772-785. doi:10.1038/sj.mp.4002088

Lopez Leon, S., Croes, E. A., Sayed-Tabatabaei, F. A., Claes, S., Van Broeckhoven, C., \& van Duijn, C. M. (2005). The dopamine D4 receptor gene 48-base-pair-repeat polymorphism and mood disorders: a meta-analysis. Biological Psychiatry, 57(9), 999-1003. doi:10.1016/j.biopsych.2005.01.030

Meerlo, P., Sgoifo, A., \& Suchecki, D. (2008). Restricted and disrupted sleep: effects on autonomic function, neuroendocrine stress systems and stress responsivity. Sleep Med Rev, 12(3), 197-210. doi:10.1016/j.smrv.2007.07.007

Miller, R., Wankerl, M., Stalder, T., Kirschbaum, C., \& Alexander, N. (2013). The serotonin transporter gene-linked polymorphic region (5-HTTLPR) and cortisol stress reactivity: a meta-analysis. Molecular Psychiatry, 18(9), 1018-1024. doi:10.1038/mp.2012.124

Murray, C. J., \& Lopez, A. D. (1996). Evidence-based health policy--lessons from the Global Burden of Disease Study. Science, 274(5288), 740-743.

Palagini, L., Baglioni, C., Ciapparelli, A., Gemignani, A., \& Riemann, D. (2013). REM sleep dysregulation in depression: state of the art. Sleep Med Rev, 17(5), 377-390. doi:10.1016/j.smrv.2012.11.001

Palmer, C. A., \& Alfano, C. A. (2017). Sleep and emotion regulation: An organizing, integrative review. Sleep Med Rev, 31, 6-16. doi:10.1016/j.smrv.2015.12.006

Polito, L., Davin, A., Vaccaro, R., Abbondanza, S., Govoni, S., Racchi, M., \& Guaita, A. (2015). Serotonin transporter polymorphism modifies the association between depressive symptoms and sleep onset latency complaint in elderly people: results from the 'InveCe.Ab' study. Journal of Sleep Research, 24(2), 215-222. doi:10.1111/jsr.12248

Riemann, D., Berger, M., \& Voderholzer, U. (2001). Sleep and depression - results from psychobiological studies: an overview. Biological Psychology, 57(1-3), 67-103. doi:10.1016/S0301-0511(01)00090-4

Riemann, D., Spiegelhalder, K., Feige, B., Voderholzer, U., Berger, M., Perlis, M., \& Nissen, C. (2010). The hyperarousal model of insomnia: a review of the concept and its evidence. Sleep Med Rev, 14(1), 19-31. doi:10.1016/j.smrv.2009.04.002

Riemann, D., Spiegelhalder, K., Nissen, C., Hirscher, V., Baglioni, C., \& Feige, B. (2012). REM sleep instability--a new pathway for insomnia? Pharmacopsychiatry, 45(5), 167 176. doi:10.1055/s-0031-1299721

Ripke, S., Wray, N. R., Lewis, C. M., Hamilton, S. P., Weissman, M. M., Breen, G., . . . Sullivan, P. F. (2013). A mega-analysis of genome-wide association studies for major depressive disorder. Molecular Psychiatry, 18(4), 497-511. doi:10.1038/mp.2012.21

Sapolsky, R. M. (2015). Stress and the brain: individual variability and the inverted-U. Nature Neuroscience, 18(10), 1344-1346. doi:10.1038/nn.4109

Schneider-Helmert, D., \& Spinweber, C. L. (1986). Evaluation of L-tryptophan for treatment of insomnia: a review. Psychopharmacology, 89(1), 1-7.

Silber, B. Y., \& Schmitt, J. A. (2010). Effects of tryptophan loading on human cognition, mood, and sleep. Neuroscience and Biobehavioral Reviews, 34(3), 387-407. doi:10.1016/j.neubiorev.2009.08.005

Sullivan, P. F., Neale, M. C., \& Kendler, K. S. (2000). Genetic epidemiology of major depression: review and meta-analysis. American Journal of Psychiatry, 157(10), 15521562. doi:10.1176/appi.ajp.157.10.1552 
Uher, R., \& McGuffin, P. (2010). The moderation by the serotonin transporter gene of environmental adversity in the etiology of depression: 2009 update. Molecular Psychiatry, 15(1), 18-22. doi:10.1038/mp.2009.123

Ursin, R. (2002). Serotonin and sleep. Sleep Med Rev, 6(1), 55-69.

van Praag, H. M. (2004). Can stress cause depression? Progress in NeuroPsychopharmacology and Biological Psychiatry, 28(5), 891-907. doi:10.1016/j.pnpbp.2004.05.031

van Roekel, E., Hartmann, J. A., Wichers, M., \& Verhagen, M. (2016). The 5-HTTLPR genotype moderates the association between sleep quality and positive affect: A replication study. European Neuropsychopharmacology, 26(8), 1350-1351. doi:10.1016/j.euroneuro.2016.06.001

Vos, T., Flaxman, A. D., Naghavi, M., Lozano, R., Michaud, C., Ezzati, M., . . . Memish, Z. A. (2012). Years lived with disability (YLDs) for 1160 sequelae of 289 diseases and injuries 1990-2010: a systematic analysis for the Global Burden of Disease Study 2010. Lancet, 380(9859), 2163-2196. doi:10.1016/s0140-6736(12)61729-2

Way, B. M., \& Taylor, S. E. (2010). The serotonin transporter promoter polymorphism is associated with cortisol response to psychosocial stress. Biological Psychiatry, 67(5), 487-492. doi:10.1016/j.biopsych.2009.10.021

Wisor, J. P., Wurts, S. W., Hall, F. S., Lesch, K. P., Murphy, D. L., Uhl, G. R., \& Edgar, D. M. (2003). Altered rapid eye movement sleep timing in serotonin transporter knockout mice. Neuroreport, 14(2), 233-238. doi:10.1097/01.wnr.0000054963.21656.bf

Wray, N. R., Pergadia, M. L., Blackwood, D. H., Penninx, B. W., Gordon, S. D., Nyholt, D. R., . . . Sullivan, P. F. (2012). Genome-wide association study of major depressive disorder: new results, meta-analysis, and lessons learned. Molecular Psychiatry, 17(1), 36-48. doi:10.1038/mp.2010.109 
Summary 
Major depression is one of the most prevalent psychiatric conditions. With a point prevalence rate estimated at 5\% and a lifetime prevalence of around 15\% (Kessler et al., 2003), depression has been identified as one of the primary causes of disability worldwide (Vos et al., 2012). These findings emphasize the need to gain insight into the pathophysiological mechanisms of this heterogeneous (Kendler, Aggen, \& Neale, 2013) and frequently recurrent condition (Mueller et al., 1999).

Uncovering the genetic architecture of depression has been identified as one of the greatest challenges in mental health research (Collins et al., 2011). Despite a heritability estimate of 31\%-42\% (Sullivan, Neale, \& Kendler, 2000), genetic association studies have not produced replicable genetic variants involved in major depression (Flint \& Kendler, 2014; Ripke et al., 2013). Recent theories of depression suggest that genetic influences may depend on environmental context (i.e. gene-environment interaction) and thereby potentially explain the limited success of genetic studies (Lesch, 2004). Although initially promising, results from the explored gene-environment interactions only produced limited advances in the identification of genetic risk factors for depression (Wray et al., 2012).

Reduced functioning of the serotonin (5-hydroxytriptamine; 5-HT) system has long been implicated in the pathophysiology of depression (Hasler, 2010) and therefore provides an evident source for candidate genes. By controlling 5-HT reuptake, the 5-HT transporter is a crucial regulator of 5-HT functioning including the magnitude and duration of 5-HT signaling (Lesch et al., 1996). The 5-HT transporter is particularly present in cortical and limbic regions involved in emotional processing (Varnas, Halldin, \& Hall, 2004) and represents one of the main targets of effective and commonly prescribed antidepressants (Tamminga et al., 2002), supporting its involvement in depression. In 1996, Heils et al. reported a functional polymorphism that regulates the transcriptional efficacy of the gene coding for the 5-HT transporter (SLC6A4). This 5-HT transporter gene-linked polymorphic region (5-HTTLPR) comprises an allelic variation of which the short $(\mathrm{S})$ allele is associated with a reduced mRNA expression relative to the long (L) allele (Heils et al., 1996). The related reduction in 5-HT transporter binding sites and 5-HT reuptake (Murphy \& Lesch, 2008) is thought to predispose the risk for depression in this allelic variant.

Initial investigations provided promising support for the involvement of 5-HTTLPR in depression. Following the first report describing a direct relationship (Collier et al., 1996), the field gained particular momentum when a prospective longitudinal study revealed that the association between stressful life events and depression was more pronounced in individuals carrying one or two copies of the S-allele (Caspi et al., 2003). The vast amount of studies 
aimed to replicate these initial findings, however, produced great controversy and available meta-analyses stimulate an ongoing debate whether allelic variation in 5-HTTLPR predisposes the development of (stress-related) depression (Bleys, Luyten, Soenens, \& Claes, 2018; Clarke, Flint, Attwood, \& Munafo, 2010; Culverhouse et al., 2018; Karg, Burmeister, Shedden, \& Sen, 2011; Munafò, Durrant, Lewis, \& Flint, 2009; Risch, Herrell, Lehner, \& et al., 2009).

These equivocal findings presumably result from the heterogeneity of depression. Hence, depression is not considered a homogenous disorder but rather comprises a final common pathway of different pathophysiological mechanisms (Charney et al., 2002). In relation, it has been suggested that the effect of 5-HTTLPR on the risk for stress-related depression is not broadly generalizable and only observable in specific circumstances (Culverhouse et al., 2018). Elucidating the pathways by which 5-HTTLPR contributes to the development of depression would therefore profoundly advance the understanding of this genetic contribution. Encouraged by the intimate relationship between sleep and depression (Riemann, Berger, \& Voderholzer, 2001), the present thesis aims to evaluate whether sleep may have a central role in the association between 5-HTTLPR and depression.

It has been well-established that insomnia independently contributes to the etiology of depression. A recent meta-analysis demonstrated that insomnia confers a two-fold risk increase in non-depressed individuals, thereby classifying sleep impairment as one of the primary risk factors for depression (Baglioni et al., 2011). A presumed elevated risk for insomnia in 5-HTTLPR S-allele carriers (Deuschle et al., 2010; Huang et al., 2014) may therefore provide a promising pathway that predisposes the development of depression in this allelic variant. The potential relevance of insomnia in this relationship is further supported by the consistent observation that the 5-HTTLPR S-allele promotes the development of sleeprelated affective symptomatology (Bouvette-Turcot et al., 2015; Carskadon, Sharkey, Knopik, \& McGeary, 2012; J. A. Hartmann et al., 2014; van Roekel, Hartmann, Wichers, \& Verhagen, 2016).

Given the common inconsistencies in candidate gene-research (Flint \& Kendler, 2014), the study presented in Chapter 1 was specifically designed to replicate established relationships between 5-HTTLPR and insomnia. In contrast to previous investigations (Deuschle et al., 2010; Huang et al., 2014), results did not reveal an association between 5HTTLPR and (stress-related) insomnia. While the results described in Chapter 2 also failed to detect a presumed interaction between 5-HTTLPR and stress on subjective sleep quality (Brummett et al., 2007), the findings presented in Chapter 3 provide some support for 
diminished sleep quality in 5-HTTLPR S-allele relative to L-allele carriers. Although these equivocal findings challenge the postulation that a differential risk for insomnia may contribute to the association between 5-HTTLPR and depression, the majority of available investigations continue to support this particular involvement (Brummett et al., 2007; Davis et al., 2017; Deuschle et al., 2010; Huang et al., 2014; Polito et al., 2015).

The studies presented in Chapter $\mathbf{2}$ and $\mathbf{3}$ elaborate on the presumed differential susceptibility for sleep impairment in S-allele and L-allele carriers by investigating whether 5HTTLPR moderates the sleep-promoting effects of the 5-HT precursor tryptophan (E. Hartmann \& Greenwald, 1984; Schneider-Helmert \& Spinweber, 1986; Silber \& Schmitt, 2010). Results of these investigations revealed that tryptophan augmentation may particularly improve subjective sleep quality in 5-HTTLPR S-allele relative to L-allele carriers. Hence, this supports a 5-HT vulnerability for sleep impairment in this allelic variant (Brummett et al., 2007; Davis et al., 2017; Deuschle et al., 2010; Huang et al., 2014; Polito et al., 2015) and indicates that tryptophan augmentation might become a promising treatment strategy to compensate for this predisposition. Moreover, as 5-HTTLPR S-allele carriers are found to be particularly prone to experience sleep-related affective changes (Bouvette-Turcot et al., 2015; Carskadon et al., 2012; J. A. Hartmann et al., 2014; van Roekel et al., 2016), these findings suggests that this pharmacological intervention might concurrently alleviate the depression susceptibility associated with this allelic variant.

An elevated stress reactivity of the hypothalamic-pituitary-adrenal (HPA) axis has been recognized as one of the main mechanisms predisposing the risk for depression in 5HTTLPR S-allele carriers (Way \& Taylor, 2010). Although a recent meta-analysis confirmed an elevated cortisol stress response in S-allele relative to L-allele carriers (Miller, Wankerl, Stalder, Kirschbaum, \& Alexander, 2013), there is little understanding about the origin of conflicting results. The systematic review included in Chapter 4 reveals that a reduced sleep quality potentiates the stress sensitivity of the HPA axis, suggesting that sleep could be an important variable in this relationship. In line with this postulation, the study presented in Chapter 5 provides preliminary evidence that sleep quality modulates the association between 5-HTTLPR and HPA stress reactivity. Results demonstrated that a higher cortisol stress response in S-allele relative to L-allele carriers gradually reduces as sleep quality declines as this was found to exclusively promote stress reactivity in 5-HTTLPR L-allele carriers. Taken together, the findings described in these articles suggest that an increased stress sensitivity of the HPA axis could be a potential mechanism linking inadequate sleep to the etiology of depression. Although current results confirm that an elevated stress reactivity 
of the HPA axis may indeed contribute to an elevated risk for depression in S-allele relative to L-allele carriers, variations in sleep quality may profoundly confound this relationship.

A disinhibition of rapid eye movement (REM) sleep (i.e. reduced REM sleep latency, increased REM sleep time, elevated REM density) represents a well-replicated biological alteration in clinical depression (Riemann et al., 2001). This characteristic sleep architecture is regarded as being more than an epiphenomenon of depression that may contribute to the pathophysiology and/or reflect underlying neurobiological abnormalities (Palagini, Baglioni, Ciapparelli, Gemignani, \& Riemann, 2013). As a reduced genetic expression of the 5-HT transporter has been found to promote the occurrence of REM sleep in animal studies (Alexandre et al., 2006; Wisor et al., 2003), the 5-HTTLPR S-allele is very well-positioned to promote such REM sleep alterations. The study presented in Chapter 6 therefore investigated whether allelic variation in 5-HTTLPR influences REM sleep regulation in healthy volunteers. While allelic variation in 5-HTTLPR was not found to influence the features of REM sleep predominantly associated with depression vulnerability (i.e. REM sleep latency, REM density), results revealed a significantly lower REM sleep percentage in S-allele relative to L-allele carriers. Although these findings do not support a role for REM sleep in predisposing the risk for depression in healthy 5-HTTLPR S-allele carriers, a lower amount of REM sleep might precede REM sleep disinhibition and may support an elevated risk for insomnia in this allelic variant (Riemann et al., 2012).

To summarize, the results and literature presented in this dissertation suggest that sleep might be an important factor in the relationship between 5-HTTLPR and depression. Together, these findings indicate that variations in sleep quality could be an important mediating or moderating factor in this association. Conflicting findings however challenge the hypothesis that the influence of 5-HTTLPR on the risk for insomnia may explain the differential depression susceptibility associated with this allelic variation. The majority of previous investigations, however, provide substantial evidence for an elevated risk for insomnia in 5-HTTLPR S-allele relative to L-allele carriers and this is further supported by an elevated sensitivity to 5-HT manipulations as well as a reduced amount of REM sleep in this allelic variant. Although these findings support a mediating role for sleep impairment, findings on the combined influence of 5-HTTLPR and sleep on affective symptomatology and neuroendocrine stress sensitivity suggest a moderating role where inadequate sleep could either reinforce or confound the relationship between 5-HTTLPR and depression. In conclusion, regardless of the precise involvement, the relationships addressed in this thesis 
Summary

illustrate that incorporating sleep in future research may provide valuable opportunities to elucidate the genetic underpinnings of depression. 


\section{References}

Alexandre, C., Popa, D., Fabre, V., Bouali, S., Venault, P., Lesch, K. P., . . . Adrien, J. (2006). Early life blockade of 5-hydroxytryptamine 1A receptors normalizes sleep and depression-like behavior in adult knock-out mice lacking the serotonin transporter. The Journal of neuroscience : the official journal of the Society for Neuroscience, 26(20), 5554-5564. doi:10.1523/JNEUROSCI.5156-05.2006

Baglioni, C., Battagliese, G., Feige, B., Spiegelhalder, K., Nissen, C., Voderholzer, U., . . . Riemann, D. (2011). Insomnia as a predictor of depression: A meta-analytic evaluation of longitudinal epidemiological studies. Journal of Affective Disorders, 135(1-3), 10-19. doi:10.1016/j.jad.2011.01.011

Bleys, D., Luyten, P., Soenens, B., \& Claes, S. (2018). Gene-environment interactions between stress and 5-HTTLPR in depression: A meta-analytic update. Journal of Affective Disorders, 226, 339-345. doi:10.1016/j.jad.2017.09.050

Bouvette-Turcot, A. A., Pluess, M., Bernier, A., Pennestri, M. H., Levitan, R., Sokolowski, M. B., . . G Gaudreau, H. (2015). Effects of Genotype and Sleep on Temperament. Pediatrics, 136(4), e914-921. doi:10.1542/peds.2015-0080

Brummett, B. H., Krystal, A. D., Ashley-Koch, A., Kuhn, C. M., Zuchner, S., Siegler, I. C., . . . Williams, R. B. (2007). Sleep quality varies as a function of 5-HTTLPR genotype $\begin{array}{llll}\text { and stress. } & \text { Psychosomatic }\end{array}$ doi:10.1097/PSY.0b013e31814b8de6

Carskadon, M. A., Sharkey, K. M., Knopik, V. S., \& McGeary, J. E. (2012). Short Sleep as an Environmental Exposure: A Preliminary Study Associating 5-HTTLPR Genotype to Self-Reported Sleep Duration and Depressed Mood in First-Year University Students. Sleep, 35(6), 791-796. doi:10.5665/sleep.1876

Caspi, A., Sugden, K., Moffitt, T. E., Taylor, A., Craig, I. W., Harrington, H., . . Poulton, R. (2003). Influence of life stress on depression: moderation by a polymorphism in the 5HTT gene. Science, 301(5631), 386-389. doi:10.1126/science.1083968

Charney, D. S., Barlow, D. H., Botteron, K., Cohen, J. D., Goldman, D., Gur, R. E., . . . Zalcman, S. J. (2002). Neuroscience research agenda to guide development of a pathophysiologically based classification system. In A research agenda for DSM-V. (pp. 31-83). Arlington, VA, US: American Psychiatric Association.

Clarke, H., Flint, J., Attwood, A. S., \& Munafo, M. R. (2010). Association of the 5- HTTLPR genotype and unipolar depression: a meta-analysis. Psychological Medicine, 40(11), 1767-1778. doi:10.1017/s0033291710000516

Collier, D. A., Stober, G., Li, T., Heils, A., Catalano, M., Di Bella, D., . . . Lesch, K. P. (1996). A novel functional polymorphism within the promoter of the serotonin transporter gene: possible role in susceptibility to affective disorders. Molecular Psychiatry, 1(6), 453-460.

Collins, P. Y., Patel, V., Joestl, S. S., March, D., Insel, T. R., \& Daar, A. S. (2011). Grand challenges in global mental health: A consortium of researchers, advocates and clinicians announces here research priorities for improving the lives of people with mental illness around the world, and calls for urgent action and investment. Nature, 475(7354), 27-30. doi:10.1038/475027a

Culverhouse, R. C., Saccone, N. L., Horton, A. C., Ma, Y., Anstey, K. J., Banaschewski, T., . . . Bierut, L. J. (2018). Collaborative meta-analysis finds no evidence of a strong interaction between stress and 5-HTTLPR genotype contributing to the development of depression. Molecular Psychiatry, 23(1), 133-142. doi:10.1038/mp.2017.44

Davis, M., Thomassin, K., Bilms, J., Suveg, C., Shaffer, A., \& Beach, S. R. H. (2017). Preschoolers' genetic, physiological, and behavioral sensitivity factors moderate links 
between parenting stress and child internalizing, externalizing, and sleep problems. Developmental Psychobiology, 59(4), 473-485. doi:10.1002/dev.21510

Deuschle, M., Schredl, M., Schilling, C., Wust, S., Frank, J., Witt, S. H., . . Schulze, T. G. (2010). Association between a serotonin transporter length polymorphism and primary insomnia. Sleep, 33(3), 343-347.

Flint, J., \& Kendler, K. S. (2014). The Genetics of Major Depression. Neuron, 81(3), 484-503. doi:10.1016/j.neuron.2014.01.027

Hartmann, E., \& Greenwald, D. (1984). Tryptophan and human sleep: an analysis of 43 studies. In Progress in tryptophan and serotonin research (pp. 297-304). Berlin: Walter de Gruyter.

Hartmann, J. A., Wichers, M., van Bemmel, A. L., Derom, C., Thiery, E., Jacobs, N., . . . Simons, C. J. P. (2014). The serotonin transporter 5-HTTLPR polymorphism in the association between sleep quality and affect. European Neuropsychopharmacology, 24(7), 1086-1090. doi:10.1016/j.euroneuro.2014.01.015

Hasler, G. (2010). Pathophysiology of depression: do we have any solid evidence of interest to clinicians? World Psychiatry, 9(3), 155-161.

Heils, A., Teufel, A., Petri, S., Stober, G., Riederer, P., Bengel, D., \& Lesch, K. P. (1996). Allelic variation of human serotonin transporter gene expression. Journal of Neurochemistry, 66(6), 2621-2624.

Huang, C., Li, J., Lu, L., Ren, X., Li, Y., Huang, Q., . . . Wang, Y. (2014). Interaction between serotonin transporter gene-linked polymorphic region (5-HTTLPR) and jobrelated stress in insomnia: a cross-sectional study in Sichuan, China. Sleep Med, 15(10), 1269-1275. doi:10.1016/j.sleep.2014.01.023

Karg, K., Burmeister, M., Shedden, K., \& Sen, S. (2011). The serotonin transporter promoter variant (5-HTTLPR), stress, and depression meta-analysis revisited: evidence of genetic moderation. Archives of General Psychiatry, 68(5), 444-454. doi:10.1001/archgenpsychiatry.2010.189

Kendler, K. S., Aggen, S. H., \& Neale, M. C. (2013). Evidence for multiple genetic factors underlying DSM-IV criteria for major depression. JAMA Psychiatry, 70(6), 599-607. doi:10.1001/jamapsychiatry.2013.751

Kessler, R. C., Berglund, P., Demler, O., Jin, R., Koretz, D., Merikangas, K. R., . . Wang, P. S. (2003). The epidemiology of major depressive disorder: results from the National Comorbidity Survey Replication (NCS-R). JAMA, 289(23), 3095-3105. doi:10.1001/jama.289.23.3095

Lesch, K. P. (2004). Gene-environment interaction and the genetics of depression. Journal of Psychiatry and Neuroscience, 29(3), 174-184.

Lesch, K. P., Bengel, D., Heils, A., Sabol, S. Z., Greenberg, B. D., Petri, S., . . Murphy, D. L. (1996). Association of anxiety-related traits with a polymorphism in the serotonin transporter gene regulatory region. Science, 274(5292), 1527-1531.

Miller, R., Wankerl, M., Stalder, T., Kirschbaum, C., \& Alexander, N. (2013). The serotonin transporter gene-linked polymorphic region (5-HTTLPR) and cortisol stress reactivity: a meta-analysis. Molecular Psychiatry, 18(9), 1018-1024. doi:10.1038/mp.2012.124

Mueller, T. I., Leon, A. C., Keller, M. B., Solomon, D. A., Endicott, J., Coryell, W., . . . Maser, J. D. (1999). Recurrence after recovery from major depressive disorder during 15 years of observational follow-up. American Journal of Psychiatry, 156(7), 10001006. doi:10.1176/ajp.156.7.1000

Munafò, M. R., Durrant, C., Lewis, G., \& Flint, J. (2009). Gene $\times$ Environment Interactions at the Serotonin Transporter Locus. Biological Psychiatry, 65(3), 211-219. doi:10.1016/j.biopsych.2008.06.009 
Murphy, D. L., \& Lesch, K. P. (2008). Targeting the murine serotonin transporter: insights into human neurobiology. Nat Rev Neurosci, 9(2), 85-96. doi:10.1038/nrn2284

Palagini, L., Baglioni, C., Ciapparelli, A., Gemignani, A., \& Riemann, D. (2013). REM sleep dysregulation in depression: state of the art. Sleep Med Rev, 17(5), 377-390. doi:10.1016/j.smrv.2012.11.001

Polito, L., Davin, A., Vaccaro, R., Abbondanza, S., Govoni, S., Racchi, M., \& Guaita, A. (2015). Serotonin transporter polymorphism modifies the association between depressive symptoms and sleep onset latency complaint in elderly people: results from the 'InveCe.Ab' study. Journal of Sleep Research, 24(2), 215-222. doi:10.1111/jsr.12248

Riemann, D., Berger, M., \& Voderholzer, U. (2001). Sleep and depression - results from psychobiological studies: an overview. Biological Psychology, 57(1-3), 67-103. doi:10.1016/S0301-0511(01)00090-4

Riemann, D., Spiegelhalder, K., Nissen, C., Hirscher, V., Baglioni, C., \& Feige, B. (2012). REM sleep instability--a new pathway for insomnia? Pharmacopsychiatry, 45(5), 167176. doi:10.1055/s-0031-1299721

Ripke, S., Wray, N. R., Lewis, C. M., Hamilton, S. P., Weissman, M. M., Breen, G., . . . Sullivan, P. F. (2013). A mega-analysis of genome-wide association studies for major depressive disorder. Molecular Psychiatry, 18(4), 497-511. doi:10.1038/mp.2012.21

Risch, N., Herrell, R., Lehner, T., \& et al. (2009). Interaction between the serotonin transporter gene (5-httlpr), stressful life events, and risk of depression: A metaanalysis. JAMA, 301(23), 2462-2471. doi:10.1001/jama.2009.878

Schneider-Helmert, D., \& Spinweber, C. L. (1986). Evaluation of L-tryptophan for treatment of insomnia: a review. Psychopharmacology, 89(1), 1-7.

Silber, B. Y., \& Schmitt, J. A. (2010). Effects of tryptophan loading on human cognition, mood, and sleep. Neuroscience and Biobehavioral Reviews, 34(3), 387-407. doi:10.1016/j.neubiorev.2009.08.005

Sullivan, P. F., Neale, M. C., \& Kendler, K. S. (2000). Genetic epidemiology of major depression: review and meta-analysis. American Journal of Psychiatry, 157(10), 15521562. doi:10.1176/appi.ajp.157.10.1552

Tamminga, C. A., Nemeroff, C. B., Blakely, R. D., Brady, L., Carter, C. S., Davis, K. L., . . . Suppes, T. (2002). Developing novel treatments for mood disorders: accelerating discovery. Biological Psychiatry, 52(6), 589-609. doi:10.1016/S0006-3223(02)014701

van Roekel, E., Hartmann, J. A., Wichers, M., \& Verhagen, M. (2016). The 5-HTTLPR genotype moderates the association between sleep quality and positive affect: A replication study. European Neuropsychopharmacology, 26(8), 1350-1351. doi:10.1016/j.euroneuro.2016.06.001

Varnas, K., Halldin, C., \& Hall, H. (2004). Autoradiographic distribution of serotonin transporters and receptor subtypes in human brain. Human Brain Mapping, 22(3), 246-260. doi:10.1002/hbm.20035

Vos, T., Flaxman, A. D., Naghavi, M., Lozano, R., Michaud, C., Ezzati, M., . . . Memish, Z. A. (2012). Years lived with disability (YLDs) for 1160 sequelae of 289 diseases and injuries 1990-2010: a systematic analysis for the Global Burden of Disease Study 2010. Lancet, 380(9859), 2163-2196. doi:10.1016/s0140-6736(12)61729-2

Way, B. M., \& Taylor, S. E. (2010). The serotonin transporter promoter polymorphism is associated with cortisol response to psychosocial stress. Biological Psychiatry, 67(5), 487-492. doi:10.1016/j.biopsych.2009.10.021 
Wisor, J. P., Wurts, S. W., Hall, F. S., Lesch, K. P., Murphy, D. L., Uhl, G. R., \& Edgar, D. M. (2003). Altered rapid eye movement sleep timing in serotonin transporter knockout mice. Neuroreport, 14(2), 233-238. doi:10.1097/01.wnr.0000054963.21656.bf

Wray, N. R., Pergadia, M. L., Blackwood, D. H., Penninx, B. W., Gordon, S. D., Nyholt, D. R., . . . Sullivan, P. F. (2012). Genome-wide association study of major depressive disorder: new results, meta-analysis, and lessons learned. Molecular Psychiatry, 17(1), 36-48. doi:10.1038/mp.2010.109 
Samenvatting 
Depressie is een van de meest voorkomende psychiatrische aandoeningen. Naar schatting lijdt $5 \%$ van de wereldbevolking aan deze stemmingsstoornis en ontwikkelt ongeveer $15 \%$ tijdens zijn of haar leven een depressieve episode (Kessler et al., 2003). Deze hoge prevalentie heeft er samen met de grote impact op kwaliteit van leven voor gezorgd dat depressie momenteel geclassificeerd wordt als een van de hoofdoorzaken van wereldwijd onwel-bevinden (Vos et al., 2012). Dit benadrukt het belang om inzicht te krijgen in de pathofysiologische mechanismen van deze heterogene (Kendler, Aggen, \& Neale, 2013) en frequent terugkerende aandoening (Mueller et al., 1999).

Het onthullen van de genetische architectuur van depressie wordt gezien als een van de grootste uitdagingen voor onderzoek in de psychopathologie (Collins et al., 2011). Ondanks een overerfbaarheid van 31\%-42\% (Sullivan, Neale, \& Kendler, 2000) heeft onderzoek geen repliceerbare genetische variaties kunnen relateren aan klinische depressie (Flint \& Kendler, 2014; Ripke et al., 2013). Recente depressietheorieën stellen dat genetische invloeden afhankelijk kunnen zijn van omgevingsfactoren (i.e. gen-omgevinginteractie) en dit zou mogelijk het beperkte succes van genetisch associatieonderzoek kunnen verklaren (Lesch, 2004). Hoewel deze benadering conceptueel aantrekkelijk is hebben onderzochte genomgevinginteracties slechts in beperkte mate inzicht gegeven in genetische risicofactoren voor depressie (Wray et al., 2012).

Sinds langere tijd wordt verondersteld dat een verminderd functioneren van het serotonine (5-hydroxytriptamine; 5-HT) systeem een belangrijke rol speelt in de pathofysiologie van depressie (Hasler, 2010) en dit vormt dan ook een belangrijke richting voor genetisch onderzoek. De 5-HT transporter verzorgt de presynaptische heropname van 5HT en is daarom een cruciale regulator van 5-HT functioneren waaronder de sterkte en duur van 5-HT neurotransmissie (Lesch, 2004). De 5-HT transporter is sterk aanwezig in corticaleen limbische structuren die betrokken zijn bij emotionele processen (Varnas, Halldin, \& Hall, 2004) en omvat een van de belangrijkste aangrijpingspunten van effectieve en frequent voorgeschreven antidepressiva (Tamminga et al., 2002) wat de specifieke betrokkenheid van de 5-HT transporter bij depressie ondersteunt. In 1996, rapporteerden Heils et al. een functioneel polymorfisme dat de transcriptie van het serotonine transporter gen (SLC6A4) reguleert. Dit 5-HT transporter gen-gelinkte polymorfisme (5-HTTLPR) omvat een allelische variatie waarvan het korte $(\mathrm{S})$ allel geassocieerd is met een verminderde mRNA expressie vergeleken met het lange (L) allel (Collier et al., 1996). Er wordt verondersteld dat de hieraan gerelateerde vermindering van 5-HT transporters en 5-HT heropname (Murphy \& Lesch, 
2008) zou kunnen leiden tot een verhoogde vatbaarheid voor depressie in deze allelische variant.

De initiële resultaten van onderzoek naar de betrokkenheid van 5-HTTLPR in de ontwikkeling van depressie waren veelbelovend. In navolging van een eerste rapport dat een directe relatie beschreef (Collier et al., 1996), werd onderzoek naar deze genetische variatie voornamelijk gestimuleerd door een prospectieve longitudinale studie die aantoonde dat de associatie tussen stressvolle gebeurtenissen en depressie sterker was in individuen met één of twee kopieën van het 5-HTTLPR S-allel (Caspi et al., 2003). De aanzienlijke hoeveelheid studies die deze resultaten getracht hebben te repliceren hebben echter tot grote controversie geleid. Beschikbare meta-analysen voeden momenteel een voortgaande discussie of allelische variatie in 5-HTTLPR daadwerkelijk bijdraagt aan het risico op (stress-gerelateerde) depressie (Bleys, Luyten, Soenens, \& Claes, 2018; Clarke, Flint, Attwood, \& Munafo, 2010; Culverhouse et al., 2018; Karg, Burmeister, Shedden, \& Sen, 2011; Munafò, Durrant, Lewis, \& Flint, 2009; Risch, Herrell, Lehner, \& et al., 2009).

De inconsistente bevindingen in dit onderzoeksveld zijn vermoedelijk toe te schrijven aan de heterogeniteit van depressie. Depressie wordt namelijk niet gezien als een homogene aandoening maar als een gezamenlijke uitkomst van verschillende pathofysiologische mechanismen (Charney et al., 2002). Hieraan gerelateerd wordt verondersteld dat het effect van 5-HTTLPR op het risico voor (stress-gerelateerde) depressie niet breed gegeneraliseerd kan worden en waarschijnlijk alleen tot uiting komt in specifieke omstandigheden (Culverhouse et al., 2018). Het belichten van dergelijke omstandigheden zou daarom het huidige begrip van deze relatie aanzienlijk kunnen vergroten. Aangemoedigd door de intieme relatie tussen slaap en depressie (Riemann, Berger, \& Voderholzer, 2001) tracht de huidige these inzicht te geven in de mogelijk centrale rol van slaap in de associatie tussen 5-HTTLPR en depressie.

Onderzoek laat overtuigend zien dat slaapproblematiek onafhankelijk bijdraagt aan het ontstaan van depressie. Een recente meta-analyse heeft aangetoond dat insomnie (i.e. chronische slapeloosheid) leidt tot een twee keer zo grote kans op depressie in depressie-vrije individuen (Baglioni et al., 2011). Een veronderstelde vatbaarheid voor insomnie in dragers van het 5-HTTLPR S-allel (Deuschle et al., 2010; Huang et al., 2014) zou daarom een veel belovend mechanisme kunnen zijn dat het verhoogde depressierisico in deze allelische variant zou kunnen verklaren. De relevantie van slaapproblematiek in de relatie tussen 5-HTTLPR en depressie wordt verder ondersteund door de consistente bevinding dat het 5-HTTLPR S-allel de gevoeligheid voor slaap-gerelateerde affectieve symptomen verhoogd (Bouvette-Turcot et 
al., 2015; M. A. Carskadon \& Rechtschaffen, 2005; J. A. Hartmann et al., 2014; van Roekel, Hartmann, Wichers, \& Verhagen, 2016).

Onderzoek naar de betrokkenheid van specifieke kandidaat genen wordt over het algemeen gekenmerkt door inconsistente bevindingen (Flint \& Kendler, 2014). Replicatieonderzoek is daarom essentieel en de studie beschreven in Hoofdstuk 1 was dan ook specifiek ontworpen om gerapporteerde relaties tussen 5-HTTLPR en insomnie te repliceren. In tegenstelling tot eerder onderzoek (Deuschle et al., 2010; Huang et al., 2014) werden geen significante relaties tussen 5-HTTLPR en (stress-gerelateerde) insomnie gevonden. Waar de resultaten beschreven in Hoofdstuk 2 een interactie tussen 5-HTTLPR en stress op subjectieve slaapkwaliteit ook niet lijken te ondersteunen (Brummett et al., 2007), leveren de bevindingen in Hoofdstuk 3 wel enig bewijs voor een verminderde slaapkwaliteit in dragers van het 5-HTTLPR S-allel vergeleken met het L-allel. Hoewel deze tegenstrijdige bevindingen de relevantie van insomnie in de relatie tussen 5-HTTLPR en depressie in twijfel trekken, blijft een meerderheid van de beschikbare studies deze mogelijke betrokkenheid ondersteunen (Brummett et al., 2007; Davis et al., 2017; Deuschle et al., 2010; Huang et al., 2014; Polito et al., 2015).

De studies beschreven in Hoofdstuk 2 en $\mathbf{3}$ gaan verder in op het mogelijke verschil in de vatbaarheid voor slaapproblematiek tussen dragers van het S-allel en L-allel door te onderzoeken of 5-HTTLPR invloed heeft op de slaap-bevorderende effecten van de 5-HT precursor tryptofaan (E. Hartmann \& Greenwald, 1984; Schneider-Helmert \& Spinweber, 1986; Silber \& Schmitt, 2010). De resultaten van dit onderzoek tonen aan dat tryptofaan suppletie voornamelijk leidt tot een verbetering van slaapkwaliteit in dragers van het S-allel vergeleken met het L-allel. Deze bevindingen ondersteunen hiermee de vermeende 5-HT gevoeligheid voor slaapproblematiek in deze allelische variant (Brummett et al., 2007; Davis et al., 2017; Deuschle et al., 2010; Huang et al., 2014; Polito et al., 2015) en laten zien dat tryptofaansuppletie een waardevolle behandelingsstrategie zou kunnen zijn om te compenseren voor deze vatbaarheid. Aangezien het 5-HTTLPR S-allel geassocieerd wordt met een verhoogde vatbaarheid voor slaap-gerelateerde affectieve veranderingen (BouvetteTurcot et al., 2015; Mary A. Carskadon, Sharkey, Knopik, \& McGeary, 2012; J. A. Hartmann et al., 2014; van Roekel et al., 2016), zouden de slaap-bevorderende eigenschappen van tryptofaan mogelijk gelijktijdig de verhoogde depressiegevoeligheid in deze allelische variant kunnen verminderen.

Een verhoogde stressreactiviteit van de hypothalamus-hypofyse-bijnier (HPA) as wordt gezien als een van de belangrijkste mechanismen dat de vatbaarheid voor depressie in 
dragers van het 5-HTTLPR S-allel zou kunnen verklaren (Way \& Taylor, 2010). Hoewel een recente meta-analyse bevestigt dat het S-allel geassocieerd is met een verhoogde cortisol stressrespons ten opzichte van het L-allel (Miller, Wankerl, Stalder, Kirschbaum, \& Alexander, 2013), is er momenteel weinig duidelijkheid over de oorzaak van tegenstrijdige bevindingen. De systematische review geïncludeerd in Hoofdstuk 4 laat zien dat een verminderde slaapkwaliteit de stressgevoeligheid van de HPA as kan verhogen. Dit veronderstelt dat slaap mogelijk een belangrijke factor zou kunnen zijn in deze relatie. In overeenstemming met deze veronderstelling levert de studie beschreven in Hoofdstuk 5 preliminair bewijs dat verschillen in slaapkwaliteit de relatie tussen 5-HTTLPR en de stress reactiviteit van de HPA as kunnen beïnvloeden. Deze resultaten laten zien dat een hogere cortisol stressrespons in dragers met een S-allel ten opzichte van een L-allel geleidelijk kan verdwijnen wanneer slaapkwaliteit vermindert omdat dit alleen in individuen met het L-allel de stressreactiviteit verhoogt. Bij elkaar genomen illustreren de resultaten beschreven in deze artikelen dat een verhoogde stressgevoeligheid van de HPA as een mogelijk mechanisme zou kunnen zijn dat de relatie tussen slaapproblematiek en het ontstaan van depressie zou kunnen verklaren. Hoewel de huidige resultaten bevestigen dat een verhoogde stressreactiviteit van de HPA as inderdaad bij zou kunnen dragen aan een verhoogd depressierisico in dragers met een S-allel ten opzichte van een L-allel, kunnen variaties in slaapkwaliteit deze relatie aanzienlijk verstoren.

Een disinhibitie van 'rapid eye movement' (REM) slaap (i.e. verkorte REM slaaplatentie, toename in hoeveelheid REM slaap, verhoogde REM dichtheid) omvat een goed-gerepliceerde bevinding in klinische depressie (Riemann et al., 2001). Deze karakteristieke slaaparchitectuur is meer dan een epi-fenomeen van depressie welke mogelijk bijdraagt aan de pathofysiologie van depressie en/of onderliggende neurobiologische abnormaliteiten reflecteert (Palagini, Baglioni, Ciapparelli, Gemignani, \& Riemann, 2013). Dieronderzoek laat zien dat een verminderde expressie van de 5-HT transporter de hoeveelheid REM slaap aanzienlijk kan verhogen (Alexandre et al., 2006; Wisor et al., 2003). Het 5-HTTLPR S-allel is daarom goed gepositioneerd om dergelijke REM slaapveranderingen te induceren. De studie gepresenteerd in Hoofdstuk 6 onderzocht daarom of allelische variatie in 5-HTTLPR invloed heeft op REM slaapregulatie in gezonde proefpersonen. Hoewel de resultaten van deze studie laten zien dat het 5-HTTLPR genotype geen invloed heeft op de aspecten van REM slaap die voornamelijk geassocieerd worden met depressie (i.e. REM slaaplatentie, REM dichtheid), was het percentage REM slaap significant lager in dragers met een $\mathrm{S}$-allel vergeleken met L-allel. Ondanks dat deze bevindingen geen 
ondersteuning bieden voor een rol voor REM slaap in de verhoogde vatbaarheid voor depressie in gezonde individuen met een S-allel, zou een lagere hoeveelheid REM slaap vooraf kunnen gaan aan REM slaap disinhibitie en mogelijk een verhoogd risico voor insomnie in deze allelische variant kunnen ondersteunen (Riemann et al., 2012).

Resumerend, de resultaten en literatuur beschreven in deze dissertatie veronderstellen dat slaap een belangrijke factor zou kunnen zijn in de relatie tussen 5-HTTLPR en depressie. Bij elkaar genomen illustreren deze bevindingen dat variaties in slaapkwaliteit een belangrijke moderator of mediator zou kunnen zijn in deze associatie. Tegenstrijdige bevindingen plaatsen echter vraagtekens bij de veronderstelling dat de invloed van 5-HTTLPR op het risico voor slaapproblematiek 5-HTTLPR gerelateerde verschillen in depressiegevoeligheid zou kunnen verklaren. Toch geeft de meerderheid van beschikbare studies aan dat het 5HTTLPR S-allel geassocieerd is met een hoger risico op insomnie vergeleken met het L-allel. Dit wordt verder ondersteund door een verhoogde gevoeligheid voor 5-HT manipulaties en een lagere hoeveelheid REM slaap in deze allelische variant. Hoewel deze bevindingen een mediërende rol voor slaapproblematiek ondersteunen, veronderstellen resultaten over de gecombineerde invloed van 5-HTTLPR en slaap op affectieve symptomen en hormonale stressreactiviteit een modererende rol waar slaapinsufficiënties de relatie tussen 5-HTTLPR en depressie zowel kunnen versterken als verminderen. Concluderend, ongeacht de precieze betrokkenheid geven de relaties beschreven in dit proefschrift aan dat het includeren van slaap in toekomstig onderzoek waardevolle mogelijkheden kan bieden om inzicht te krijgen in de genetische achtergrond van depressie. 


\section{Referenties}

Alexandre, C., Popa, D., Fabre, V., Bouali, S., Venault, P., Lesch, K. P., . . A Adrien, J. (2006). Early life blockade of 5-hydroxytryptamine 1A receptors normalizes sleep and depression-like behavior in adult knock-out mice lacking the serotonin transporter. The Journal of neuroscience : the official journal of the Society for Neuroscience, 26(20), 5554-5564. doi:10.1523/JNEUROSCI.5156-05.2006

Baglioni, C., Battagliese, G., Feige, B., Spiegelhalder, K., Nissen, C., Voderholzer, U., . . . Riemann, D. (2011). Insomnia as a predictor of depression: A meta-analytic evaluation of longitudinal epidemiological studies. Journal of Affective Disorders, 135(1-3), 10-19. doi:10.1016/j.jad.2011.01.011

Bleys, D., Luyten, P., Soenens, B., \& Claes, S. (2018). Gene-environment interactions between stress and 5-HTTLPR in depression: A meta-analytic update. Journal of Affective Disorders, 226, 339-345. doi:10.1016/j.jad.2017.09.050

Bouvette-Turcot, A. A., Pluess, M., Bernier, A., Pennestri, M. H., Levitan, R., Sokolowski, M. B., . . G Gaudreau, H. (2015). Effects of Genotype and Sleep on Temperament. Pediatrics, 136(4), e914-921. doi:10.1542/peds.2015-0080

Brummett, B. H., Krystal, A. D., Ashley-Koch, A., Kuhn, C. M., Zuchner, S., Siegler, I. C., . . . Williams, R. B. (2007). Sleep quality varies as a function of 5-HTTLPR genotype and stress. Psychosomatic Medicine, 69(7), 621-624. doi:10.1097/PSY.0b013e31814b8de6

Carskadon, M. A., \& Rechtschaffen, A. (2005). Monitoring and Staging Human Sleep. In M. H. Kryger, T. Roth, \& W. C. Dement (Eds.), Principles and Practices of Sleep Medicine (4th ed., pp. 1359-1377). Philadelphia, PA: Elsevier Saunders.

Carskadon, M. A., Sharkey, K. M., Knopik, V. S., \& McGeary, J. E. (2012). Short Sleep as an Environmental Exposure: A Preliminary Study Associating 5-HTTLPR Genotype to Self-Reported Sleep Duration and Depressed Mood in First-Year University Students. Sleep, 35(6), 791-796. doi:10.5665/sleep.1876

Caspi, A., Sugden, K., Moffitt, T. E., Taylor, A., Craig, I. W., Harrington, H., . . Poulton, R. (2003). Influence of life stress on depression: moderation by a polymorphism in the 5HTT gene. Science, 301(5631), 386-389. doi:10.1126/science.1083968

Charney, D. S., Barlow, D. H., Botteron, K., Cohen, J. D., Goldman, D., Gur, R. E., . . . Zalcman, S. J. (2002). Neuroscience research agenda to guide development of a pathophysiologically based classification system. In A research agenda for DSM-V. (pp. 31-83). Arlington, VA, US: American Psychiatric Association.

Clarke, H., Flint, J., Attwood, A. S., \& Munafo, M. R. (2010). Association of the 5- HTTLPR genotype and unipolar depression: a meta-analysis. Psychological Medicine, 40(11), 1767-1778. doi:10.1017/s0033291710000516

Collier, D. A., Stober, G., Li, T., Heils, A., Catalano, M., Di Bella, D., . . . Lesch, K. P. (1996). A novel functional polymorphism within the promoter of the serotonin transporter gene: possible role in susceptibility to affective disorders. Molecular Psychiatry, 1(6), 453-460.

Collins, P. Y., Patel, V., Joestl, S. S., March, D., Insel, T. R., \& Daar, A. S. (2011). Grand challenges in global mental health: A consortium of researchers, advocates and clinicians announces here research priorities for improving the lives of people with mental illness around the world, and calls for urgent action and investment. Nature, 475(7354), 27-30. doi:10.1038/475027a

Culverhouse, R. C., Saccone, N. L., Horton, A. C., Ma, Y., Anstey, K. J., Banaschewski, T., . . . Bierut, L. J. (2018). Collaborative meta-analysis finds no evidence of a strong 
interaction between stress and 5-HTTLPR genotype contributing to the development of depression. Molecular Psychiatry, 23(1), 133-142. doi:10.1038/mp.2017.44

Davis, M., Thomassin, K., Bilms, J., Suveg, C., Shaffer, A., \& Beach, S. R. H. (2017). Preschoolers' genetic, physiological, and behavioral sensitivity factors moderate links between parenting stress and child internalizing, externalizing, and sleep problems. Developmental Psychobiology, 59(4), 473-485. doi:10.1002/dev.21510

Deuschle, M., Schredl, M., Schilling, C., Wust, S., Frank, J., Witt, S. H., . . Schulze, T. G. (2010). Association between a serotonin transporter length polymorphism and primary insomnia. Sleep, 33(3), 343-347.

Flint, J., \& Kendler, K. S. (2014). The Genetics of Major Depression. Neuron, 81(3), 484-503. doi:10.1016/j.neuron.2014.01.027

Hartmann, E., \& Greenwald, D. (1984). Tryptophan and human sleep: an analysis of 43 studies. In Progress in tryptophan and serotonin research (pp. 297-304). Berlin: Walter de Gruyter.

Hartmann, J. A., Wichers, M., van Bemmel, A. L., Derom, C., Thiery, E., Jacobs, N., . . . Simons, C. J. P. (2014). The serotonin transporter 5-HTTLPR polymorphism in the association between sleep quality and affect. European Neuropsychopharmacology, 24(7), 1086-1090. doi:10.1016/j.euroneuro.2014.01.015

Hasler, G. (2010). Pathophysiology of depression: do we have any solid evidence of interest to clinicians? World Psychiatry, 9(3), 155-161.

Huang, C., Li, J., Lu, L., Ren, X., Li, Y., Huang, Q., . . . Wang, Y. (2014). Interaction between serotonin transporter gene-linked polymorphic region (5-HTTLPR) and jobrelated stress in insomnia: a cross-sectional study in Sichuan, China. Sleep Med, 15(10), 1269-1275. doi:10.1016/j.sleep.2014.01.023

Karg, K., Burmeister, M., Shedden, K., \& Sen, S. (2011). The serotonin transporter promoter variant (5-HTTLPR), stress, and depression meta-analysis revisited: evidence of genetic moderation. Archives of General Psychiatry, 68(5), 444-454. doi:10.1001/archgenpsychiatry.2010.189

Kendler, K. S., Aggen, S. H., \& Neale, M. C. (2013). Evidence for multiple genetic factors underlying DSM-IV criteria for major depression. JAMA Psychiatry, 70(6), 599-607. doi:10.1001/jamapsychiatry.2013.751

Kessler, R. C., Berglund, P., Demler, O., Jin, R., Koretz, D., Merikangas, K. R., . . Wang, P. S. (2003). The epidemiology of major depressive disorder: results from the National Comorbidity Survey Replication (NCS-R). JAMA, 289(23), 3095-3105. doi:10.1001/jama.289.23.3095

Lesch, K. P. (2004). Gene-environment interaction and the genetics of depression. Journal of Psychiatry and Neuroscience, 29(3), 174-184.

Miller, R., Wankerl, M., Stalder, T., Kirschbaum, C., \& Alexander, N. (2013). The serotonin transporter gene-linked polymorphic region (5-HTTLPR) and cortisol stress reactivity: a meta-analysis. Molecular Psychiatry, 18(9), 1018-1024. doi:10.1038/mp.2012.124

Mueller, T. I., Leon, A. C., Keller, M. B., Solomon, D. A., Endicott, J., Coryell, W., . . . Maser, J. D. (1999). Recurrence after recovery from major depressive disorder during 15 years of observational follow-up. American Journal of Psychiatry, 156(7), 10001006. doi:10.1176/ajp.156.7.1000

Munafò, M. R., Durrant, C., Lewis, G., \& Flint, J. (2009). Gene $\times$ Environment Interactions at the Serotonin Transporter Locus. Biological Psychiatry, 65(3), 211-219. doi:10.1016/j.biopsych.2008.06.009

Murphy, D. L., \& Lesch, K. P. (2008). Targeting the murine serotonin transporter: insights into human neurobiology. Nat Rev Neurosci, 9(2), 85-96. doi:10.1038/nrn2284 
Palagini, L., Baglioni, C., Ciapparelli, A., Gemignani, A., \& Riemann, D. (2013). REM sleep dysregulation in depression: state of the art. Sleep Med Rev, 17(5), 377-390. doi:10.1016/j.smrv.2012.11.001

Polito, L., Davin, A., Vaccaro, R., Abbondanza, S., Govoni, S., Racchi, M., \& Guaita, A. (2015). Serotonin transporter polymorphism modifies the association between depressive symptoms and sleep onset latency complaint in elderly people: results from the 'InveCe.Ab' study. Journal of Sleep Research, 24(2), 215-222. doi:10.1111/jsr.12248

Riemann, D., Berger, M., \& Voderholzer, U. (2001). Sleep and depression - results from psychobiological studies: an overview. Biological Psychology, 57(1-3), 67-103. doi:10.1016/S0301-0511(01)00090-4

Riemann, D., Spiegelhalder, K., Nissen, C., Hirscher, V., Baglioni, C., \& Feige, B. (2012). REM sleep instability--a new pathway for insomnia? Pharmacopsychiatry, 45(5), 167 176. doi:10.1055/s-0031-1299721

Ripke, S., Wray, N. R., Lewis, C. M., Hamilton, S. P., Weissman, M. M., Breen, G., . . . Sullivan, P. F. (2013). A mega-analysis of genome-wide association studies for major depressive disorder. Molecular Psychiatry, 18(4), 497-511. doi:10.1038/mp.2012.21

Risch, N., Herrell, R., Lehner, T., \& et al. (2009). Interaction between the serotonin transporter gene (5-httlpr), stressful life events, and risk of depression: A metaanalysis. JAMA, 301(23), 2462-2471. doi:10.1001/jama.2009.878

Schneider-Helmert, D., \& Spinweber, C. L. (1986). Evaluation of L-tryptophan for treatment of insomnia: a review. Psychopharmacology, 89(1), 1-7.

Silber, B. Y., \& Schmitt, J. A. (2010). Effects of tryptophan loading on human cognition, mood, and sleep. Neuroscience and Biobehavioral Reviews, 34(3), 387-407. doi:10.1016/j.neubiorev.2009.08.005

Sullivan, P. F., Neale, M. C., \& Kendler, K. S. (2000). Genetic epidemiology of major depression: review and meta-analysis. American Journal of Psychiatry, 157(10), 15521562. doi:10.1176/appi.ajp.157.10.1552

Tamminga, C. A., Nemeroff, C. B., Blakely, R. D., Brady, L., Carter, C. S., Davis, K. L., . . . Suppes, T. (2002). Developing novel treatments for mood disorders: accelerating discovery. Biological Psychiatry, 52(6), 589-609. doi:10.1016/S0006-3223(02)014701

van Roekel, E., Hartmann, J. A., Wichers, M., \& Verhagen, M. (2016). The 5-HTTLPR genotype moderates the association between sleep quality and positive affect: A replication study. European Neuropsychopharmacology, 26(8), 1350-1351. doi:10.1016/j.euroneuro.2016.06.001

Varnas, K., Halldin, C., \& Hall, H. (2004). Autoradiographic distribution of serotonin transporters and receptor subtypes in human brain. Human Brain Mapping, 22(3), 246-260. doi:10.1002/hbm.20035

Vos, T., Flaxman, A. D., Naghavi, M., Lozano, R., Michaud, C., Ezzati, M., . . . Memish, Z. A. (2012). Years lived with disability (YLDs) for 1160 sequelae of 289 diseases and injuries 1990-2010: a systematic analysis for the Global Burden of Disease Study 2010. Lancet, 380(9859), 2163-2196. doi:10.1016/s0140-6736(12)61729-2

Way, B. M., \& Taylor, S. E. (2010). The serotonin transporter promoter polymorphism is associated with cortisol response to psychosocial stress. Biological Psychiatry, 67(5), 487-492. doi:10.1016/j.biopsych.2009.10.021

Wisor, J. P., Wurts, S. W., Hall, F. S., Lesch, K. P., Murphy, D. L., Uhl, G. R., \& Edgar, D. M. (2003). Altered rapid eye movement sleep timing in serotonin transporter knockout mice. Neuroreport, 14(2), 233-238. doi:10.1097/01.wnr.0000054963.21656.bf 
Wray, N. R., Pergadia, M. L., Blackwood, D. H., Penninx, B. W., Gordon, S. D., Nyholt, D. R., . . . Sullivan, P. F. (2012). Genome-wide association study of major depressive disorder: new results, meta-analysis, and lessons learned. Molecular Psychiatry, 17(1), 36-48. doi:10.1038/mp.2010.109 
Valorization addendum 


\section{Introduction}

Major depression is one of the most prevalent psychiatric disorders. In the Netherlands, approximately $5 \%$ of the general population is affected by this disabling condition and around 19\% develops a depressive episode at some point during their lifetime (Nuijen et al., 2017). These prevalence rates correspond with international estimates including a 12-month prevalence of $3-6 \%$ and a lifetime prevalence of $4-10 \%$ (Kessler et al., 2009). Depression is characterized by persistent sadness and anhedonia (American Psychiatric Association, 2013; World Health Organization, 2016) and thereby severely impacts the quality of life of those affected. The classification of depression as one of the primary causes of disability worldwide (Vos et al., 2012) coincides with a broader societal impact. In a given year, the 550.000 individuals diagnosed with depression in the Netherlands comprise around 1.6 billion of the total healthcare costs and an approximate 1.8 billion of expenses related to leave of absence (Nuijen et al., 2017). This poses an important challenge for mental health care and emphasizes the need to develop adequate treatment and prevention strategies.

Contemporary treatments for depression comprise both psychological- and pharmacological interventions. Psychological interventions, including cognitive-behavioral therapy (Cuijpers, Cristea, Karyotaki, Reijnders, \& Huibers, 2016) and interpersonal psychotherapy (Cuijpers, Donker, Weissman, Ravitz, \& Cristea, 2016), are successful strategies to alleviate depression. Pharmacological treatments are equally effective (Robinson, Berman, \& Neimeyer, 1990). A recent meta-analysis of 522 published and unpublished randomized controlled trials demonstrated that all of the 21 included antidepressants were more efficacious relative to placebo (Cipriani et al., 2018). Despite a proven average efficacy, clinical studies report that not even half of the patients respond to the initial antidepressant prescribed. The sequential administration of multiple different antidepressants is therefore frequently needed to achieve remission, which is accomplished in around $67 \%$ of the patients (Rush et al., 2006). Together with the limited knowledge on the precise mechanisms of action of antidepressant drugs (Harmer, Duman, \& Cowen, 2017), these findings emphasize the importance to gain insight into the pathophysiology of depression.

The identification of genetic risk factors is thought to particularly advance the neurobiological understanding of depression (Levinson, 2006). Heritability studies demonstrate that genetic factors account for $30-40 \%$ of the variance in depression vulnerability (Sullivan, Neale, \& Kendler, 2000) whereas the remaining 60-70\% is explained by environmental influences and gene-environment interactions. Despite this clear genetic 
contribution, research aimed to uncover the genetic architecture of depression has been largely unsuccessful. Research failed to identify any replicable gene or gene-environment interaction that predisposes the risk for depression (Flint \& Kendler, 2014).

The limited success of genetic studies presumably relates to the heterogeneity of depression. Hence, depression is a complex condition that is characterized by profound interindividual differences in etiological background and clinical expression (Hasler, 2010). This is illustrated by the diverse range of neurobiological mechanisms implicated in the pathophysiology of depression (Hasler, 2010) and the clusters of symptoms that define a depression diagnosis according to current criteria (American Psychiatric Association, 2013; World Health Organization, 2016). These observations indicate that depression does not necessarily comprise a homogenous disorder but rather reflects a final common pathway of different pathophysiological mechanisms (Charney et al., 2002). In order to elucidate more consistent risk factors for depression, it may therefore be more valuable to focus on more homogenous subgroups of depressed patients who share common etiology or phenotypic expression instead of investigating depression as a unitary construct.

Sleep impairment comprises an important pathway in the etiology of depression. Besides representing one of the core symptoms of clinical depression (American Psychiatric Association, 2013; World Health Organization, 2016), it has been well-established that inadequate sleep independently contributes to the development of depression. A recent metaanalyses demonstrated that insomnia confers a two-fold risk increase in non-depressed individuals, thereby classifying sleep as one of the primary risk factors for depression (Baglioni et al., 2011). These findings coincide with a large body of research demonstrating that inadequate sleep results in a diverse range of alterations that resemble characteristic features of clinical depression. Encouraged by this intimate relationship, the findings presented in the following sections illustrate how sleep could advance the current understanding of depression. In line with the work presented in this dissertation, a specific emphasis is placed on the identification of genetic risk factors, pathophysiological mechanisms and treatment strategies. This valorization addendum concludes with a brief description of how the included studies utilize this conceptual framework. 


\section{The relevance of sleep in depression research}

\section{Genetic risk factors}

Despite a clear heritability of depression (Sullivan et al., 2000), recent meta-analyses of genome-wide association data including up to 9.000 patients failed to identify replicable genetic variants related to major depressive disorder (Ripke et al., 2013; Wray et al., 2012). This limited success corresponds with the assumption that the genetic architecture of depression comprises the combined influence of multiple loci of small effect (Flint \& Kendler, 2014). It is important to recognize that the effect of a single genetic variant represents an average across all etiological backgrounds and clinical representations which might conceal more consistent effects in homogenous subsets of depressed patients. It has therefore been suggested that substantial advances could be made by exploring the genetic architecture of depression in individuals that share common etiology and/or phenotypic expression (Wray et al., 2012).

Stratification by sleep-related symptomatology could provide valuable subgroups for more homogenous genetic analyses. Comorbid insomnia is common in depressed patients with approximately $40 \%$ fulfilling the criteria for clinical diagnosis (Stewart et al., 2006). Besides this frequent comorbidity, it has been well-established that insomnia independently contributes to the etiology of depression (Baglioni et al., 2011). In the light of these findings, depression with or without comorbid insomnia could represent subsets of patients with more similar etiology and clinical representation. The value of stratification by insomnia is more directly supported by genome-wide association studies of insomnia reporting a significant genetic overlap of insomnia with depressive symptoms, neuroticism and major depressive disorder (Hammerschlag et al., 2017). Differentiating the genetic architecture of insomnia without depression from the genetic makeup of depression with comorbid insomnia could therefore potentially reveal specific genetic variants involved in sleep-related depression. Investigating genetic risks factors in depressed patients free of sleep complaints could conversely help to identify variants related to different pathophysiological processes.

\section{Pathophysiological mechanisms}

Depression is characterized by a diverse range of pathophysiological mechanisms. The most robust and clinically relevant evidence has been found for neurobiological theories describing a role for psychosocial stress, stress hormones, immune function, neurotransmitters (serotonin, norepinephrine, dopamine, glutamate, and gamma - aminobutyric acid), neuro 
circuitry, neurotrophic factors and circadian rhythms (Hasler, 2010). Although the origin of these neurobiological abnormalities remains largely unknown, recent evidence suggests that impaired sleep could be an important factor contributing to most of these alterations.

Research at the intersection of sleep and the pathophysiology of depression demonstrates that impaired sleep induces various neurobiological alterations that resemble those associated with depression and/or depression susceptibility. Asides a general deterioration of mood (Palmer \& Alfano, 2017), inadequate sleep is found to negatively impact neuroendocrine stress adaptation systems (Meerlo, Sgoifo, \& Suchecki, 2008; van Dalfsen \& Markus, 2018), neuro circuitry of emotion regulation (Yoo, Gujar, Hu, Jolesz, \& Walker, 2007), immune function (Besedovsky, Lange, \& Born, 2012) and the availability of neurotrophic factors (Schmitt, Holsboer-Trachsler, \& Eckert, 2016). Together with the independent contribution of sleep impairment to the development of depression (Baglioni et al., 2011), these findings indicate that inadequate sleep may have a prominent role in the pathophysiology of depression.

The neurobiological connection between sleep and depression is further illustrated by the shared neurotransmitter systems involved in both sleep- and mood regulation. Evidence from these different research disciplines suggest that the neurotransmitter abnormalities associated with depression are very-well positioned to promote sleep alterations. This predominantly relates to the serotonergic system which is one of the most extensively studied neurotransmitters in depression (Hasler, 2010) and known to have a prominent role in sleepwake regulation (Ursin, 2002). Experimental reductions in serotonin synthesis have for instance been found to cause a deterioration of mood in depression vulnerable individuals (Neumeister et al., 2002; Neumeister et al., 2004) and induce severe sleep impairment (Jouvet, 1972; Koella, Feldstein, \& Czicman, 1968). The neurobiological overlap between sleep and depression is further illustrated by the observation that the profound REM sleep disinhibition observed in clinical depression can be reversed by antidepressant treatment (Palagini, Baglioni, Ciapparelli, Gemignani, \& Riemann, 2013). Taken together, these findings suggest that sleep and depression share common neurobiological underpinnings. This emphasizes the relevance to study these factors in concert and could provide valuable opportunities to improve contemporary treatment. 


\section{Treatment strategies}

Comorbid insomnia is common in clinical depression (Stewart et al., 2006). The independent contribution of insomnia to the etiology of depression (Baglioni et al., 2011) illustrates that sleep impairment may negatively influence the clinical course of depression. This is more directly supported by clinical evidence demonstrating that insomnia is associated with an increased risk for depression, elevated depression severity, prolonged duration of a depressive episode and higher relapse rates (Franzen \& Buysse, 2008; Riemann, 2009). These findings illustrate the importance to target sleep-related symptomatology in the treatment for depression and suggest that sleep-related interventions could be a promising treatment strategy for depression.

Several studies investigated whether the treatment of insomnia in depressed patients may concurrently alleviate affective symptomatology. Although not consistently observed, several studies have shown that adjunctive sleep medication may improve depression outcomes following antidepressant treatment (for review see: (Riemann, 2009)). Moreover, accumulating evidence suggests that the singular treatment of insomnia (cognitive behavioral therapy for insomnia; CBT-I) alleviates depression with a comparable efficacy as antidepressants and psychotherapy (for review see: (Cunningham \& Shapiro, 2018)). The improvement in depressive symptomatology following CBT-I is mediated by a reduction in insomnia symptoms, directly supporting the relevance of targeting sleep-related symptomatology in the treatment for depression.

The role of sleep impairment in the treatment for depression may have important implications for the prescription of antidepressants and could provide valuable opportunities for the development of more innovative pharmacological agents. In general, most antidepressants suppress REM sleep and thereby reduce the REM sleep disinhibition that characterizes clinical depression (Palagini et al., 2013). Based on the antidepressant properties of selective REM sleep deprivation (Vogel, McAbee, Barker, \& Thurmond, 1977), it has been suggested that this inhibition of REM sleep contributes to the clinical efficacy of antidepressants (Vogel, Buffenstein, Minter, \& Hennessey, 1990). However, the few effective antidepressants that do not suppress REM sleep challenge this hypothesis (Palagini et al., 2013). In contrast to a relative consistent influence on REM sleep regulation, contemporary antidepressants vary considerably on the effects on symptoms of insomnia. These differences are mainly observed during the first weeks of treatment and most agents improve sleep after three to four weeks of treatment analogous to their therapeutic efficacy (Wilson \& Argyropoulos, 2005). Taken together, these findings support a role for sleep in the 
pharmacological treatment for depression and suggest that dysfunctional sleep, either insomnia or REM sleep abnormalities, could be an important target for the development of antidepressants.

\section{Conclusion}

Sleep and depression are closely related. This intimate relationship provides valuable opportunities to advance current understanding of depression by facilitating the discovery of genetic risk factors, pathophysiological mechanisms and more efficacious treatment strategies. The present thesis aimed to utilize this conceptual framework by investigating sleep-related influences of a functional polymorphism presumed to modulate the risk for depression (serotonin transporter gene-linked polymorphic region; 5-HTTLPR). The systematic reviews and studies included in this dissertation illustrate how this genetic variation may modulate the risk for insomnia, sleep-related affective symptomatology, sleeppromoting effects of pharmacological interventions, sleep-related neuroendocrine stress sensitivity and REM sleep architecture. Taken together, the presented findings illustrate how sleep may contribute to depression research that either aims to uncover genetic risk factors, pathophysiological mechanisms or pharmacological interventions. 


\section{References}

American Psychiatric Association. (2013). Diagnostic and Statistical Manual of Mental Disorders: Dsm-5: Amer Psychiatric Pub Incorporated.

Baglioni, C., Battagliese, G., Feige, B., Spiegelhalder, K., Nissen, C., Voderholzer, U., . . . Riemann, D. (2011). Insomnia as a predictor of depression: A meta-analytic evaluation of longitudinal epidemiological studies. Journal of Affective Disorders, 135(1-3), 10-19. doi:10.1016/j.jad.2011.01.011

Besedovsky, L., Lange, T., \& Born, J. (2012). Sleep and immune function. Pflugers Archiv : European journal of physiology, 463(1), 121-137. doi:10.1007/s00424-011-1044-0

Charney, D. S., Barlow, D. H., Botteron, K., Cohen, J. D., Goldman, D., Gur, R. E., . . . Zalcman, S. J. (2002). Neuroscience research agenda to guide development of a pathophysiologically based classification system. In A research agenda for DSM-V. (pp. 31-83). Arlington, VA, US: American Psychiatric Association.

Cipriani, A., Furukawa, T. A., Salanti, G., Chaimani, A., Atkinson, L. Z., Ogawa, Y., . . . Geddes, J. R. (2018). Comparative efficacy and acceptability of 21 antidepressant drugs for the acute treatment of adults with major depressive disorder: a systematic review and network meta-analysis. Lancet, 391(10128), 1357-1366. doi:10.1016/s0140-6736(17)32802-7

Cuijpers, P., Cristea, I. A., Karyotaki, E., Reijnders, M., \& Huibers, M. J. H. (2016). How effective are cognitive behavior therapies for major depression and anxiety disorders? A meta-analytic update of the evidence. World psychiatry : official journal of the World Psychiatric Association (WPA), 15(3), 245-258. doi:10.1002/wps.20346

Cuijpers, P., Donker, T., Weissman, M. M., Ravitz, P., \& Cristea, I. A. (2016). Interpersonal Psychotherapy for Mental Health Problems: A Comprehensive Meta-Analysis. American Journal of Psychiatry, 173(7), 680-687. doi:10.1176/appi.ajp.2015.15091141

Cunningham, J. E. A., \& Shapiro, C. M. (2018). Cognitive Behavioural Therapy for Insomnia (CBT-I) to treat depression: A systematic review. Journal of Psychosomatic Research, 106, 1-12. doi:10.1016/j.jpsychores.2017.12.012

Flint, J., \& Kendler, K. S. (2014). The Genetics of Major Depression. Neuron, 81(3), 484-503. doi:10.1016/j.neuron.2014.01.027

Franzen, P. L., \& Buysse, D. J. (2008). Sleep disturbances and depression: risk relationships for subsequent depression and therapeutic implications. Dialogues Clin Neurosci, 10(4), 473-481.

Hammerschlag, A. R., Stringer, S., de Leeuw, C. A., Sniekers, S., Taskesen, E., Watanabe, K., . . . Posthuma, D. (2017). Genome-wide association analysis of insomnia complaints identifies risk genes and genetic overlap with psychiatric and metabolic traits. Nature Genetics, 49(11), 1584-1592. doi:10.1038/ng.3888

Harmer, C. J., Duman, R. S., \& Cowen, P. J. (2017). How do antidepressants work? New perspectives for refining future treatment approaches. Lancet Psychiatry, 4(5), 409418. doi:10.1016/s2215-0366(17)30015-9

Hasler, G. (2010). Pathophysiology of depression: do we have any solid evidence of interest to clinicians? World Psychiatry, 9(3), 155-161.

Jouvet, M. (1972). The role of monoamines and acetylcholine-containing neurons in the regulation of the sleep-waking cycle. Ergebnisse der Physiologie, Biologischen Chemie und Experimentellen Pharmakologie, 64, 166-307.

Kessler, R. C., Aguilar-Gaxiola, S., Alonso, J., Chatterji, S., Lee, S., Ormel, J., . . Wang, P. S. (2009). The global burden of mental disorders: an update from the WHO World Mental Health (WMH) surveys. Epidemiologia e Psichiatria Sociale, 18(1), 23-33. 
Koella, W. P., Feldstein, A., \& Czicman, J. S. (1968). The effect of para-chlorophenylalanine on the sleep of cats. Electroencephalography and Clinical Neurophysiology, 25(5), 481-490. doi:10.1016/0013-4694(68)90158-2

Levinson, D. F. (2006). The genetics of depression: a review. Biological Psychiatry, 60(2), 84-92. doi:10.1016/j.biopsych.2005.08.024

Meerlo, P., Sgoifo, A., \& Suchecki, D. (2008). Restricted and disrupted sleep: effects on autonomic function, neuroendocrine stress systems and stress responsivity. Sleep Med Rev, 12(3), 197-210. doi:10.1016/j.smrv.2007.07.007

Neumeister, A., Konstantinidis, A., Stastny, J., Schwarz, M. J., Vitouch, O., Willeit, M., . . . Kasper, S. (2002). Association between serotonin transporter gene promoter polymorphism (5HTTLPR) and behavioral responses to tryptophan depletion in healthy women with and without family history of depression. Archives of General Psychiatry, 59(7), 613-620.

Neumeister, A., Nugent, A. C., Waldeck, T., Geraci, M., Schwarz, M., Bonne, O., . . . Drevets, W. C. (2004). Neural and behavioral responses to tryptophan depletion in unmedicated patients with remitted major depressive disorder and controls. Archives of General Psychiatry, 61(8), 765-773. doi:10.1001/archpsyc.61.8.765

Nuijen, J., van Bon-Martens, M., de Graaf, R., van der Poel, A., de Beurs, D., Nielen, M., . . . Voorrips, L. (2017). Zicht op depressie: de aandoening, preventie en zorg. Themarapportage van de Staat van Volksgezondheid en Zorg.

Palagini, L., Baglioni, C., Ciapparelli, A., Gemignani, A., \& Riemann, D. (2013). REM sleep dysregulation in depression: state of the art. Sleep Med Rev, 17(5), 377-390. doi:10.1016/j.smrv.2012.11.001

Palmer, C. A., \& Alfano, C. A. (2017). Sleep and emotion regulation: An organizing, integrative review. Sleep Med Rev, 31, 6-16. doi:10.1016/j.smrv.2015.12.006

Riemann, D. (2009). Does effective management of sleep disorders reduce depressive symptoms and the risk of depression? Drugs, 69 Suppl 2, 43-64. doi:10.2165/11531130-000000000-00000

Ripke, S., Wray, N. R., Lewis, C. M., Hamilton, S. P., Weissman, M. M., Breen, G., . . . Sullivan, P. F. (2013). A mega-analysis of genome-wide association studies for major depressive disorder. Molecular Psychiatry, 18(4), 497-511. doi:10.1038/mp.2012.21

Robinson, L. A., Berman, J. S., \& Neimeyer, R. A. (1990). Psychotherapy for the treatment of depression: a comprehensive review of controlled outcome research. Psychological Bulletin, 108(1), 30-49.

Rush, A. J., Trivedi, M. H., Wisniewski, S. R., Nierenberg, A. A., Stewart, J. W., Warden, D., . . . Fava, M. (2006). Acute and longer-term outcomes in depressed outpatients requiring one or several treatment steps: a STAR*D report. American Journal of Psychiatry, 163(11), 1905-1917. doi:10.1176/ajp.2006.163.11.1905

Schmitt, K., Holsboer-Trachsler, E., \& Eckert, A. (2016). BDNF in sleep, insomnia, and sleep deprivation. Annals of Medicine, 48(1-2), 42-51. doi:10.3109/07853890.2015.1131327

Stewart, R., Besset, A., Bebbington, P., Brugha, T., Lindesay, J., Jenkins, R., . . Meltzer, H. (2006). Insomnia comorbidity and impact and hypnotic use by age group in a national survey population aged 16 to 74 years. Sleep, 29(11), 1391-1397.

Sullivan, P. F., Neale, M. C., \& Kendler, K. S. (2000). Genetic epidemiology of major depression: review and meta-analysis. American Journal of Psychiatry, 157(10), 15521562. doi:10.1176/appi.ajp.157.10.1552

Ursin, R. (2002). Serotonin and sleep. Sleep Med Rev, 6(1), 55-69.

van Dalfsen, J. H., \& Markus, C. R. (2018). The influence of sleep on human hypothalamicpituitary-adrenal (HPA) axis reactivity: A systematic review. Sleep Med Rev, 39, 187194. doi:10.1016/j.smrv.2017.10.002 
Vogel, G. W., Buffenstein, A., Minter, K., \& Hennessey, A. (1990). Drug effects on REM sleep and on endogenous depression. Neuroscience and Biobehavioral Reviews, 14(1), 49-63. doi:10.1016/S0149-7634(05)80159-9

Vogel, G. W., McAbee, R., Barker, K., \& Thurmond, A. (1977). Endogenous depression improvement and REM pressure. Archives of General Psychiatry, 34(1), 96-97.

Vos, T., Flaxman, A. D., Naghavi, M., Lozano, R., Michaud, C., Ezzati, M., . . . Memish, Z. A. (2012). Years lived with disability (YLDs) for 1160 sequelae of 289 diseases and injuries 1990-2010: a systematic analysis for the Global Burden of Disease Study 2010. Lancet, 380(9859), 2163-2196. doi:10.1016/s0140-6736(12)61729-2

Wilson, S., \& Argyropoulos, S. (2005). Antidepressants and sleep: a qualitative review of the literature. Drugs, 65(7), 927-947. doi:10.2165/00003495-200565070-00003

World Health Organization. (2016). ICD 10 International statistical classification of diseases and related health problems (10 ed.).

Wray, N. R., Pergadia, M. L., Blackwood, D. H., Penninx, B. W., Gordon, S. D., Nyholt, D. R., . . . Sullivan, P. F. (2012). Genome-wide association study of major depressive disorder: new results, meta-analysis, and lessons learned. Molecular Psychiatry, 17(1), 36-48. doi:10.1038/mp.2010.109

Yoo, S. S., Gujar, N., Hu, P., Jolesz, F. A., \& Walker, M. P. (2007). The human emotional brain without sleep--a prefrontal amygdala disconnect. Current Biology, 17(20), R877-878. doi:10.1016/j.cub.2007.08.007 
Dankwoord 
Tijdens mijn studie raakte ik geïnteresseerd in de relatie tussen slaap en depressie en ik heb altijd de ambitie gehad om onderzoek te doen naar deze associatie. De afgelopen jaren heb ik dan ook met veel plezier aan mijn promotieonderzoek gewerkt met als uiteindelijk resultaat het schrijven van dit proefschrift. Ik wil iedereen bedanken die op enige wijze bijgedragen heeft aan de totstandkoming van dit proefschrift en een paar mensen zou ik graag in het bijzonder willen noemen.

Allereerst wil ik mijn promotor, Prof. Dr. C. Rob Markus, hartelijk danken voor de fijne samenwerking. Beste Rob, ik ben je zeer erkentelijk voor je inzet om een promotietraject op dit onderwerp te realiseren en mijn aanstelling aan Universiteit Maastricht te continueren. Ik ben je heel dankbaar voor de kansen die je mij hebt geboden, je vertrouwen in mij als onderzoeker, en de vrijheid in onderzoek die ik tijdens mijn promotieonderzoek heb gekregen. Ik wil je in het bijzonder bedanken voor de goede begeleiding. Ik heb zowel op het gebied van onderzoek als onderwijs onbeschrijfelijk veel van jou geleerd waar ik nog veel aan zal hebben tijdens mijn verdere wetenschappelijke carrière. Je bent een groot voorbeeld en ik voel me vereerd dat dit mij als onderzoeker gevormd heeft. Mijn tijd als promovendus was naast een zeer leerzame ook een bijzonder leuke periode en ook daar wil ik je hartelijk voor bedanken. Ik liep bijna dagelijks even bij jou binnen en denk met heel veel plezier terug aan de enthousiaste discussies over ons onderzoeksveld en de vele gesprekken over alles wat ons naast de wetenschap bezig houdt. De vriendschap die wij in de afgelopen jaren hebben opgebouwd is mij zeer dierbaar.

Daarnaast wil ik Dr. Lisa M. Jonkman hartelijk danken voor haar betrokkenheid bij dit promotietraject. Beste Lisa, ik ben je zeer dankbaar voor je hulp en expertise bij het verrichten van elektro-encefalografische studies en de mogelijkheden die je mij hebt geboden om ervaring op te doen in dit onderzoeksveld. Ik wil je bedanken voor je bijdrage als coauteur, je uitgebreide en kritische feedback heeft belangrijke inzichten gebracht en tot betere manuscripten geleid. Ik heb me bij jou en Rob altijd zeer welkom gevoeld en daar wil ik bij dezen graag mijn waardering voor uitspreken.

Graag wil ik Prof. Dr. W. J. Riedel, Prof. Dr. A. J. W. van der Does, Prof. Dr. G. A. Kerkhof, Prof. Dr. F. P. M. L. Peeters, Prof. Dr. T. Smeets en Prof. Dr. C. Firk hartelijk danken voor het lezen en beoordelen van mijn proefschrift. Ik waardeer het zeer dat jullie als oppositie 
aanwezig zijn bij de verdediging en voel me vereerd om met jullie van gedachten te mogen wisselen.

Verder wil ik mijn collega's van de Faculteit Psychologie en Neurowetenschappen, in het bijzonder de afdeling Neuropsychologie en Psychofarmacologie, bedanken voor de fijne werkomgeving de afgelopen jaren. Het was mij een genoegen om deel uit te mogen maken van deze verscheidenheid aan onderzoekers.

Ik wil mijn paranimfen en goede vrienden, Thom Lunenborg en Sjoerd Gulikers, hartelijk danken voor hun betrokkenheid en ondersteuning. Ik voel me vereerd om dit mooie moment met jullie te delen.

Ik wil mijn proefschrift graag opdragen aan mijn ouders, Evelyn van Dalfsen en Jan van Dalfsen. Ik kan met recht zeggen dat hun liefde, ondersteuning en aanmoediging een belangrijke basis heeft gevormd voor het schrijven van dit proefschrift. Lieve mama, ik wil je hartelijk danken dat jij er altijd voor mij bent. Toen ik klein was zat je altijd klaar met een kopje thee na schooltijd en ook op latere leeftijd kon, en kan, ik altijd bij jou terecht met alles wat er in mijn leven speelt. Je hebt me altijd gestimuleerd om te leren en mijn hart te volgen. Jij hebt mij als geen ander gevormd tot wie ik nu ben en daar ben ik je zeer dankbaar voor. Lieve papa, ik wil jou ook hartelijk danken voor alles wat je voor mij hebt gedaan. Als werkstudent heb jij veertig jaar geleden de weg vrij gemaakt naar de academische wereld en daar kan ik nu als zoon van profiteren. Je hebt me altijd gestimuleerd om de tijd te nemen om mij te ontwikkelen en de vrijheid en ondersteuning geboden om lang te studeren. Dat we nu allebei in de wetenschap werken is een mooie illustratie dat wij op eenzelfde manier kunnen werken. Lieve mama en papa, jullie hebben samen voor een zeer fijne omgeving gezorgd om in op te groeien wat alle kansen heeft geboden om mij te ontwikkelen, daar ben ik jullie veel dank voor verschuldigd. Ik hou ontzettend veel van jullie. 
Dankwoord 
Curriculum vitae 
Jens H. van Dalfsen was born on December $26^{\text {th }}, 1987$ in Smallingerland, the Netherlands. Following his graduation from pre-university education (2008) he completed a bachelor in Biological Psychology (2012) as well as a master in Neuropsychology (2013) at Maastricht University. During the psychology bachelor he developed a great interest in the relationship between sleep and depression while writing an article on the value of sleep deprivation as a treatment strategy for depression. This encouraged the writing of a bachelor thesis concerning neurobiological relationships between sleep and depression in relation to clinical interventions under supervision of Prof. Dr. L. Blomert. During the neuropsychology master he further elaborated on this interest by writing his master thesis on the influence of genetic expression of the serotonin transporter on sleep under supervision of Prof. Dr. C. R. Markus. After obtaining his Master of Science degree he worked as a research assistant at the Department of Neuropsychology and Psychopharmacology (Prof. Dr. C. R. Markus) as well as the Department of Cognitive Neuroscience of Maastricht University (Dr. L. M. Jonkman). In August 2014 he started his $\mathrm{PhD}$ research at the Department of Neuropsychology and Psychopharmacology of Maastricht University. 
